\title{
MOTIVATION INTERVENTIONS VIA STUDY PROGRAMMES FOR UNDER-ACHIEVING STUDENTS, FOCUSING ON PASIFIKA STUDENTS
}

\author{
BY \\ PETER SANDERS
}

\begin{abstract}
A thesis
submitted to the Victoria University of Wellington in fulfilment of the requirements for the degree of Doctor of Philosophy in Education
\end{abstract}

Victoria University of Wellington

2015 
Motivation Interventions via Study Programmes for Under-achieving Students 


\section{Abstract}

Research has shown that lower motivation orientations are associated with underachievement and that ethnicity may also be associated with motivation and achievement. This study investigates if student motivation can be altered by two intervention programmes - a traditional study (TS) programme and a motivationenhanced study (MS) programme. A total of 57 students participated, from three different groups, attending Year 11 (median age 15 years) at two New Zealand Secondary Schools. This mixed-methods study used Martin's (2008) Student Motivation and Engagement Scale (MES-HS) and Meyer, McClure, Walkey, McKenzie and Weirs' (2008) Survey of NCEA Goals Year 10 and Year 11 Students to gain quantitative data. Qualitative data about perceptions on motivation and achievement were gained from interviews with students. MS students, across all three groups, had steeper gains in academic achievement, showed decreases in maladaptive intrapersonal motivation orientations and increases in inter-personal motivation orientations compared to corresponding TS students. However, Pasifika students had the highest gains in achievement, showed stronger decrease on intra-personal adaptive motivation factors, and greater increases on inter-personal motivation orientations compared to non-Pasifika students. These results are discussed within a theoretical framework of how changes in intra-personal and inter-personal motivation orientations may be associated with ethnicity and achievement-related outcomes.

Keywords: motivation, achievement, Pasifika, secondary schooling 
Motivation Interventions via Study Programmes for Under-achieving Students 
Motivation Interventions via Study Programmes for Under-achieving Students

\section{Dedication}

I dedicate this thesis to Brigit Vaughan 
Motivation Interventions via Study Programmes for Under-achieving Students 


\section{Acknowledgements}

I would like to express my thanks to the following people who assisted me with this thesis:

Brigit who supported me every day of this journey.

My family - Natalie, Iain, Timothy, Zoe, Jacqueline, Benjamin, Oscar and Frankie.

My supervisors - Professor Luanna Meyer and Dr John Dickie, who patiently guided me through this process with great skill. Both Luanna and John have been extremely generous with their time in critiquing and supporting me leading up to submission of the thesis.

Dr Flaviu Hodis who guided me in quantitative aspects of the thesis.

My cultural advisors, Isa-Uana Toelupe, Filomena Leaupepe and Fuapepe Rimoni, for sharing their cultural insights.

Timothy Vaughan-Sanders for his professional editing skills.

The Ministry of Education for giving me time and financial resources.

The staff of the Education Faculty at Victoria University.

The students whose voices made this study meaningful. 
Motivation Interventions via Study Programmes for Under-achieving Students 


\section{Summary of Contents}

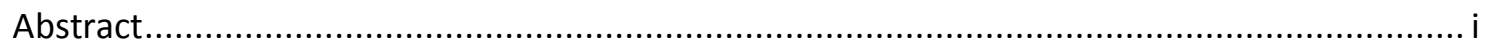

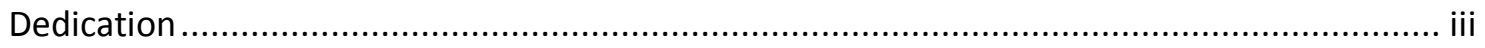

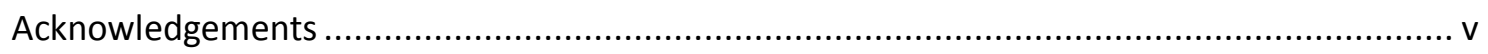

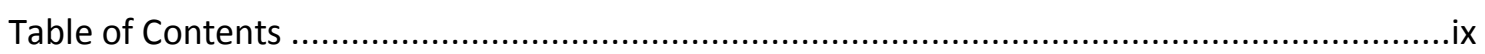

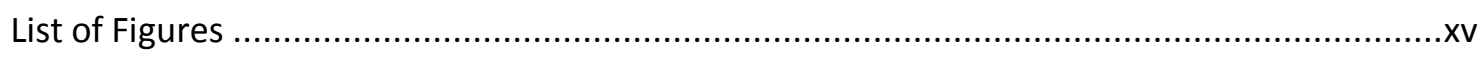

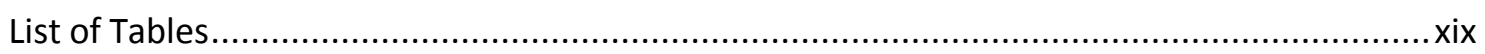

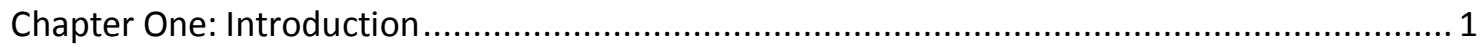

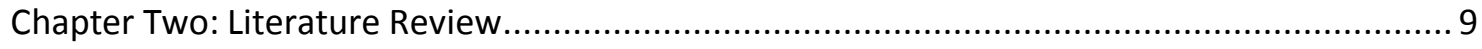

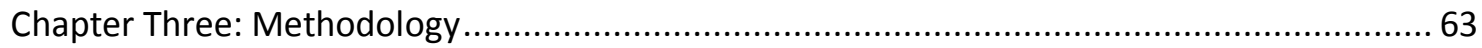

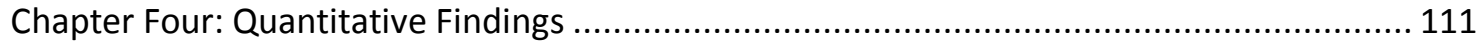

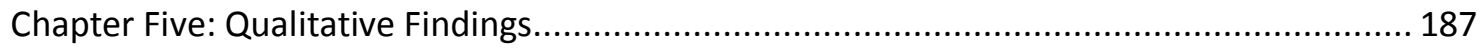

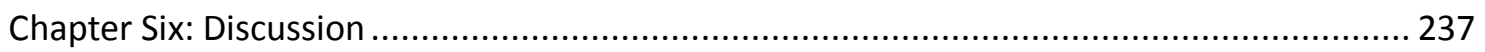

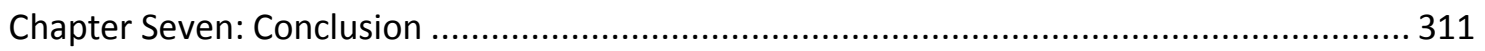

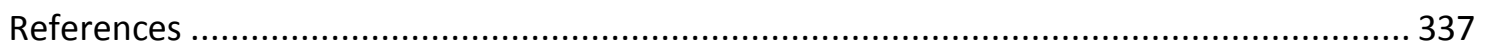

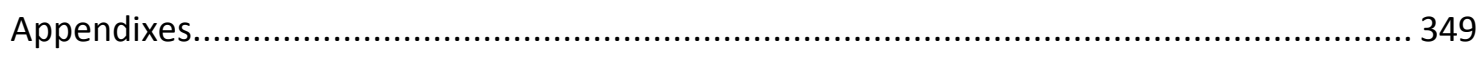


Motivation Interventions via Study Programmes for Under-achieving Students 


\section{Table of Contents}

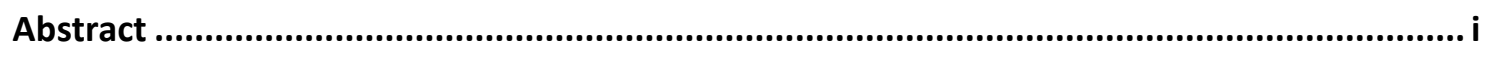

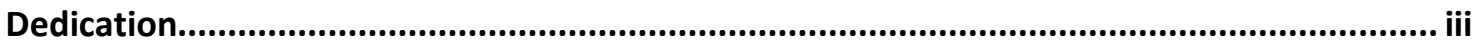

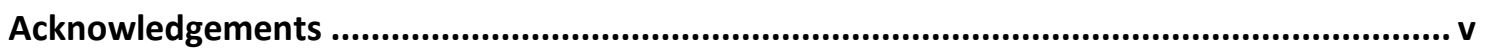

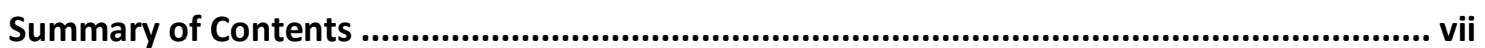

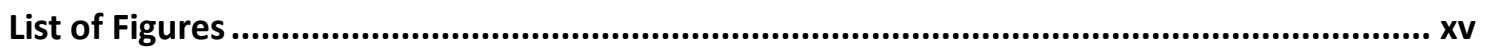

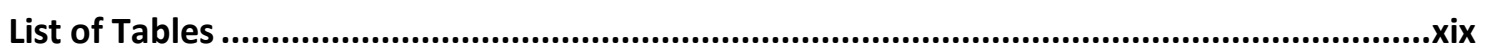

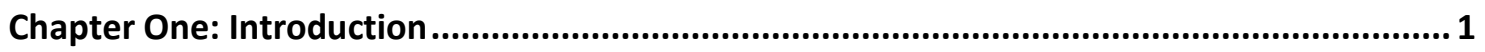

What is known about Pasifika Student Achievement in New Zealand Secondary Schools? ....... 1

Chapter Two: Literature Review .................................................................................................

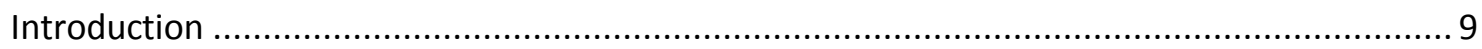

Section One: The Field (and Related Fields) of this Research ............................................... 10

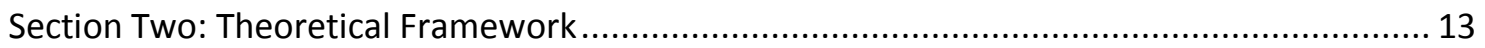

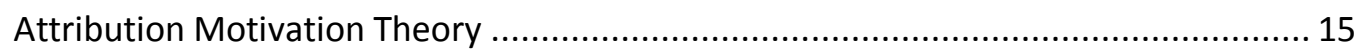

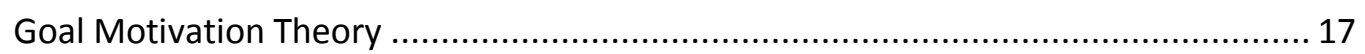

Expectancy-value Motivation Theory …................................................................. 17

Self-determination, Self-efficacy and Self-worth Motivation Theories ....................... 19

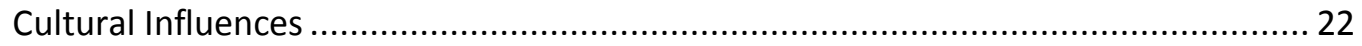

Section Three: Pasifika Student Achievement in the NZ Context ......................................... 31

Section Four: What does the Literature Say about the Impact of Attribution Retraining on

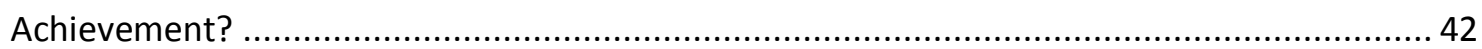

Section Five: A Review of the Literature about Interventions based on Goal Theory ............... 54

Section Six: How does Martin's $(2005,2008)$ Intervention Material Assist Understanding about Interventions that Affect Motivation and Achievement? ........................................ 57

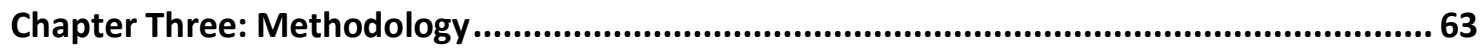

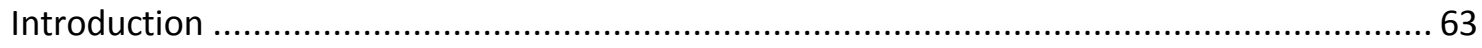

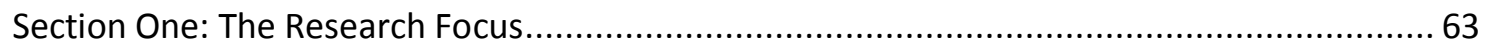

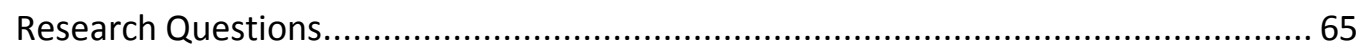

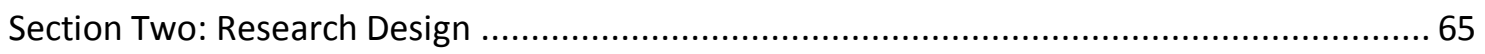

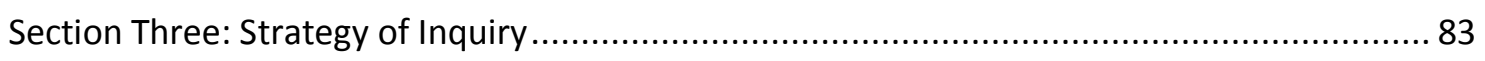

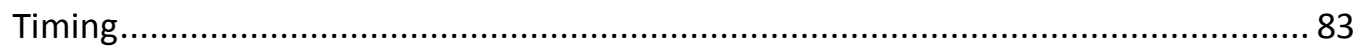

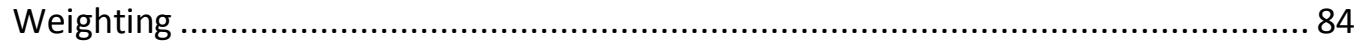


Motivation Interventions via Study Programmes for Under-achieving Students

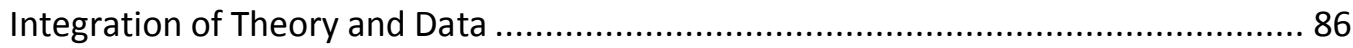

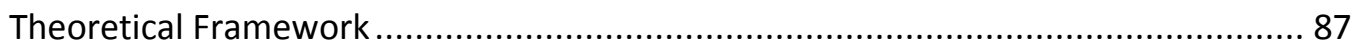

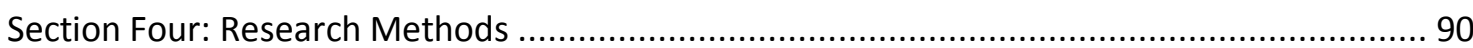

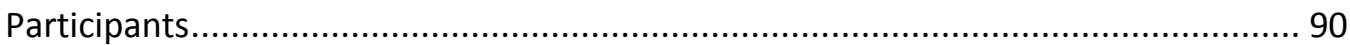

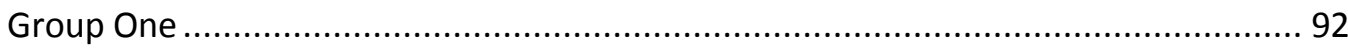

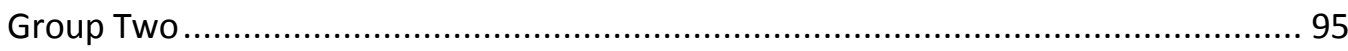

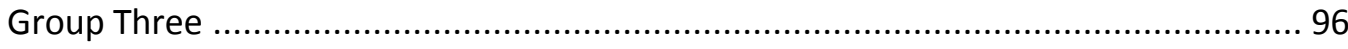

The Traditional Study Support Programme (TS) .................................................. 97

The Motivation-enhanced Study Support Programme (MS)................................... 98

Assignment of Students to Groups ............................................................... 100

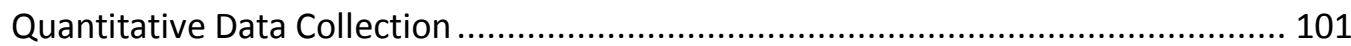

Instruments Used in Quantitative Data Collection ................................................. 102

Measures of Achievement-related Outcomes ......................................................... 103

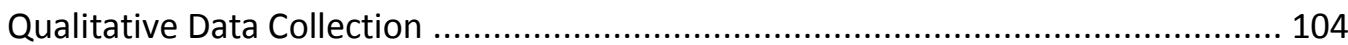

Analysis of Quantitative Data ........................................................................... 106

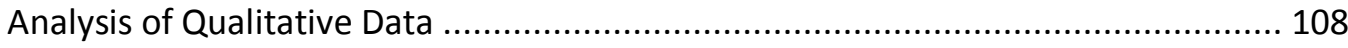

Chapter Four: Quantitative Findings .................................................................................... 111

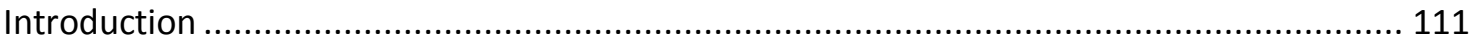

Statistical Tests used in this Study ................................................................. 112

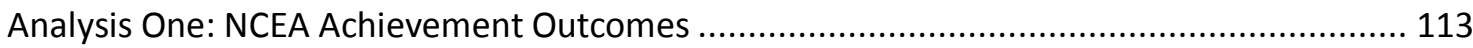

Section One: NCEA Achievement Outcomes by All Students in the MS and TS Intervention Programmes ............................................................................... 113

Section Two: NCEA Achievement Outcomes by Pasifika Students in the MS and TS Intervention Programmes .............................................................. 116

Analysis Two: Changes in Adaptive Intra-personal Motivation Orientations ........................ 118

Section One: Changes in Adaptive Intra-personal Motivation Orientations for All Students in the MS and TS Programmes .................................................... 118

Section Two: Changes in Adaptive Intra-personal Motivation Orientations for Pasifika Students in the MS and TS Programmes............................................. 124

Analysis Three: Changes in Maladaptive Intra-personal Motivation .................................. 128

Section One: Changes in Maladaptive Intra-personal Motivation Factors for All Students in the MS and TS Programmes........................................................ 129

Section Two: Changes in Maladaptive Intra-personal Motivation Orientations for Pasifika Students in the MS and TS Programmes ............................................... 133

Analysis Four: Changes in the Motivation Orientations Doing My Best and

Doing Just Enough 
Motivation Interventions via Study Programmes for Under-achieving Students

Section One: Changes in Doing My Best and Doing Just Enough Motivation

Orientations for Students in the MS and TS Programmes

Section Two: Changes in Doing My Best and Doing Just Enough Motivation

Orientations for Pasifika Students in the MS and TS Programmes

Analysis Five: Changes on Inter-personal Motivation Factors

Section One: Changes on Inter-personal Motivation Factors for All Students

in the MS and TS Programmes.

Section Two: Changes in Inter-personal Motivation Orientations for Pasifika

Students in the MS and TS Programmes ............................................................. 143

Analysis Six: Changes in Attributions for Best Marks on Assessments................................. 144

Section One: Changes in Attributions for Best Marks ........................................... 145

Section Two: Changes in Attributions for Best Marks in Assessments for Pasifika

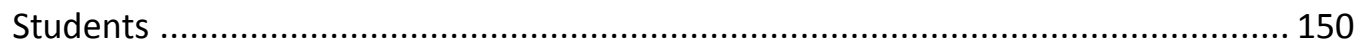

Analysis Seven: Changes in Attributions for Worst Marks in Assessments ............................ 156

Section One: Changes in Attributions for Worst Marks in Assessments.................... 156

Section Two: Changes in Attributions by Pasifika Students for worst marks in

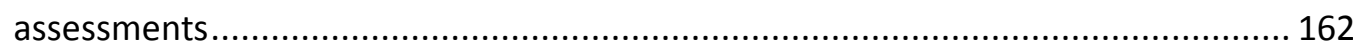

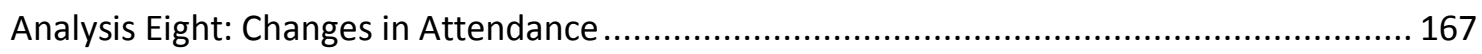

Section One: Changes in Attendance for All Students in the MS and TS

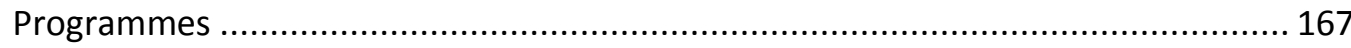

Section Two: Changes in Attendance for Pasifika Students in the MS and TS

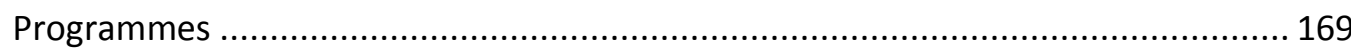

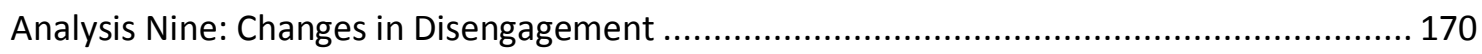

Section One: Changes in Disengagement for All Students in the MS and TS

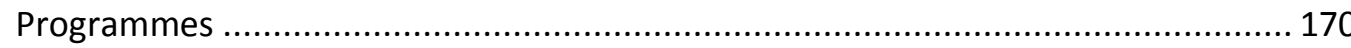

Section Two: Changes in Disengagement for Pasifika Students in the MS and TS

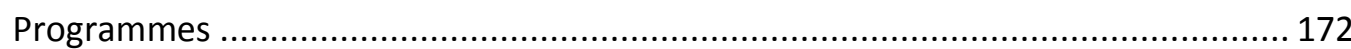

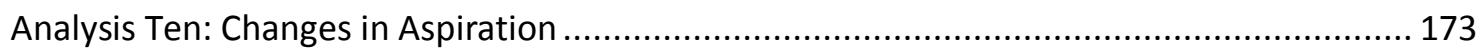

Section One: Changes in Aspiration for All Students in the MS and TS Programmes. 174

Section Two: Changes in Aspiration for Pasifika Students in the MS and TS

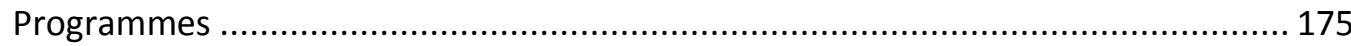

Summary

Explanatory note about changes in social attributions for best and worst marks and achievement.

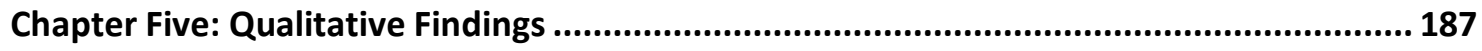

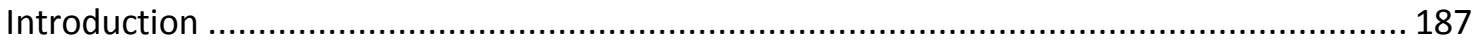

Analysis One: Changes in Adaptive Intra-personal Motivation........................................... 190 
Analysis Two: Changes in Maladaptive Intra-personal Motivation..................................... 194

Analysis Three: Changes in Doing My Best (DMB) and Doing Just Enough (DJE) ................... 197

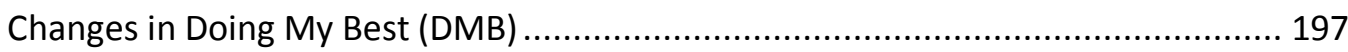

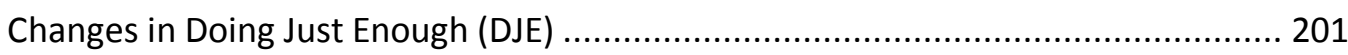

Analysis Four: Changes in Inter-personal Motivation Orientations .................................... 203

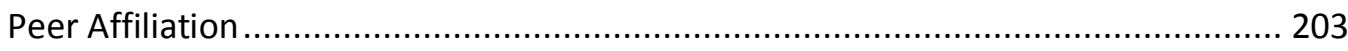

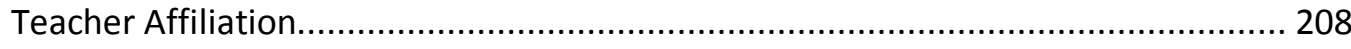

Analysis Five: Changes in Attributions for Best Marks in Assessments.............................. 213

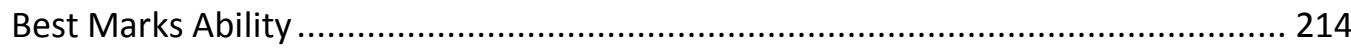

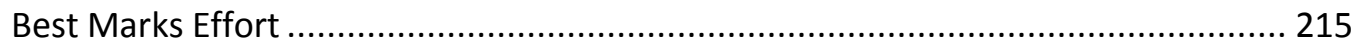

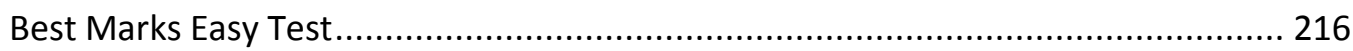

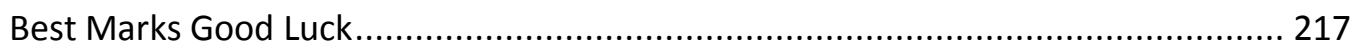

Social Attributions for Best Marks ......................................................................... 218

Analysis Six: Changes in Attributions for Worst Marks in Assessments .................................. 220

Worst Marks Lack of Ability............................................................................ 221

Worst Marks Lack of Effort............................................................................ 222

Worst Marks Hard Test ................................................................................. 223

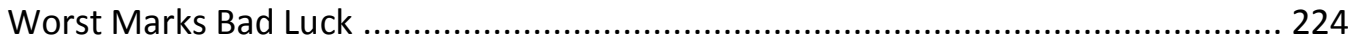

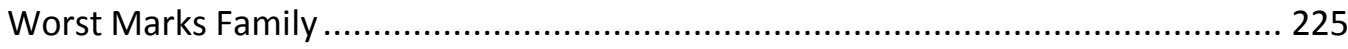

Worst Marks Teachers ….............................................................................. 226

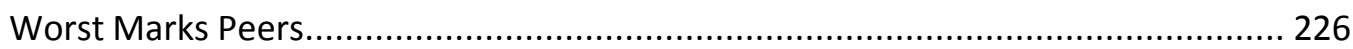

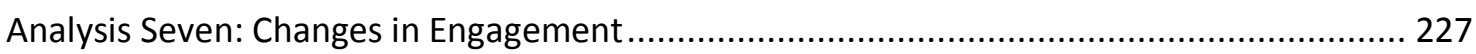

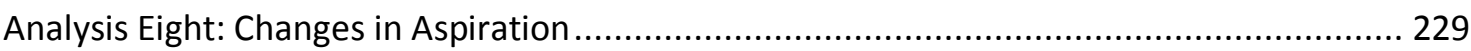

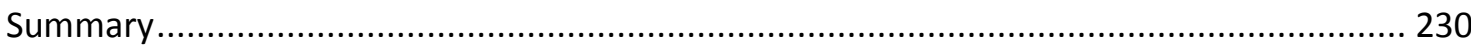

Section One: Where Qualitative and Quantitative Findings Agreed ....................... 231

Section Two: Where Qualitative Findings Challenged Quantitative Findings ............ 232

Section Three: Where the Quantitative Findings were Elaborated by the Qualitative Findings ...................................................................................... 233

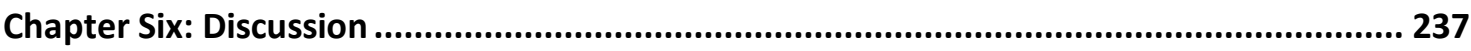

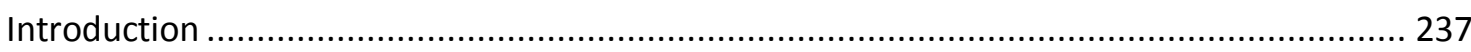

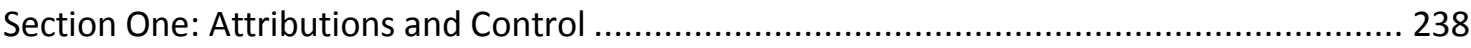

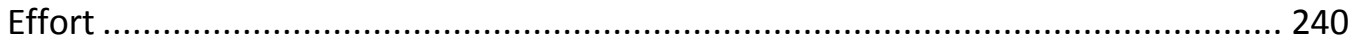

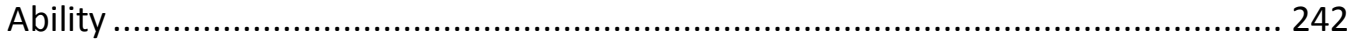

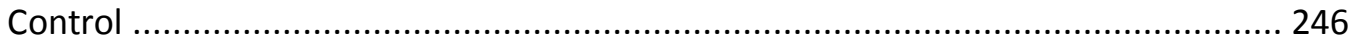




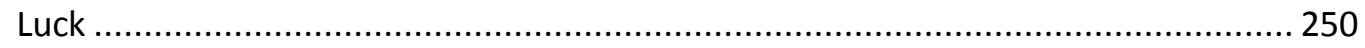

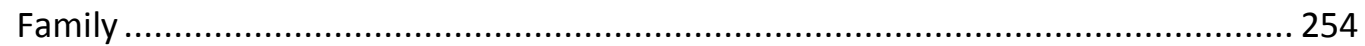

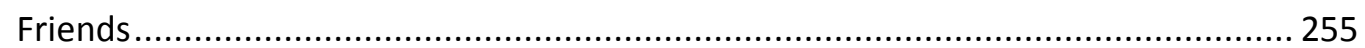

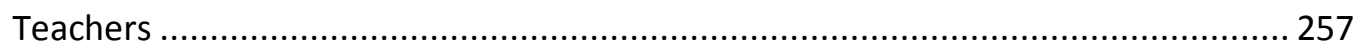

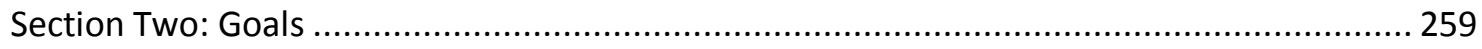

Section Three: Intra-personal Motivation Orientations …..................................................... 297

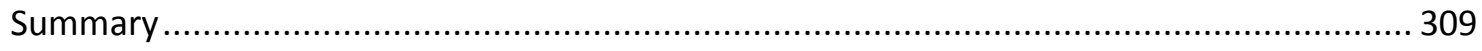

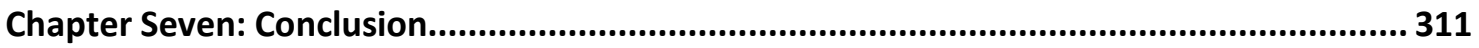

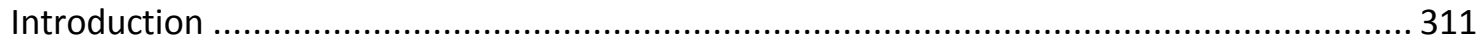

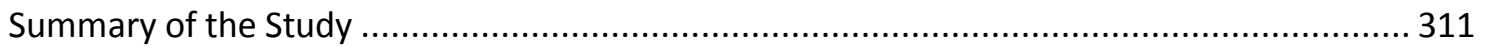

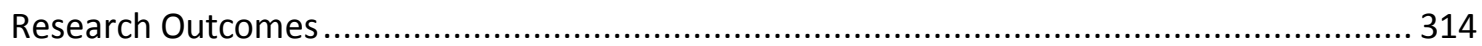

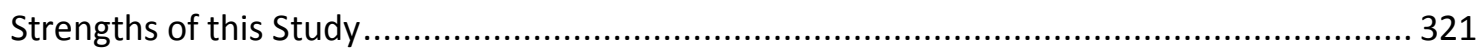

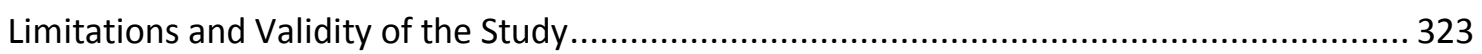

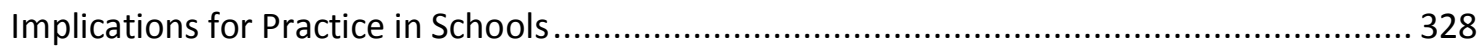

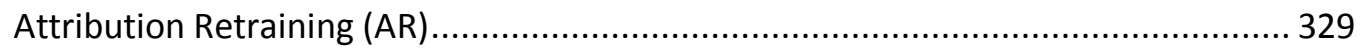

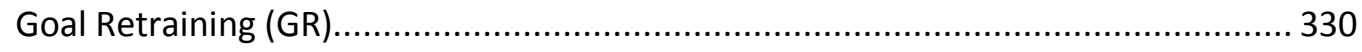

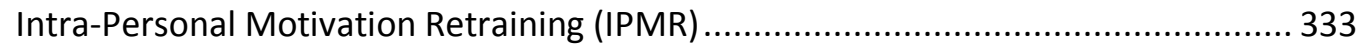

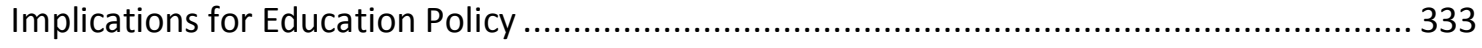

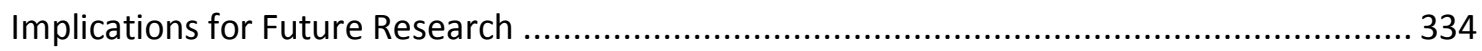

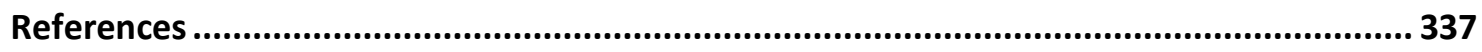

Appendixes

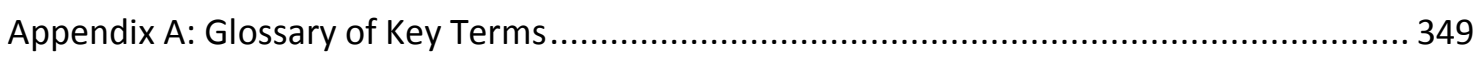

Appendix B: The Traditional Study (TS) and Motivation-enhanced Study (MS) Support

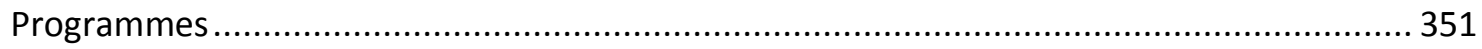

Appendix C: Motivation and Engagement Scale - High School (MES-HS) ............................. 377

Appendix D: Survey of NCEA Goals: Year 10 and Year 11 Students ..................................... 378

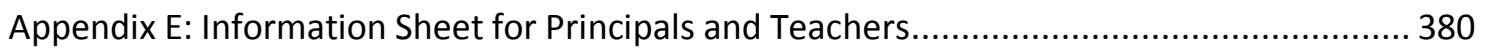

Research Project: The Effectiveness of Study Programmes on Achievement

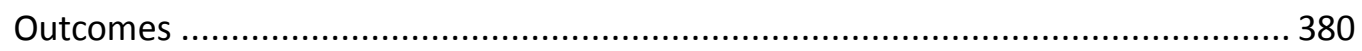

Appendix F: Consent Form for Principals of Participating Schools..................................... 382

Research Project: The Effectiveness of Study Programmes on Achievement

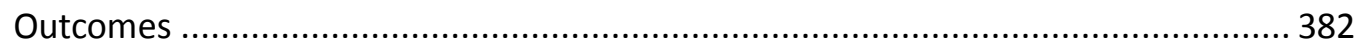

Appendix G: Parents/Caregivers Consent Form for their Child ............................................ 384

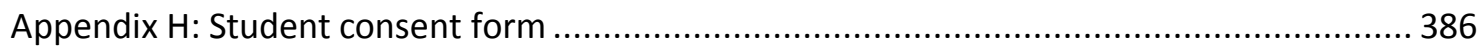


Motivation Interventions via Study Programmes for Under-achieving Students 


\section{List of Figures}

Figure 1. NCEA Level 3 leaving qualifications for Year 13 students, by ethnicity (source: Education Counts, www.educationcounts.govt.nz)......

Figure 2. Percentage of school leavers with a University entrance standard (2004 to 2010)

(source: The Pasifika Education Plan: Monitoring Report, 2010)

Figure 3. Visual model of the two-phase, sequential, explanatory, mixed-method research

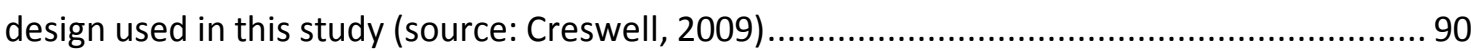

Figure 4. Module contents for the Traditional Study Support Programme (TS) ...................... 98

Figure 5. Formula used to calculate Cohen's $d$ for effect size for unequal groups in the

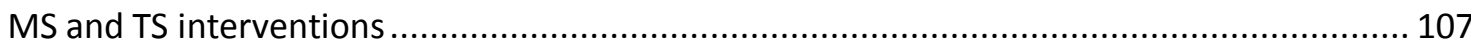

Figure 6. Formula used to calculate Cohen's $d$ in the MS and TS interventions .................... 113

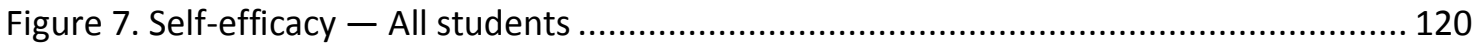

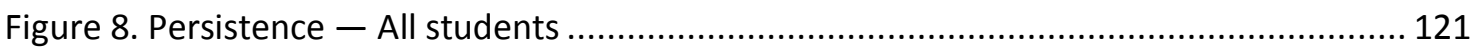

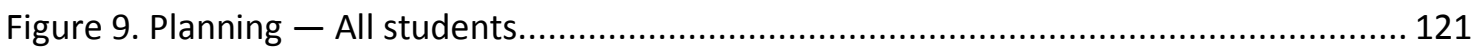

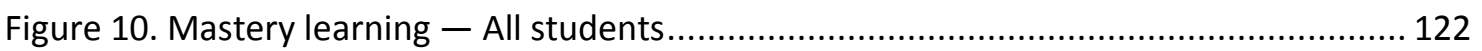

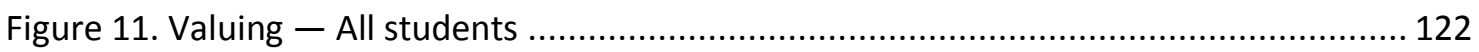

Figure 12. Task management - All students................................................................. 123

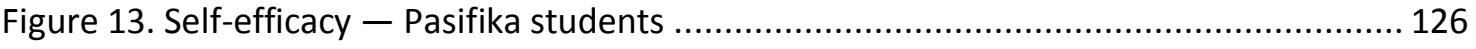

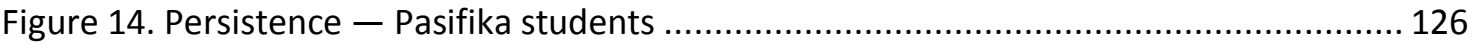

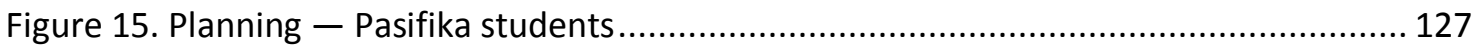

Figure 16. Mastery learning — Pasifika students ............................................................. 127

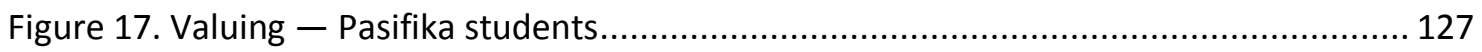

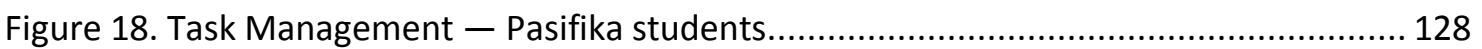

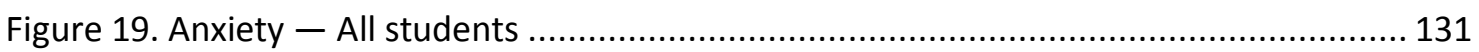

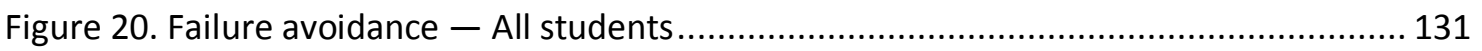

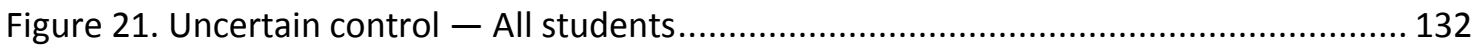

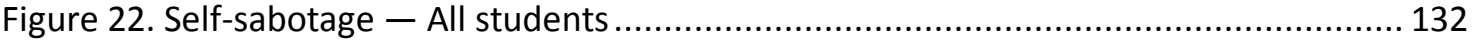

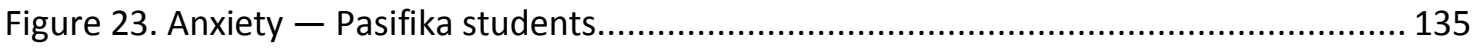

Figure 24. Failure-avoidance - Pasifika students............................................................. 135

Figure 25. Uncertain control - Pasifika students ............................................................ 136

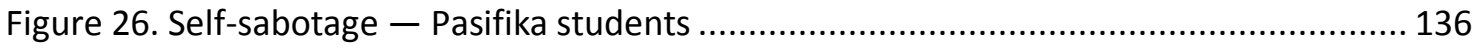

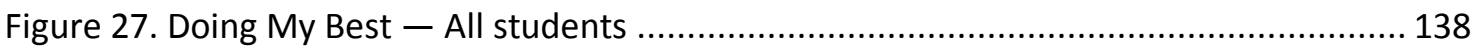




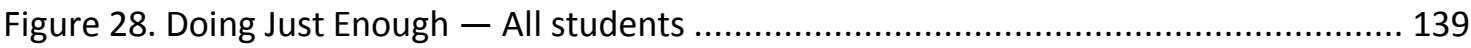

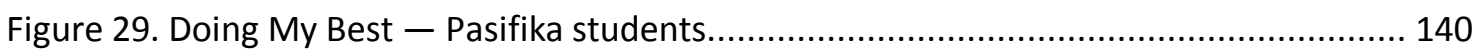

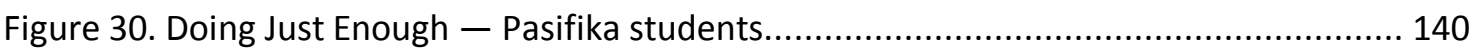

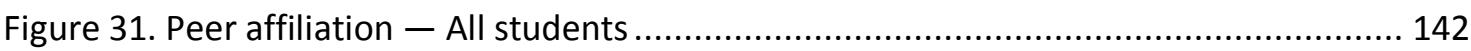

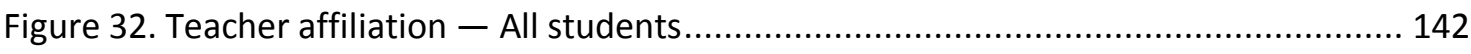

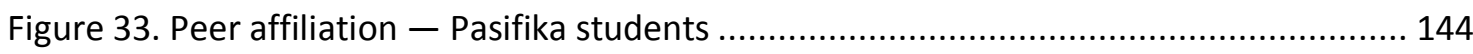

Figure 34. Teacher affiliation — Pasifika students .......................................................... 144

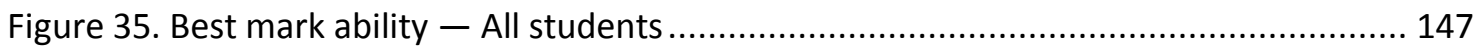

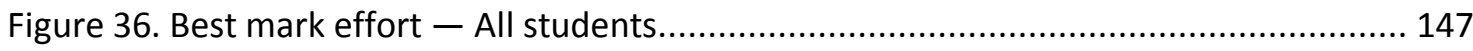

Figure 37. Best mark easy test - All students........................................................... 148

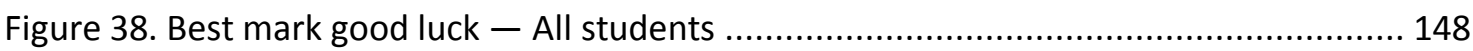

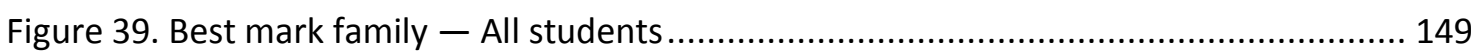

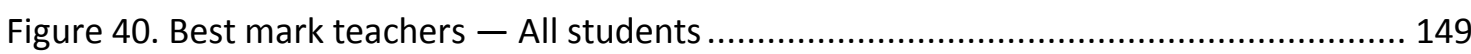

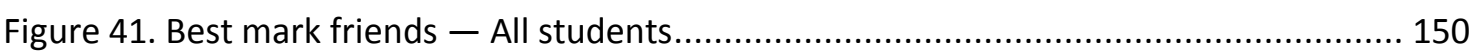

Figure 42. Best mark ability — Pasifika students ............................................................ 152

Figure 43. Best mark effort - Pasifika students............................................................... 153

Figure 44. Best mark easy test - Pasifika students ........................................................ 153

Figure 45. Best mark good luck — Pasifika students.......................................................... 154

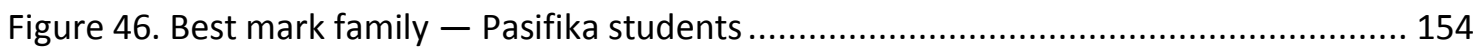

Figure 47. Best mark teacher — Pasifika students............................................................ 155

Figure 48. Best mark friends — Pasifika students ................................................................. 155

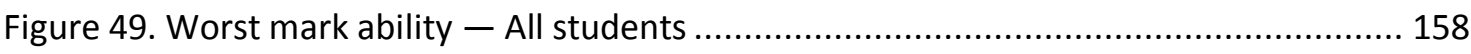

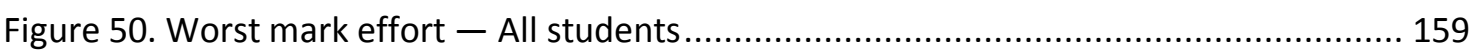

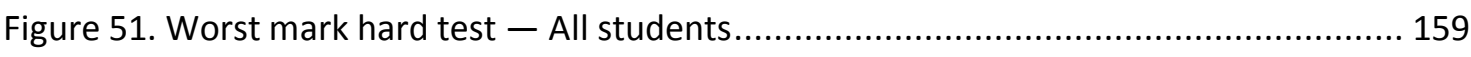

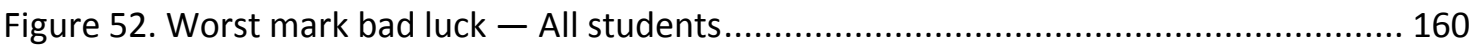

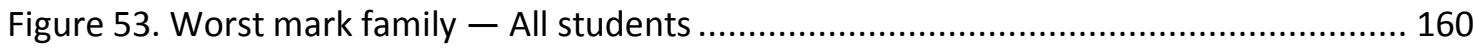

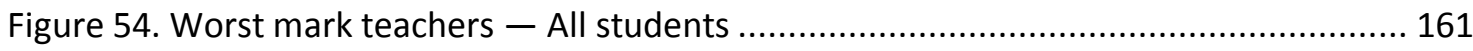

Figure 55. Worst mark friends - All students ............................................................... 161

Figure 56. Worst mark ability — Pasifika students ............................................................. 164

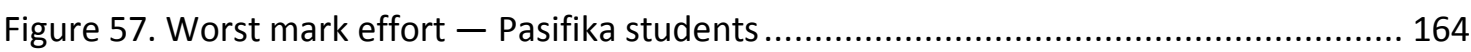

Figure 58. Worst mark hard test - Pasifika students ....................................................... 165

Figure 59. Worst mark bad luck — Pasifika students ...................................................... 165

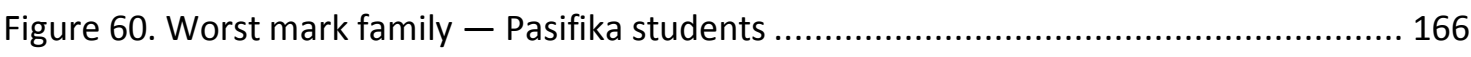

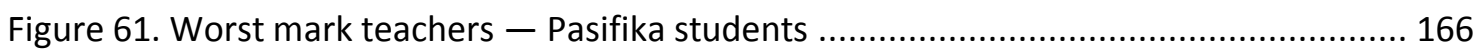


Figure 62. Worst mark friends - Pasifika students ....................................................... 167

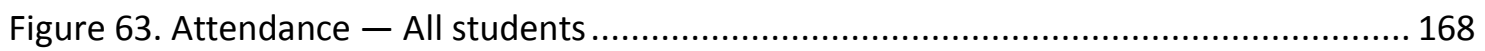

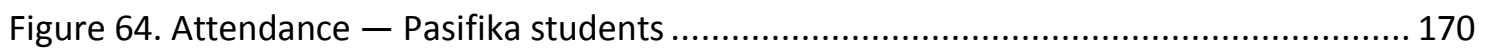

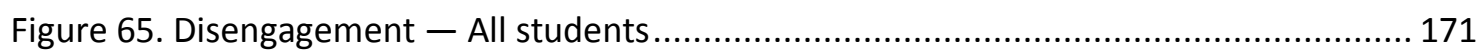

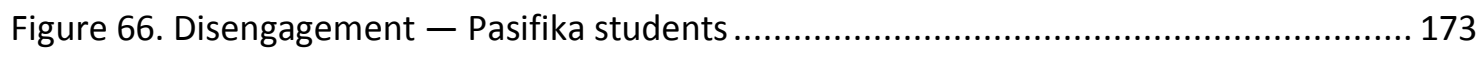

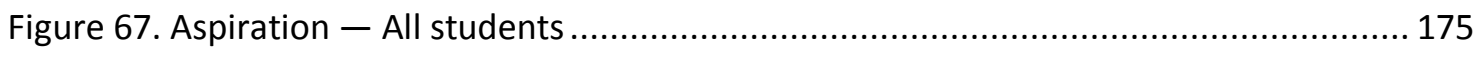

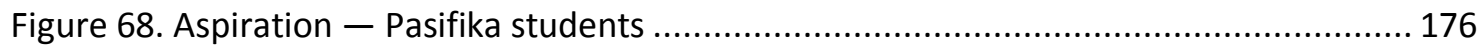


Motivation Interventions via Study Programmes for Under-achieving Students 


\section{List of Tables}

Table 1. Motivation Theories and Associated Constructs 58

Table 2. Adaptive and Maladaptive Motivation Constructs 59

Table 3. Module Contents for the Motivation-enhanced Study (MS) Support Programme...... 99

Table 4. Experimental design of this study 102

Table 5. NCEA Achievement Results as Mean Credits Earned by All Students

Participating in the Motivation-enhanced (MS) versus Traditional Study (TS) Skills Intervention Programmes

Table 6. Independent Samples Tests on Differences in NCEA Credits Earned by All Students in the MS versus TS Intervention Programmes

Table 7. NCEA Achievement Results as Mean Credits Earned by Pasifika Students Participating in the Motivation-enhanced Study (MS) versus Traditional Study (TS) Skills Intervention

Table 8. Independent Samples Tests on Differences in NCEA Credits Earned by Pasifika Students Only in the MS versus TS Intervention Programmes.....

Table 9. Adaptive Intra-personal Motivation Orientation Means for All Students Participating in the MS versus TS Programmes.

Table 10. Independent Samples Tests and Effect Size Calculations on Change Scores for the Adaptive Intra-personal Motivation Factors for All Students in the MS versus TS Intervention Programmes.

Table 11. Adaptive Intra-personal Motivation Orientation Means for Pasifika Students Participating in the MS versus TS Programmes.

Table 12. Independent Samples Tests and Effect Size Calculations on Change Scores for the Adaptive Intra-personal Motivation Factors for Pasifika Students in the MS versus TS Intervention Programmes.

Table 13. Changes in Maladaptive Intra-personal Motivation Orientations for All Students in the MS and TS Intervention Programmes.

Table 14. Independent Samples Tests and Effect Size Calculations on Change Scores for the Maladaptive Intra-personal Motivation Factors for All Students Participating in the MS versus TS Intervention Programmes

Table 15. Maladaptive Intra-personal Motivation Orientation Means for Pasifika Students Participating in the MS versus TS Programmes.

Table 16. Independent Samples Tests and Effect Size Calculations on Change Scores for the Maladaptive Intra-personal Motivation Factors for Pasifika Students Participating in the MS versus TS Intervention Programmes..... 
Table 17. Motivation Orientation Means for DMB and DJE for All Students Participating in the MS and TS Programmes.

Table 18. Independent Samples Tests and Effect Size Calculations on Change Scores for the Motivation Factors DMB and DJE for All Students in the MS versus TS Intervention Programmes

Table 19. Motivation Orientation Means for DMB and DJE for Pasifika Students

Participating in the MS and TS Programmes 139

Table 20. Independent Samples Tests and Effect Size Calculations on Change Scores for the Motivation Factors DMB and DJE for Pasifika Students in the MS versus TS Intervention Programmes.

Table 21. Inter-personal Motivation Factor - Means for All Students Participating in the MS versus TS Programmes

Table 22. Independent Samples Tests and Effect Size Calculations on Change Scores for the Inter-personal Motivation Orientations Peer Affiliation and Teacher Affiliation for All Students in the MS versus TS Programmes

Table 23. Peer Affiliation and Teacher Affiliation Means for Pasifika Students Participating in the MS versus TS Programmes.

Table 24. Independent Samples Tests and Effect Size Calculations on Change Scores for the Inter-personal Factors Peer Affiliation and Teacher Affiliation for Pasifika Students in the MS versus TS Programmes

Table 25. Best Mark Attributions Mean Scores by All Students Participating in the MS versus TS Programmes.

Table 26. Independent Samples Tests and Effect Size Calculations on Change Scores for Student Attributions for Best Marks in Assessments by All Students in the MS versus TS Intervention Programmes.

Table 27. Best Mark Attribution Mean Scores for Pasifika Students Participating in the MS versus TS Programmes.

Table 28. Independent Samples Tests and Effect Size Calculations on Change Scores for Attributions for Best Marks in Assessments for Pasifika Students in the MS versus TS Intervention Programmes.

Table 29. Worst Mark Attributions Mean Scores by All Students Participating in the MS versus TS Programmes.

Table 30. Independent Samples Tests and Effect Size Calculations on Change Scores for Attributions for Worst Marks in Assessments for All Students in the MS versus

TS Intervention Programmes

Table 31. Attribution Means for Worst Marks for Pasifika Students Participating in the MS versus TS Programmes.

Table 32. Independent Samples Tests and Effect Size Calculations on Change Scores for Attributions for Worst Marks in Assessments for Pasifika Students in the MS versus TS Intervention Programmes. 
Table 33. Attendance Means for All Students Participating in the MS versus

TS Programmes

Table 34. Independent Samples Tests and Effect Size Calculations on Change Scores for Attendance for All Students in the MS versus TS Intervention Programmes 168

Table 35. Attendance Means for Pasifika Students Participating in the MS versus TS Programmes

Table 36. Independent Samples Tests and Effect Size Calculations on Change Scores for Attendance for Pasifika Students in the MS versus TS Intervention Programmes

Table 37. Disengagement Means for All Students Participating in the MS versus TS Programmes

Table 38. Independent Samples Tests and Effect Size Calculations on Change Scores for Disengagement for All Students in the MS versus TS Intervention Programmes

Table 39. Disengagement Means for Pasifika Students Participating in the MS versus TS Programmes....

Table 40. Independent Samples Tests and Effect Size Calculations on Change Scores for Disengagement for Pasifika Students in the MS versus TS Intervention Programmes

Table 41. Aspiration Means for All Students Participating in the MS versus TS Programmes. 174

Table 42. Independent Samples Tests and Effect Size Calculations on Change Scores for Aspirations for all Students in the MS versus TS Intervention Programmes

Table 43. Aspiration Means for Pasifika Students Participating in the MS versus TS Programmes

Table 44. Independent Samples Tests and Effect Size Calculations on Change Scores for Aspirations for Pasifika Students in the MS versus TS Intervention Programmes....

Table 45. Summary of Changes on Motivation Orientations for Total Student Group and Pasifika Only Student Scores following the MS and TS Intervention Programmes.

Table 46. Summary of Changes on Mark Attributions for Total Student Group and Pasifika Only Student Group Mean scores following the MS and TS Intervention Programmes.....

Table 47. Summary of Changes on Mark Attributions for Total Student Group and Pasifika Only Student Group Mean scores following the MS and TS Intervention Programmes 
Motivation Interventions via Study Programmes for Under-achieving Students 


\section{Chapter One Introduction}

\section{What is known about Pasifika Student Achievement in New Zealand Secondary Schools?}

The under-achievement of some students in New Zealand secondary schools is of concern to educators, academics and policy-makers in the Ministry of Education. Of particular concern are patterns that show that Pasifika students have lower achievement outcomes than students from other ethnic groups. It is important to address the term "Pasifika". Schuster (2008) explained that:

"Pasifika is a collective term used to refer to people of Pacific heritage or ancestry who have migrated, or been born here in Aotearoa, New Zealand, Australia and the United States. Pasifika include recent migrants or first, second, third and subsequent generations of New Zealand-born Pasifika people. Pasifika are men, women and children of single or mixed heritages who identify themselves with their indigenous Pacific countries of origin because of ancestry or heritage, family and cultural connections with Samoa, Cook Islands, Tonga, Niue, Tokelau, Fiji, Solomon Islands, Tuvalu and other Pacific countries. Pasifika people are not homogenous and Pasifika does not refer to a single ethnicity, nationality, gender or culture" (p.12). 
The focus of this study is the academic under-achievement, by some students in New Zealand secondary schools. This research has a focus (but not an exclusive focus) on the under-achievement of some Pasifika students and interventions to address this challenge. Under-achievement is used in the context of school measures of assessment.

The under-achievement of some students is not new as shown by Biddulph, Biddulph and Biddulph's (2003) research which analysed all the major national and international assessment studies used to monitor achievement in New Zealand schools by ethnicity. The five major national and international assessment studies used to monitor achievement in New Zealand schools were the Third International Mathematics and Science Study (TIMSS) for Year 5 students; the National Education Monitoring Project (NEMP) for Years 4 and 8 students; the School Entry Assessment (SEA) for Year 1 students; the International Association for the Evaluation of Educational Achievement (IEA) on reading achievement for Year 5 students; and the Programme for International Student Assessment (PISA) for 15 year old students. Biddulph et al. (2003) concluded that in every one of these studies the achievement of Māori and Pasifika students was significantly lower compared to European and Asian students (p.50).

More recent research from 2008 showed that Pasifika students still had lower levels of academic achievement compared to students from other ethnic groups and that these differences were exhibited from a relatively early age. The NEMP (2008) Reading and 
Speaking website noted that "Year 4 Pasifika students scored moderately lower than pākehā students in both reading and speaking, a disparity which has decreased a little over the past eight years, but the corresponding differences for year 8 students are quite large and not decreasing". Phillips, McNaughton and McDonald (2002) also reported a gap in literacy after four years at school, evidencing significant differences in achievement between both Māori and Pasifika students and other students (p.11). This ethnic achievement pattern continues as students progress to secondary education with Māori and Pasifika students leaving school with significantly lower qualifications than Asian and European students. Analysis of the most recent data from the Education Counts website (www.educationcounts.govt.nz) - as at August 2014 - is shown in Figure 1 below. This shows that, although the achievement differences between ethnic groups may be decreasing, Pasifika students generally have lower levels of achievement than students in the other major ethnic groups in New Zealand secondary schools.

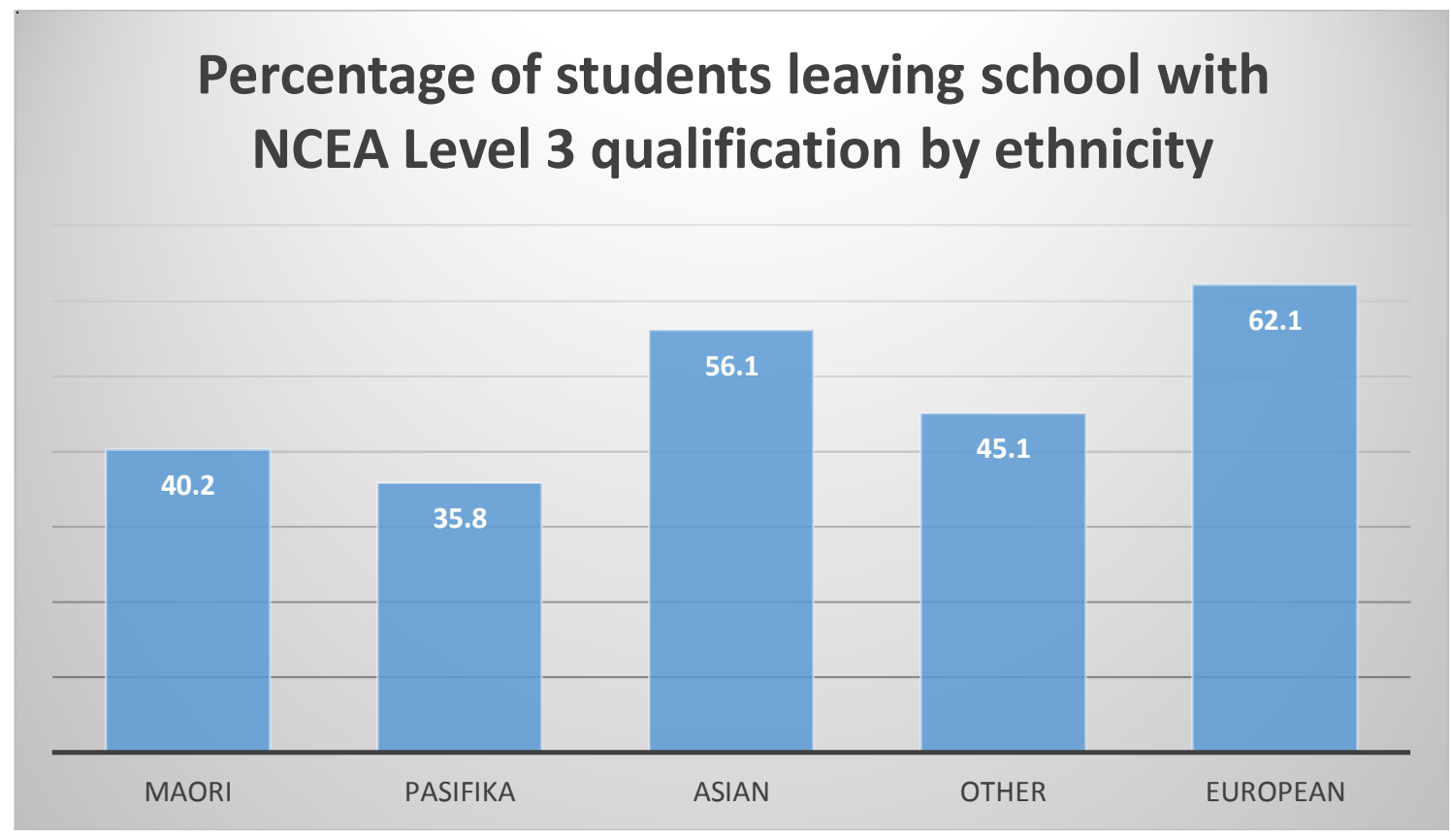

Figure 1. NCEA Level 3 leaving qualifications for Year 13 students, by ethnicity (source: Education Counts, www.educationcounts.govt.nz) 
Motivation Interventions via Study Programmes for Under-achieving Students

Other data show that there has been some improvement in Pasifika student achievement. For example, the most recent Pasifika Education Plan: Monitoring Report (2010) reported that $87 \%$ of Pasifika school leavers achieved National Certificate of Educational Achievement (NCEA) Level 1 literacy and numeracy requirements. The authors of this report considered that "This reflects the consistently increasing attainment trend for Pasifika students" and further reported that "Since 2005 there has been a total increase of 18.0 percentage points and that if this positive trend continues as expected, the 2012 forecast of $93 \%$ of Pasifika school leavers achieving NCEA Level 1 literacy and numeracy requirements will be met" (p.24). However, when the data about University Entrance are analysed there is still a problem. Students in New Zealand secondary schools can gain University entrance by attaining 14 credits towards the national Certificate of Achievement (NCEA) in three approved subjects. The Pasifika Education Plan: Monitoring Report (2010) notes that University Entrance (UE) "is not a qualification per se but is still a useful measure of success and future opportunity". This report also noted that "the gap between the proportion of Pasifika and the proportion of non-Pasifika students leaving school achieving a university entrance standard has stayed relatively even and large across the years" (p.32) as shown in Figure 2 below. 


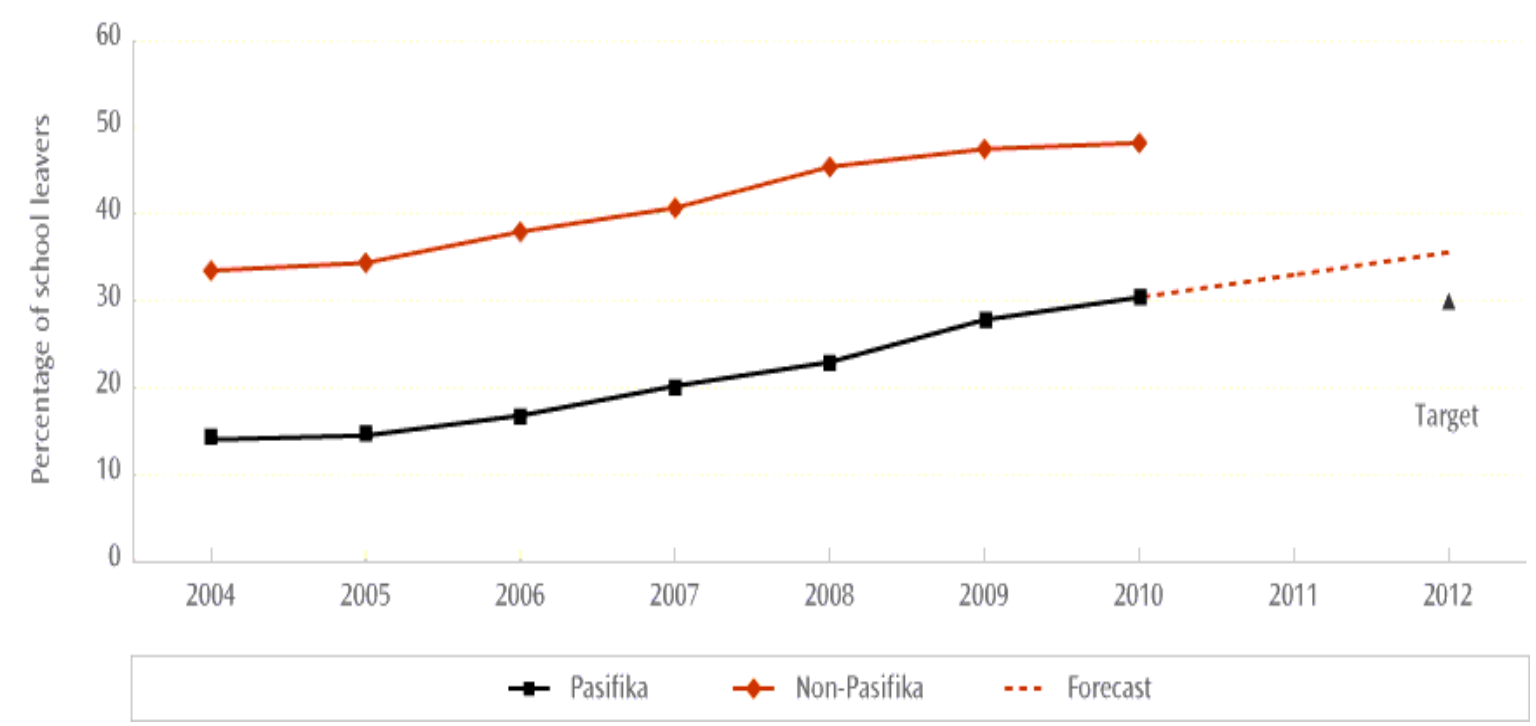

Figure 2. Percentage of school leavers with a University entrance standard (2004 to 2010) (source: The Pasifika Education Plan: Monitoring Report, 2010)

These data are of concern because low secondary school qualifications can limit student access to tertiary education including gaining entrance to university. The authors of the Pasifika Education Plan (2010) note that there has been a relative improvement between the numbers of Pasifika student school leavers achieving University entrance standard compared to non-Pasifika students but also note that "without intervention the disparity will remain large across the years to come" (p.32).

Hipkins (2013) analysed other data about New Zealand Secondary School students who had attained a minimum of NCEA Level 2 or an equivalent qualification, from 2003-2011. Hipkins reported that "Across the decade there have been steady gains in success rates for all ethnic groups, although only Asian students are achieving at the target level (85\%)" (p.5). Hipkins concluded that "the rate of these increases will need to be accelerated if the target is to be met because there were still clear differences in the achievement rates of students with differing ethnic backgrounds and that success 
rates for Māori students will require the strongest boost, followed by those for Pasifika students" (p.5).

One other reason that the achievement of Pasifika students is of particular interest to policy makers, academics and educators in New Zealand is that the Pasifika population is growing at a faster rate than some other ethnic groups. For example, the Literacy Environments for Accelerated Progress Programme (LEAP) (2009) website noted that the percentage of Pasifika students in New Zealand schools is predicted to double over the next 40 years and this increased diversity in classrooms will require teachers to respond to the learning needs of Pasifika students. Alton-Lee (2003) also reported that by 2040 , projections indicated that the majority of students in New Zealand primary schools would be Māori and Pasifika (p.5). Because the student populations of individual Pacific Island nation children in New Zealand secondary schools are relatively small, researchers have tended to amalgamate individual Pacific Island nation student achievement as "Pasifika" student achievement. Biddulph et al. (2003) reported that while there are common elements among students who make up the ethnic group termed "Pasifika" students, in fact they are not a homogenous group (p.47). Alton-Lee (2003) also noted that the expression "Pasifika umbrella" covered a wide range of Pacific Island diversity (p.6). Robinson and Timperley (2004) noted that there was pressure on the Ministry of Education to improve the achievement of Pasifika students and that this was an urgent issue (p.108). For these reasons this research investigates interventions to improve the under-achievement of some students at New Zealand Secondary Schools that enrol large percentages of Pasifika students. 
The next chapter investigates literature related to improving motivation and achievement in a Secondary School context. Four inter-related bodies of work are discussed, starting with the large collection of international research from the field of motivation and achievement. Next, New Zealand research which examined the impact of the NCEA on student motivation and achievement in New Zealand secondary schools is considered. This includes Meyer, McClure, Walkey, McKenzie, and Weir (2006); Meyer, Weir, McClure, Walkey, and McKenzie (2007); Meyer, Weir, McClure, Walkey, and McKenzie (2009); Graham, Meyer, McKenzie, McClure, and Weir (2010); McClure, Meyer, Garisch, Fischer, Weir, and Walkey (2011); and Walkey, McClure, Meyer, and Weir (2013). Third, research about interventions which have been designed to change motivation and achievement is reviewed. This includes analyses by Allan, Pianta, Gregory, Mikami and Lun (2011), Wigfield and Wentzel (2007) as well as research in an Australian context from Martin (2005, 2008). Finally, literature from the field of culturally responsive teaching is reviewed including Sleeter (2011) and the New Zealand based Te Kotahitanga research from Bishop, Berryman, Cavanagh and Teddy (2009). 
Motivation Interventions via Study Programmes for Under-achieving Students 


\section{Chapter Two \\ Literature Review}

\section{Introduction}

This chapter provides an overview of the relevant research literature about this study's basic premise - that motivation can be influenced by intervention and that, following intervention, changes in motivation may be associated with changes in achievement. This chapter has six sections:

- Section one locates the research in the context of the field and related fields motivation, achievement and interventions.

- Section two outlines the theoretical framework of this study which is based on six major motivation theories - self-efficacy, expectancy-value, goal, selfdetermination, self-worth and attribution motivation theory.

- Section three reviews literature about Pasifika education research findings in the New Zealand context.

- Section four reviews literature about interventions based on attribution theory.

- Section five reviews literature about interventions based on goal theory.

- Section six reviews literature about interventions based on intra-personal motivation theory. 


\section{Section One: The Field (and Related Fields) of this Research}

The major fields in which this research is located are interventions associated with motivation and achievement theories. This research focuses on the effectiveness of a motivation-enhanced study skills intervention programme to address the achievement outcomes of under-achieving students in New Zealand high schools. The study also has a focus, but not a sole one, on the achievement outcomes of Pasifika students. In a special issue of Educational Psychologist Wentzel and Wigfield (2007) discussed research about the topic "Motivation Interventions That Work". They outlined four issues that remain a challenge for motivation interventions, all of which are relevant to this research.

The first is "the importance of having clear theoretical foundations and constructs for the development of successful interventions" (p.262). The theoretical framework of this research is outlined fully in section 2 of this chapter. However the field of motivation achievement theory is wide and this research focused on interventions which were based upon attribution, goal and intra-personal motivation theories. One other important aspect of this study with regard to its theoretical foundations is that this study focuses on both traditional and less traditional views of motivation and achievement. This study considers "Western" views of motivation and achievement such as traditional attribution theory - ability, effort, luck and task difficulty. However, the study also investigates less traditional "non-Western" goal theory, such as how interventions may affect social goals and achievement. 
Wentzel and Wigfield (2007) also reported that it was important to have "further consideration of what, if anything, is unique about one's ethnic experiences at school that might require specific intervention strategies to enhance their motivation, as compared to attempting to develop interventions that are aimed at all students" (p.262). This idea is important to this research because one focus of this study is the effects of a motivation-enhanced intervention on the achievement of under-achieving Pasifika students in New Zealand high schools.

Wentzel and Wigfield (2007) also reported that "the role of social relationships and supports in motivating positive social adjustment and achievement in school" (p.262) was important. This study followed a social-cognitive view of motivation and achievement including the importance of the role that teachers play in motivation and achievement. This supports Hattie's (2009) conclusion that "The major message is simple - what teachers do matters... in particular they intervene in calculated and meaningful ways to alter the direction of learning to attain various shared, specific, and challenging goals" (p.22).

Finally Wentzel and Wigfield (2007) noted "the need for interventions to use strong research designs and high-quality measures" (p.262). The methodology of this research is outlined fully in Chapter Three of this study which fully explains the twophase, sequential explanatory mixed-methods design of this study. Quantitative data about the effects of the two motivation interventions in this study are based on two main instruments. The first is Martin's $(2001,2005,2008)$ Student Motivation and Engagement Scale (MES-HS). Martin (2005) stated that the Student Motivation and 
Engagement Scale was based on valid and reliable psychometric principles. For example, Martin had previously used factor analysis procedures to examine the structure of the MES-HS which confirmed the instrument's reliability, normal dimensions of distribution, significant association with achievement outcomes as well as being "sensitive to age and gender related differences in motivation" (p.181).

The second instrument used in this study is the Survey of NCEA Goals Year 10 and Year 11 Students (2008) designed and tested by Meyer and her colleagues. Meyer et al. (2009) explain that this instrument was "designed to solicit self-ratings from Year 10 and Year 11 students on their motivation orientations, attributions about performance on assessments, and the influences of family/whānau, teachers and friends/peers on student learning and achievement" (p.18). Meyer et al. (2009) also reported that the Survey of NCEA Goals Year 10 and Year 11 Students had been analysed using Confirmatory Factor Analyses. They confirmed that the four factors their instrument measured "performed well statistically" (p.64), with "high reliability" which generated “highly predictive results" (p.4).

It may be considered that this study addresses four of Wentzel and Wigfield's (2007) issues about motivation intervention research because this study is based upon clear theoretical foundations and constructs, considers motivation and achievement from an ethnic minority student perspective, follows social-cognitive concepts and utilises two psychometrically validated survey measures in a mixed-methods research design. The next section of this chapter outlines the theoretical framework of this study in more detail. 


\section{Section Two: Theoretical Framework}

The theoretical framework of this study is situated within six seminal motivation theories - self-efficacy, expectancy-value, goal, self-determination, self-worth and attribution motivation theory. Ames and Ames (1984) believe that one reason educators are interested in motivation is because there is a general assumption that higher levels of motivation are related to higher levels of achievement (p.536). Martin (2001) also reported that motivation underpins achievement (p.1). Ames and Ames (1984) further noted that, while motivation is generally regarded as a mediating factor in achievement outcomes, motivation can also be viewed as a goal in itself (p.536). In this way, motivation has intrinsic value as well as being extrinsically related to achievement.

Atkinson (1957) noted that a "motive" may be viewed as a non-directive, energising drive or disposition to strive for a certain kind of satisfaction; for example a motive for affiliation, power or achievement (p.360). Martin (2002) concurred, conceptualising motivation as a "student's energy and drive to learn, (to) work hard, achieve at school, and (to) engage in the necessary behaviours to maximise achievement following this energy and drive (p.35). However more recent work from Martin (Martin and Dowson, 2009) is closer to Wentzel's (1999) ideas which defined motivation as a set of interrelated beliefs and emotions that influence and direct behaviour (p.328). Martin and Dowson (2009) may have shifted from viewing motivation solely as a quantitative concept towards appreciating both quantitative and qualitative perspectives of motivation. When motivation is viewed as a quantitative variable, motivation is an 
entity associated with activity, energy and persistence, but when motivation is viewed as a qualitative variable, motivation can be defined as a student's cognition of their academic performance (Ames and Ames, 1984:535).

Martin and Dowson (2009) have expanded their definition of motivation because they believe that key motivation theories and achievement can be better understood using the concept of "relationships" as an overarching framework (p.327). They based their views on relationships, motivation and achievement on the concept of "modelling" of behaviour. If a student has a good relationship with a teacher, then that student may internalise some of the teacher's beliefs and values about schoolwork. For example, if a teacher believed that persistence, goal-striving and self-regulation were important to achievement, a student who related well to that teacher is more likely to show enhanced levels of persistence, goal-striving and self-regulation (p.330).

This research assumes there is value in gaining and analysing both quantitative and qualitative data about motivation for several reasons. First, the key messages the intervention delivered, for example "Yes it is hard but keep trying" and "You belong here", are clearly relational and more qualitative in nature. Second, this study sought the views of the students who were part of the intervention programme asking them, for example, "What part of the programme helped you the most? What part didn't help you or didn't make sense to you?" and these are also qualitative questions. Third, measures of motivation are made using instruments from Meyer et al. (2009) and Martin (2008), as these are more quantitative in nature. Finally, this study adopts a 
mixed-method research design, as both quantitative and qualitative data were gathered, analysed and discussed.

Martin and Dowson (2009) listed the main achievement motivation theories as attribution, expectancy-value, goal, self-determination, self-efficacy and self-worth motivation theories (p.330). Martin (2001) believed that an understanding of each of these individual theories would assist educators to improve their understanding of why, how, and the way students are motivated to achieve (p.1). This section gives a detailed explanation of how these major motivation theories are related to achievement and how the relationship construct can be viewed as being common or overarching to all motivation theories. Therefore the theoretical framework for this study is particularly based on an intervention informed by attribution, goal and intrapersonal motivation theories and how these may be associated with changes in achievement.

\section{Attribution Motivation Theory}

Weiner (1985) explained that attribution motivation theory attempted to answer "why" an event has occurred (p.549). Martin and Dowson (2009) noted that in the education context, four attributions are commonly held by students; luck, task difficulty, ability and effort (p.333). Weiner (1985) further reported that attribution motivation theory had a three-dimensional nature: locus, stability and control (p.551). These dimensions have been carefully studied and reported upon by various researchers (for example, Ng, McClure, Walkey and Hunt, 1995; Martin and Dowson, 
2009; Meyer et al., 2009; Weiner, 1985). They explained that locus refers to the location of the attribution as being internally or externally located in a student's mind. Ability and effort are considered internally positioned, whereas task difficulty and luck are externally located. Control refers to a student's belief about how their preparation for a particular assessment affects the subsequent outcome.

For example, if a student attributes a poor test result to lack of effort, they may believe that with more effort they could do better in another test situation. Effort is considered easy to change, less de-motivating, and perhaps even motivating. Conversely if the student attributes the poor test result to their own low level of ability, this attribution may be considered less easy to change and more demotivating. This links to the third dimension of attribution - stability - which is exemplified by how hard a student thinks it would be to change the mark they received in an assessment. Martin and Dowson (2009) showed that in an education context, the concept of relationships can lead to increased understanding of attribution motivation theory by considering teacher feedback. In a classroom assessment situation, a teacher may give positive feedback such as "Well done, you must have worked hard". The student may attribute their grade to their effort and have increased motivation to achieve. Conversely, negative feedback, like "Did you even study for the test?" could cause negative attributions about results, and subsequent student de-motivation to achieve (p.334). This means that attribution motivation theory needs to consider more than just the traditional attributions of luck, task difficulty, ability and effort. Social attributions - how students perceive their teachers, peers, and family to be associated with their best and worst marks in 
assessments - also need to be considered. These social attributions may also be impacted by intervention which in turn could affect achievement (McClure et al., 2011).

\section{Goal Motivation Theory}

Martin and Dowson (2009) explained that goal motivation theory was related to achievement through the meanings and goals students attached to assessments. They further outlined that goal motivation theory was useful in the educational context because it "located" where a student was on an "approach-avoidance" continuum. For example, a student who willingly chooses to participate in a classroom activity would be more positively motivated than a student who avoids taking an assessment because they think they will fail. Again the relationship concept can assist understanding of this motivation theory because a good teacher-student relationship can assist a sense of "belonging" in the classroom, which is fundamental to student achievement (p.335). However, it is important to remember that goal theory incorporates more than performance and mastery goals and this study includes a full consideration of the possible effects of interventions on social goals and achievement (Dowson and Mclnerney, 2003; Urdan and Maehr, 1995; Wentzel, Battle, Russell and Looney, 2010).

\section{Expectancy-value Motivation Theory}

Atkinson (1957) explained that under expectancy-value motivation theory, motivation was the product of motive, multiplied by expectancy of success, multiplied by 
incentive to succeed (p.360). Martin and Dowson (2009) explained that in an educational context a student had higher motivation if they valued the task and had a high expectation they would succeed (p.334). Again the relationship construct helps educators understand expectancy-value motivation theory. Wigfield, Galper, Denton and Seefeldt (1999) reported that teachers who expected less of particular students gave them correspondingly less demanding work (p.98). They also reported that teachers could accurately predict the achievement level that a student would attain in advance and concluded that this proved teacher expectation was a valid predictor of student achievement (p.104). However Rubie-Davies, Hattie and Hamilton (2003) disagreed because they found that teachers predicted lower achievement for Māori students despite teachers using pre-test data that showed Māori students had the same achievement levels as students from other ethnic groups. Subsequent Māori students' achievement was worse than other ethnic groups and Rubie-Davies et al. (2003) concluded that teacher expectation was actually a self-fulfilling prophecy (p.12). Turner (2014) reported that the effect of teacher expectation on achievement is still a current issue in New Zealand schools.

Some New Zealand research shows differences in teacher expectations by school decile level. For example Meyer et al. (2007) reported that teachers at high decile schools were more inclined to categorise students as having low or high motivation or seeing students as belonging to low, middle or high achievement groups. They reported that "In contrast, preliminary focus group data from teachers and students at wharekura and low decile schools rejected categorisations and instead considered that all students can be motivated to do their best to achieve" (p.3). These findings 
may indicate that some teachers in higher decile schools may hold negative views of some students' levels of motivation and achievement potential, and support the findings of Bishop et al. (2009) about some teachers' deficit views of some students. These ideas about variations in teacher-expectations are relevant to this study because Meyer et al. (2007) further reported that "teacher, parent and student attitudes about whether motivations can be changed are crucial to interventions to promote positive student achievement" (p.3).

\section{Self-determination, Self-efficacy and Self-worth Motivation Theories}

Martin and Dowson (2009) explained that self-determination motivation theory was based on the concept that a student's psychological needs of relatedness, competence and autonomy must be met before achievement could occur. The relationship concept is relevant to this motivation theory because a student's perception of the teacherstudent relationship will affect their self-determination, motivation and subsequent achievement (p.335).

Bandura (2007) reported that self-efficacy motivation theory accounted for some of the observed variance in student's academic achievement (p.650) and Martin (2001) explained that students with high self-efficacy could find alternative solutions more easily, made more effort and were more persistent at tasks compared to students with lower levels of self-efficacy who tended to focus on their deficiencies (p.3). Martin and Dowson (2009) concluded that student self-efficacy could be enhanced 
through positive teacher-student relationships because self-efficacy was usually improved through positive relationships with others in a social setting (p.336).

Finally, Covington and Omelich (1980) explained that self-worth motivation theory was important to a student's perception of ability. Self-worth improves when effort in the classroom results in the student gaining confidence in their ability to succeed. Conversely there are negative consequences for self-worth if a student does try hard but is not successful as this could lead to the student concluding they have low ability. There is common ground here between self-worth theory and attribution theory and Meyer, McClure, Walkey, McKenzie and Weir (2006) cited Dweck (1992) who showed that students can view ability in one of two ways: "either a static entity that cannot be changed or an incremental set of skills and knowledge that can be expanded" (p.9). Meyer et al. (2006) further noted that harm can occur if a student believes "they are simply not smart enough to do what is expected of them in school" and believed that students needed to see ability as being an expandable set of skills or they may adopt a “maladaptive helpless orientation" (p.9). Martin (2007) viewed motivation orientations as being adaptive or maladaptive (p.414). This dual nature of motivation orientation is fundamental to the theory base of this research proposal because any planned intervention will attempt to lessen maladaptive student motivation and increase adaptive motivation orientations. Again the concept of relationship can assist understanding of self-worth motivation theory. Martin and Dowson (2009) reported that good parent-child relationships were important because a child models their behaviour on the way they see their parents dealing with their own self-worth issues (p.337). Wentzel (1999) also associated self-worth motivation orientation with 
relationships and showed that teacher approval was correlated with a student's sense of self-worth (p.77).

In addition to the association between relationships and motivation, there is a considerable field of literature that reports the importance of relationships to general student achievement at school. Both teacher-student and parent-child relationships are important, although teacher-student relationships have been shown to have greater impact on achievement than parent-child relationships. Field, Diego and Sanders (2002) reported that parent-child relationships and achievement are related. They noted that high-quality parent relationships were significantly related to a higher grade point average compared to low-quality parent-child relationships (p.125). Martin, Marsh, Mclnerney, Green and Dowson (2007) analysed the role of teacherstudent and parent-child relationships played in students' academic motivation and engagement, self-concept and general esteem. They found that while both types of relationships were important to these issues, teacher-student relationships were most strongly associated with academic concepts (p.118).

The effect a teacher has on student achievement has been quantified. Hattie (2003) reported that six factors were related to observed variation in student achievement: curricula, policy, school climate, the teacher, teaching strategies, and the home. In his meta-analysis of research in this area, Hattie calculated the effect-size of each factor on student achievement and concluded that students themselves account for $50 \%$ of the observed variance in achievement, teachers contribute $30 \%$, and the home contributes just $5-10 \%$ of the variation. Hattie concluded that apart from the students 
themselves, the teacher makes the greatest difference in variance in student achievement.

Hattie (2003) concluded that, because enhancing what the teacher does in the classroom may have the greatest effect on achievement, "we should focus on the greatest source of variance that can make the difference - the teacher and her or his teaching. We must work to support what I see as the new direction from the Ministry of Education to highlight teachers and teaching as the policy focus. We need to ensure that the influence of teachers is optimised to have powerful and sensationally positive effects on the learner. We need to direct attention at higher quality teaching" (p.10).

\section{Cultural Influences}

Some research shows that some Pasifika students may be operating from a collectivist rather than an individualistic view. These ideas are relevant to the theoretical framework of this study because, as McClure et al. (2011) explained, some Pasifika students may hold ideas that "outcomes are construed not only in terms of the individual but in terms of their effects for the family and other people" and may have a "concept of the self [that] includes these others who are close to them" (Markus and Kitayama, 1991). Research indicates that "participants from more collectivist societies attribute their outcomes to social influences more than people from individualistic cultures" (p.72). 
A mixture of internal and external factors are relevant to the wider context of influences on under-achievement for all students, and there are some that are more specific for Pasifika students. When a student is considered to be under-achieving, this may be considered to be a cumulative product of the particular student's experiences. These experiences all contribute to achievement or under-achievement and may have been internalised by the student. These include a student's prior achievement at school, personality influences, socio-economic status, and parental and family expectations. Suggestions from the Pasifika Education Plan are important here. Friends and classmates also have an influence on student achievement, as well as school system factors, including the way NCEA is structured, the effects of part-time work, looking after children responsibilities and knowing about endorsements in NCEA. Finally, the impact of teachers on students' achievement is considered, especially teacher-student relationships and teacher strategies that have been shown to be associated with Pasifika student achievement

Ideas about prior achievement at school are relevant to the study because by the time students get to be in Year 11 of the New Zealand Secondary School system they have experienced 10 years of schooling. Very likely most Year 11 students have a clear perception of how well they are going to do in their first year of in NCEA based upon how well they have done those previous 10 years. Hattie (2009) reported that high school students are accurate in their self-assessment and their understanding of their achievement levels across all subjects, and Kuncel, Crede, and Thomas (2005) suggested that students" "own expectations of success (which are sometimes set lower than students could attain) may become a barrier for some students as they 
may only perform to whatever expectations they already have of their ability" (p.43). For example, Hattie (2009) reported that "students not only bring to school their prior achievement (from preschool, home, and genetics), but also a set of personal dispositions that can have a marked effect on the outcomes of schooling" (p.41). Hattie reported that what the child brings to the classroom each year is very much related to their achievement in previous years, often referred to as the "Matthew effect", where students who have experienced success in previous years of schooling are likely to continue on a sharper trajectory of achievement than students who have experienced a lower level of achievement.

Personality influences held by individual students such as self-concept, self-estimates of ability and persistence have been shown to influence achievement (for example, Ross, 1988; Findlay and Cooper, 1983). The ideas students hold about ability are relevant to the study because it is important to ensure that students understand that their prior views of their "ability" are not fixed and can change in relation to the amount of effort that they put in. These personality influences are also related to the intra-personal motivation orientations, which are part of the motivation enhanced study skills programme. Another personality influence is a student's sense of control over their learning. This relates to the idea that a student gets a particular mark in an assessment and understands why they got that mark, as well as how to replicate it (assuming that it was a good mark). Decreasing uncertain control is another part of the motivation enhanced study skills programme. 
Socio-economic status (SES) is relevant to this study. Some Pasifika families may hold low-waged occupations, but study rejects the deficit views held by some educators who view influences from a student's home in a negative way, and use SES arguments to explain lack of achievement (for example Bishop et al., 2009). SES may be used in a fatalistic way to explain student under-achievement, but this intervention study promotes the view that educators are resourced to raise the achievement of the students in a particular year, regardless of SES.

Most families in New Zealand, including Pasifika families, have high parental expectations and aspirations for the educational success of their sons and daughters. For example, Hattie (2009) reported that the "Flaxmere study found that, when their children started school, 98 percent of the parents considered that education was very or extremely important to their children's future. Two-thirds of these parents expected their children to attain diplomas and degrees" (p.71). However, since many teachers in New Zealand schools are non-Pasifika, it is important that schools understand Pasifika cultural values. For example, Hunter and Andrews (2011) reported that research argues "for classrooms to be more inclusive and to build on the cultural capital of Pasifika students - and respect their concept of community and collectivism" (p.104). Fletcher et al., (2009) concurred and reported that "The Ministry of Education (2003b, 2006) stresses that teachers need to view diversity as enriching the classroom community and so allow students to utilise their prior knowledge as a foundation for scaffolding their learning. They emphasise that making connections between the meanings children gain from their own worlds and the meanings they gain from their school enhances learning" (p.28). 
Meyer et al., (2009) reported that students said "their families expected them to do well, took an interest in their schoolwork, and even offered specific rewards for achievement outcomes. There were several comments about older siblings who had left school early and had limited career opportunities or other serious difficulties they were less than positive models and were cited as motivators for them to stay in school and achieve so that their future would be better" (p.5).

The Pasifika Education Plan 2013-2017 puts "Pasifika learners, their parents, families and communities at the centre, so that all activities ensure the Ministry of Education and Education Partner Agencies are responding to the identities, languages and cultures of each Pasifika group. Pasifika success will be characterised by demanding, vibrant, dynamic, successful Pasifika learners, secure and confident in their identities, languages and cultures, navigating through all curriculum areas such as the arts, sciences, technology, social sciences and mathematics. Data and information will be used to increase the knowledge and voice of Pasifika learners, parents, families and communities, so they can demand better outcomes and influence the education system from within" (p.3). The associated PEP Implementation Plan 20132017 outlines a number of actions, and Action Point 6 is the most relevant to this research - implement focused programmes and activities in targeted secondary and primary schools with high Pasifika rolls to increase and accelerate Pasifika achievement. The PEP Implementation Plan 2013-2017 gives as one example the Pasifika PowerUP programme, which is described as "a programme that has been designed specifically for you and your children, your family and community. It 
supports the Ministry of Education's Pasifika Education Plan 2013-2017 and focuses on increasing Pasifika student achievement and success in education. The programme is focused at raising NCEA level achievement" (p.8).

Friends and classmates have an influence on student achievement. These influences can be both positive and negative; for example Meyer et al., (2009) investigated the influences of friends on achievement and reported that "[f]riends could motivate higher achievement by supporting study behaviour, by not distracting students with social demands, and through 'friendly competition' with one another to see who could get the highest number of Merit and Excellence credits. Friends could also be a negative influence, and students didn't like to be in groups that were predominantly comprised of poorly motivated and low achieving students. They emphasised the difficulties of being motivated and working hard when surrounded by others who didn't seem to care or couldn't do the work" (p.5). In related research Fletcher et al., (2006) showed that many of the Pasifika students who were under-achieving in reading were concerned about the noisy classroom environments and the misbehaviour of some of their non-Pasifika classmates. Many New Zealand classrooms encourage working collaboratively with peers and engaging in active discussion on relevant issues which Fletcher et al., (2006) explain can lead to a situation where "[a] dichotomy can occur for Pasifika students and particularly their parents whose schooling, in their islands of origin, would have comprised of a more authoritarian approach (Taleni, Fletcher, Parkhill, \& Fa'afoi, 2005)” (p.32). 
Motivation Interventions via Study Programmes for Under-achieving Students

System factors can impact on under-achievement. These include the way NCEA is structured, the effects of part-time work, and childcare responsibilities. Meyer et al., (2009) reported that, although students liked internal assessments for NCEA, they were concerned about the differences between schools that allowed the resubmission of internally assessed standards and had mixed opinions about the relative value of unit standards and achievement standards (p.5).

Finally school factors, especially teachers, impact on students' achievement. For example Meyer et al., (2009) investigated the influences of teachers on achievement and reported that while most of these comments were positive, such as comments about "teachers who knew their subject but also made learning fun and interesting, and teachers who treated them with respect" (p.5), there were also negative comments such as those about "teachers who seemed to have favourites, were sexist, got angry, and/or who couldn't control their classes" (p.5).

Meyer et al., (2009) investigated the connection between student motivation patterns and relationships with teachers. They found "significant relationships between the motivation dimensions and these interpersonal influences: Students high on Doing Just Enough reported that their teachers did not take a personal interest in their achievement, whereas students high on Doing My Best reported that teachers showed interest in them and in their work" (p.12). Fletcher et al., (2008) concurred and reported that Pasifika students wanted their teachers to care. Some Pasifika students interpret a poor teacher student relationship as racism (see, for example, Fletcher et al., 2008). 
There is some research that reports differences in Pacifika and non-Pacifika students about respect for teachers in the classroom. Hunter and Anthony (2011) reported that “Jones (1991) and Clarke (2001) describe how Pasifika students and their studies identified listening to the teacher is an appropriate way to learn. The students considered the teacher to be the elder and therefore their knowledge unquestionable. Likewise, the student's view arguing with, or asking teachers questions, to be respectful because it was their responsibility to listen closely and learn from the teacher" (p.103). However this view of respect for the teacher may result in passive participation. For example, Hunter and Anthony (2011) reported that some Pasifika students "outlined how for them learning mathematics entailed listening to the teacher, working hard, and paying close attention to what the teacher said or did. They considered that it was his responsibility to tell them what to do, explain the mathematics, show them a range of different strategies, and question them" (p.107).

There are a variety of teacher strategies that may enhance Pacifika student achievement that educators could try in the classroom. For example Fletcher et al., (2008) reported that feedback and "feedforward" was important to Pasifika students. Another strategy is group work learning, which many teachers use in classrooms. Hunter and Anthony (2011) asked students about why they prefer to work in groups and reported that "[t]he students outlined how the smaller group provided opportunities to learn from each other, noting that they now regarded mathematics as more difficult to learn on their own" (p.108). There appear to be sound educational reasons why smaller groups work better. One student in Hunter and Anthony's (2011) 
Motivation Interventions via Study Programmes for Under-achieving Students

study further explained: "When we are talking in a big circle there are too many people and so I do not ask a question" (p.108). Another student reported that "[w]orking in the group, is a lot better because I have people to help me and I learn different strategies from other people. Working in a group this year has been important for my learning and that is what is helping me" (p.109).

The reason that group work may lead to increased achievement is because students may increase in confidence to offer suggestions in the wider group. As another student in Hunter and Anthony's (2011) study explained: "It is just like saying you don't really get it and then others help you. Your team helps you to explain it for the bigger group. You are learning by building your confidence. You are learning as well because you are working out a problem, you are working out a problem and you are speaking at the same time. Before you speak, you have to think and work it out first" (p.110). Hunter and Anthony explained that "[t]he importance of asking questions in both the small and larger group was also readily acknowledged by the students. They stated an increase in confidence and competence to ask questions" (p.110). Further Hunter and Anthony explained that now students "had a range of ways to participate and meet mathematical challenges head on. These included discussion with other individuals, the teacher, their group, or with themselves. The teacher was positioned as only one source (among others) to draw on and they described how they requested his help only when they were really stuck" (p.112).

For these sorts of reasons, section three reviews literature about Pasifika education research findings in the New Zealand context. 


\section{Section Three: Pasifika Student Achievement in the NZ Context}

In 2002, Coxon, Anae, Mara, Wendt-Samu and Finau (2002) produced the Literature Review on Pasifika Education Issues which aimed to "Identify and review existing research on Pasifika education issues across the whole of the education sector and including those involving Pasifika communities" (p.2). This review aimed to identify "research topics which the Ministry [of Education in New Zealand] may investigate as part of the initiatives aimed at improving achievement and reducing disparities for Pasifika students" (p.2).

From the compulsory education sector, Coxon et al. (2002) discussed the Strengthening Schools in Mangere and Otara (SEMO) Ministry of Education initiative that was "designed to strengthen the capacity of the schools and communities of Mangere and Otara to offer high quality learning environments for children where resident populations are predominantly Māori and Pasifika, and where primary and secondary schools are predominantly decile one" (p.54). A variety of reports about research emanated from the SEMO initiative, including one from Milward, Neal, Kofoed, Parr, Kuin Lai and Robinson (2001), about a literacy intervention at Dawson Road Primary School which is located in Otara. Coxon et al. (2002) reported that "The overall outcome of this study for the teachers of the school was 'a valuable contribution to the overall awareness of the importance of regular and consistent monitoring of students'” (p.58). 
From the Secondary Education sector, which is directly relevant to this study, Coxon et al. (2002) reported on research from Hindmarsh, Hohepa and Murphy (1995) who developed an intervention to encourage "Māori and Pasifika 15-16 year olds, the group most likely to have left school by the third year in secondary education" in formal education. Unfortunately Coxon et al. (2002) reported that "Although the programme is reported to have had significant potential as a means of addressing the identified problem, its implementation, described as politically rather than educationally driven, prevented its realisation" (p.77).

The Strengthening Schools in Mangere and Otara (SEMO) initiative operated in secondary schools and Coxon et al. (2002) reported that "These Ministry initiatives also had evaluative research components integrated within them, and the reports which have been produced have been sources of 'inspiration' and informed response for Pacific educators and researchers" (p.77). However, Coxon et al. (2002) also concluded that "Earlier Ministry-funded interventions in some areas appear to have been somewhat ad hoc in conceptualisation and implementation, and insufficiently evaluated" (p.137)

Other relevant research was from Fusitu'a and Coxon (1998) about a Tongan homework centre, which was a parent initiative. Coxon et al. (2002) reported that "This study not only explored Tongan parents expectations of New Zealand secondary schooling, and the aspirations they held for their children, it also examined Tongan students' perceptions of their school experiences" (p.80). 
Hawk and Hill $(1996,1998,1999)$ produced research about the Ministry of Education's AIMHI (Achievement in Multicultural High Schools) project, which was established in 1995. Coxon et al. (2002) reported that "The overall aim of this project was to raise achievement levels of students in eight low decile urban schools with very high ratios of Maori and Pacific students" (p.81). Coxon et al. (2002) reported that AIMHI investigated the qualities of good teaching for Pasifika students and "While it could be argued that they are qualities and skills that any fine teacher in any school would have, the teachers in schools with high proportions of Pacific Island and Maori students are able to apply these qualities in a special way that acknowledges and respects the backgrounds and experiences of these particular students" (p.82). These ideas support the concepts of culturally responsive teaching (Bishop, 2009; Sleeter, 2011) and are also congruent with the final research report reviewed by Coxon et al., a study by Pasikale (1999), who concluded that teacher empathy and not ethnicity was most important for academic success. "Students in her study valued educators with empathy, who 'cared' about the whole person" (Coxon et al., p.84).

In 2004, Robinson and Timperley sought the views of Pasifika teachers and Ministry of Education officials about what they believed was needed to raise achievement of Pasifika students. Solutions fell into eight categories with the most favoured being teacher-quality and home-school liaison (p.xv). Robinson and Timperley (2004) concluded that most of these strategies have been tried in some form, but few have been evaluated "systematically in terms of their success in raising student achievement" (p.xvi). Robinson and Timperley (2004) also reported that the literature showed only one study with substantive empirical data (Phillips et al., 2002) that gave 
a solution to the under-achievement of some Pasifika students (p.108). Phillips et al. (2002), in their Early Childhood Primary Links via Literacy (ECPL) Project, aimed to raise student achievement in schools which enrolled large numbers of Pasifika students. They found that their intervention reduced the risk children faced of not achieving expected literacy results (p.12). Robinson and Timperley (2004) concluded that this did not mean that only one solution was possible, but that it was the only solution that had been empirically validated (p.108). They reported that much has been done to improve outcomes for Pasifika students including staffing more Pasifika teachers, offering more bilingual classes and organising home-school programmes to make parents welcome. What has not occurred is comparative research across initiatives to enhance Pasifika student achievement (p.108).

The Coxon et al. (2002) review was updated in a second comprehensive literature review of Pasifika education issues by Chu, Glasgow, Rimoni, Hodis and Meyer (2013) in their report An analysis of recent Pasifika education research literature to inform improved outcomes for Pasifika learners. Chu et al. (2013) explained that "It was further agreed by Working Group members that the literature review should build on the knowledge and understandings reported in an earlier review (Literature Review on Pacific Education Issues, Coxon, Anae, Mara, Wendt-Samu, and Finau, 2002). This would then enable comparisons to be made about the nature and extent of Pasifika education research findings up until 2002 and what is available today, 10 years later" (p.iv). The Coxon et al. (2002) report made a number of recommendations for research development in the secondary school sector. They suggested that research was needed in several areas, and the most relevant compared to this study is the area 
of effective teaching and learning strategies, where the following questions were examined: "Which teaching and learning strategies, if any, do Pacific students respond to most?" and "What are some examples of "best practice'?" (p.97). Chu et al. (2013) considered that considerable progress has been made in the intervening ten years in two areas related to effective learning strategies: (a) research about the effects of teacher-learner relationships with Pasifika students in the classroom; and (b) research on the relationship between the NCEA and student motivation and achievement.

Dealing first with research about the effects of teacher-learner relationships with Pasifika students in the classroom, Dickie (2008) explained the importance of obtaining student voice within the context of teacher-learner relationships. He explained that "Research with children should reflect the children's own ability to investigate and reflect on their own experience" (p.82). In this way, research "accepted the validity of children's voices" (p. 57). Taleni, Parkhill, Fa'afoi, and Fletcher (2007) concurred and reported that "Children too often have been seen as passive recipients rather than active participants who can offer perceptions of their own lives and their learning" (p.58). Chu et al. (2013) also reported that "The relationship between teacher and learner was identified as significant in supporting Pasifika students in the secondary school classroom" (p.80). For example Averill (2009) reported "There is evidence that for many Māori, Pasifika, and low socio-economic students, mathematics teachers can enhance students' motivation and mathematical achievement by using explicitly caring practices" (p.i). Siope (2011) gave this example: "My wagging buddies and I respected him because we believed him to be genuine in his interest and care of us and this was made manifest by his unrelenting 
determination to share his passion of maths with us and that we would achieve. Despite our best efforts to run and hide, he never gave up on seeking us and returning us to the classroom. It was this one attribute of consistency that eventually won us over" (p.117). Chu et al. concluded that "Teacher caring for their learning is viewed by Pasifika students as a key motivator to enhance achievement" and "There is research evidence of a growing consensus among educationalists that culturally responsive pedagogies, such as the use of languages and culturally appropriate learning and teaching, are important to support learning, including the achievement of Pasifika learners (p.87).

Chu et al. (2013) supported this idea stating that "There is growing evidence of the importance of teacher skills and understandings in culturally responsive pedagogies for enhancing educational outcomes for Pasifika learners" (p.87). Te Ava, Airini, and Rubie-Davies (2011) reported that "For pedagogy for Pasifika students to be correctly defined, it should reflect the cultural values of Pasifika peoples and be attuned to context" (p.119). These ideas about how educators can implement culturally responsive teaching are usefully informed by the work of Bishop and his colleagues (2003, 2005, 2007, 2009). Although Chu et al. (2013) reported that the culturally responsive teaching material edited by Sleeter (2011) was focused "on evidence of the impact of culturally responsive pedagogies for Māori student achievement, the reported series of studies provides an exemplar for investigating empirically the impact of teacher use of such pedagogies, including association with student outcomes" (p.24). This means that culturally responsive teaching concepts developed for Māori student achievement as reported by Sleeter (2011) and Bishop and his 
colleagues could be adopted for better teaching and learning for Pasifika students in NZ secondary schools.

Educators may need to consider the needs of students from different Pacific nations. For example, Kepa and Manu'atu (2006) explained that the FetuiakiMalie concept could be adopted to better understand the language, beliefs and aspirations of the Fonua of Tonga, Samoa, Niue, Tokelau, Fiji and the Cook Islands which are marginalised cultures within the NZ education system. Kepa and Manu'atu (2006) believe that FetuiakiMalie, which brings people together to talk about sense of place, should be considered when educators make decisions about "Pasifika" students. This has particular importance when considering the effects of initiatives on and for "Pasifika" students when it would be preferable to consider the needs of, for example, Samoan, Tongan, and other individual Pacific nations. Latu (2009) explained that, for example, Tongan students in NZ secondary schools would probably be familiar with the concept of talanoa. "Talanoa is commonly practised by those who live in the Pacific Islands (Capell, 1991) and specifically on Tonga. Talanoa is the medium of knowing, the source of knowing, and the ways of knowing among Tongan people. In other words, Talanoa is the knowing theory in which people know about things from enacting talanoa. Talanoa stems from cultures in which oratory and verbal negotiation have deep traditional roots (Vaioleti, 2003). The concept of talanoa, for Tongans, is the same as it is for Samoans, Fijians and other nations situated in the Pacific Ocean, although some may have local variations" (Latu, 2009, (p.20). 
Chu et al. (2013) also reported that considerable progress has been made in the intervening ten years in a second area related to effective learning strategies: the relationship between the NCEA and student motivation and achievement. This refers to "the body of longitudinal research by Meyer and colleagues from 2006 to 2011 which has investigated the relationship between the NCEA and student motivation and achievement (Hodis et al., 2011; Meyer, McClure, Walkey, McKenzie \& Weir, 2006; Meyer, McClure, Walkey, Weir \& McKenzie, 2009; Meyer, Weir, McClure, Walkey \& McKenzie, 2007, 2009)." (p.80). For example, Meyer et al., (2006) found that negative motivation orientations were associated with lower achievement, reporting that "the strongest predictors of high academic achievement and higher grades were a high motivation orientation towards Doing My Best and a low motivation orientation towards Doing Just Enough" (p.2). Meyer et al. (2006) concluded that "students aiming to do just enough may actually fail to achieve their goal, not because they lack the required ability but because their motivation orientation leads them to achieve less than they are capable of. If these same students are motivated to do their best, they are more likely to pass the required number of credits, and also obtain Merit and Excellence grades" (p.2). This finding is directly relevant to this study because it investigates the effectiveness of a motivation-enhanced study support programme (MS) in comparison to a traditional study support programme (TS) with the focus primarily on lower achievement.

Meyer et al. (2006) also found that ethnicity was associated with achievement, reporting that "Pasifika students gained fewer achievement standard credits than all other ethnic groups" (p.39). The quality of grades was also an issue as "Māori and 
Pasifika students gained significantly fewer achievement standards with Merit than Asian and European students" and "Māori and Pasifika students achieved fewer standard credits with Excellence than all other ethnic groups" (p.40). These findings also support the need for research on intervention programmes aimed at improving the academic achievement of Pasifika students in New Zealand secondary schools.

Meyer et al. (2009) discussed the importance of teacher-student relationships and motivation noting there was "a significant relationship between the motivation dimensions and relationships with peers and teachers" (p.2). They also noted that "students high on Doing Just Enough reported that their teachers did not take a personal interest in their achievement, whereas students high on Doing My Best reported that teachers showed interest in them and in their work" (p.2). Again these findings are directly relevant to this study because the intervention programmes operated in lower decile schools within the context of culturally responsive teacherstudent relationships.

Subsequent research from Meyer et al. (2007) included a follow-up study of the two motivation orientations they labelled as Doing My Best and Doing Just Enough. They reported that "Doing My Best and Doing Just Enough were the strongest predictors of subsequent school achievement" (p.2). Meyer and her colleagues developed the Survey of NCEA Goals Year 10 and Year 11 Students (2008) (part of which is attached as Appendix C). They reported that their findings supported the "predictive validity and utility of the screening tool" (p.2). This finding is also directly relevant to this study 
because their instrument was used to measure changes in achievement outcomes during the intervention programmes.

Meyer et al. (2007) also reported on associations between motivation orientations and attribution theory noting that "students who attributed their best work to internal factors of ability and effort showed the most positive achievement pattern overall and were most likely to report the Doing My Best orientation" (p.3). Conversely Meyer et al. (2007) reported that "students reporting a Doing Just Enough orientation were more likely to attribute best marks to luck and worst marks to a lack of ability" and "were more likely to attain credits with Achieved rather than Merit or Excellence" (p.3). Meyer et al. (2007) concluded that students "will have little motivation to exert more effort in future tasks and opportunities unless strategies are identified to change these motivations and attributions" (p.3). These finding are relevant to this study as it has the strategy of a motivation-enhanced study intervention as a possible way to change motivations and attributions to address the challenge of the underachievement of some Pasifika students in New Zealand secondary schools.

Meyer and her colleagues' (2007) findings correlate with those of Jones (1991) who investigated the question "Where does learning ability come from?" with female Pasifika students at a secondary school in New Zealand. Pasifika students attributed their lack of academic success almost entirely to a lack of "brains" (ability), rather than to effort (p.147). Ability is a key issue in this research and it is significant that AltonLee (2003) citing Nuthall (1999) considered that "Ability appears to be the consequence, not the cause of differences, in what students learn from their 
classroom experiences" (p. 213). Nuthall seems to be indicating that cultural mismatch may be associated with Pasifika students' attribution of ability, and so addressing cultural issues about students' perceptions of their ability was an issue addressed in this current study.

One measure adopted by schools to address student under-achievement is the provision of a study programme. Again there is little empirical evidence on the effectiveness of such programmes but Gorinski (2005) reported that the provision of a study centre at some Pacific Island School-Parent-Community Liaison Programme (PISPCL) schools "had been an effective mechanism for supporting student achievement" (p.18). Chu et al. (2013) also noted that "Based on these findings, we recommend the priorities given below for research in the area of academic achievement, literacy and numeracy. Under Priority \#7: Longitudinal research on effective interventions to enhance motivation and achievement. 7.1 Effectiveness of various approaches to in-school homework programmes (e.g., motivation-enhanced versus traditional study-skills orientation)" (p.25).

The Chu et al. (2013) literature review concluded that "research on educational outcomes for Pacifica in educational initiatives needs good data gained from valid and reliable measures of educational outcomes. There also needs to be consensus about which measures should be used and ensuring that all schools have expertise to use task management systems to monitor achievement and outcomes for individual students rather than just reporting ethnic group statistics" (p.3). Chu et al. (2013) also reported that "there is a need for research that provides evidence of intervention 
programmes developed in schools that enhance secondary school achievement, monitoring and achievement-related attitudinal aspects as well as achievement outcomes for Pacifica students" (p.48). These ideas identify a possible "gap" in our understanding. This study may therefore be an example of an educational initiative that gained good data from valid and reliable measures of educational outcomes. The analysis and discussion of these data about the effectiveness of motivation interventions via study programmes for under-achieving students, focusing on Pasifika students, may help to expand existing knowledge in the fields of motivation, achievement and interventions. The next section reviews the literature about interventions based on attribution theory.

\section{Section Four: What does the Literature Say about the Impact of Attribution Retraining on Achievement?}

Chodkiewicz and Boyle (2014) explained that Weiner's body of work (including his 1979 and 2010 studies) enabled researchers and educators to understand how attribution theory worked. "Weiner (1979) observed that people do not make causal attributions in isolation, but rather develop patterns of thinking which influence their behaviour in similar events. These patterns were labelled as attributional style and they have the potential to be adaptive when thoughts produce positive behaviours and destructive when thoughts lead to negative outcomes" (p.79). Most of Weiner's work was in the area of traditional attributions - ability, effort, luck, and task difficulty. 
Meyer et al. (2009) explained how students' attributions for their own success and failure at school can have an impact on motivation and achievement. "If students see their failure as having been caused by something that is difficult or even impossible to change, such as the difficulty level of the test or one's ability, this attribution has a negative impact on motivation and achievement. By contrast, if they attribute their failure on an assessment to a lack of effort, this attribution is more likely to enhance the student's motivation to try harder on future tasks and is unlikely to lessen motivation" (p.8). Chodkiewicz and Boyle (2014) concurred stating that "The explanation attributed to the failure on the test will subsequently influence behaviour". They explain that although one student may fail a test and "may use this experience as a motivation to study harder for the next test", another student who fails the test "may exert even less effort since he or she may be thinking 'why try if I am too stupid to succeed anyway?"' (p.79). Chodkiewicz and Boyle (2014) concluded that "it is not the experience in itself that shapes us, but how we attribute why the experience occurs, that mediates how we feel and react" (p.79).

These ideas lead to the concept of adaptive and maladaptive attributional styles. Chodkiewicz and Boyle (2014) explained that "it is advantageous to have a slightly optimistic perception of one's capabilities" (p.79). They explain that students who hold an adaptive attributional style may attribute success to their ability and their failure to lack of effort.

However there is a considerable body of research which shows that attributional styles can be modified. For example, Blackwell, Trzesniewski and Dweck (2007) 
Motivation Interventions via Study Programmes for Under-achieving Students

showed that students holding incremental views of their ability had higher achievement outcomes than students who held entity views of ability. Meyer et al. (2009) offered practical advice for educators in the classroom. "When teachers see students struggling with new tasks, statements such as 'Keep trying, it's easy!' are likely to affect students negatively rather than encouraging them. If they succeed on something the teacher said was 'easy', the accomplishment has been devalued. If they fail, they are likely to infer that they lack the required ability because, after all, the teacher said this task was supposed to be easy. Thus, a more helpful thing to say would be: 'This is a difficult task, and you really have to work at it. Keep trying, and I'll check later to see if you need some help'” (p.9). These ideas, which Blackwell, Trzesniewski and Dweck (2007) and Meyer et al. (2009) outlined, are behind the concept of attributional retraining (AR). Chodkiewicz and Boyle (2014) explain that AR "is an intervention aiming to improve the academic performance of students by encouraging adaptive attributional beliefs. The central premise of this approach is that attributional styles can be changed through modelling and education" (p.81). These ideas are relevant to this study because aspects of the motivation enhanced study skills programme are based upon AR. For example, students received messages about the benefits of viewing ability as incremental rather than holding entity views of ability and the benefits of effort within the context of a task-focused achievement structure - NCEA (Walkey et al., 2009).

Attribution retraining programmes have been associated with improved achievement outcomes. Chodkiewicz and Boyle (2014) reported that "Programmes have been run across various educational settings working with diverse groups. Many studies have 
found attribution retraining to be effective in changing students' attributions and achievement" (p.82). For example Van Overwalle and Metsenaere (1990) reported that an intervention that aimed to increase students' motivation for their study was associated with increased achievement. In comparison students who participated in a conventional study programme showed no increase in achievement. Perry, Stupnisky, Hall, Chipperfield, and Weiner (2010) reported that "AR encouraged all students to endorse controllable attributions and de-emphasize uncontrollable attributions in explaining achievement outcomes and that AR improved subsequent in-class tests, final course grades, and first-year GPAs" (p.669).

Chodkiewicz and Boyle (2014) reported that not all the research on AR has been associated with increased achievement outcomes, stating that "Some studies failed to observe any change in attributional style" (p.80). For example, they reported a study by Okolo (1992) that was in this category. However Okolo (1992) actually reported that while "Results did not support the contention that attribution retraining would have a significant impact on students' attribution, that attribution retraining students had higher achievement outcomes than students who received only neutral feedback" (p.327). This seems to indicate that research about AR generally finds positive associations with AR and achievement. This is supported by two meta-analyses about the effects of AR and achievement by Försterling (1985) and Robertson (2000). Försterling (1985) concluded that from the review of 15 programmes that $A R$ "methods have been consistently successful in increasing persistence and performance" (p.509). Robertson (2000) concurred stating that "Although mixed results were found in the attribution studies reviewed, overall attribution training was 
beneficial in the majority of the cases, though the best form of attribution training has not been settled" (p.132). It may be concluded from this research about AR and achievement that attribution retraining programmes are positively associated with achievement. However there are several issues about AR and achievement which the literature shows have yet to be conclusively settled. These include:

- how can educators implement AR in regular classroom settings;

- do AR programmes which focus on changing effort have more effect on achievement than AR programmes that focus on changing ability attributions;

- what are the possible mechanisms by which AR may lead to increased achievement;

- how does AR using traditional attributions differ from AR using social attributions;

- how do AR interventions relate to ethnicity; and

- how is AR associated with the field of social-psychological interventions.

The first issue is about the feasibility of attribution retraining in naturalistic settings such as regular classroom settings. Chodkiewicz and Boyle (2014) reported that Robertson (2000) "concluded that attribution retraining has a greater impact when administered in a small group context than in a larger classroom setting" (p.81). Robertson (2000) gave reasons such as group size being too large which meant that feedback could not be given. There were also issues around whether regular classroom teachers were able to effectively run AR programmes. Chodkiewicz and Boyle (2014) also reported on the Horner and Gaither (2004) research which 
"suggested that attribution retraining administered in a large group setting could be effective for increasing positive attributional styles". Positive outcomes were also reported in the Ziegler and Heller (2000) and Yasutake et al. (1996) studies. These results are encouraging because they suggest that "both teachers and even students themselves can induce positive change through attribution retraining techniques" (Chodkiewicz and Boyle, 2014, p.83). These ideas are pertinent to the study because the motivation enhanced study skills programme was delivered within a natural classroom setting and the researcher did not have prior AR delivery experience. This means that this study may add to our understanding of how educators can introduce $A R$ interventions in regular classrooms even if they have had little prior experience in AR.

There is a second issue to the question of whether changing effort attributions has more effect on achievement than changing ability attributions. McClure et al. (2011) reported that there were three points of view on this question in the literature. The first is that effort attributions are more predictive of achievement than ability attributions, a finding that is consistent with helplessness theory (e.g., Liu et al., 2009). However there is also considerable research reporting a second view, that ability attributions are more predictive of achievement than effort attributions. McClure et al. (2011) listed these as Kurtz-Costes and Schneider (1994); Meyer, Weir, McClure, Walkey, and McKenzie (2009); O'Sullivan and Howe (1996); Vispoel and Austin (1995). The third view is that ability and effort attributions are equally predictive of achievement (e.g., Watkins and Gutierrez, 2001). McClure et al. (2011) also noted that Bong (2004) suggested that "when people are explaining their achievements in 
general, rather than their single best achievement, their effort attribution is the strongest predictor of achievement" and that "This claim is consistent with Weiner's (1985) theory and Liu et al.'s (2009) findings" (p.72). However McClure et al. (2011) also noted the value of Elliott's (2005) claim "that a combination of mastery orientation (effort attributions) and performance orientation (ability attributions) is the most adaptive strategy" (p.72). This body of research is relevant to this study because this study evaluates the effects of ability and effort attributions on achievement and may add to our understanding of how a motivation-enhanced intervention affects effort attributions compared to ability attributions.

A third issue relates to the actual mechanism by which attribution retraining may be associated with achievement. Chodkiewicz and Boyle (2014) reported that students with maladaptive attributional styles may be less motivated than students with adaptive attributional styles. "When a student has a maladaptive attributional style they feel less motivated and confident than students with adaptive attributional styles" (p.80). They also reported that students with maladaptive attributional styles "engage less in positive learning behaviours, such as persisting on difficult questions, and engage more in behaviours that are destructive to their learning process, such as task avoidance. In turn, these behaviours negatively impact learning and performance when faced with future academic tasks" (Fyrsten, Nurmi, and Lyytinen, 2006; Shmulsky and Gobbo, 2007, p.80). Chodkiewicz and Boyle (2014) proposed a cyclical interaction mechanism which has similarities to the recursive cycle concept mentioned in the body of research about social-cognitive interventions which is reviewed later in this chapter (see for example Cohen et al., 2006; and Paunesku, 
2013). Again this research is relevant to this study because the mechanism of the motivation-enhanced study skills programme intervention programme could be associated with interruption of the recursive cycle. Another possible mechanism explaining how attribution retraining may lead to improved motivation and achievement may be linked to the theories of control and learned helplessness. Control is generally associated with mastery and hopefulness, and lack of control is associated with helplessness. Casserley (2013) noted that "Humphrey and Mullins (2002) use attribution theory relating to dyslexia incorporating aspects of locus of control, learned helplessness and motivation to explain individuals' attribution for success and failure. These aspects are also related to other influential theories of attribution such as Weiner's (1986) theory of motivation and Abrahamson, Seligman and Teasdale's (1978) theory of learned helplessness which can significantly affect children's future performance of academic tasks" (p.80). This body of research is relevant to this study because this study may add to our understanding of how interventions can change students' perception of their control over achievement outcomes.

The fourth issue relates to how AR interventions which focus on traditional attributions differ compared to AR interventions which focus on social attributions. This relates to how students perceive teachers, peers, and family to be associated with their attributions for best and worst marks in assessments. Although Weiner's theory would view social attributions as being externally located, McClure et al. (2011) noted that "students may construe attributions to the influence of family, friends, and teachers in different ways than the external causes cited by Weiner (task difficulty and 
luck) (e.g., Liu et al., 2009). For example, whereas people see external causes such as task difficulty as contributing to failure more than success, they may see family as contributing to their success more than their failure ( $\mathrm{Ng}$ et al., 1995)" (p.71). One relevant concept here is whether some Pasifika students operate from a collectivist perspective rather than an individualistic view (Duda and Allison, 1989). These ideas may be related to social attributions and achievement where McClure et al. (2011) reported that Vispoel and Austin (1995) found that "attributing success to family influence was linked to higher marks, whereas attributing failure to these influences was linked to lower marks" (p.72). This research is relevant to this study because the motivation enhanced study skills programme measures changes in these social attributions. This study may add to our understanding of how interventions affect Pasifika students' social attributions compared to non-Pasifika students.

A fifth issue relates to AR interventions and ethnicity. McClure et al. (2011) reported that "Pasifika students rate family as the second highest cause of success, rating family as more important in their success than their ability. In contrast, students of European ethnicity rate the influence of family significantly lower than both internal causes: ability and effort" (p.72). This finding supports research from Fletcher, Parkhill, Fa'afoi, and Taleni and O'Regan (2009) who reported that some "Pasifika students reported that their parents played an active role in supporting their literacy learning" (p.7). Graham, Meyer, McKenzie, McClure and Weir (2010) also reported that "Social agents were seen to be major influences on motivation, consistent with the cultural values of Māori and Pacific people" (p.162). These results may also be associated with findings from Richer, Godfrey, Partington, Harslett, and Harrison (1998) who found a high 
percentage of Aboriginal students in Australia experienced relationship problems with their teachers (p.7). They surveyed 473 Aboriginal students about student perceptions of teacher attitudes and reported that $37 \%$ disagreed strongly or disagreed with the statement "my teacher cares what happens to me", and 58\% disagreed strongly or disagreed with the statement "I like the teacher". While no data were produced in that report about the attitudes of corresponding non-Aboriginal students, it could be concluded that a significant percentage of Aboriginal students in that study had a relationship issue with their teachers. Low academic outcomes of Aboriginal students may be linked to these reported poor relationships with their teachers. Martin (2006) believes that relationships are important to Aboriginal student achievement on three levels: between the teacher and student, between the student and the school and between the student and pedagogy. Martin (2006) also noted that teachers need to be warm, have positive expectations, get to know their students and respect them as individuals to allow a good relationship to develop and avoid a poor relationship that could impede achievement (p.40). Martin's (2006) study has commonalities with the Te Kotahitanga project, as reported by Bishop, Berryman, Cavanagh and Teddy (2009), which showed that relationships were important to the achievement of Māori students in New Zealand secondary schools. Bishop et al. (2009) cite Alton-Lee (2003) who stated that "The quality of classroom relations and interactions within schools has more to do with the creation of educational disparities than the decile ranking of the schools" (p.7). This research is relevant to this study because the motivation enhanced study skills programme measured changes in attributions for both Pasifika and non-Pasifika students. This study may add to our understanding of how 
interventions affect Pasifika students' attributions for best and worst marks compared to non-Pasifika students.

The sixth and final issue is how attribution retraining can be associated with the field of social-psychological interventions. Cohen (2011) explained that "social psychology, has made breakthroughs in interventions to solve social problems" and these were based on ideas such as identifying "the pressure points where a small nudge might have large consequences" (p.178). It is possible to locate many of the concepts used in the motivation-enhanced MS intervention programme in this study with ideas from social-psychological interventions. For example, the MS students were encouraged to view intelligence from an incremental perspective rather than an entity view. Aronsen, Fried and Good (2002) reported on an intervention where students were also encouraged to view intelligence from an incremental perspective rather than an entity view. They reported that "The African American students (and, to some degree, the White students) encouraged to view intelligence as malleable reported greater enjoyment of the academic process, greater academic engagement, and obtained higher grade point averages than their counterparts in two control groups" (p.113). Other relevant research in this field of social-psychological interventions included research by Blackwell, Trzesniewski and Dweck (2007) who also implemented an intervention which encouraged incremental intelligence theory and reported that "students in the control group displayed a continuing downward trajectory in grades, while this decline was reversed for students in the experimental group" (p.246). Cohen, Garcia, Apfel and Master (2006) noted that "What these interventions share is that they are grounded in science, found effective in randomized experiments, have 
surprisingly large and durable effects" (p.178). These ideas are also relevant to the MS intervention as the research design of this study was based on random assignment of student participants to the two groups - the Motivation-enhanced Study support programme (MS), or the Traditional Study support programme (TS). There is a comprehensive body of social-psychology research including Cohen et al. (2006), and Cohen, Garcia, Purdie-Vaughns, Apfel, and Brzustoski (2009), who investigated stereotype threat interventions; and Harackiewicz, Rozek, Hulleman, Hyde (2012) who reported on an intervention designed to encourage a greater uptake of mathematics and science courses in high school. They reported that "This relatively simple intervention led students whose parents were in the experimental group to take, on average, nearly one semester more of science and mathematics in the last 2 years of high school, compared with the control group" (p.899). The "small nudge" concept that Cohen (2011) referred to is important here because the MS programme fits this view that an apparently short intervention can have effects on achievement. It is possible to locate the MS intervention in this social-psychological intervention field as explained by Paunesku (2013) who reported that "Over the last several decades, a handful of seemingly small psychological field interventions, lasting hours or even minutes, have affected students' achievement over periods of months or years" (p.7).

However, attribution motivation theory is only part of the motivation enhanced intervention programme. Perry et al. (1993) noted that "A further limitation of current research is the exclusive focus on changing attributions only, even though other aspects of attribution theory lend themselves to interventions" (p.713). For this reason other relevant theoretical frameworks in this study include goal theory and 
self-views (intra-personal) motivation. Another reason to widen the theoretical framework is because McClure et al. (2011) investigated whether attributions are better predictors of achievement than other motivational factors and concluded goals had more impact on achievement than attributions. Toland and Boyle (2008) also reported that "Changing children's attributions opens up possibilities for wider progress, and may well be a pre-requisite for progress to be made" (p.300). This could be interpreted as meaning that when educators change students' attributions it may open up the mechanism for other effort-related motivation ideas to operate. For example the next section, section five, investigates how interventions based on goals may be associated with changes in achievement. Toland and Boyle's (2008) ideas could also help explain how attributions and goals are linked. For example, if AR interventions can change effort attributions, this may be a precursor to improved achievement. The motivation-enhanced MS intervention also attempted to change goals such as reducing work avoidance goals within the context of NCEA achievement. For these reasons the next section, section five, investigates how interventions based on goals may be associated with changes in achievement.

\section{Section Five:}

\section{A Review of the Literature about Interventions based on Goal Theory}

This study measures changes in four goals: Doing My Best (DMB), Doing Just Enough (DJE), peer affiliation (PA) and teacher affiliation (TA). DMB and DJE can be categorised as traditional goals, and TA and PA can be categorised as social goals. Considering the nature and effects of DMB and DJE first, McClure et al. (2011) explained that 
attribution theory can be compared to goal theory because as Elliot and Dweck (1988) showed that different attributions relate to different motivational goals, "in that effort attributions relate to mastery goals, whereas ability attributions relate to performance goals" (p.81).

However, as Wosnitza and Volet (2012) explained, goals were previously defined as "two conceptually different achievement goal orientations, namely performance or ability approach goal orientation and mastery or task goal orientation" (p.513). Goal definition has evolved, and Wosnitza and Volet (2012) explained that "there may be two dimensions in students' performance goal orientation, namely an approach and an avoidance tendency" (p.514). Wosnitza and Volet further explained that this is due to an increased acceptance of the idea of multiple goals including social goals. McClure et al. (2011) explained that this second motivational distinction between approach goals and avoidance goals (Elliott, 2005) has some parallels with the motives to DMB and DJE (Meyer, McClure, Walkey, Weir, and McKenzie, 2009). "The DMB motive relates to approach goals, whereas the DJE motive relates to avoidance goals" (p.71). However, McClure et al. (2011) further explained that "these motives differ from both Dweck's and Elliot's goal theories in that the motives [DMB] and [DJB] concern the level of effort expended" (p.71). More importantly McClure et al. (2011) also explained that "previous research has shown that these two motivation orientations significantly predict future student achievement" (Meyer, McClure, et al., 2009; Meyer, Weir, et al., 2007) (p.71). 
Motivation Interventions via Study Programmes for Under-achieving Students

That research which shows that DMB and DJE predict achievement is useful to this study because these two goals are fundamental aspects of the motivation-enhanced intervention programme. The study measures how DMB and DJE were affected by the intervention programmes. However, the literature on goal retraining is limited in comparison with the literature on AR. Given this gap in the literature, this intervention study based on increasing DMB and decreasing DJE has the potential to add to our understanding of interventions about goal motivation and achievement in a natural classroom setting within the context of the task-focused assessment structure of the NCEA.

McClure et al. (2011) investigated how attributions predicted achievement in comparison with how DMB and DJE predicted achievement. They noted that "there is a need to show whether these two motives predict achievement when attributions are taken into account, to clarify whether attributions and motivation orientations are distinct dimensions rather than different labels for the same constructs" (p.71-73). McClure et al. (2011) showed that: DJE was the strongest predictor of NCEA total credits; that DJE was twice as strong a predictor compared to effort attributions for best marks; and that DJE was four times as strong a predictor of NCEA total credits compared to DMB. This research shows that DJE may be the strongest predictor of total NCEA credits and that DMB is much less predictive of future total NCEA credits.

However Meyer et al. (2009) reported "that traditional motivation orientations including our own Doing My Best and Doing Just Enough reflect individualistic, more typically 'Western' values and approaches" (p.9) and as such ignored how social goals 
such as peer affiliation and teacher affiliation may be associated with student achievement. These ideas are congruent with the culturally responsive teaching concepts outlined earlier in this chapter. Meyer et al. (2009) reported that they incorporated measures about teacher affiliation and peer affiliation into the Survey of NCEA Goals Year 10 and Year 11 Students (2008). The intention was that this instrument would be able to better measure the goal orientations of students who may hold multiple goals, including social goals (Bong, 2006; Dowson and Mclnerney, 2003; Wosnitza and Volet, 2012). These ideas also support research from Wentzel (1999) who showed that "social goals are strong and consistent predictors of academic outcomes" (p.226). That research which shows that TA and PA predict achievement is useful to this study because these two goals are also fundamental aspects of the motivation-enhanced intervention programme. Section six of this literature review chapter considers the effects of the two intervention programmes on intra-personal motivation orientations.

\section{Section Six: How does Martin's $(2005,2008)$ Intervention Material Assist Understanding about Interventions that Affect Motivation and Achievement?}

Martin (2002) conceptualised achievement motivation by amalgamating the key theories of academic motivation into a multi-dimensional model called "The Student Motivation Wheel". While Martin (2002, 2005, 2007) considered that this model incorporated all the major motivation achievement theories, it is probably more accurate to say that this model represents all of the major intra-personal motivation 
theories. This model incorporated all the major motivation achievement theories and showed how the main motivation constructs of interest to educators were associated with each theory, as shown in the tables which follow.

\section{Table 1}

Motivation Theories and Associated Constructs

\begin{tabular}{ll}
\hline \multicolumn{1}{c}{ Motivation theories } & \multicolumn{1}{c}{ Constructs emerging from theories } \\
\hline Need achievement & Failure avoidance \\
& Self-sabotage \\
Self-worth motivation & Anxiety \\
& Low control \\
& Self-belief \\
Attribution and control & Low control \\
Motivation orientation & Learning focus \\
& Persistence \\
& Planning and monitoring \\
Self-efficacy & Study management \\
Expectancy-value & Self-belief \\
\hline
\end{tabular}

(Source: Martin, 2007)

Martin (2002) then showed that these constructs that emerged from these theories could be grouped into two broad behavioural outcomes - "boosters" and "guzzlers", as shown in the table below. Martin (2002) believes interventions that aimed to change motivation should try to increase boosters and decrease guzzlers (p.181). 


\section{Table 2}

Adaptive and Maladaptive Motivation Constructs

\begin{tabular}{lc}
\hline \multicolumn{1}{c}{ Motivation boosters (adaptive) } & Motivation guzzlers (maladaptive) \\
\hline Self-efficacy & Self-handicapping \\
Mastery orientation & Failure-avoidance \\
Value of schooling & Uncertain control \\
Persistence & Anxiety \\
Planning & \\
Study management & \\
\hline
\end{tabular}

(Source: Martin, 2007)

Martin (2005) reported The Student Motivation Wheel model enabled students and teachers to easily understand motivation concepts and this made interventions designed to change motivation more successful (p.181). Martin (2005) reported that The Student Motivation Wheel had been tested on previous occasions (2001 and 2003) and the results of these studies have led to the conclusion that The Student Motivation Wheel was a valid and reliable instrument to measure motivation (p.181). Martin (2005) investigated the impact of an intervention programme on participants' academic motivation over two sessions of programme delivery and again after 6-8 weeks (p.184). Martin (2005) used a pre-test/post-test design with 53 Year 10 male and female Secondary School students. Martin found that the levels of some adaptive/booster motivation constructs were higher, both immediately after the intervention, and 6-8 weeks later (p.194). Martin (2005) believed the results of this study were significant because they showed that even a brief, but well-targeted, intervention could yield significant positive changes in motivation. Martin also concluded that these results showed that it was possible to embed a motivation programme into a larger youth enrichment programme. These points have relevance 
Motivation Interventions via Study Programmes for Under-achieving Students

for this study because the intervention programmes were delivered within a framework for study programmes that are common in New Zealand schools. Martin (2008) reported on another intervention that aimed to measure and change motivation. Martin (2008) also used a pre-test, post-test, control group design to investigate the impact of an intervention on the motivation and engagement of 53 male high school students in Australia. The modules Martin used were considered as part of the design of the motivation-enhanced intervention which aimed to improve the achievement of Pasifika students in New Zealand secondary schools (p.264-266). Martin (2008) reported an improvement in targeted aspects of motivation constructs as evidenced by significant effect sizes ranging from $0.38-0.64$ in the treatment group, in comparison to the control group.

Martin (2008) suggested that further research to test associations between changes in motivation and changes in achievement would be useful (p.263). Meyer et al. (2006) noted that "there is strong support for the proposition that the design of effective interventions towards achieving a long-term impact on student learning outcomes requires consideration of student motivational orientations for anything other than short-term behaviour change" (p.5). Meyer et al. (2009) also noted that "An approach to intervention that highlighted intrapersonal motivation orientations could add significant value to the more traditional approach of academic remediation only; Martin's work in Australia provides an excellent example of this" (Martin, 2008) (p.104). Consequently this study implements an intervention that aimed to change motivation orientations as a new way to address the under-achievement of some 
Motivation Interventions via Study Programmes for Under-achieving Students

Pasifika students in New Zealand secondary schools. The next chapter covers the methodology followed in this study. 
Motivation Interventions via Study Programmes for Under-achieving Students 


\section{Chapter Three Methodology}

\section{Introduction}

This chapter is divided into four sections. Section one describes the research focus and research questions. The next three sections outline the three broad steps the researcher took for the design of this study including: (a) an examination of the methodology appropriate for this study and why a pragmatic mixed-method design was used; (b) an outline of the two-phase, sequential explanatory strategy of inquiry design of this study; and (c) an explanation of the specific research methods used in this study covering details about participants, instruments, data collection and data analysis.

\section{Section One: The Research Focus}

As outlined earlier, the under-achievement of students in New Zealand secondary schools is of concern to educators, academics and policy-makers in the Ministry of Education. The particular issue this study focuses upon is the pattern that shows that Pasifika students have lower achievement outcomes than students from other ethnic groups. Analysis of Education Counts (2009) data shows that although the achievement differences between ethnic groups may be decreasing at Level One of 
the National Certificate of Educational Achievement (NCEA), fewer Pasifika and Māori students left secondary school in 2008 with Level Three NCEA compared to Asian and New Zealand European students.

Of the total Pasifika students who leave school, 30.4\% leave with a University Entrance standard with compared to $48.2 \%$ of Non-Pasifika students (Education Counts, 2012). These statistics are one reason why this study investigates the effects of motivation interventions via study programmes for under-achieving students, focusing on Pasifika students in New Zealand secondary schools. There are a variety of reasons for student under-achievement but this study concentrated on how motivation is related to achievement as well as how motivation can be influenced by intervention in the context of culturally responsive teacher-student relationships. Another aim of this study is to find more data about what motivates Pasifika students to work hard. This research is consistent with the Teu le va research principles which call for "strategic, evidence-based, outcomes-focused, Pasifika success (research) where every Pasifika learner in New Zealand should succeed educationally to maximise the exposing of Pasifika voices, and the issues and concerns of Pasifika learners so that new knowledge and understandings are generated" (Airini, Anae, Mila-Schaaf, Coxon, Mara and Sanga, 2010). In order to investigate this topic the research questions were as follows. 


\section{Research Questions}

Were there differences in achievement, motivation, engagement and attendance outcomes for students who participated in a Traditional Study (TS) support programme compared to students who participated in a Motivation-enhanced Study (MS) support programme?

Were there differences in the achievement, motivation, engagement and attendance outcomes of Pasifika students who participated in a TS support programme compared to Pasifika students who participated in a MS support programme?

How did students perceive the relative value and helpfulness of the TS and MS support programmes towards supporting their learning and achievement? What were the perceptions of Pasifika students regarding programme components?

The next section of this chapter outlines methodology decisions made in this study (Creswell, 2009).

\section{Section Two: Research Design}

Creswell (2009) explained that research methodology covers four possible worldviews

- post-positivism, constructivism (or interpretivism), advocacy/participatory and pragmatism (p.6). Leech, Dellinger, Brannagan and Tanaka (2010) concurred with Creswell (2009) stating that "Currently, most educational research is situated on a continuum that spans from the post-positivistic to the constructivist paradigms" 
(p.18). This study is best described as a mixed-method study with a pragmatic worldview because it draws on aspects of both post-positivism and constructivism and follows a pragmatic view using both qualitative and quantitative methods, mixing the two methods when beneficial. The research draws from both quantitative and qualitative assumptions, uses pluralistic approaches to derive knowledge about the problem of Pasifika student achievement and is based on assumptions that include both deterministic and interpretivist ideas about motivation and achievement (Bryman, 2007; Morgan, 2007).

One post-positivist idea that informed this study is that changes in intra-personal motivation are associated with achievement-related outcomes. For example, this study uses Martin's $(2001,2005,2008)$ Student Motivation and Engagement Scale (MES-HS) which represents an "empirically derived intervention methodology designed to reflect an integrative framework for representing seminal motivation and engagement theory" (p.241). The MES-HS is based on intra-personal motivation principles which reflect a western view of achievement motivation. This states that student achievement can increase when adaptive intra-personal motivation orientations - for example, self-belief and persistence - increase. Conversely, students can become de-motivated and fail to achieve if maladaptive intra-personal motivation orientations such as self-sabotage and failure-avoidance increase.

One social constructivist idea followed in this study is that changes in inter-personal motivation are associated with achievement-related outcomes. The second instrument used in this study is the Survey of NCEA Goals Year 10 and Year 11 
Students (2008) designed and tested by Meyer and her colleagues. Similar to the MESHS, the Screening Tool is designed to measure changes in intra-personal motivation orientations but the ST can also examine inter-personal motivation beliefs such as "how social goals might influence motivation and achievement" (Meyer et al., 2009:10). The view that inter-personal motivation can affect achievement is based on a non-western interpretation of achievement motivation - that students may be motivated to improve achievement by enhancing inter-personal concepts such as peer, teacher and or family affiliation.

Another constructivist idea investigated in this study is how "individuals seek an understanding of the world in which they live and work" (Creswell, 2009:8). These ideas were investigated by asking students for their views on the value and helpfulness of the study skills intervention programmes in which they participated. Students were also asked how their peers and teachers supported their learning and achievement and why they worked hard at school. This study purposively sought a wide range of participant views about motivation and achievement by selecting schools with diverse student populations, including many students from a Pasifika background. Constructivist views also informed how the qualitative data were analysed. Grounded theory was used to interpret a wide range of student opinions about motivation and achievement in an attempt to examine "a complexity of views rather than narrowing meanings into a few categories or ideas" (Creswell, 2009:8). Data from more than 20 interviews were analysed with the intention that student responses could confirm existing theories of motivation and achievement or generate new meanings about what motivates students to work hard at school. The interviews 
Motivation Interventions via Study Programmes for Under-achieving Students

started with general questions such as: "tell me about the study programme? why did you participate? and what did you like about it?" As the research progressed, and codes were able to be generated, the researcher asked more specific questions like "why do you think you got the number of credits you did in the National Certificate of Educational Achievement (NCEA)?" and "tell me why you work hard at school?" An advantage of using a pragmatic mixed-methods research design is enhanced triangulation of data. This is because using multiple sources for data improves the richness of information and allows broad numeric trends from the quantitative data to be compared with the detail of the qualitative data (Creswell, 2009). Rossman and Wilson (1985) explained that triangulation can be used in three ways - to corroborate, elaborate or initiate findings (p.627). Rossman and Wilson (1985) concluded that a mixed-methods study which examines both quantitative and qualitative data "can work iteratively to derive a more complete understanding of the phenomenon in question". They stated that "both quantitative and qualitative methods can be used fruitfully to corroborate, elaborate or initiate findings from the other method and that neither necessarily take precedence over the other" (p.633).

This study corroborates data gathered in the quantitative phase when students were asked to confirm their ideas about effort in follow-up interviews. One student's scores from the quantitative data indicated that he did not want to work hard at school and was happy to "do just enough" (Meyer et al., 2006, 2007, 2009). When interviewed later, the same student agreed that he did not put much effort into his studies but that this was his choice and that he was old enough to make his own decisions. 
Elaboration of ideas gathered from quantitative data was followed up in interviews. Jick (1979) explained that "elaboration can lend strength to an argument and provide a different perspective on the same phenomenon" (p.632). Data from one participant showed he attributed his best marks in assessments to luck. In a follow-up interview the same student explained that luck meant "gods" to him, luck appeared to have a spiritual aspect. This elaboration of this student's ideas about luck was different to most participants who dismissed luck as an excuse for poor achievement. This variety of views supports Bergman's (2010) view about the value of the mixed-methods approach because it allows the researcher to "explore variations in the construction of meaning of concepts in relation to how respondents, for instance, make sense of their experiences or report on attitudes in interviews or questionnaires, respectively" (p.172).

Initiation of new ideas about motivation and achievement were also gained from data. For example, some students reported they did not stay the full three hours in external examinations. Educators usually interpret early exit as lack of effort, however some students gave other reasons for leaving early; one student said he had no pen and believed that he could not ask for one, so he left a three-hour examination after 45 minutes.

Another advantage of using a pragmatic mixed-methods research design is improved understanding of the relationship between the researcher and the research process. Morgan (2007) argues that the pragmatic mixed-methods approach removes the "forced dichotomy between subjective (qualitative) and objective (quantitative) 
relationship between the researcher and the research process" (p.71). He suggests that researchers should move between the two approaches and that pragmatism allows the researcher to "achieve a sufficient degree of mutual understanding with not only the people who participate in our research but also the colleagues who read and review the products of our research" (p.72). This study is firmly contextualised in the lives of "students at school" and the researcher spent considerable time getting familiar with the students' school communities, accessing students and planning the most appropriate way to deliver the study skills programmes. Time was spent at each school going to assemblies and other school events before any programmes were delivered so that the researcher could better understand the specific context of each school and the school setting of the participants. This process was followed because this study aims to "focus on the specific contexts in which people live and work, in order to understand the historical and cultural settings of the participants" (Creswell, 2009:8).

An important aspect of this study was to facilitate good researcher-student relationships. This is because under-achieving students may have poor relationships with their teachers, whereas research conducted by Bishop, Berryman, Cavanagh and Teddy (2009) in New Zealand Secondary Schools showed that "when Māori students have good relationships with their teachers, they thrive at school" (p.3). The relationship between the researcher and teachers at the school is also important in this study. Sometimes the researcher would arrive at a school to have a scheduled interview only to find a particular student was not at school that day. This meant the researcher would set out to find a replacement interview because time was precious. 
Many of the Year 11 students in intervention programmes took Art and the Art teacher at School A became quite tolerant of the researcher dropping into his class and looking for students to arrange interviews. He exemplified the helpful response from teachers - always friendly and giving easy access to students - even at short notice. Students would have observed this researcher-teacher relationship and the positive responses from their own teachers towards the researcher may have assisted the student-researcher relationship. This student-researcher relationship may be summarised in the following way: the researcher was from the university, was some sort of teacher and so able to teach them study skills in a context of mathematics and science, but clearly not an actual teacher at their school. This meant that students knew the researcher had no authority to enforce their school rules, but this may have assisted the research process as students were open and receptive. This study accepts that this pragmatic mixed-methods approach could be considered to have compromised researcher objectivity as it raises issues about researcher subjectivity/objectivity (Creswell, 2009). However, taking a pragmatic approach does not necessarily lead to a less objective study and it is possible better data was gained from this study by fostering positive researcher-student relationships. Morgan (2007) concurred noting that "although one often hears arguments about the impossibility of 'complete objectivity', it is just as hard to imagine what 'complete subjectivity' would be" (p.71).

This research followed culturally responsive principles by considering the advice of researchers who have knowledge and experience about research and Pasifika students. This included consulting the Pasifika Education Research Guidelines (Anae, Coxon, 
Motivation Interventions via Study Programmes for Under-achieving Students

Mara, Wendt-Samu and Finau, 2001), An analysis of recent Pasifika education research literature to inform and improve outcomes for Pasifika learners (Chu et al., 2013) and the Pasifika Education Plan (Ministry of Education). Other relevant research about Pasifika students by Dickie (2008) explained that research with and about Pasifika should include "consultations, using translations, face-to-face meetings and the need to build rapport with participants who are being interviewed". Dickie (2008) also emphasised that data should be shared with participants which is particularly important when the researcher is Palagi, as is the case in this research (p.81). One point raised is that researchers should consider possible differences in the world view Pasifika and non-Pasifika students may hold when considering the most appropriate research methodologies to use when working with Pasifika participants.

The participants in this study consisted of about $50 \%$ Pasifika and $50 \%$ non-Pasifika students. This research accepts there may have been differences in the world views held by the participants in this study. For example, Anae and her colleagues (2001) explained that students coming from a Western world view may hold ideas such as "democratic principles based on the assumption that the individual, his [sic] rights and freedoms, forms the basic unit of society, market-driven economies and ideology, capitalist paradigms, and focus on the individual as opposed to the collective" (p.13). In comparison students who hold a Pasifika world view may hold values which include "respect, reciprocity, communalism, collective responsibility, gerontocracy, humility, love, service and spirituality" (p.14). Hunter and Anthony (2011) further suggested that there may be more "positive outcomes for Pasifika students when teachers 
explicitly build on the Pasifika values of reciprocity, communalism, and collectivity" (p.104).

This research was based on the culturally responsive research methodology called Talanoa (Capell, 1991; Latu, 2009; Vaioleti, 2003). Vaioleti (2006) explains Talanoa as "a personal encounter where people story their issues, their realities and aspirations" and "allows more mo'oni (pure, real, authentic) information to be available for Pacific research than data derived from other research methods" (p.21). The point made here about hearing students' stories, issues, their realities and their aspirations is very relevant to this research as much of the data came from interviews with students and it was important that these interviews made the participants feel as comfortable as possible. Anae et al., (2001) outlined some of the issues that researchers should consider when designing research with Pasifika participants. These include consideration about methodology; interview design and practice; how the researcher relates to the participants, including building rapport and hospitality; confidentiality of data that was received and how data would be shared with others; shared ownership of the research; and the importance of receiving advice from cultural advisors.

The methodology used in this study followed a mixed-methods research design. Because at least half of the students in this study were Pasifika students, it was considered important to include gather, analyse and discuss qualitative data as well as gaining quantitative data. This approach complements what Anae et al., (2001) explained as "[t]he growing engagement amongst researchers in Pacific communities with qualitative research methodologies such as ethnographic research approaches. 
Motivation Interventions via Study Programmes for Under-achieving Students

Such approaches have been used to complement quantitative analyses. More importantly, these approaches are integral to the refinement of a Pacific research methodology" (p.31).

This research adopted an informal interview structure where the researcher invited all students to be interviewed but students were not compelled to attend or talk. While most of the students were interviewed, not all students put themselves forward for interviews and this was considered perfectly acceptable to the researcher. Students were interviewed in pairs (which they chose themselves). The researcher deliberately held the interviews in a public space (the library); however, all interviews were held in a relatively private corner of the library which meant other people were around but could not overhear the interviews. This research used open-ended questions rather than closed questions because this encouraged spontaneous discussion. A downside was that sometimes the discussed issues indirectly related to the effects of study skills motivation interventions which meant that a huge amount of data was gathered. However the upside was that students' views about motivation and achievement often emerged after more general discussion about students' views about school. This was because some students initially made general comments about how they felt about school and later their views on how teachers, parents and their peers affected their motivation emerged more indirectly. This approach meant that data that was gained through the interviews was richer than could have been gained from interviews based on closed questions. The interview design was informed by ideas from Anae and her colleagues (2001) who advised that "[t]he most effective type of qualitative interviews for Pacific peoples are face-to-face interviews, whether with 
individuals or groups. This is largely due to the opportunity it provides for potential interviewees to build familiarity not only with the interviewer but also with the research topic, questions and methodology. It also provides the opportunity for both parties to gain a realistic sense of commitment to the relationships being established as well as to the research exercise proper" (p.36).

This research focused on positive teacher-student relationships by taking time to get to know each of the students, treating each student as an individual and trying to avoid stereotyping students. Since this research is based on an educator/practitioner investigating the differences between traditional and motivation-enhanced study skills programmes, it was important that the research promoted good relationships with the participants. Hunter and Anthony (2011) reported that "responsive and caring relationships be-tween the teachers and students in the classrooms were central in overcoming disparities and increasing inclusivity" (p.104). The participants in the study knew the researcher was an educator and that the researcher was some sort of teacher but not their teacher, so the researcher took the opportunity to promote positive research-participant interactions wherever possible.

Associated with this idea of promoting positive research-participant and teacherstudent relationships was the importance of the researcher getting to know the participants. Before the research even began the researcher spent considerable time visiting the school, meeting the principal, teachers and students, attending assemblies and generally absorbing the culture of the school by being present as much as possible. After the groups had been formed, the researcher attempted to develop rapport with 
the participants in this study by being open with students about the research process. For example, the researcher explained to the students that while the researcher was an educator, the researcher was not "their" teacher and that the information they shared with the researcher would be treated confidentially. Students appeared to understand and accept this situation and were quite open in their responses. It was also apparent that the more interaction that the researcher had with the students the easier it was to reduce the perhaps natural mistrust some students have about teachers. Anae and her colleagues (2001) explained that building rapport with participants is important and "the researcher is encouraged to observe those rapport building tools, such as the use of humour, sharing a meal, sharing common experiences, and being attentive. The importance of building rapport with participants cannot be understated, as it is critical to gaining valuable information, particularly where research topics might be personally sensitive or generally culturally taboo" (p.38).

This research was based on principles of good hospitality, where food and drink were provided during study skills sessions and interviews. Students appeared to appreciate the food and drink, and the very open responses that the participants offered during the interviews may have been one way of reciprocating the hospitality shown by the researcher. Anae and her colleagues (2001) explained the significance of gifting with food or other forms of appreciation: "The Pacific practice of providing gifts, such as food or cash as listed below, is its ability to give tangible form to Pacific principles of reciprocity, love and respect. The customary provision of a 'gift' is, as discussed earlier, 
in recognition and acknowledgement of the information and time shared by each participant" (p.41)

The researcher worked actively to ensure that students knew the information they shared was confidential. It was important to the researcher that participants received explicit information about what was to happen to the data they gave, and how and with whom it would be shared. The researcher considered confidentiality was very important so that participants would feel relaxed about giving their views safe with the knowledge that there would be no repercussions. The researcher made it clear that there was shared ownership of the research. Some students asked the researcher what would be done with the information that they gave during interviews. The researcher explained that perhaps there would be a book and also explained that it would take considerable time for information to finally be published; while it might not help them by the time that was published, perhaps their younger brothers, sisters and cousins would benefit from ideas from this research. Students were fully consulted prior to and during all stages of the research and the researcher sought and gained written permission from all students and their families before the research began. Anae and her colleagues (2001) explained that "[o]ften participants are reluctant to impart information fearing repercussions on families and/or family members, or that somehow they will be identified as the giver of confidential information. In these cases explaining the confidentiality principle and other ethical guidelines to the participant, and perhaps more the consequences for breach of guidelines, together with the explanation about the importance or value of the research, might each help to alleviate some of this pressure" (p.40). Anae and her 
colleagues (2001) also explained that it was important to outline the research parameters before the research begins covering ideas such as "[w]hat the research will and will not be addressing and why ... To do so helps to alleviate any false expectations that the interviewee might derive and/or address any misinterpretations that the interviewee might perceive. The researcher is encouraged to highlight how the research might be of benefit to the participant and to do so as part of the introductory discussion around the aims of the research" (p.38).

The researcher explained to all the participants before the interviews that the interviews would be taped and that the researcher was aware that this could be a sensitive issue for some students. Some students asked questions about why the interviews were to be taped, and the interviewer explained that he could not write fast enough to record all their ideas accurately. All participants accepted the taping of interviews, and subsequently all interviews were taped. Had there been any continued resistance to taping the researcher would have stopped recording, but this did not eventuate. At the end of each interview there was an opportunity for students to review what had been said and for them to withdraw information if they wanted to. Students were more concerned about the anonymous side of their data rather than withdrawing the data; as long as it could not be traced back to them they appeared to be satisfied with giving their points of view. Anae and her colleagues (2001) recommended that "[f]ull and clear explanations of the value of note taking and taping to the research exercise should be provided. In almost all cases note taking has been accepted, however, for some Pacific persons, taping is more problematic, as Pacific peoples often do not want their stories recorded. It is here that building good 
rapport with the interviewee can assist in alleviating some of their concerns towards taping" (p.39).

The researcher was assigned a cultural advisor by the university. Dickie (2008) explained that cultural advisors' support could include "advice on the interview questions, appropriate protocols for the investigation, guidance about gathering data, the type of questions asked, how the data were gathered, gaining consent for student participation and ongoing consultation about organising the students in the project" (p.81). In addition to the official Victoria University of Wellington cultural advisor, the researcher also had the assistance of two school-based cultural advisors who were part of a Pasifika mentor programme with whom the researcher had previously worked. The researcher consulted the cultural advisors at all phases of this thesis and the advisors gave valuable insight into better ways to work with Pasifika students and their families. This included, for example, the importance of pronouncing students' names carefully and correctly, using cooperative groups for work during the delivery of the study skills programmes, interviewing students in pairs for more comfort and in a public place like a library, the importance of establishing rapport with students before asking information about family interests, finding out about the students, the importance of deliberate hospitality and providing food and drink, and taking a consultative approach gathering data in a face-to-face manner rather than in a more impersonal way.

Another advisor commented on the issue this research raised about Pasifika students showing lower levels of academic achievement compared to students from other 
ethnic groups at a relatively early age. This cultural advisor suggested that, because studying is a very individualistic activity, it suited non-Pasifika students better than Pasifika students because many Pasifika students are part of a community with multiple responsibilities whereas non-Pasifika students may not be. The advisor suggested that the motivation orientations Doing My Best and Doing Just Enough may be viewed differently from a Pasifika perspective compared to a non-Pasifika perspective. The advisor reminded the researcher that educators must understand the reality that many Pasifika students may have with conflicting priorities of the household, extended families, and possible church and village commitments. This explanation meant that this researcher should consider the view that a student who may be considered by a school to be doing just enough academically, may in fact be doing a very good job of balancing possible conflicting demands of his or her worlds in a way a non-Pasifika student may not have to do.

The cultural advisors agreed with the importance of teacher-student relationships that this thesis argues is crucial to Pasifika student achievement. The advisors said that messages such as "you are important to the school", "you matter" and "you have a place/belong" were important to Pasifika students. The advisors also had a view about how some Pasifika students viewed the concept of ability. One advisor's experience was that many Pasifika students believed they had limited ability and there was a need for the MS study programme to attempt to change these ideas. The cultural advisors also agreed that negative stereotypes about Pasifika peoples were reinforced by bad news stories. They believed that both students and teachers may then generalise these views onto Pasifika students who are achieving well at school. One 
advisor reported that many people including teachers only know about Pasifika peoples through the media (having no real knowledge). For example, one advisor recounted the reality of being a Pasifika person was that some Palagi did not identify her as being Samoan because she was not obese, unemployed and uneducated.

Finally another advisor reminded the researcher that using the term "Pasifika" to describe students who come from six individual Pacific nations as a homogenous group was a Western ideology which may encourage stereotypes. The cultural advisor outlined possible dangers of transfer and countertransference perspectives where some teachers may hold a view that the European race is superior to all others and may bring these beliefs into the classroom. The advisor believed that these ideas had some historical origins based on missionary work by Europeans when Samoan students may have received messages that their culture was inferior to that of the Europeans, and that these ideas may still exist in the minds of some European and Pacific peoples.

The main criticism of using the pragmatic mixed-methods approach is the quality of integration of the quantitative and qualitative data. (Bryman, 2007; Greene, Caracelli and Graham, 1989; Yin, 2006). To ensure good quality integration in a mixed-methods study Creswell (2009) suggests researchers ask two key questions (p.207). His first question is "when does mixing occur?" This study mixed the data at both phases, beginning with the initial quantitative results which in turn informed the secondary qualitative data collection. In this way the two forms of data collection were separate but connected. Creswell's (2009) second question is "how does mixing occur?" This 
Motivation Interventions via Study Programmes for Under-achieving Students

study mixed data from the quantitative phase first and then followed up any unexpected findings with interviews in the second qualitative phase. In the final phase a mixture of all findings were discussed and interpreted. How theory and data were integrated in this study is discussed more fully later in this chapter.

Another problem identified with mixed-methods research is how to deal with conflicting findings. This was an issue in this study as some quantitative data showed that students reported decreased levels of some intra-personal motivation factors after intervention and yet other data showed increased NCEA achievement. Findings like these were explored in subsequent interviews in an attempt to find areas of convergence or divergence, following the advice of Slonim-Nevo and Nevo (2009) who stated that "conflicting findings should be integrated, and that consistency is restored by admitting complexity in the phenomenon under investigation" (p.109).

Two other issues commonly identified with mixed-methods research are the length of time a study can take and managing the resources needed to complete the study (Bernardi, Keim, and von der Lippe, 2007:23; Bryman, 2007; Ivankova, Creswell and Stick, 2006; Creswell, 2009). Molina-Azorín (2011) reported that mixed-methods research may require a broader set of skills, resources and effort and concluded that "researchers should consider whether it is appropriate and worthwhile to carry out a mixed methods study" (p.7). In this study the researcher had sufficient time to research full-time and to deliver the study-skills intervention programmes as well as being fortunate to receive research grant assistance. The next section of this chapter 
discusses the strategy of inquiry used in this study and how decisions were made to adopt a two-phase, sequential explanatory mixed-methods design.

\section{Section Three: Strategy of Inquiry}

Creswell (2009) identified three possible strategies of inquiry in a pragmatic mixedmethods study - sequential (in phases), concurrent (at the same time) or transformative (action research). Creswell (2009) further explained that decisions about which mixed-method strategy to use in a particular study should be based on four criteria - timing, weighting, mixing and theorising (p.206). Ivankova, Creswell and Stick (2006) concurred with this list outlining their criteria as "priority, implementation, and integration of the quantitative and qualitative approaches" (p.9). Although the terms sound different, implementation is the same as timing, priority is synonymous with weighting, and mixing and integration are the same; thus, the only extra concept from Creswell (2009) is theorising.

\section{Timing}

The main timing (or implementation) issue in this study was when the data would be collected. This study uses a sequential design so that the qualitative data in phase two could be used to corroborate, elaborate or initiate findings from the quantitative data from phase one (Rossman and Wilson, 1985). It was decided to take a sequential approach because this allows better integration of data, even though collecting both sets of data concurrently would have saved time. Another reason for choosing a two- 
phase sequential design rather than a concurrent strategy was because motivation can be viewed as a quantitative and a qualitative variable. By planning to analyse the quantitative data first it was hoped that these data about motivation and achievement could be enhanced by hearing the qualitative views of students. Subsequent analysis of the qualitative data also enabled the researcher to probe more deeply into the different aspects of the programmes and how they were perceived by the students in relation to their learning.

\section{Weighting}

The weighting of this study related to the emphasis given to the qualitative or quantitative data during the data gathering and data analysis processes. Creswell (2009) explained that decisions about weighting hinge on the interests of the researcher, the emphasis of the investigator and the audience for the study (p.207). This study places approximately even weight on both the quantitative and qualitative data; similar importance was given to the qualitative data from interviews with students as these data explained and elaborated patterns in the quantitative data. However, it could be considered that this study gives more priority to the quantitative data because this was collected first and analysis of quantitative data informed the collection of the qualitative data from interviews. Also, in terms of weighting of research questions, there were two quantitative research questions but only one qualitative research question used in this study. 
The intended audience of this study includes educators, researchers and policymakers. When designing this study it was considered important to gather empirical quantitative data because Robinson and Timperley (2004) noted there is a lack of empirical studies in relation to Pasifika student achievement. They sought the views of Pasifika teachers and Ministry of Education officials about what they believed was needed to raise achievement of Pasifika students; solutions fell into eight categories, with the most favoured being teacher-quality and home-school liaison (p.xv). Robinson and Timperley (2004) concluded that most of these strategies have been tried in some form, but few have been evaluated "systematically in terms of their success in raising student achievement" (p.xvi). Robinson and Timperley (2004) also reported that the literature showed only one study with substantive empirical data (Phillips et al., 2002) that gave a solution to the under-achievement of some Pasifika students (p.108). This study was from Phillips, McNaughton and MacDonald (2001), who reported on their Early Childhood Primary Links via Literacy (ECPL) Project, which aimed to raise student achievement in schools enrolling large numbers of Pasifika students. They found that their intervention reduced the risk children faced of not achieving expected literacy results (p.12). Robinson and Timperley (2004) concluded that this did not mean that only one solution (to Pasifika student achievement) was possible, but rather that this was the only solution that had been empirically validated (p.108). Robinson and Timperley (2004) reported that much has been done to improve outcomes for Pasifika students including staffing more Pasifika teachers, offering more bilingual classes and introducing more home-school programmes to make parents welcome. What has not occurred is comparative research across initiatives to enhance Pasifika student achievement (p.108). It is hoped that this study will add to empirical 
data about Pasifika student achievement by examining the effects of study skills intervention programmes.

\section{Integration of Theory and Data}

This research followed the view that the quality of integration was the most important of the four criteria which informed what strategy of inquiry this research would follow (Bryman, 2007; Greene, Caracelli and Graham, 1989; Rossman and Wilson, 1985; Tashakkori and Creswell, 2007). Bryman (2007) noted that "the key issue in a mixedmethods project is whether the end product is more than the sum of the individual quantitative and qualitative parts" (p.8). Tashakkori and Creswell (2007) further explained that "Mixed methods research is more than just mixing the strategies of inquiry and methods but rather mixed methods is the integration of two approaches to research (quantitative and qualitative)" (p.4). Bryman (2007) reported that while many studies claim to use mixed methods, of 232 articles that professed to be mixedmethods research (published from 1994-2003) just 18\% of those articles genuinely integrated the quantitative and the qualitative findings" (p.22).

Morgan (2007) explained that deduction is the process that connects theory and data in quantitative research, whereas in qualitative research this is termed induction and in the pragmatic mixed-method approach it is called abduction. Morgan explained that abduction allows the researcher to ask questions like "Did the data support the theory?" or "What theory can be derived from the data?" Morgan (2007) noted that abductive reasoning "moves back and forth between induction and deduction" (p.72). Morgan (2007) further stated "That this particular version of the abductive process is 
quite familiar to researchers who combine qualitative and quantitative methods in a sequential fashion" (p.72). In this way Morgan (2007) reported that "the inductive results from a qualitative approach can serve as inputs to the deductive goals of a quantitative approach, and vice versa" (p.71). In this study the deductive results from the quantitative data analysis served as inputs to the inductive goals of the qualitative phase. For example, data gained from the quantitative phase of the research showed there were ethnic variations in the effects of the interventions that were further investigated in the qualitative phase. Martin and Dowson (2009) showed that the motivation and achievement of some non-Western learners may be related to interpersonal concepts such as relationships with significant others - teachers, family and peers. Inconclusive data gathered and analysed in this study from Pasifika students about changes in their intra-personal motivation may be evidence that some Pasifika students hold a non-Western view of motivation. This theory was tested by subsequent qualitative interviews with students asking about motivation and achievement within an abductive process. Morgan (2007) explained that "This movement back and forth between different approaches to theory and data ... is an interesting option to explore the potential for working back and forth between kinds of knowledge" (p.71).

\section{Theoretical Framework}

The theoretical perspective of this research lies in the field of motivation achievement theory and is consistent with six seminal theories - self-efficacy, expectancy-value, goal, self-determination, self-worth and attribution motivation theory. The field of motivation achievement theory is wide, and this research targets some motivation 
theories more than others. For example, heavy emphasis is given to the intra-personal motivation factors of "doing just enough" and "doing my best" and the associated concept of "effort" in the MS programme. Less emphasis is given to the more generic intra-personal motivation factor of persistence. This is because there was more locally and culturally relevant empirical evidence regarding "doing just enough" and "doing my best" and the associated concept of "effort" than more generic intra-personal motivation factors such as persistence. A possible result of these emphases could be that students who participated in the MS programme were more affected by emphasised intra-personal motivation factors such as effort but less by intra-personal motivation concepts that were not covered in the MS programme such as persistence. It is also possible that this study may find data that show motivation impacts on achievement outcomes via indirect pathway constructs, rather than directly. For example, Martin (2008) reported that goal motivation theory explained why failure affected some students more than others. This was because students who had a performance focus were more threatened by failure because failing equalled lack of ability, whereas learning-focused students believed failure reflected their effort rather than their ability (p.25).

The MS intervention had an overarching relational motivational perspective because this approach may hold benefits for "at-risk" groups such as indigenous students (Martin and Dowson, 2009:340) and this study considers that "at-risk" students could reasonably include under-achieving Pasifika students in New Zealand Secondary Schools. Richer et al. (1998) also reported that "many indigenous students experience difficulties with their teacher so interpersonal relationships are a critical concern when 
schools are seeking to enhance indigenous students' educational outcomes" (p.340). Bishop et al. (2009) noted techniques that culturally responsive teachers could employ with Māori students in New Zealand Secondary Schools. These included caring for students as culturally-located individuals, creating social interactions through maintaining fluid teacher-student relationships, demonstrating connectedness with all students, and rejecting deficit theorising about Māori student achievement (p.4). These ideas are similar to what Dowson and Martin (2009) proposed as recommendations for teachers in classrooms that are characterised by diversity, especially students who may be academically disadvantaged including indigenous Australians, Native Americans, African Americans, and Mexican Americans (p.341). These principles could be appropriate for teachers in New Zealand classrooms who are looking to raise the achievement of Pasifika students. The MS intervention programme adopted some of these principles which were expressed in key messages such as "you belong here" and "we accommodate diversity." 


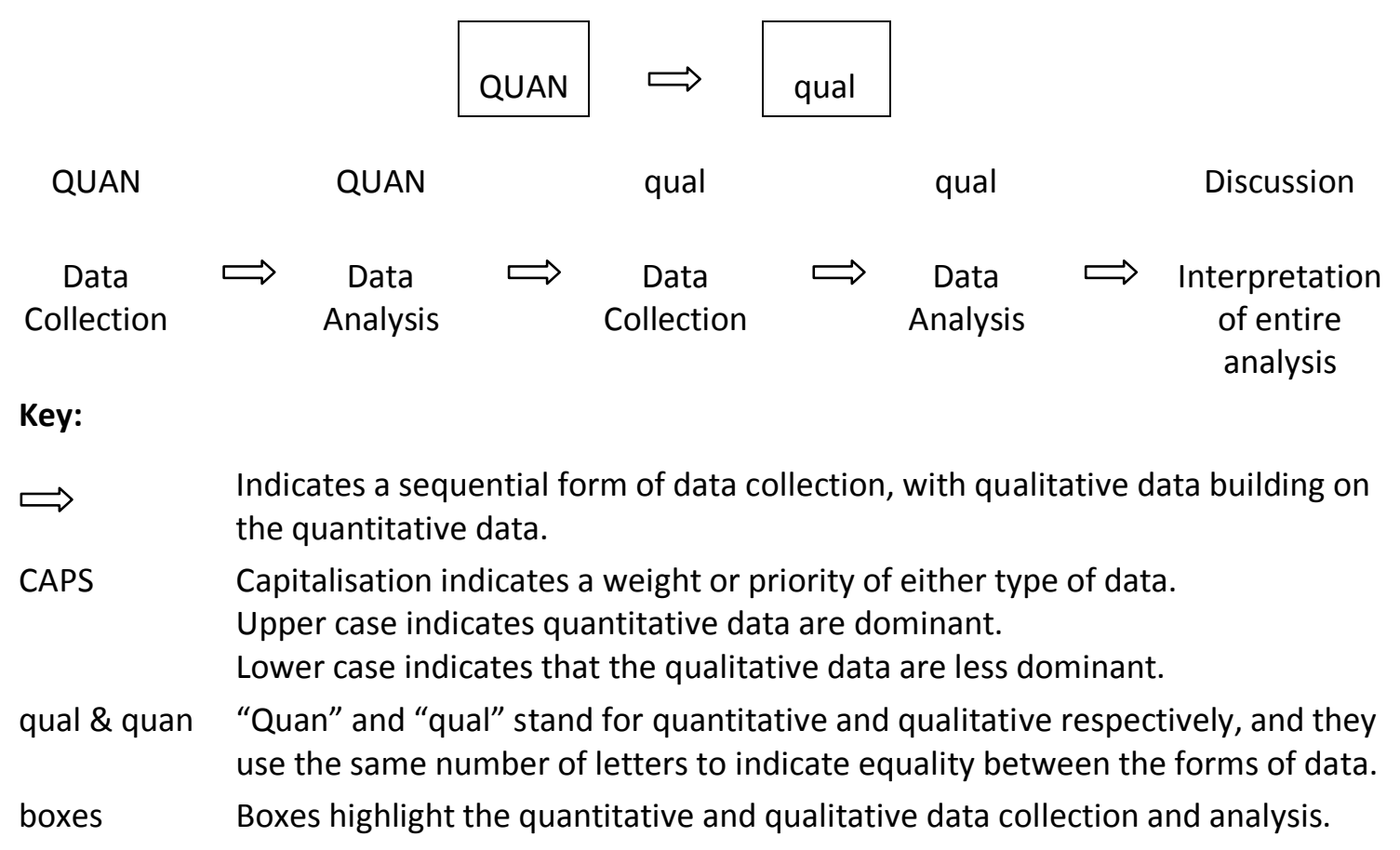

Figure 3. Visual model of the two-phase, sequential, explanatory, mixed-method research design used in this study (source: Creswell, 2009)

The final part of this chapter, section four, covers details about the research methods used in this study - including the participants, instruments, and how the data were collected and analysed.

\section{Section Four: Research Methods}

\section{Participants}

Student samples were recruited from two Secondary Schools selected purposively for the following factors: proximity to transport (as the researcher made many visits to the schools), diversity of student ethnic backgrounds (especially significant numbers of Pasifika students), co-educational state Secondary Schools and the schools' willingness to allow a researcher into their school. Two schools that fitted these criteria agreed to 
participation (the identity of the two schools is confidential). Both schools were in a similar geographical area but had different decile ratings - School A was a decile 6 (considered mid-decile) school and School B a decile 1 (considered low-decile) school. The New Zealand Ministry of Education (www.minedu.govt.nz) explain that "Decile 1 schools are the $10 \%$ of schools with the highest proportion of students from low socioeconomic communities, whereas decile 10 schools are the $10 \%$ of schools with the lowest proportion of these students".

Participants in this study were in Year 11 and had an average age of 15 years. The New Zealand Ministry of Education (www.minedu.govt.nz) explains that "New Zealand children are educated in primary schools from year 1-8 and at the end of year 8 students move on to a secondary school, also known as a high school or college". There are no formal national examinations in Year 9 and 10, but since the students in this study were in Year 11 they were experiencing Level 1 NCEA "the main secondary school qualification for students in years 11-13. NCEA can be gained at three levels usually Level 1 in Year 11, Level 2 in Year 12, and Level 3 in Year 13."

The Year 11 students in this study were initially identified by a nominated liaison teacher at each school as students who could benefit from a study skills programme. Teachers were informed that the focus of the programme was student underachievement and that the intervention was open to students of all ethnicities. They were also told that the researcher hoped that sufficient Pasifika students would be involved so meaningful data about the lower achievement of some Pasifika students could be investigated. Once nominated, individual students and their 
parents/caregivers received an invitation from the school on behalf of the researcher seeking their voluntary participation in a programme to enhance achievement. The invitation indicated that there would be an attendance requirement and formal recognition following completion of the programme. All parents/caregivers and students gave written consent to participate in this research (as shown in Appendices $\mathrm{G}$ and $\mathrm{H})$. Originally it was believed that the programmes would be held before or after school and that this could lead to attendance issues for students who may have competing activities after school. However, both schools generously allowed the researcher to deliver the MS and TS study skills intervention programmes during the regular school day and this presumably improved attendance rates in the intervention programmes.

\section{Group One}

Group one was a Year 11 class which had 24 students and was located in School A where the students in this group were attempting to gain credits for their Level 1 NCEA. The teacher of this class was receptive to allowing the students to be involved in this research because many students in the class could be classified as underachieving students. This was partly because School A operated a streaming system which placed students into low, middle or high ability groups based on prior achievement. Group one students had been placed in a low ability stream, and many of the students were classified as English Speakers of Other Languages (ESOL) students which meant that English was not their first language. The ethnicity of students in 
group one was evenly mixed between equal numbers of Pasifika and non-Pasifika students.

The science curriculum School A chose to deliver to this group of students tended to be at a basic level, with their science course consisting mainly of unit standards worth small numbers of credits (usually two credits). The science curriculum that students in group one received was different to that offered to other students in other "streams" at School A. "Higher ability" students in middle and top streams were offered a curriculum composed mainly of achievement standards, whereas group one students worked towards a mixture of unit standards and achievement standards. The NZMoE website (2012b) explains individual schools can set their own curriculum as "All schools have their own curriculum that outlines their teaching and learning programme. The school's curriculum is based on the national curriculum and achievement standards align to this. Achievement standards can be earned with achieved, merit or excellence, depending on how well the student performs. Unit standards aren't usually related directly to the NZ curriculum and tend to be used more in workplace-related subjects, such as hospitality, tourism and engineering. Most unit standards are assessed as either achieved or not achieved." These curriculum designs are relevant to this study because "ability" was a concept covered in this study and so it is possible that students in group one who knew they were in a lower stream class may have had different perceptions of their own "ability" compared with students in middle or higher streams. 
To get even MS and TS sub-groups from within the larger group one students, the classroom teacher assisted providing achievement data about the class from previous assessments. Using these data, students were ranked by level of achievement from 1 to 24 and allocated to either the MS or TS intervention study programmes. In order to create two similar groups, students were allocated to the MS or TS groups in matched pairs - the top ranked student went into the MS group and the 2 nd ranked student to the TS group. This meant the MS group contained students ranked as $1,3,5,7,9,11$, $13,15,17,19,21$, and 23 and the TS group contained students ranked as $2,4,6,8,10$, $12,14,16,18,20,22$, and 24 .

Group one students were allocated four science lessons each week. The researcher and the teacher discussed the context in which the study skills programme would be delivered, deciding that the researcher and the classroom teacher would each teach a different science unit standard to group one students. The researcher used the context of a unit standard called Science and the Car (New Zealand Qualifications Authority (NZQA), 2012a). This design meant the researcher was able to teach study skills alongside and as part of teaching a science unit standard, enabling students to gain study skills and credits towards their level one NCEA. It was hoped that providing the study skills programmes within a context of getting NCEA credits would add relevance and "value" to the programme. The decision about delivering the TS and MS programmes was based on research that study skills programmes delivered within a context are more effective that study skills programmes delivered as "stand-alone" study skills programmes (Hattie, 2009). Hattie (2009) reported that "Study skills alone can have an effect on the surface level information, but it is necessary to combine the 
study skills with the content to have an effect on the deeper levels of understanding" (p.189). All students received eight hours of the MS or TS study skills programme with the researcher. This time included pre-testing, teaching the study skills program, assessing students, offering a re-assessment opportunity, and finally post-testing.

\section{Group Two}

A similar research design as described for students in group one was followed for students in group two. Group two students also attended School A, and the regular classroom teacher of group two taught them Year 11 mathematics. Their teacher was also receptive to this research because although group two was streamed as a middle ability group, there were still some students in group two who were under-achieving students and it was considered that all students in group two would benefit from a study skills programme. The ethnicity of group two was predominantly non-Pasifika, with just four out of a total of 21 students in group two reporting their first ethnicity as Pasifika. Again the classroom teacher and the researcher discussed how to best deliver the intervention programmes and it was decided that the researcher would teach a unit standard about algebra - Demonstrate basic algebra skills (NZQA, 2012b). The students in group two were divided into two equal groups in a similar way to the process used for group one. All students received eight hours of intervention time, including pre-testing and post-testing, over four weeks. 


\section{Group Three}

Group three students came from School B, a school located in the same geographical area as School A but classified as a decile one school. Group three students at School B were taught year 11 science and were streamed by their school as a high ability group. The ethnicity of students in group three was predominantly Pasifika, with all but one student in group three reporting their first ethnicity as Pasifika. However, the one student who reported her first ethnicity as non-Pasifika also reported that her second ethnicity was Pasifika. For research purposes, group three is considered fully Pasifika and effects of the MS and TS programmes on students in group three may be more representative of programme effects for Pasifika students than students in groups one and two.

The classroom teacher and the researcher again discussed the context in which the intervention programme should be delivered. Since group three students were taught their Year 11 science course based fully on achievement standards, it was decided that the researcher would use the context of a chemistry achievement standard Describe Aspects of Chemistry (NZQA, 2012c). This achievement standard was externally assessed, unlike the unit standards used for groups one and two which were internally assessed. This meant that the researcher was not able to offer credits during the delivery of the intervention programmes which had been available to groups one and two students. The delivery of the group three MS and TS intervention programmes was slightly different to that of groups one and two because group three students received their study skills programme during an extended form time during the school day. This extended form time lasted 25 minutes, so that group three 
students received more frequent but shorter duration MS and TS sessions than group one or two students. Group three students received a total of 14 TS and MS sessions, which made a total delivery time of 350 minutes. This was similar to the 360 minutes of intervention time that groups one and two students received.

Data about a total of 57 students across the three groups were gathered and analysed in this study. A total of 69 students were initially invited to participate in the MS and TS programmes but some of the 69 students were absent at pre-testing or post-testing or completely absent during the delivery of the MS and TS programmes. This resulted in incomplete data for 12 students and a final total of 57 participants in this study.

\section{The Traditional Study Support Programme (TS)}

The content of the TS programme was NZQA curriculum based where TS students were taught NCEA Level 1 mathematics or science content as well as being taught study skills such as time management, reading skills and how to take tests. The TS support programme was an innovation designed to be different to what students would receive in a normal classroom teaching situation. The TS programme can be described as an innovation rather than normal teaching because it fits four criteria for an innovation - content, design, provider and evaluation. Specifically the TS studyskills programme was categorised as a meta-cognitive intervention because the focus of the TS programme was on "planning; monitoring; and where, when, and how to use strategies" (Hattie, Biggs and Purdie, 1996:99). The TS programme was delivered and designed by the researcher and data gathered and analysed about the effects of the 
TS programme was more comprehensive than would normally be available in a regular classroom situation. This was because data about motivation, engagement and attendance - as well as NCEA achievement data - were analysed. The study skills taught in the programme were generic in design and could be generally applied to other teaching-learning situations. The outline of the TS study-skills intervention programme - delivered as six modules - is shown in the following figure.

\begin{tabular}{ll}
\hline \multicolumn{1}{c}{ Module } & \multicolumn{1}{c}{ Study Skill } \\
\hline One & Organising my study \\
Two & Time management \\
Three & Reading skills \\
Four & Doing effective classwork \\
Five & Doing assignments - writing skills \\
Six & Preparing for tests \\
\hline
\end{tabular}

Figure 4. Module contents for the Traditional Study Support Programme (TS)

\section{The Motivation-enhanced Study Support Programme (MS)}

The MS support programme incorporated all the components of the TS support programme, plus additional, motivation-based components. These motivation components of the MS programme were focused on getting students to understand how intra-personal and inter-personal motivation factors are associated with improved achievement and how to control attributions for best and worst marks. MS study skills sessions were delivered by the researcher within a context of improved belongingness, peer affiliation and teacher affiliation. For example, some students were adamant that their teachers did not like them and so some time was spent discussing that teachers may not like a student's behaviour, such as disruptive calling out in class, but that this was not the same thing as a personal dislike of a student by a 
teacher. The MS intervention programme can be categorised as a mixture between a meta-cognitive and an affective intervention because as well as focusing on "planning; monitoring; and where, when, and how to use strategies" the MS programme also focused on "non-cognitive features of learning - motivation" (Hattie, Biggs and Purdie, 1996:99). It is important to note that the incorporation of motivation elements in the MS programme did not diminish the content of the MS programme in comparison to the TS programme and MS students were taught study skills as described above in the same way as their TS counterparts. The MS programme contained six modules based on concepts from achievement motivation theories and focused on mastery learning within a climate of co-operation (including Ames, 1992; Ames and Ames, 1984; Blumenfeld, 1992; Martin, 2008; Martin and Dowson, 2009; O'Mara, Marsh, Craven, and Debus, 2006; Wentzel and Caldwell, 1997). These and other ideas influenced the culturally responsive MS study skills intervention programme which is shown in the table below.

\section{Table 3}

Module Contents for the Motivation-enhanced Study (MS) Support Programme

\begin{tabular}{lll}
\hline \multicolumn{1}{c}{ Module } & \multicolumn{1}{c}{ Study Skill } & \multicolumn{1}{c}{ Motivation component } \\
\hline One & Organising my study & Mastery learning \\
Two & Time management & Self-belief \\
Three & Reading skills & $\begin{array}{l}\text { Expectancy-value } \\
\text { Four }\end{array}$ \\
Doing effective classwork & $\begin{array}{l}\text { Failure avoidance and self- } \\
\text { sabotage }\end{array}$ \\
Five & Doing assignments - writing & Attribution and control \\
Six & skills & \\
& Preparing for tests & $\begin{array}{l}\text { Mastery learning and } \\
\text { "personal bests" }\end{array}$ \\
\hline
\end{tabular}




\section{Assignment of Students to Groups}

The quantitative component of the research involved random assignment of Year 11 student participants to the two groups, the MS support programme or the TS support programme. Participants in this study knew there were two programmes, and that both programmes focused on study support using two different approaches in order to test the effectiveness of the approaches. Students did not choose which study support programme they attended because they were allocated to one of the two study programmes in matched pairs, as described earlier, with the aim of creating two groups that were as similar in subject-related achievement as possible. The exact composition of the two groups was influenced by administrative arrangements at each of the schools because students came from intact class groups that were predetermined by the timetable at that school. This meant that the students in this study may not necessarily reflect all Year 11 students at either school or Year 11 students in New Zealand co-educational Secondary Schools in general. The stratified random allocation of students to groups in this study may be considered equitable to all students because both the TS and MS study programmes were designed to have positive learning effects; regardless of which programme the student was allocated to, all students should have received a useful learning opportunity. The final decision regarding which students received the MS or TS programme was made after students were identified for the groups to avoid the possibility of biased group membership. The researcher randomly selected whether group one students at School A had their MS programme on a Monday and the TS programme on the Tuesday, for example, or vice-versa by the flip of a coin. In School A, where two different groups of students received the study skills programme, the order of the two programmes automatically 
became the opposite for the second group. A variety of pre-tests were administered to all students at both groups before the intervention programme and post-tests after the final session. These pre- and post-tests are outlined in the instruments section of this chapter.

\section{Quantitative Data Collection}

In phase one, quantitative data were gathered from a two-group pre-/post-test randomized experiment that aimed to determine whether achievement-related outcomes of the two intervention programmes were different. Achievement-related outcomes of students from each group were determined using the six indicators as outlined in the measures of achievement-related outcomes section of this chapter. As shown on the next page, the design of this experiment can be represented by two lines - one for each group - with an $\mathrm{R}$ at the beginning of each line which indicates that the groups were randomly assigned to one of two groups, MS and TS. Students in groups one and two were from School A. Group three students were from School B. Equal numbers of students from each of the three groups received the TS support programme, which was the control group. Equal numbers of students from each of the three groups received the MS support programme, which was the relative comparison group. Any pre-tests administered by the researcher were not for the purpose of group assignment as students were randomly assigned to the two conditions on the assumption that the two groups were probabilistically equivalent. Rather, pre-testing was carried out to allow investigation post-hoc for any differences between groups despite the stratified random sampling process designed to ensure that the groups 
would be equivalent. Administration of any pre-tests allowed for evaluation of group equivalence as well as measuring changes in achievement, motivation and engagement over time. The research design can be expressed as follows:

\section{Table 4}

Experimental design of this study

\begin{tabular}{|c|c|c|c|c|c|c|c|}
\hline Group one & MS: & $\mathrm{R}$ & ----- & O ----- & MS & ----- & $\mathrm{O}$ \\
\hline Group one & TS: & $\mathrm{R}$ & ----- & O ----- & TS & --- & 0 \\
\hline Group two & MS: & 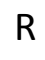 & - & O ---- & MS & --- & 0 \\
\hline Group two & TS: & $\mathrm{R}$ & ----- & O ----- & TS & ----- & $\mathrm{O}$ \\
\hline Group three & MS: & $\mathrm{R}$ & ----- & O ----- & MS & ----- & 0 \\
\hline Group three & TS: & $\mathrm{R}$ & ----- & O ----- & TS & ----- & $\mathrm{O}$ \\
\hline
\end{tabular}

Key:

$\mathrm{R}=$ Random assignment of matched-pairs of students.

$\mathrm{O}=$ Relevant achievement, motivation and engagement measures administered as pre-tests and post-tests (pre-testing was before first study session for all students; post-testing after last study session for all students).

MS = The experimental condition - the Motivation-enhanced Study support programme.

TS = The control condition - the Traditional Study support programme.

\section{Instruments Used in Quantitative Data Collection}

Two main instruments were used in this study. The first is Martin's $(2001,2005,2008)$

Student Motivation and Engagement Scale (MES-HS). Martin (2005) states that design of the Student Motivation and Engagement Scale was based on valid and reliable psychometric principles. For example, Martin has previously used linear structural relations (LISREL) factor analysis procedures to examine the structure of the MES-HS and has confirmed instrument reliability, normal dimensions of distribution, significant association with achievement outcomes as well as the instrument being "sensitive to 
age and gender related differences in motivation" (p.181). The second instrument used in this study is the Survey of NCEA Goals Year 10 and Year 11 Students (2008) designed and tested by Meyer and her colleagues. Meyer et al. (2007) reported on the validity and reliability of the Screening Tool stating that "a brief screening tool for student motivation not only correlates with the longer motivation survey developed by Meyer et al. (2006), but has high reliability and generates highly predictive results" (p.4). Due to copyright issues these measuring instruments cannot be reproduced in full, but sample questions are shown in Appendixes C and D.

\section{Measures of Achievement-related Outcomes}

Data about the following measures of achievement, motivation, engagement and attendance were gathered and analysed in this study.

1. NCEA Level 1 achievement - including unit standards and achievement standards credits, credits at Achieved, Merit and Excellence grades, and credits attempted but failed.

2. Intra-personal and inter-personal motivation orientations - as measured by the Screening Tool (ST) (Meyer et al., 2008) - pre-test (at the beginning of the intervention) and post-test (at the end of the intervention).

3. Intra-personal motivation orientations and changes in engagement as measured by the Motivation and Engagement Scale-High School (MES-HS) (Martin, 2008), pre-test (at the beginning of the intervention) and post-test (at the end of the intervention). 
Motivation Interventions via Study Programmes for Under-achieving Students

4. School attendance as measured by analysis of students' daily school attendance data.

\section{Qualitative Data Collection}

In phase two, following initial analysis of quantitative data, qualitative data were gathered from interviews with a sub-sample of students from all three groups. Students were interviewed in pairs to ensure students' comfort by being with another student during the interview. All interviews were conducted in a public area - the school library in both schools - as this was found to be a non-threatening environment which encouraged open responses. While it was noisy at times with other students and some teachers in other parts of the library, interviewing students in a neutral place, where there were many other students present, seemed to make students feel more relaxed. All interviews with students were carried out in pairs because this gave students a sense of support and, since students chose the interview pair, it was usually a friend. Interview responses were unlikely to be overheard by others, as the researcher ensured there was sufficient distance from other students. In addition there was always medium-level background noise from other students in the library, which was sufficient to ensure a reasonable level of privacy for the interviews. All students received small food and drink inducements to encourage and reinforce participation in the interviews. Students seemed willing to assist in the research process; if their designated interview partner was not available because they were away that day, students often helped to find a replacement. Students were more open with each other and the researcher and often reacted to each other's comments so it 
appeared to the researcher that interviewing them in pairs facilitated voluntary and rich responses to the questions.

It was planned that the interviews would generally be comprised of either two female students or two male students to avoid any possibility of gender dominance. This was usually the case but occasionally students themselves chose mixed-gender pairs. Since students were asked to volunteer to be interviewed and students also chose their interview partner, the researcher accepted student decisions about who was to be interviewed with whom. The researcher interviewed pairs of students from each of the MS and TS programmes at each of the schools until such time as the data were saturated. All students were invited for interviews, and the researcher interviewed as many students as was practicable within the timeframe. Interviews were conducted with 45 of 57 participants. Twelve students were not interviewed (four from the MS programme and eight from the TS programme) because these students were absent when interviews were scheduled, despite rescheduled interview times being made. Since a focus of this proposed study was Pasifika students, the researcher encouraged Pasifika students to be interviewed, and many were. Interviews were approximately 45 minutes long, were tape recorded and transcribed. No students were identified by their names. Encouraging a positive relationship between the researcher and the participant enhanced the research process.

A feature of the semi-structured design used in this study was that this process may approximate what Creswell (2009) calls a "broadening of questions" which has the advantage that "the participants can construct meaning, typically forged in discussions 
or interactions with other persons" (p.8). Often during an interview, the students would make comments about motivation and achievement to one another almost as if they had forgotten they were being interviewed; they would then turn back to the researcher and explain what they had been discussing. This open and less structured inter-subjective interview approach also seemed to facilitate students openly sharing their diverse views about school rules - such as smoking - which are elaborated later in the qualitative findings chapter. Other students explained their views about disengagement with school and why they did not attend classes; students seemed comfortable to talk about wagging as there was a tacit understanding that the researcher would not pass on this information. Students appeared to trust that the researcher was seeking their views but was not going to identify them or divulge information to their teachers or caregivers. To ensure comparability between schools, this research was conducted in two state, co-educational, similar decile Secondary Schools in a matching geographic location. The interview questions used in initial interviews are outlined in Chapter Four. These questions were varied in subsequent interviews based on the findings emerging from the quantitative and qualitative analyses. Subsequent interviews explored whether these sorts of themes which emerged from initial interviews were commonplace among other students in this study.

\section{Analysis of Quantitative Data}

In the first phase of data analysis, quantitative data were analysed using independent sample t-tests to investigate the difference between the two means of the MS and the 
TS groups for each of the factors being tested. A 0.05 criterion of statistical significance was used for all tests and a $95 \%$ confidence interval $(\mathrm{Cl})$ was reported. To supplement the evaluation of statistical significance with measures of practical significance, effect sizes (Cohen's $d$ ) were calculated. Since the numbers of students in the MS and TS interventions in this study were not the same (MS = 30 and TS $=27$ ), the formula below was used to calculate Cohen's $d$ for effect size for unequal groups (Lomax (2007)).

$$
d=\frac{\mathrm{Y} 1-\mathrm{Y} 2}{S p}
$$

Key:

$\begin{array}{lll}\mathrm{d} & = & \text { Effect size } \\ \mathrm{Y} 1 & = & \text { Mean end of treatment } \\ \mathrm{Y} 2 & = & \text { Mean beginning of treatment } \\ \mathrm{Sp} & = & \text { Pooled sample standard deviation }\end{array}$

Figure 5. Formula used to calculate Cohen's d for effect size for unequal groups in the MS and TS interventions

The inclusion of effect sizes in the analysis had the additional advantage of offering information for subsequent meta-analyses that could be performed across the literature on particular issues. The rationale for analysing the quantitative data this way is because the dependent variables targeted by this study belong to four different conceptual domains (that is, achievement, motivation, engagement, and attendance). As a result, information was needed on individual variables underlying specific dimensions and not on a heterogeneous conglomerate that was not substantively defensible. SPSS was used to analyse quantitative data collected in this study and the results of the phase one quantitative analysis is discussed before phase two, qualitative data collection. The process of abduction was used to allow the deductive 
results from the quantitative data analysis to serve as inputs for the inductive goals of the qualitative phase.

\section{Analysis of Qualitative Data}

After analysis of the quantitative data, qualitative data were collected and analysed with the aim of building on patterns emerging from the initial quantitative analyses. Mixing of the data occurred when the initial quantitative data informed the qualitative data collected and was subsequently analysed. In this way, the study followed a sequential explanatory design, which aimed to explain and interpret the quantitative results by collecting and analysing follow-up qualitative data. This was particularly useful to examine the unexpected results that arose from the interviews, for example how some students used their study time and their understandings of some examination procedures.

This study used grounded theory to analyse the data from interviews in the systematic stages of open, axial and selective coding. The open coding process generated initial categories of information and axial coding facilitated selection of the categories by positioning them into the theoretical perspective of this study. The final interconnection of the generated categories into a coherent description was achieved in the final process of selective coding (Creswell, 2009:184). Some of the data which emerged from the initial analysis of the qualitative data provided themes or codes that were investigated in this study, such as patterns about maladaptive intra-personal motivation orientations (for example, self-sabotage). These codes were positioned 
within the theoretical framework proposed by Meyer, Weir, McClure, Walkey, and McKenzie (2009) which outlined three categories where motivation may influence achievement - intra-personal, inter-personal and external motivational effects (pp.811). Intra-personal motivational influences include an individual's self-perception of ability or their sense of self-belief. Students may also be motivated by inter-personal motivational concepts such as peer-affiliation, teacher-affiliation or family-affiliation - rather than just intra-personal factors such as self-belief. External influences on motivation and achievement could include sport, caring for other children in the family and part-time work (p.8).

The next chapter reports findings based on eight analyses of quantitative data for students in the MS and TS intervention programmes in this study. The chapter analyses differences in NCEA achievement, changes in adaptive intra-personal motivation orientations, changes in maladaptive intra-personal motivation orientations, changes in inter-personal motivation orientations, changes in attributions for best and worst marks in assessments, changes in engagement and changes in attendance. 
Motivation Interventions via Study Programmes for Under-achieving Students 


\section{Chapter Four Quantitative Findings}

\section{Introduction}

This chapter reports findings based on ten analyses of the quantitative data. These were:

Analysis One: Changes in NCEA achievement outcomes

Analysis Two: Changes in adaptive intra-personal motivation orientations

Analysis Three: Changes in maladaptive intra-personal motivation orientations

Analysis Four: Changes in Doing My Best (DMB) and Doing Just Enough (DJE)

Analysis Five: Changes in interpersonal motivation orientations

Analysis Six: Changes in attributions for best marks in assessments

Analysis Seven: Changes in attributions for worst marks in assessments

Analysis Eight: Changes in attendance

Analysis Nine: Changes in disengagement

Analysis Ten: Changes in aspiration

Each of the ten analyses has two sections. Section One reports the analyses of data for all students who participated in either the Motivation-enhanced Study (MS) support programme $(\mathrm{N}=30)$, compared with all students who participated in the Traditional Study (TS) support programme $(N=27)$. These findings address research question one 
investigating achievement, motivation, engagement, and attendance outcomes for all students who participated in the two programmes. Section Two reports the analyses of data for Pasifika students in the MS programme $(N=16)$ compared with Pasifika students who participated in the TS programme $(N=12)$. These findings address research question two investigating achievement, motivation, engagement, and attendance outcomes for Pasifika students who participated in either the MS programme $(\mathrm{N}=16)$ compared with Pasifika students who participated in the TS programme $(\mathrm{N}=12)$. Consistent with the research questions, no analyses were planned or undertaken for other major ethnic groups, European, Māori and Asian. Furthermore, the numbers of students in each of these ethnic groups was either too small or unevenly distributed across the two intervention programmes to permit statistical analysis on a post-hoc basis. For example, there were only two Asian students in each programme, and there was only one Māori student in the MS programme versus seven in the TS programme.

\section{Statistical Tests used in this Study}

This study used independent sample $t$-tests to compare post-intervention to preintervention change scores on the various dependent variables between the MS and TS programme groups. This means that the $t$-test comparisons were analysing the change scores for each group (post-test minus pre-test equals change or gain score). The $p<0.05$ criterion of statistical significance was used for all tests and a $95 \%$ confidence interval $(\mathrm{Cl})$ reported. To supplement the evaluation of statistical significance with measures of practical significance, effect sizes (i.e., Cohen's $d$ score) 
were calculated (Hattie, 2009; Lomax, 2007). Since the numbers of students in each group were not equal (MS $=30$ and TS $=27)$ this study used the Lomax $(2007: 123)$ formula to calculate Cohen's $d$ for effect size (unequal groups) as below.

$$
d=\frac{\mathrm{Y} 1-\mathrm{Y} 2}{S p}
$$

Key:

$\mathrm{d} \quad=\quad$ Effect size

$\mathrm{Y} 1=$ Mean end of treatment

$\mathrm{Y} 2=$ Mean beginning of treatment

$\mathrm{Sp}=$ Pooled sample standard deviation

Figure 6. Formula used to calculate Cohen's $d$ in the MS and TS interventions

\section{Analysis One: NCEA Achievement Outcomes}

This study analysed change scores on seven academic achievement outcomes based on credits gained at Level 1 of the New Zealand National Certificate of Educational Achievement (NCEA). NCEA outcomes were similar across the experimental versus comparison groups for both all students and for the Pasifika students only. Students in the MS programme achieved more credits overall than those in the TS programme but the differences were small. Each of the analyses is reported next.

\section{Section One: NCEA Achievement Outcomes by All Students in the MS and TS Intervention Programmes}

Table 5 presents means and standard deviations data on NCEA achievement for all students participating in the MS and TS programmes. 


\section{Table 5}

NCEA Achievement Results as Mean Credits Earned by All Students Participating in the Motivation-enhanced (MS) versus Traditional Study (TS) Skills Intervention Programmes

\begin{tabular}{lcc}
\hline NCEA credits earned & \multicolumn{2}{c}{ Intervention groups } \\
\cline { 2 - 3 } & MS (N = 30) & TS (N = 27) \\
\cline { 2 - 3 } & Credit means (SD) & Credit means (SD) \\
\cline { 2 - 3 } Total credits (US and AS) & $87(32)$ & $78(35)$ \\
Total Unit Standard credits (US only) & $38(13)$ & $37(16)$ \\
Total Achievement Standard credits (AS only) & $49(24)$ & $40(25)$ \\
Total credits at Achieved Level (both AS and US) & $74(25)$ & $64(28)$ \\
Total credits at Merit level (AS only) & $10(12)$ & $10(10)$ \\
Total credits at Excellence level (AS only) & $3(7)$ & $3(5)$ \\
Total credits at Not Achieved level (both US and AS) & $46(21)$ & $51(21)$ \\
\hline
\end{tabular}

Table 6 presents the results of the independent samples tests for differences in NCEA achievement for all students in the MS versus TS programmes. 


\section{Table 6}

Independent Samples Tests on Differences in NCEA Credits Earned by All Students in the MS versus TS Intervention Programmes

\begin{tabular}{|c|c|c|c|c|c|c|c|c|c|}
\hline \multirow{2}{*}{$\begin{array}{l}\text { NCEA Credits } \\
\text { earned }\end{array}$} & \multirow[t]{2}{*}{$\mathbf{F}$} & \multirow[t]{2}{*}{ Sig } & \multirow{2}{*}{$\begin{array}{c}t \\
\text { (df) }\end{array}$} & \multirow{2}{*}{$\begin{array}{c}\text { Sig } \\
(2- \\
\text { tailed }\end{array}$} & \multirow{2}{*}{$\begin{array}{c}\text { Mean } \\
\text { Diff }\end{array}$} & \multirow{2}{*}{$\begin{array}{l}\text { Std } \\
\text { Error } \\
\text { Diff }\end{array}$} & \multicolumn{2}{|c|}{$95 \% \mathrm{Cl}$} & \multirow{2}{*}{$\begin{array}{c}\text { Cohen's } \\
\text { d }\end{array}$} \\
\hline & & & & & & & LL & UL & \\
\hline $\begin{array}{l}\text { Total credits (US } \\
\text { and AS) }\end{array}$ & 0.15 & 0.70 & $\begin{array}{l}1.08 \\
(55)\end{array}$ & 0.29 & 9.44 & 8.81 & -8.82 & 27.10 & 0.30 \\
\hline $\begin{array}{l}\text { Total Unit } \\
\text { Standard Credits } \\
\text { (US Only) }\end{array}$ & 1.95 & 0.17 & $\begin{array}{l}0.12 \\
(55)\end{array}$ & 0.90 & 0.46 & 3.90 & -7.36 & 8.29 & 0.01 \\
\hline $\begin{array}{l}\text { Total } \\
\text { Achievement } \\
\text { Standard Credits } \\
\text { (AS Only) }\end{array}$ & 0.42 & 0.52 & $\begin{array}{l}1.48 \\
(55)\end{array}$ & 0.15 & 9.46 & 6.43 & -3.43 & 22.35 & 0.39 \\
\hline $\begin{array}{l}\text { Total credits at } \\
\text { Achieved Level } \\
\text { (Both AS and US) }\end{array}$ & 0.64 & 0.43 & $\begin{array}{l}1.33 \\
(55)\end{array}$ & 0.19 & 9.29 & 7.05 & -4.83 & 23.42 & 0.35 \\
\hline $\begin{array}{l}\text { Total credits at } \\
\text { Merit level } \\
\text { (AS Only) }\end{array}$ & 0.52 & 0.47 & $\begin{array}{l}0.16 \\
(55)\end{array}$ & 0.88 & 0.45 & 2.88 & -5.32 & 6.22 & 0.04 \\
\hline $\begin{array}{l}\text { Total credits at } \\
\text { Excellence level } \\
\text { (AS only) }\end{array}$ & 0.33 & 0.57 & $\begin{array}{l}0.04 \\
(55)\end{array}$ & 0.96 & 0.07 & 1.56 & -3.06 & 3.20 & 0.01 \\
\hline $\begin{array}{l}\text { Total credits at } \\
\text { Not Achieved } \\
\text { level } \\
\text { (US and AS) }\end{array}$ & 0.02 & 0.88 & $\begin{array}{c}-0.76 \\
(55)\end{array}$ & 0.45 & -4.27 & 5.61 & -15.52 & 6.98 & -0.20 \\
\hline
\end{tabular}

These data show that students in the MS intervention programme attained more NCEA credits than students in the TS skills programme, but none of the differences were statistically significant. Calculations of effect size (Cohen's $d$ ) revealed four small effect size differences between the two groups. Using the criterion of small effect sizes defined as $d>0.20$ there were small effects favouring the MS programme for mean credit attainment including Achievement Standard credits at all levels ( $d=0.39$ ), total credits overall $(d=0.30)$, Achievement Standards credits at the achieved level $(d=$ $0.35)$, and credits not achieved $(d=-0.20)$. 
Students in both the MS and TS groups achieved only a small number of NCEA credits at either the Merit or Excellence level, with no significant differences across the groups.

\section{Section Two: NCEA Achievement Outcomes by Pasifika Students in the MS and TS Intervention Programmes}

Table 7 presents the means and standard deviations data on NCEA achievement for Pasifika students participating in the MS and TS programmes.

\section{Table 7}

NCEA Achievement Results as Mean Credits Earned by Pasifika Students Participating in the Motivation-enhanced Study (MS) versus Traditional Study (TS) Skills Intervention

\begin{tabular}{lcc}
\hline NCEA credits earned & \multicolumn{2}{c}{ Intervention groups } \\
\cline { 2 - 3 } & MS (N = 16) & TS (N = 12) \\
\cline { 2 - 3 } & Credit means (SD) & Credit means (SD) \\
\hline Total credits (US and AS) & $79(31)$ & $72(40)$ \\
Total Unit Standard credits (US only) & $35(13)$ & $34(15)$ \\
Total Achievement Standard credits (AS only) & $44(23)$ & $36(26)$ \\
Total credits at Achieved level (both AS and US) & $65(21)$ & $57(31)$ \\
Total credits at Merit level (AS only) & $9(12)$ & $9(11)$ \\
Total credits at Excellence level (AS only) & $5(8)$ & $5(7)$ \\
Total credits at Not Achieved level (both US and AS) & $45(21)$ & $49(24)$
\end{tabular}

Table 8 presents the results of the independent samples tests for differences in NCEA achievement for Pasifika students only in the MS versus TS intervention programmes. 


\section{Table 8}

Independent Samples Tests on Differences in NCEA Credits Earned by Pasifika Students Only in the MS versus TS Intervention Programmes

\begin{tabular}{|c|c|c|c|c|c|c|c|c|c|}
\hline $\begin{array}{l}\text { NCEA credits } \\
\text { earned }\end{array}$ & $F$ & Sig & $t$ (df) & $\begin{array}{c}\text { Sig } \\
(2- \\
\text { tailed }\end{array}$ & $\begin{array}{c}\text { Mean } \\
\text { Diff }\end{array}$ & $\begin{array}{l}\text { Std } \\
\text { Error } \\
\text { Diff }\end{array}$ & LL & UL & $\begin{array}{c}\text { Cohen's } \\
\text { d }\end{array}$ \\
\hline $\begin{array}{l}\text { Total credits (US } \\
\text { and AS) }\end{array}$ & 1.40 & 0.25 & $\begin{array}{l}0.57 \\
(26)\end{array}$ & 0.57 & 7.65 & 13.82 & -20.77 & 36.06 & 0.14 \\
\hline $\begin{array}{l}\text { Total Unit } \\
\text { Standard credits } \\
\text { (US only) }\end{array}$ & 0.02 & 0.90 & $\begin{array}{l}0.10 \\
(26)\end{array}$ & 0.92 & 0.52 & 5.49 & -10.76 & 11.80 & 0.02 \\
\hline $\begin{array}{l}\text { Total } \\
\text { Achievement } \\
\text { Standard credits } \\
\text { (AS only) }\end{array}$ & 1.16 & 0.29 & $\begin{array}{l}0.88 \\
(26)\end{array}$ & 0.38 & 8.21 & 9.45 & -11.22 & 27.64 & 0.26 \\
\hline $\begin{array}{l}\text { Total credits at } \\
\text { Achieved level } \\
\text { (Both AS and US) }\end{array}$ & 2.11 & 0.16 & $\begin{array}{l}0.87 \\
(26)\end{array}$ & 0.39 & 8.50 & 10.28 & -12.64 & 29.64 & 0.28 \\
\hline $\begin{array}{l}\text { Total credits at } \\
\text { Merit level (AS } \\
\text { only) }\end{array}$ & 0.00 & 0.99 & $\begin{array}{l}0.14 \\
(26)\end{array}$ & 0.89 & 0.60 & 4.25 & -8.13 & 9.34 & 0.02 \\
\hline $\begin{array}{l}\text { Total credits at } \\
\text { Excellence level } \\
\text { (AS only) }\end{array}$ & 0.00 & 0.94 & $\begin{array}{l}-0.21 \\
(26)\end{array}$ & 0.83 & -0.63 & 2.88 & -6.55 & 5.30 & 0.06 \\
\hline $\begin{array}{l}\text { Total credits at } \\
\text { Not Achieved } \\
\text { level (US and AS) }\end{array}$ & 0.10 & 0.75 & $\begin{array}{l}-0.48 \\
(26)\end{array}$ & 0.64 & -4.02 & 8.56 & -21.61 & 13.57 & -0.29 \\
\hline
\end{tabular}

These data show that Pasifika students in the MS intervention programme attained more NCEA credits than Pasifika students in the TS skills programme, but none of the differences were statistically significant. Effect size calculations revealed only three small effects favouring the MS programme for Pasifika students, including total Achievement Standard credits $(d=0.26)$, Achievement Standards credits at the Achieved level $(d=0.28)$, and credits Not Achieved $(d=0.29)$. 
Students in both intervention programmes were provided the opportunity to earn the exact same number of credits, and a stratified random sampling procedure was used to assign students to one of the two intervention programmes from the same whole class group referred for the intervention. Overall, there were only a few differences on

NCEA achievement favouring participation in the motivation-enhanced MS programme, supported by small effect sizes on only some of the variables. In all cases, the differences were small, both for all students and for Pasifika students only across the two intervention programmes.

\section{Analysis Two: Changes in Adaptive Intra- personal Motivation Orientations}

Student responses on six adaptive intra-personal motivation orientations were measured before and after the two intervention programmes: self-efficacy, mastery learning, valuing of school, persistence, planning, and task management (see Appendix D to review specific items for each construct).

\section{Section One: Changes in Adaptive Intra-personal Motivation Orientations for All Students in the MS and TS Programmes}

Table 9 presents the means and standard deviations for the adaptive intra-personal motivation orientations rated by students before and after participation in the programmes. 


\section{Table 9}

Adaptive Intra-personal Motivation Orientation Means for All Students Participating in the MS versus TS Programmes

\begin{tabular}{lccc}
\hline $\begin{array}{l}\text { Intra-personal } \\
\text { motivation factor }\end{array}$ & Intervention group & Pre-test mean (SD) & Post-test mean (SD) \\
\hline Self-efficacy & MS & $81(12)$ & $83(11)$ \\
Persistence & TS & $76(21)$ & $80(16)$ \\
& MS & $67(14)$ & $71(14)$ \\
Planning & TS & $62(19)$ & $66(18)$ \\
& MS & $58(17)$ & $57(18)$ \\
Mastery learning & TS & $55(22)$ & $56(18)$ \\
& MS & $90(9)$ & $87(11)$ \\
Valuing & TS & $83(15)$ & $82(15)$ \\
& MS & $85(11)$ & $84(11)$ \\
Task management & TS & $79(18)$ & $80(17)$ \\
& MS & $66(19)$ & $65(23)$ \\
& TS & $65(21)$ & $68(20)$ \\
\hline
\end{tabular}

Table 10 presents the results of the independent samples tests for differences in adaptive intra-personal motivation orientation change scores for students in the MS versus TS programmes. This means that the $t$-test comparisons were analysing the change scores for each group (post-test minus pre-test equals change or gain score). 


\section{Table 10}

Independent Samples Tests and Effect Size Calculations on Change Scores for the Adaptive Intra-personal Motivation Factors for All Students in the MS versus TS Intervention Programmes

\begin{tabular}{|c|c|c|c|c|c|c|c|c|c|}
\hline \multirow{2}{*}{$\begin{array}{l}\text { Intra-personal } \\
\text { motivation factor }\end{array}$} & \multirow[t]{2}{*}{$\mathbf{F}$} & \multirow[t]{2}{*}{ Sig } & \multirow[t]{2}{*}{$t(d f)$} & \multirow{2}{*}{$\begin{array}{c}\text { Sig } \\
(2- \\
\text { tailed }\end{array}$} & \multirow{2}{*}{$\begin{array}{c}\text { Mean } \\
\text { Diff }\end{array}$} & \multirow{2}{*}{$\begin{array}{c}\text { Std } \\
\text { Error } \\
\text { Diff }\end{array}$} & \multicolumn{2}{|c|}{$95 \% \mathrm{Cl}$} & \multirow{2}{*}{$\begin{array}{c}\text { Cohen's } \\
\text { d }\end{array}$} \\
\hline & & & & & & & LL & UL & \\
\hline Self-efficacy & 0.23 & 0.63 & $\begin{array}{l}-0.55 \\
(55)\end{array}$ & 0.58 & -2.19 & 4.01 & -10.22 & 5.84 & -0.15 \\
\hline Persistence & 6.05 & 0.02 & $\begin{array}{l}-0.16 \\
(55)\end{array}$ & 0.88 & -0.49 & 3.16 & -6.81 & 5.84 & -0.04 \\
\hline Planning & 8.28 & 0.01 & $\begin{array}{l}-0.39 \\
(55)\end{array}$ & 0.70 & -1.78 & 4.76 & -11.31 & 7.75 & -0.10 \\
\hline Mastery learning & 0.41 & 0.53 & $\begin{array}{l}-0.34 \\
(55)\end{array}$ & 0.73 & -1.03 & 2.99 & -7.02 & 4.95 & -0.09 \\
\hline Valuing & 0.02 & 0.88 & $\begin{array}{l}-0.59 \\
(55)\end{array}$ & 0.56 & -2.06 & 3.51 & -9.08 & 4.97 & -0.16 \\
\hline Task management & 0.79 & 0.38 & $\begin{array}{l}-0.68 \\
(55)\end{array}$ & 0.50 & -2.97 & 4.43 & -11.85 & 5.91 & -0.18 \\
\hline
\end{tabular}

Figures 7-12 provide graphic illustrations of changes for both groups on each of the six intra-personal motivation factors.

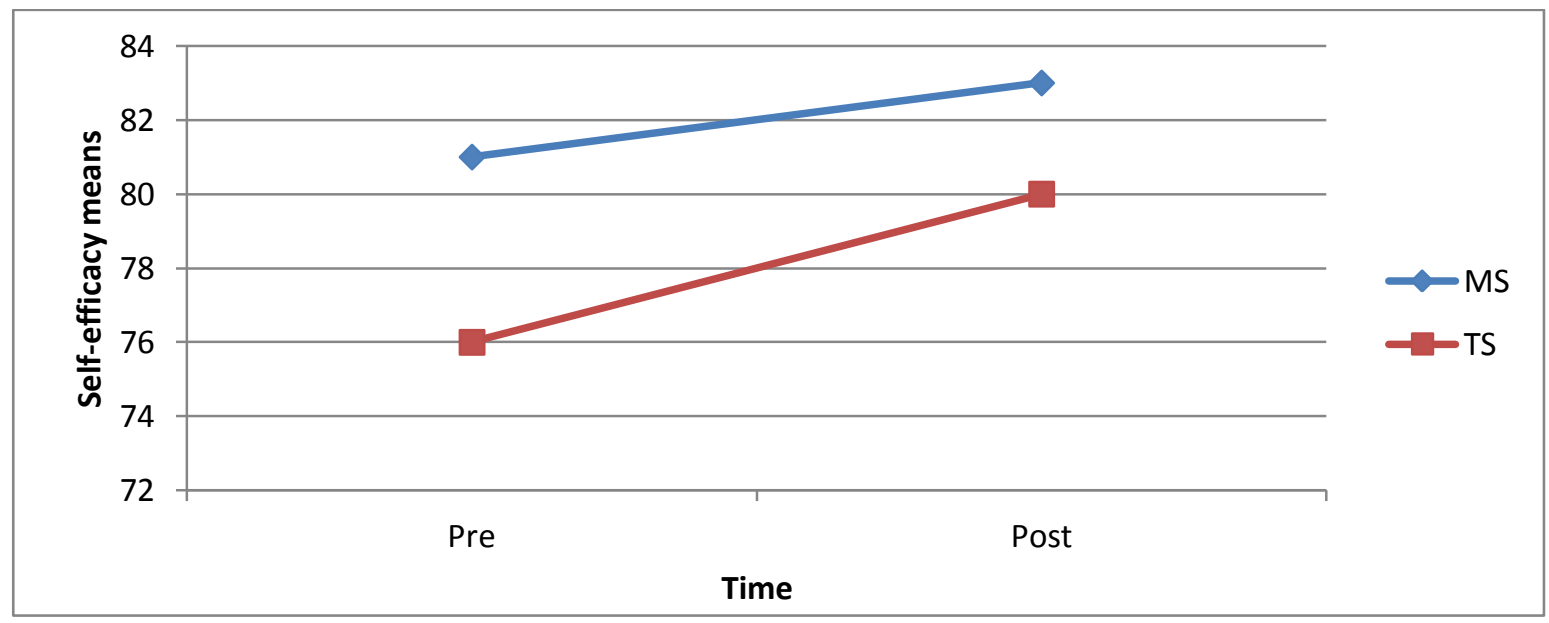

Figure 7. Self-efficacy - All students 
Motivation Interventions via Study Programmes for Under-achieving Students

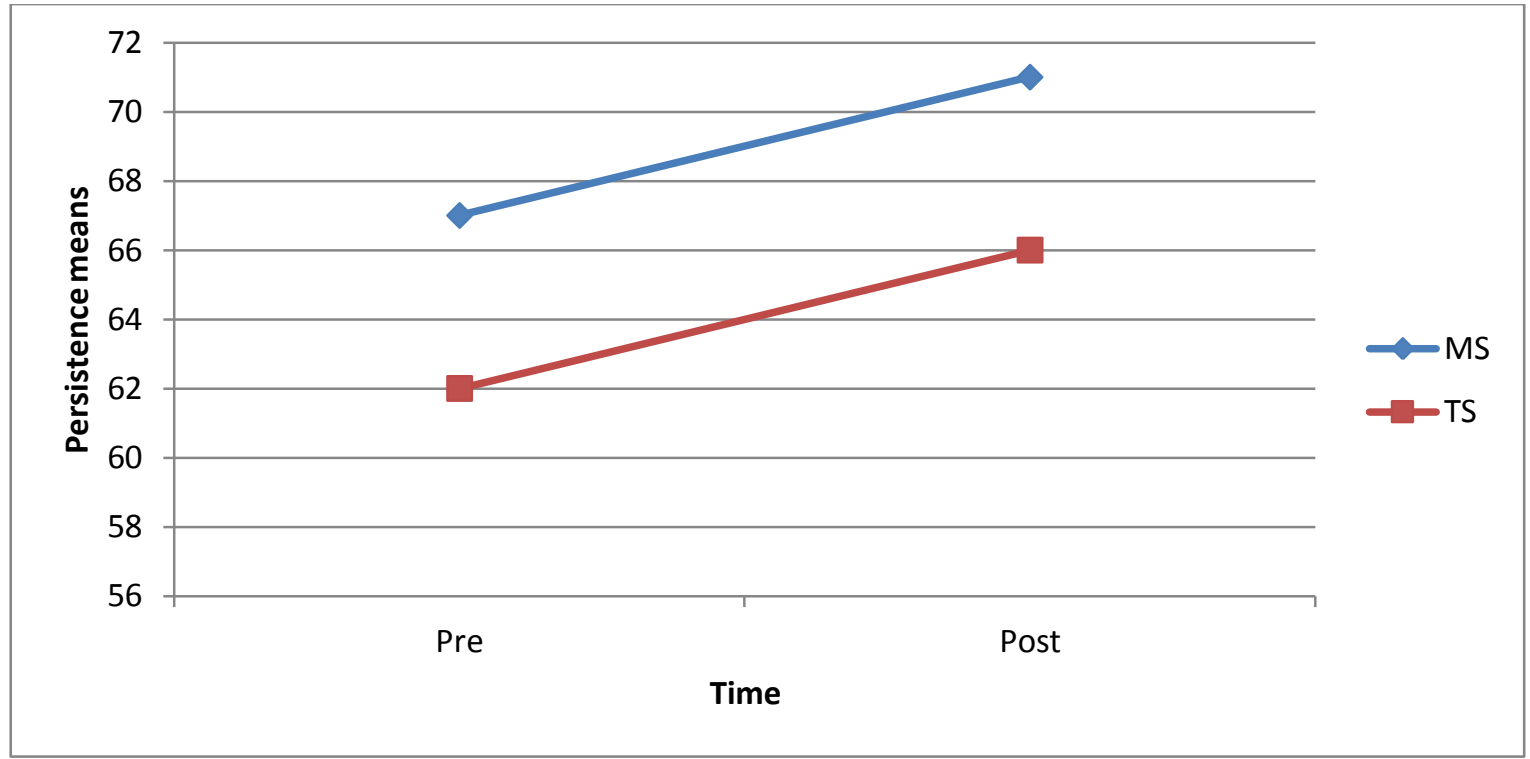

Figure 8. Persistence - All students

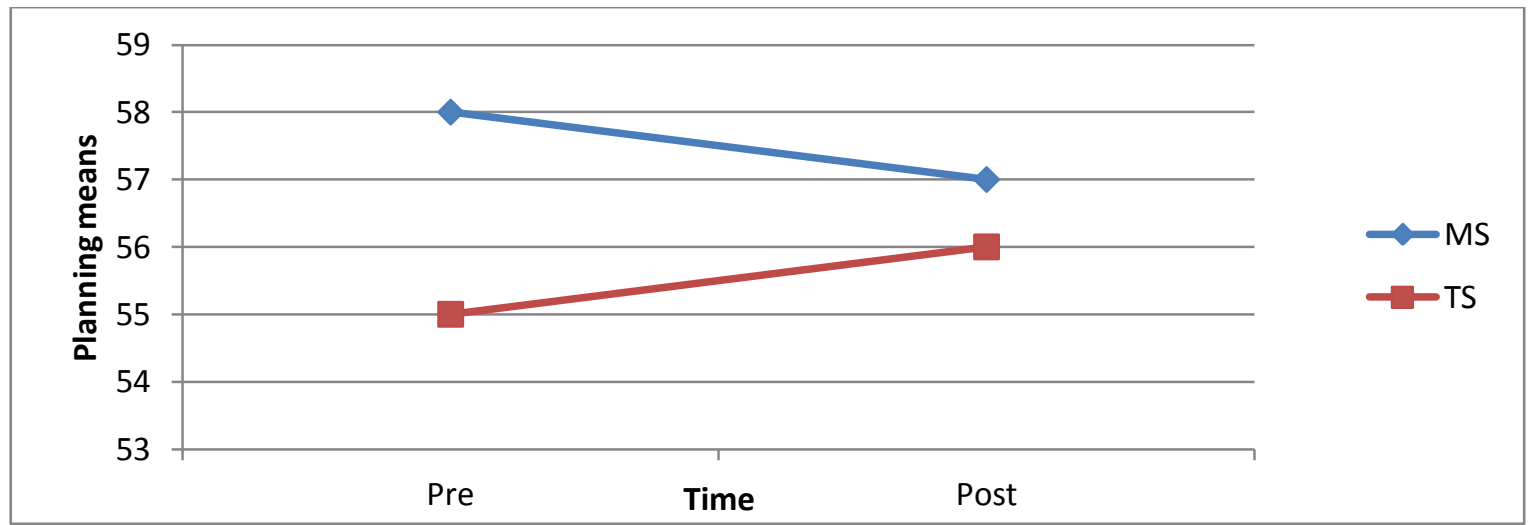

Figure 9. Planning - All students 
Motivation Interventions via Study Programmes for Under-achieving Students

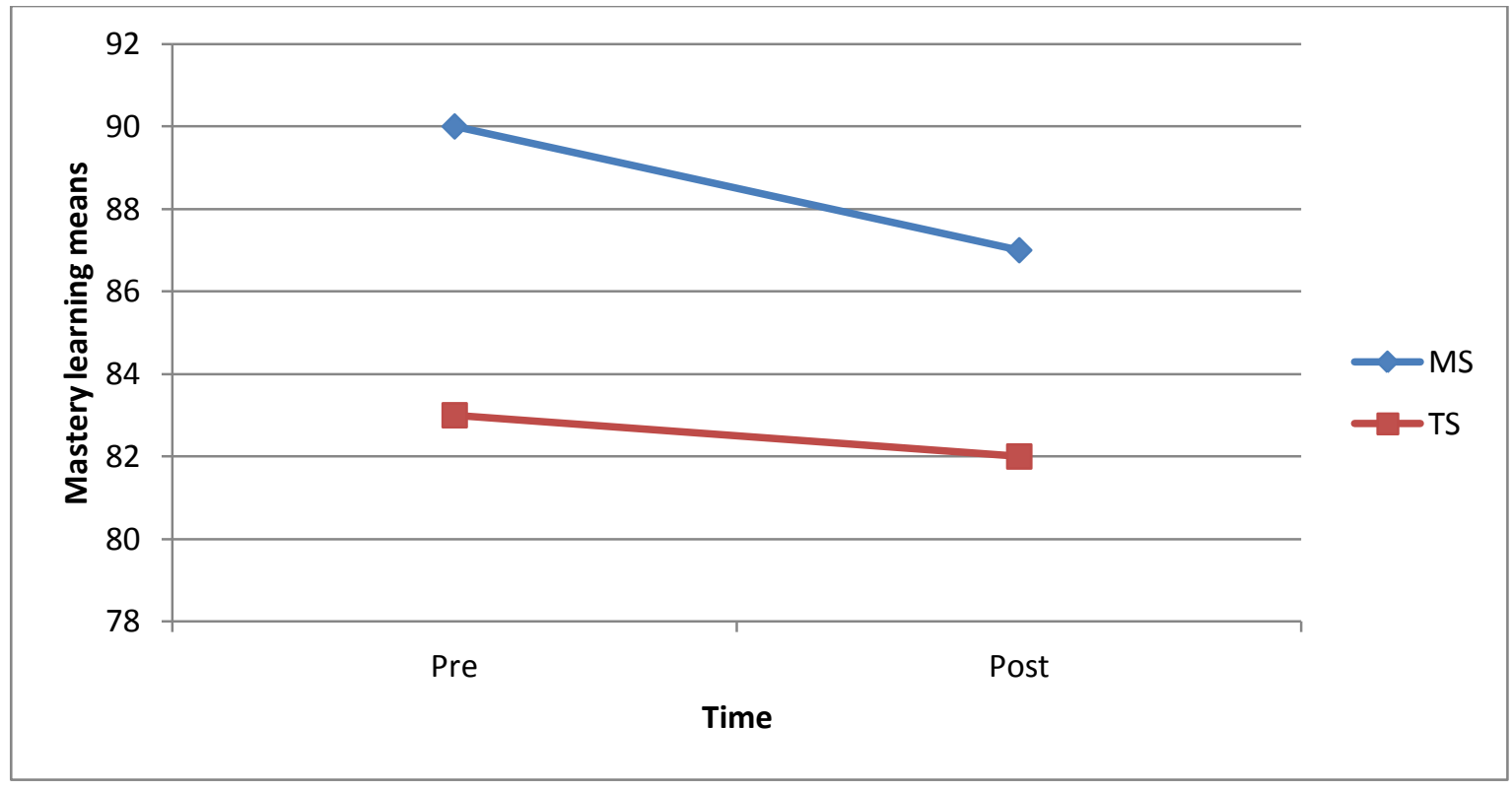

Figure 10. Mastery learning - All students

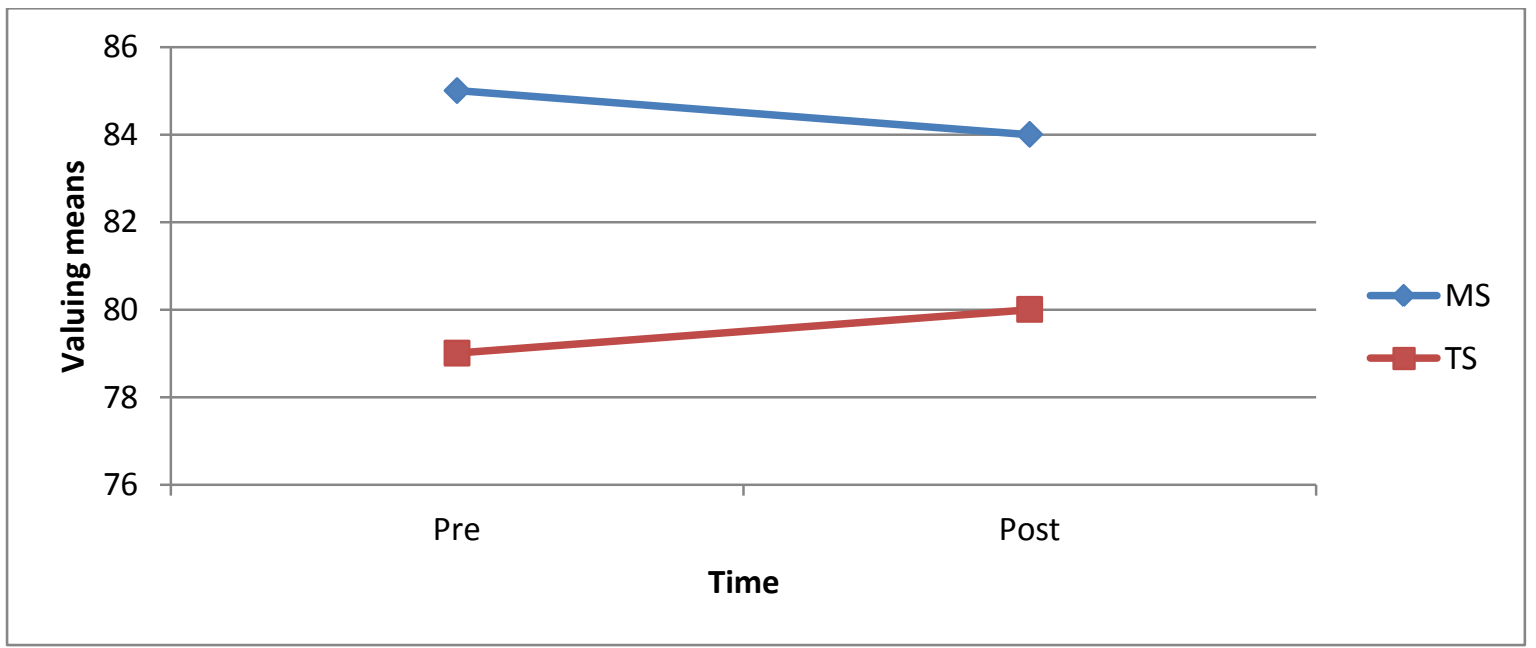

Figure 11. Valuing - All students 


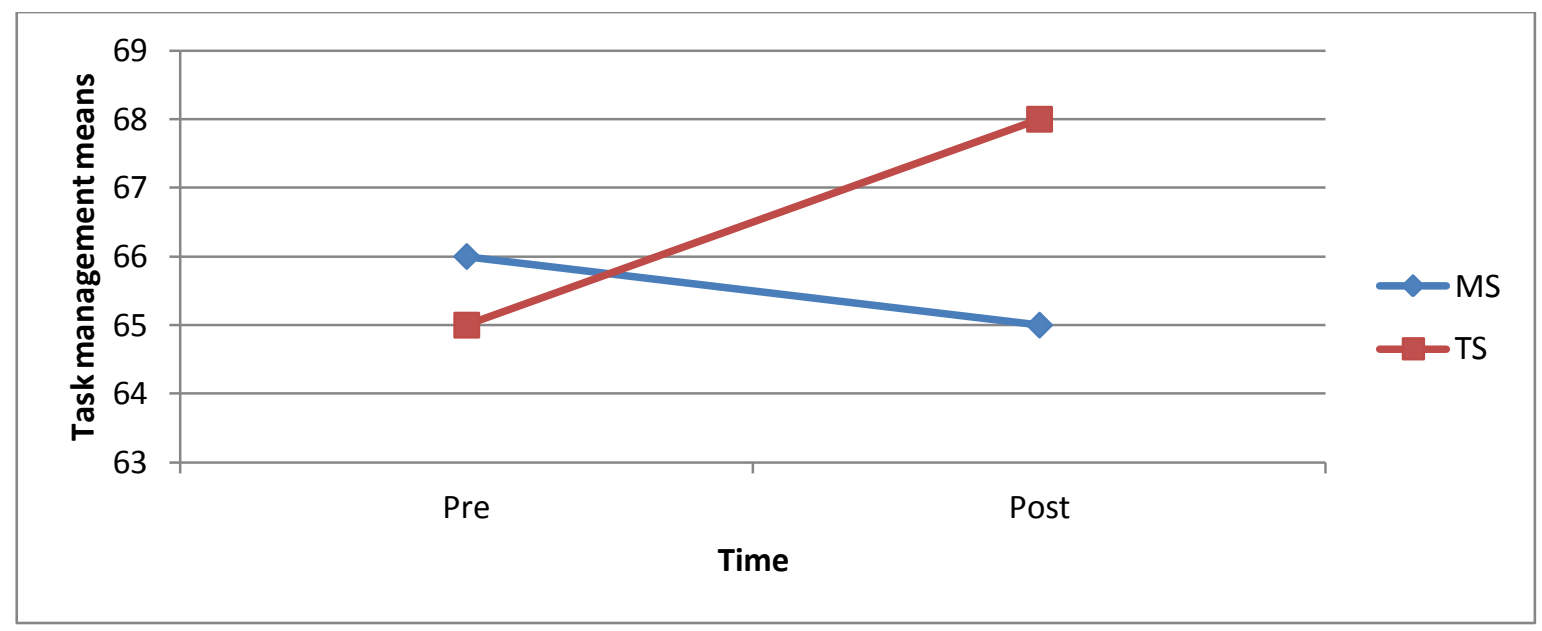

\section{Figure 12. Task management - All students}

Only two of the change scores were statistically significant, and none of the effect sizes reached even the level regarded as small using the criterion of $d>0.20$. Generally, changes from the pre-test to post-test survey ratings were small for each of the six intra-personal motivation orientations; this was true regardless of intervention programme. Interestingly, students in the TS programme increased their self-rating score on task management whereas those in the MS programme decreased slightly. Again, these are small differences statistically, and these data did not reach the level required for even a small effect size. Nevertheless, given the focus of the TS programme on study skills such as task management, this change is consistent with expectations. 


\section{Section Two: Changes in Adaptive Intra-personal Motivation Orientations for Pasifika Students in the MS and TS Programmes}

This section reports data on changes in adaptive intra-personal motivation orientations for the Pasifika students who participated in the MS and TS programmes.

Table 11 presents the means and standard deviations for both intervention groups.

\section{Table 11}

Adaptive Intra-personal Motivation Orientation Means for Pasifika Students Participating in the MS versus TS Programmes

\begin{tabular}{lccc}
\hline Variable & $\begin{array}{c}\text { Intervention } \\
\text { group }\end{array}$ & $\begin{array}{c}\text { Pre-test } \\
\text { mean (SD) }\end{array}$ & $\begin{array}{c}\text { Post-test } \\
\text { mean (SD) }\end{array}$ \\
\hline Self-efficacy & MS & $84(9)$ & $81(11)$ \\
Persistence & TS & $76(14)$ & $81(18)$ \\
Planning & MS & $71(12)$ & $72(11)$ \\
& TS & $59(16)$ & $66(15)$ \\
Mastery learning & MS & $62(13)$ & $59(16)$ \\
& TS & $51(21)$ & $54(14)$ \\
Valuing & MS & $88(9)$ & $88(11)$ \\
& TS & $88(14)$ & $86(15)$ \\
Task management & MS & $88(8)$ & $84(11)$ \\
& TS & $83(19)$ & $83(16)$ \\
& MS & $70(17)$ & $64(22)$ \\
\hline
\end{tabular}

Table 12 presents the results of the independent samples tests for differences in adaptive intra-personal motivation orientation change scores for Pasifika students only who participated in the two intervention programmes. 


\section{Table 12}

Independent Samples Tests and Effect Size Calculations on Change Scores for the Adaptive Intra-personal Motivation Factors for Pasifika Students in the MS versus TS Intervention Programmes

\begin{tabular}{|c|c|c|c|c|c|c|c|c|c|}
\hline Variable & $\mathbf{F}$ & Sig & $t$ (df) & $\begin{array}{c}\text { Sig } \\
\text { (2-tailed) }\end{array}$ & $\begin{array}{c}\text { Mean } \\
\text { Diff }\end{array}$ & $\begin{array}{l}\text { Std Error } \\
\text { Diff }\end{array}$ & $\begin{array}{l}95 \% \mathrm{Cl} \\
\text { Lower }\end{array}$ & $\begin{array}{l}95 \% \mathrm{Cl} \\
\text { Upper }\end{array}$ & $\begin{array}{c}\text { Cohen's } \\
\text { d }\end{array}$ \\
\hline Self-efficacy & 0.98 & 0.33 & $\begin{array}{c}-1.60 \\
(26)\end{array}$ & 0.12 & -7.76 & 5.09 & -18.22 & 2.90 & -0.61 \\
\hline Persistence & 7.05 & 0.01 & $\begin{array}{c}-1.72 \\
(26)\end{array}$ & 0.10 & -5.59 & 4.07 & -14.85 & 1.89 & -0.57 \\
\hline Planning & 1.12 & 0.30 & $\begin{array}{c}-1.15 \\
(26)\end{array}$ & 0.26 & -6.03 & 5.56 & -17.46 & 5.41 & -0.44 \\
\hline $\begin{array}{l}\text { Mastery } \\
\text { learning }\end{array}$ & 0.45 & 0.51 & $\begin{array}{l}0.49 \\
(26)\end{array}$ & 0.63 & 1.79 & 3.53 & -5.47 & 9.04 & +0.19 \\
\hline Valuing & 0.13 & 0.72 & $\begin{array}{c}-0.95 \\
(26)\end{array}$ & 0.35 & -4.60 & 5.01 & -14.90 & 5.69 & -0.50 \\
\hline $\begin{array}{l}\text { Task } \\
\text { management }\end{array}$ & 4.17 & 0.05 & $\begin{array}{l}2.50 \\
(26)\end{array}$ & 0.02 & -14.38 & 6.09 & -26.90 & -27.17 & -0.95 \\
\hline
\end{tabular}

These data show two statistically significant increases: Pasifika students in the TS programme made more gains on the adaptive intra-personal motivation factors of persistence and task management than their Pasifika peers in the MS programme. The effect size analyses revealed additional results favouring the TS skills programme over the MS programme, including moderate effect sizes for improvements in the ratings for self-efficacy, persistence, and valuing; a small to moderate effect size for planning; and a large effect size for task management. Figures 13-18 illustrate the changes for the two intervention programme groups considering the Pasifika students only. The figures make clear that these variables either stayed the same or decreased for the MS programme Pasifika students. In contrast, self-ratings by the Pasifika students in the TS programme either stayed the same or increased slightly on these variables. 
Motivation Interventions via Study Programmes for Under-achieving Students

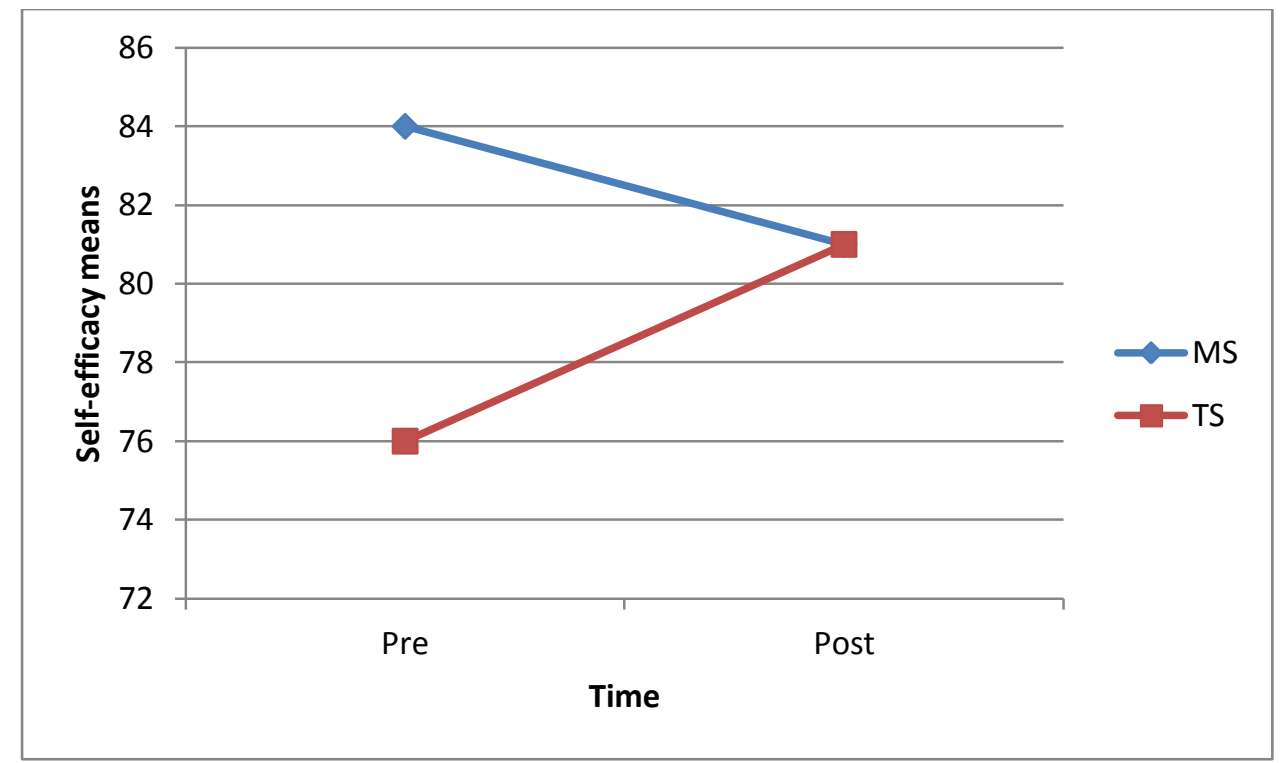

Figure 13. Self-efficacy — Pasifika students

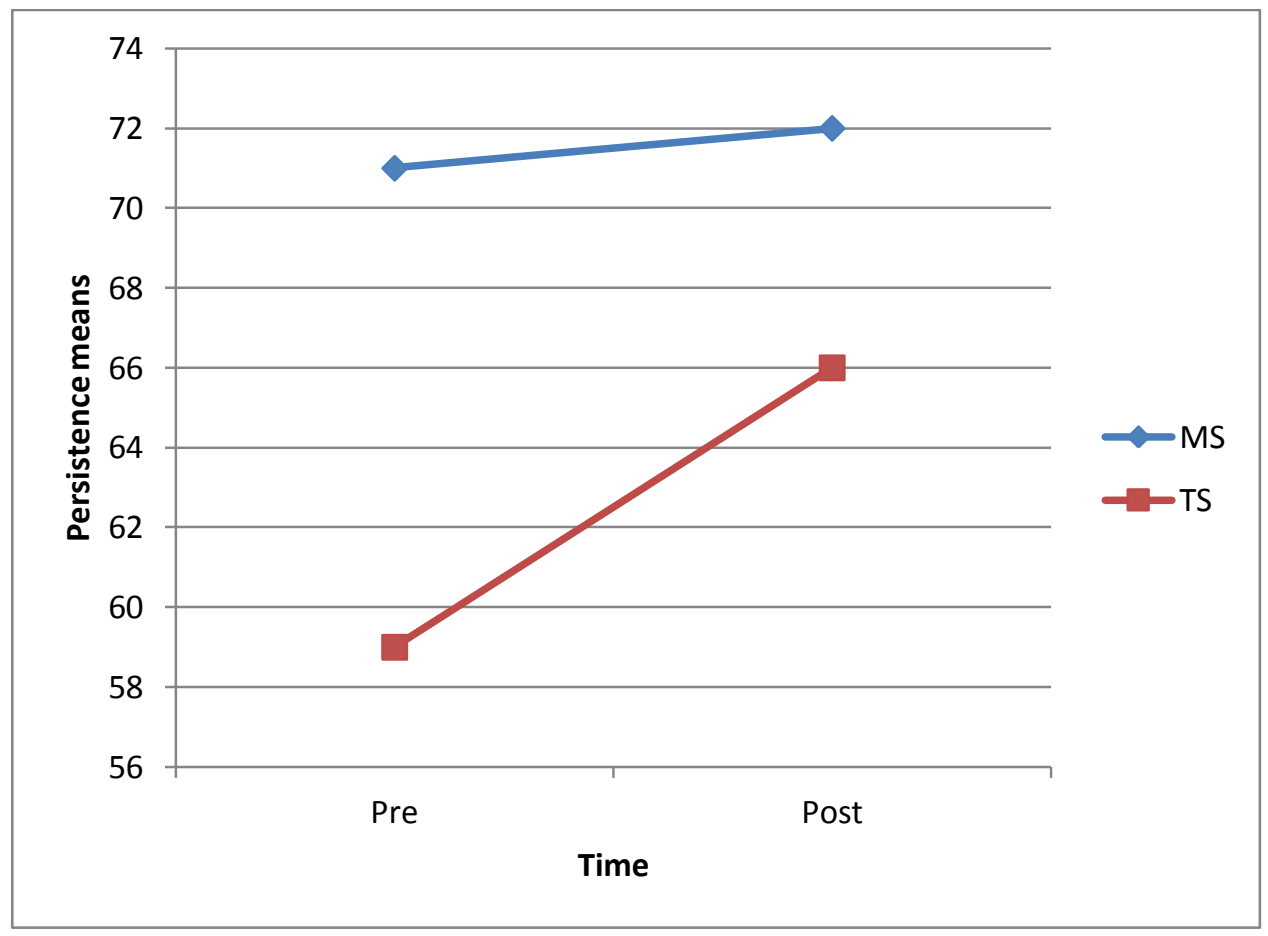

Figure 14. Persistence - Pasifika students 


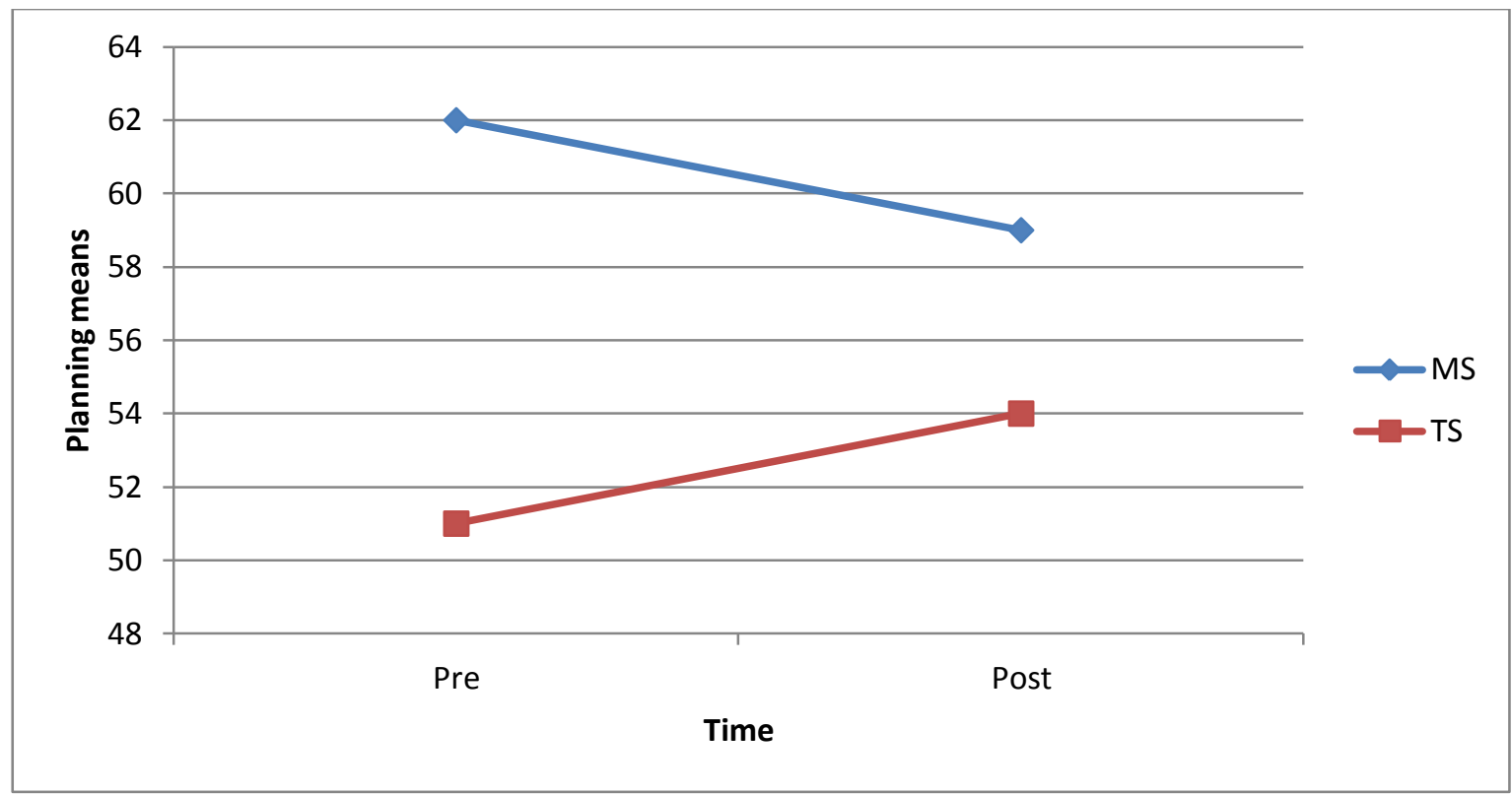

Figure 15. Planning — Pasifika students

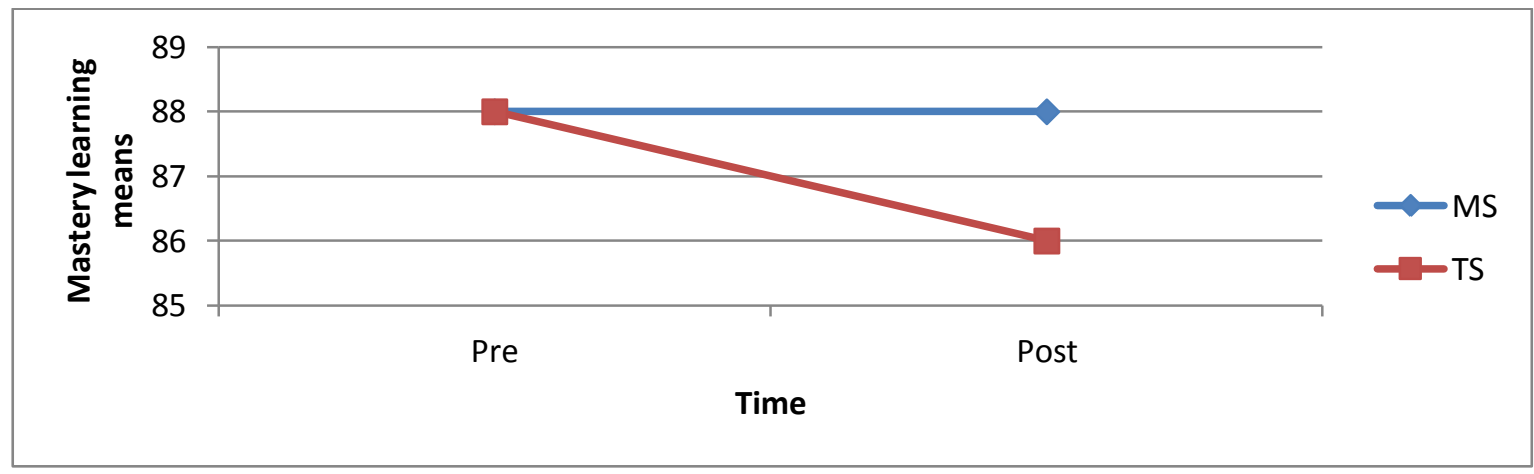

Figure 16. Mastery learning - Pasifika students

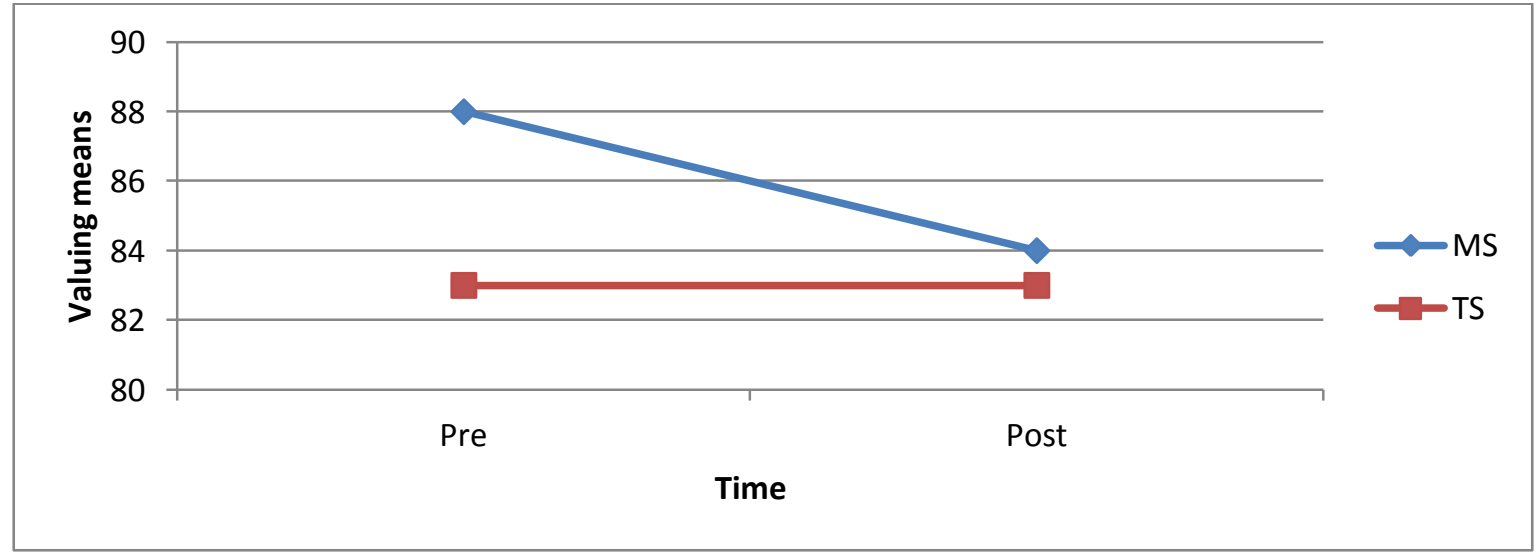

Figure 17. Valuing - Pasifika students 


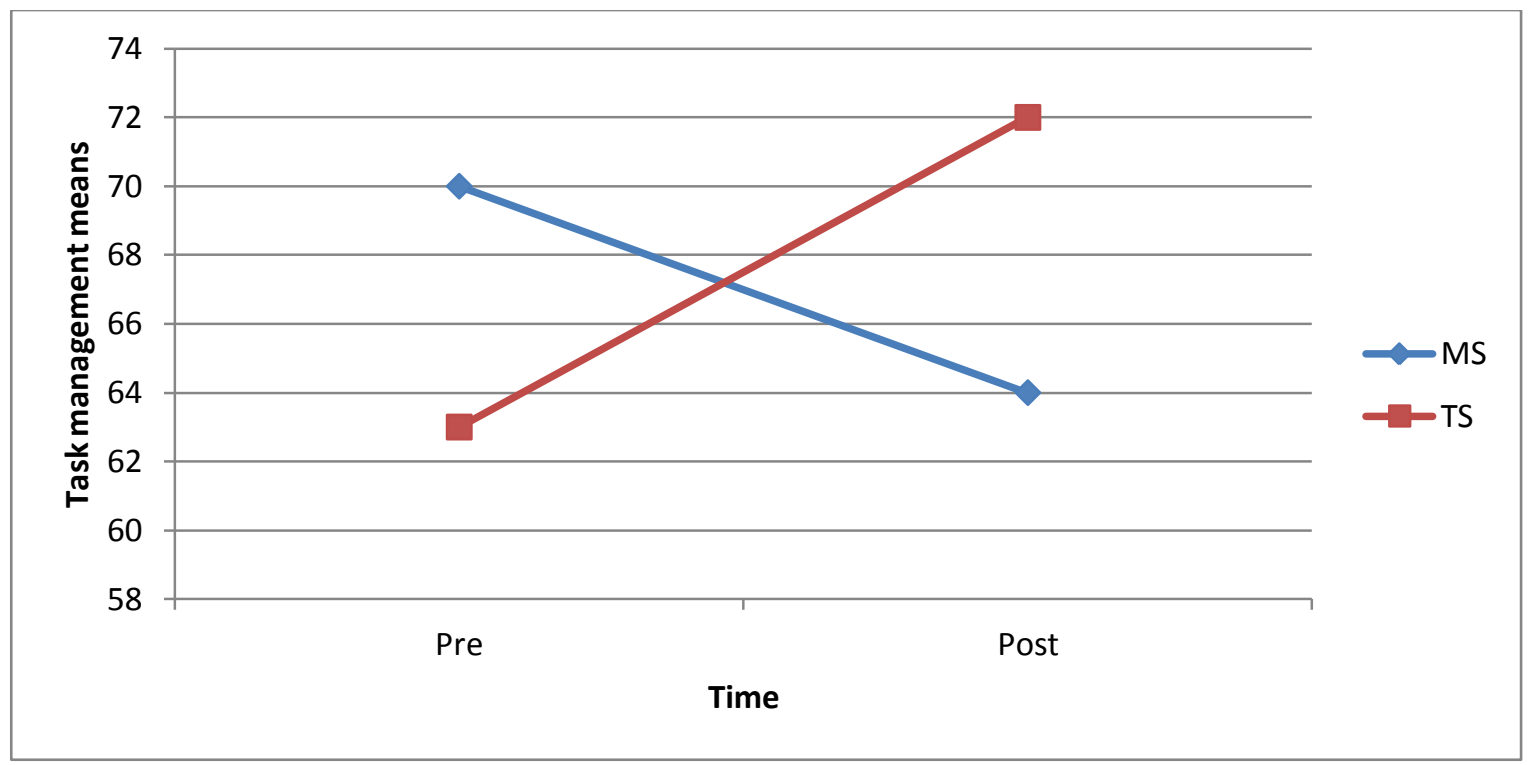

Figure 18. Task Management — Pasifika students

In summary, these results largely favour the TS skills programme over the MS programme for Pasifika student participants, even more so than for all students. Given the focus on study skills in the TS programme, these results are perhaps consistent with expectations. Indeed, it may be that these factors actually reflect selfassessments regarding study skills. This will be discussed further in the final discussion chapter.

\section{Analysis Three: Changes in Maladaptive Intra-personal Motivation}

Four maladaptive intra-personal motivation factors were measured including anxiety, failure avoidance, uncertain control, and self-sabotage. Responses from students in the MS programme were compared with those from students in the TS programme (see Appendix $\mathrm{C}$ for a copy of the measure and items). Since these are maladaptive 
factors viewed as interfering with achievement, a positive result would be a decrease for each of the four intra-personal motivation factors.

\section{Section One: Changes in Maladaptive Intra-personal Motivation Factors for All Students in the MS and TS Programmes}

Table 13 presents the means and standard deviations for students in the two comparison programmes and shows changes in maladaptive intra-personal motivation orientations before and after each intervention.

\section{Table 13}

Changes in Maladaptive Intra-personal Motivation Orientations for All Students in the MS and TS Intervention Programmes

\begin{tabular}{lcccc}
\hline Variable & Group & $\mathbf{N}$ & $\begin{array}{c}\text { Pre-test } \\
\text { mean (SD) }\end{array}$ & $\begin{array}{c}\text { Post-test } \\
\text { mean (SD) }\end{array}$ \\
\hline Anxiety & MS & 30 & $75(10)$ & $71(17)$ \\
Failure & TS & 26 & $76(14)$ & $69(22)$ \\
avoidance & MS & 30 & $58(22)$ & $52(24)$ \\
Uncertain & TS & 27 & $55(18)$ & $51(19)$ \\
control & MS & 30 & $60(16)$ & $53(20)$ \\
Self-sabotage & TS & 27 & $57(20)$ & $54(18)$ \\
& MS & 30 & $50(21)$ & $44(24)$ \\
& TS & 27 & $44(24)$ & $48(24)$ \\
\hline
\end{tabular}

Table 14 presents the results of the independent samples tests for differences in maladaptive intra-personal motivation change scores for students in the MS versus TS programmes. 


\section{Table 14}

Independent Samples Tests and Effect Size Calculations on Change Scores for the Maladaptive Intra-personal Motivation Factors for All Students Participating in the MS versus TS Intervention Programmes

\begin{tabular}{|c|c|c|c|c|c|c|c|c|c|}
\hline \multirow[t]{2}{*}{ Variable } & \multirow[t]{2}{*}{$\mathbf{F}$} & \multirow[t]{2}{*}{ Sig } & \multirow{2}{*}{$\begin{array}{c}t \\
\text { (df) }\end{array}$} & \multirow{2}{*}{$\begin{array}{c}\text { Sig } \\
(2- \\
\text { tailed) }\end{array}$} & \multirow{2}{*}{$\begin{array}{c}\text { Mean } \\
\text { Diff }\end{array}$} & \multirow{2}{*}{$\begin{array}{c}\text { Std } \\
\text { Error } \\
\text { Diff }\end{array}$} & \multicolumn{2}{|c|}{$95 \% \mathrm{Cl}$} & \multirow{2}{*}{$\begin{array}{l}\text { Cohen's } \\
\text { d }\end{array}$} \\
\hline & & & & & & & $\mathbf{L L}$ & UL & \\
\hline Anxiety & 1.43 & 0.24 & $\begin{array}{l}0.73 \\
(54)\end{array}$ & 0.47 & 3.29 & 4.60 & -5.94 & 12.52 & 0.20 \\
\hline Failure avoidance & 0.37 & 0.54 & $\begin{array}{c}-0.52 \\
(55)\end{array}$ & 0.60 & -2.22 & 4.19 & -10.61 & 6.17 & -0.14 \\
\hline Uncertain control & 0.20 & 0.66 & $\begin{array}{c}-0.80 \\
(55)\end{array}$ & 0.43 & -3.64 & 4.57 & -12.80 & 5.51 & -0.21 \\
\hline Self-sabotage & 0.17 & 0.68 & $\begin{array}{c}-1.60 \\
(55)\end{array}$ & 0.12 & -9.44 & 5.97 & -21.40 & 2.52 & -0.42 \\
\hline
\end{tabular}

Across both intervention programmes, there was a decrease in self-scores for these maladaptive motivation variables. Notable was the increase on the self-sabotage score for the TS group whereas the MS group decreased their self-ratings on this negative factor. However, none of the change score differences were statistically significant. There were small effect sizes for three of the maladaptive variables (see also figures 19-22), with the effect size for self-sabotage approaching the medium range at $d=$ 0.42 . 
Motivation Interventions via Study Programmes for Under-achieving Students

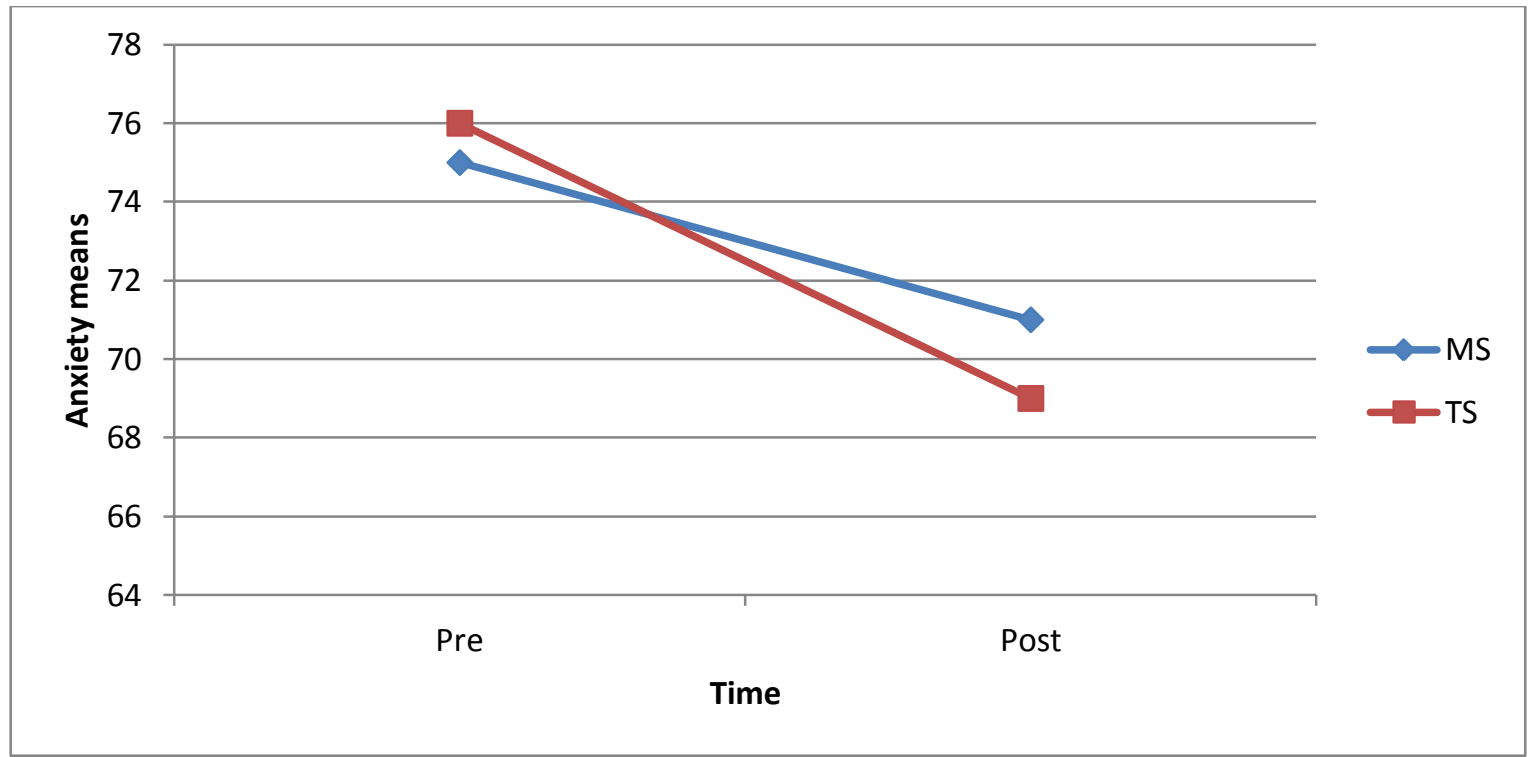

Figure 19. Anxiety - All students

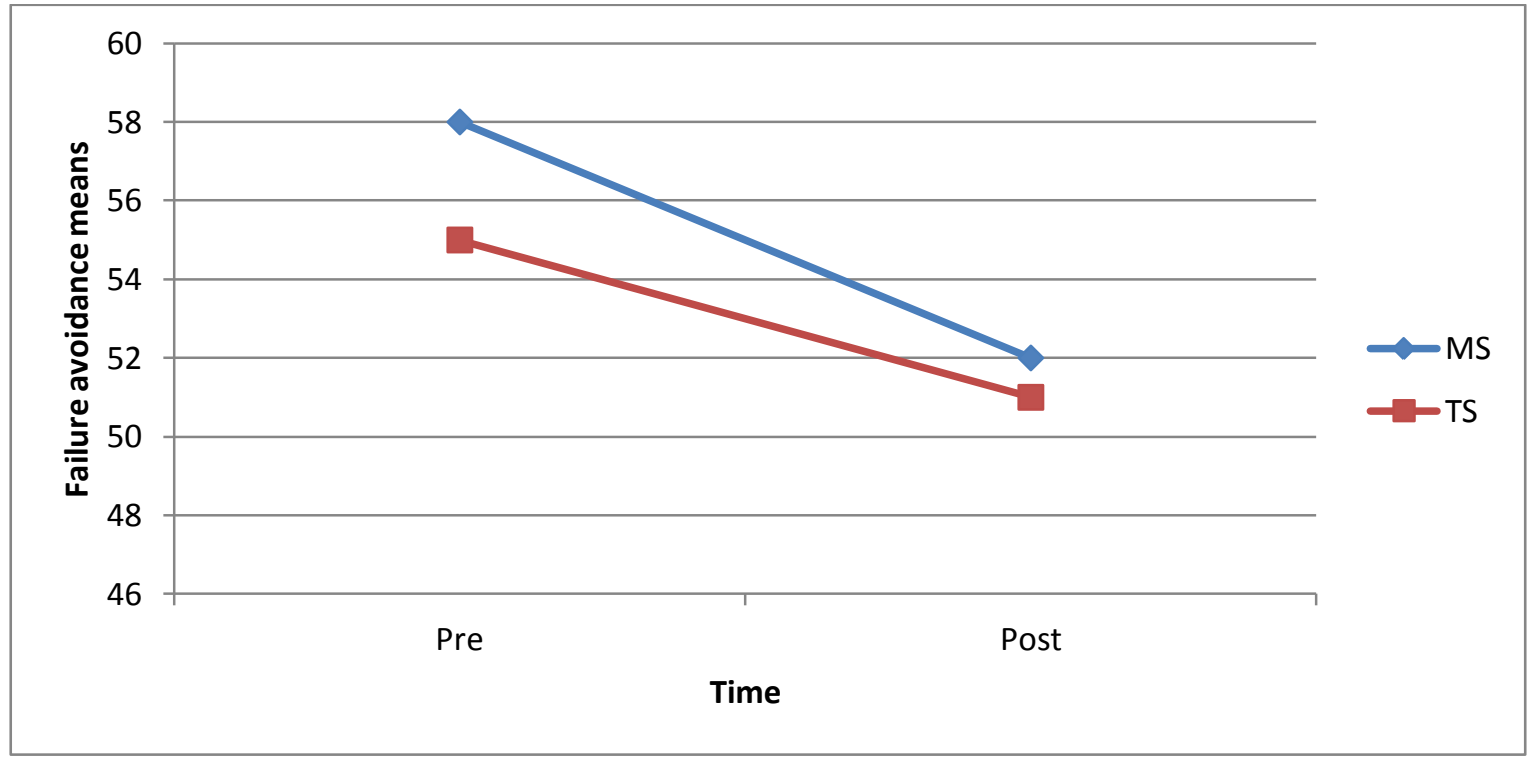

Figure 20. Failure avoidance - All students 
Motivation Interventions via Study Programmes for Under-achieving Students

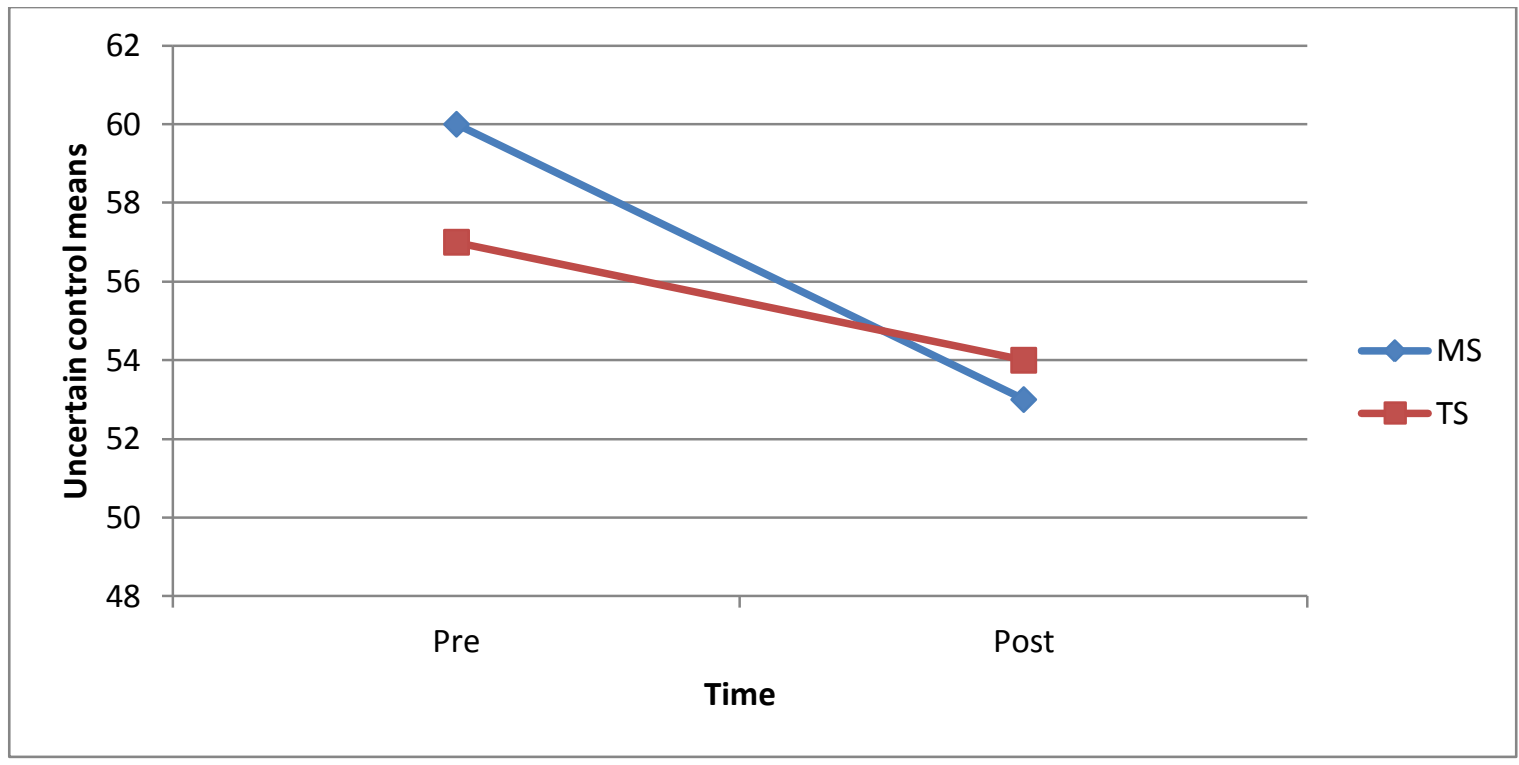

Figure 21. Uncertain control - All students

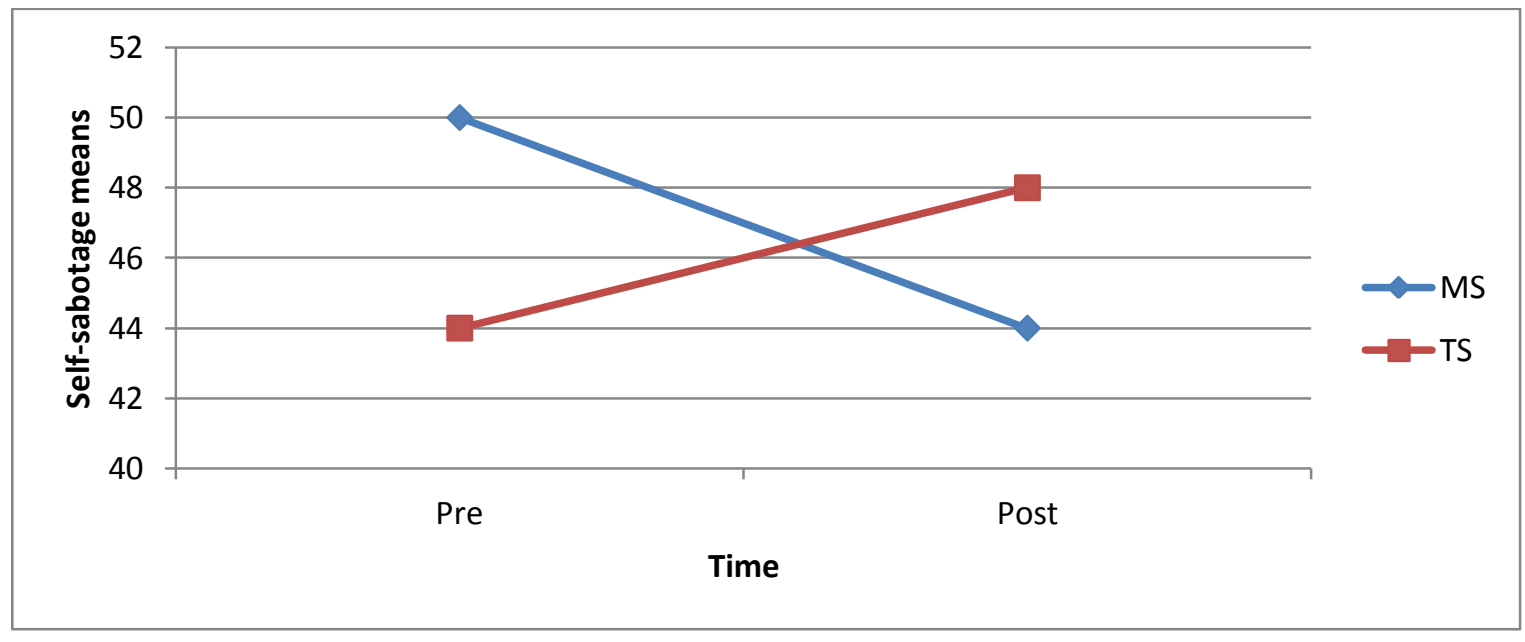

Figure 22. Self-sabotage - All students 
Overall, these data indicate that the MS programme was associated with greater decreases in maladaptive intra-personal motivation factors in comparison with results for the TS programme.

\section{Section Two: Changes in Maladaptive Intra-personal Motivation Orientations for Pasifika Students in the MS and TS Programmes}

Table 15 presents the means and standard deviations on the measure of maladaptive intra-personal motivation factors before and after intervention for the Pasifika students.

\section{Table 15}

Maladaptive Intra-personal Motivation Orientation Means for Pasifika Students Participating in the MS versus TS Programmes

\begin{tabular}{lcccc}
\hline Variable & Group & $\mathbf{N}$ & Pre-test mean (SD) & Post-test mean (SD) \\
\hline Anxiety & MS & 16 & $74(10)$ & $69(13)$ \\
& TS & 12 & $74(15)$ & $74(19)$ \\
Failure & MS & 16 & $61(21)$ & $49(22)$ \\
avoidance & TS & 12 & $55(16)$ & $52(14)$ \\
Uncertain & MS & 16 & $60(15)$ & $55(20)$ \\
control & TS & 12 & $53(18)$ & $57(16)$ \\
Self-sabotage & MS & 16 & $52(23)$ & $48(28)$ \\
& TS & 12 & $41(22)$ & $50(23)$ \\
\hline
\end{tabular}

Table 16 presents the results of the independent samples tests for differences in maladaptive intra-personal motivation orientation change scores for Pasifika students only who participated in the two intervention programmes. 


\section{Table 16}

Independent Samples Tests and Effect Size Calculations on Change Scores for the Maladaptive Intra-personal Motivation Factors for Pasifika Students Participating in the MS versus TS Intervention Programmes

\begin{tabular}{lccccccccc}
\hline Variable & F & Sig & $\mathbf{t}(\mathbf{d f})$ & $\begin{array}{c}\text { Sig (2- } \\
\text { tailed) }\end{array}$ & $\begin{array}{c}\text { Mean } \\
\text { Diff }\end{array}$ & $\begin{array}{c}\text { Std } \\
\text { Error } \\
\text { Diff }\end{array}$ & LL & UL & $\begin{array}{c}\text { Cohen's } \\
\mathbf{d}\end{array}$ \\
\hline Anxiety & 0.05 & 0.83 & $\begin{array}{c}-0.69 \\
(25)\end{array}$ & 0.50 & -3.52 & 5.32 & -14.47 & 7.42 & -0.19 \\
$\begin{array}{l}\text { Failure } \\
\text { avoidance }\end{array}$ & 0.00 & 0.98 & $\begin{array}{c}-1.17 \\
(26)\end{array}$ & 0.25 & -8.19 & 6.65 & -21.87 & 5.49 & $-\mathbf{0 . 2 1}$ \\
$\begin{array}{l}\text { Uncertain } \\
\text { control }\end{array}$ & 3.67 & 0.07 & $\begin{array}{c}-2.33 \\
(26)\end{array}$ & 0.03 & -9.61 & 3.83 & -17.49 & -1.73 & $-\mathbf{0 . 7 8}$ \\
$\begin{array}{l}\text { Self-sabotage } \\
0.18\end{array}$ & 0.67 & $\begin{array}{c}-1.32 \\
(26)\end{array}$ & 0.20 & -12.81 & 9.91 & -33.18 & 7.55 & $-\mathbf{0 . 5 1}$ \\
\hline
\end{tabular}

These data show that Pasifika students in the MS programme decreased on all four maladaptive intra-personal motivation factors compared with Pasifika students in the TS programme. These differences in change scores were not statistically significant, although this small sample size affects the power of this analysis. The effect size analyses revealed that the comparisons of effects on anxiety and failure avoidance, both at approximately 0.20 , reached the level required for small effects. There was a medium effect size favouring the MS group on the self-sabotage factor $(d=-0.51)$ and an effect size that could be considered large $(d=-0.78$, just under 0.80$)$ on the factor of uncertain control. Figures 23-26 illustrate these pre-test and post-test self-ratings for Pasifika students. 


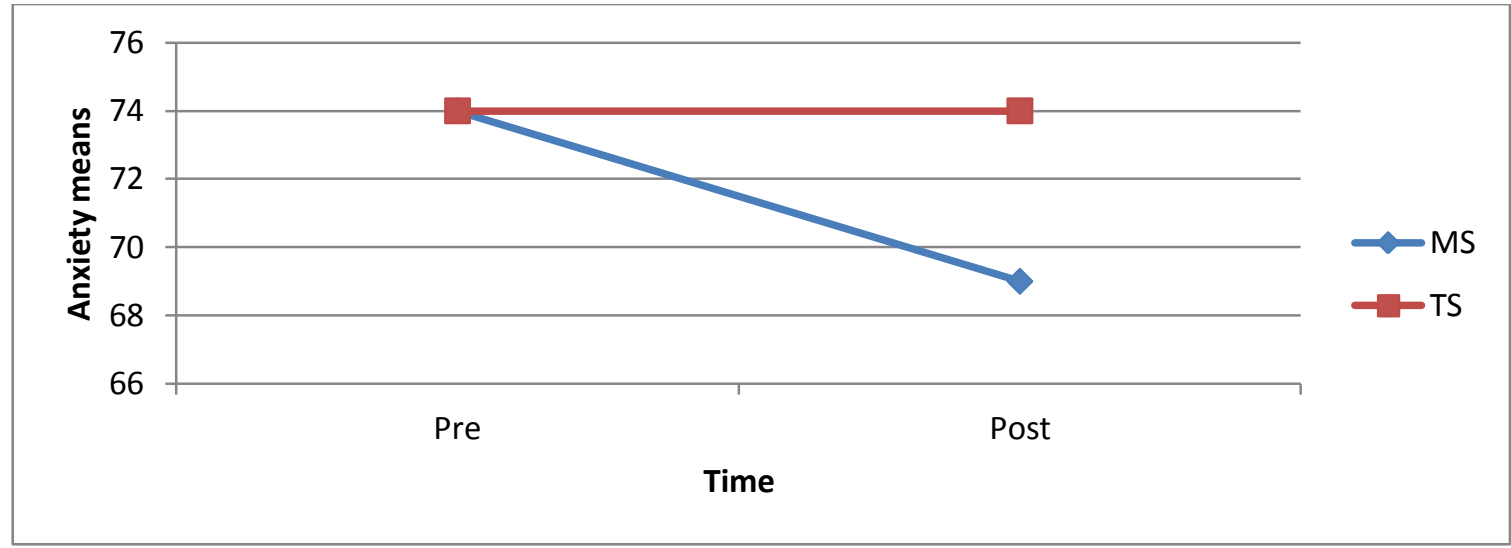

Figure 23. Anxiety — Pasifika students

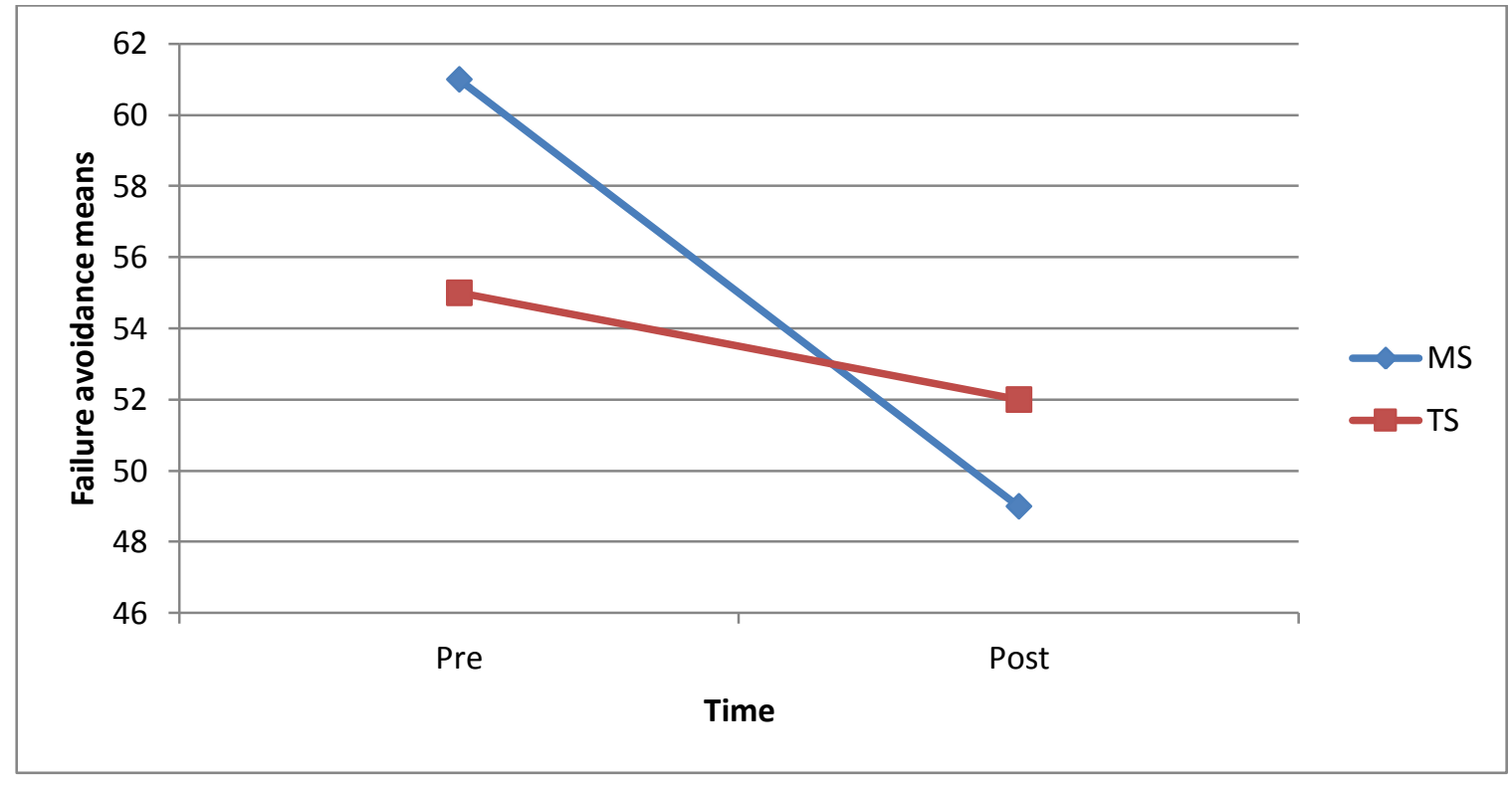

Figure 24. Failure-avoidance — Pasifika students 


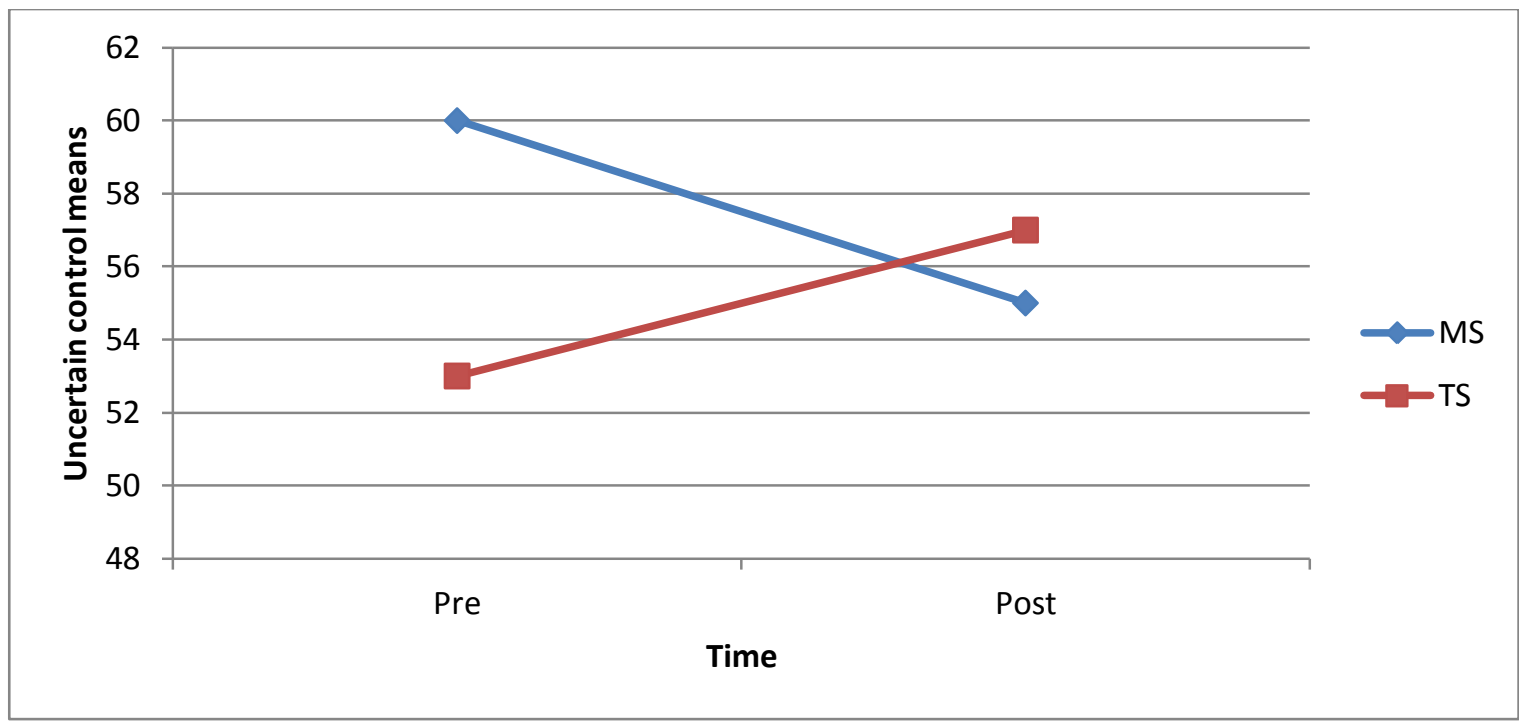

Figure 25. Uncertain control - Pasifika students

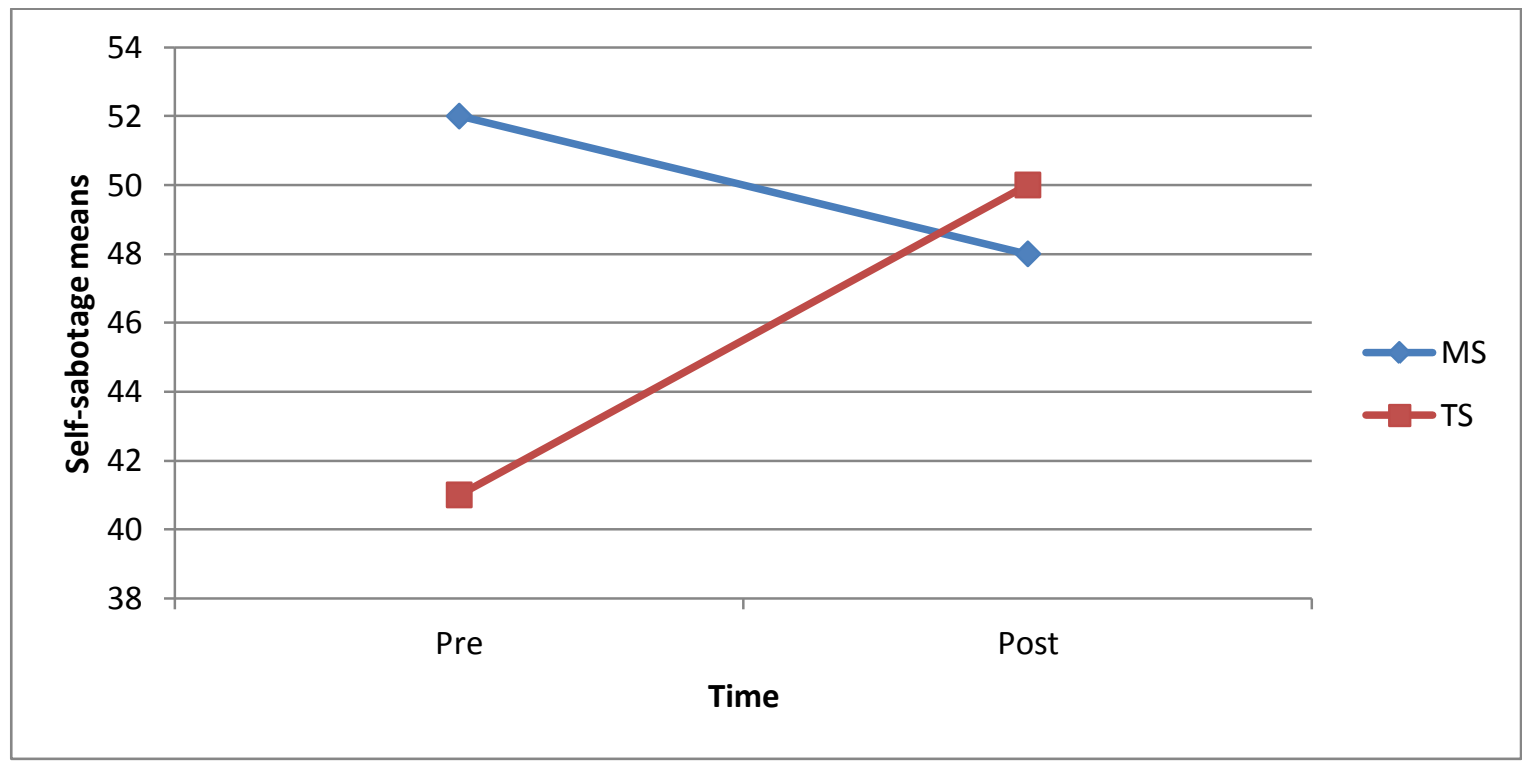

Figure 26. Self-sabotage - Pasifika students

These data show decreases in maladaptive intra-personal motivation orientations associated with the MS programme for Pasifika students that were greater than those occurring for their Pasifika peers in the TS programme. These results are in the same direction as those evident for all students, but the results for Pasifika students in reducing maladaptive motivation factors are more pronounced with larger effect sizes. 


\section{Analysis Four: \\ Changes in the Motivation Orientations Doing My Best and Doing Just Enough}

Data about changes on two intra-personal motivation orientations, Doing My Best (DMB) and Doing Just Enough (DJE), were measured in this study using the Screening Tool (Meyer et al., 2010; see Appendix D for a copy of the measure). These data are reported separately from the other adaptive and maladaptive intra-personal motivation orientations such as self-belief and failure-avoidance partly because they were measured by a different instrument: the Motivation and Engagement Scale High School (MES-HS, Martin, 2008).

Section One: Changes in Doing My Best and Doing Just Enough Motivation Orientations for Students in the MS and TS Programmes

Table 17 presents the means and standard deviations for the variables DMB and DJE for all students in the two groups before and after the two programmes.

\section{Table 17}

Motivation Orientation Means for DMB and DJE for All Students Participating in the MS and TS Programmes

\begin{tabular}{lcccc}
\hline Variable & Group & N & $\begin{array}{c}\text { Pre-test } \\
\text { mean (SD) }\end{array}$ & $\begin{array}{c}\text { Post-test } \\
\text { mean (SD) }\end{array}$ \\
\hline Doing My Best & MS & 30 & $67(18)$ & $69(17)$ \\
& TS & 27 & $69(19)$ & $67(18)$ \\
Doing Just Enough & MS & 30 & $63(21)$ & $57(20)$ \\
& TS & 27 & $58(19)$ & $59(20)$ \\
\hline
\end{tabular}




\section{Table 18}

Independent Samples Tests and Effect Size Calculations on Change Scores for the Motivation Factors DMB and DJE for All Students in the MS versus TS Intervention Programmes

\begin{tabular}{lccccccccc}
\hline Variable & F & Sig & $\mathbf{t}$ (df) & $\begin{array}{c}\text { Sig } \\
\text { (2- } \\
\text { tailed) }\end{array}$ & $\begin{array}{c}\text { Mean } \\
\text { Diff }\end{array}$ & $\begin{array}{c}\text { Std } \\
\text { Error } \\
\text { Diff }\end{array}$ & LL & UL & \\
\hline $\begin{array}{l}\text { Doing My } \\
\text { Best }\end{array}$ & 0.22 & 0.64 & $\begin{array}{c}0.78 \\
(55)\end{array}$ & 0.44 & 2.87 & 3.70 & -4.55 & 10.28 & 0.21 \\
$\begin{array}{l}\text { Doing Just } \\
\text { Enough }\end{array}$ & 2.28 & 0.14 & $\begin{array}{c}-1.80 \\
(55)\end{array}$ & 0.08 & -5.84 & 3.30 & -12.45 & 0.77 & -0.48 \\
\hline
\end{tabular}

The differences in change scores from pre-test to post-test for the two groups were not statistically significant. However, the small and medium effect sizes for the increased positive motivation orientation $\mathrm{DMB}$ and decreased negative motivation orientation DJE, respectively, favoured the MS group. Figures 27 and 28 illustrate these changes for all students across the two intervention programmes.

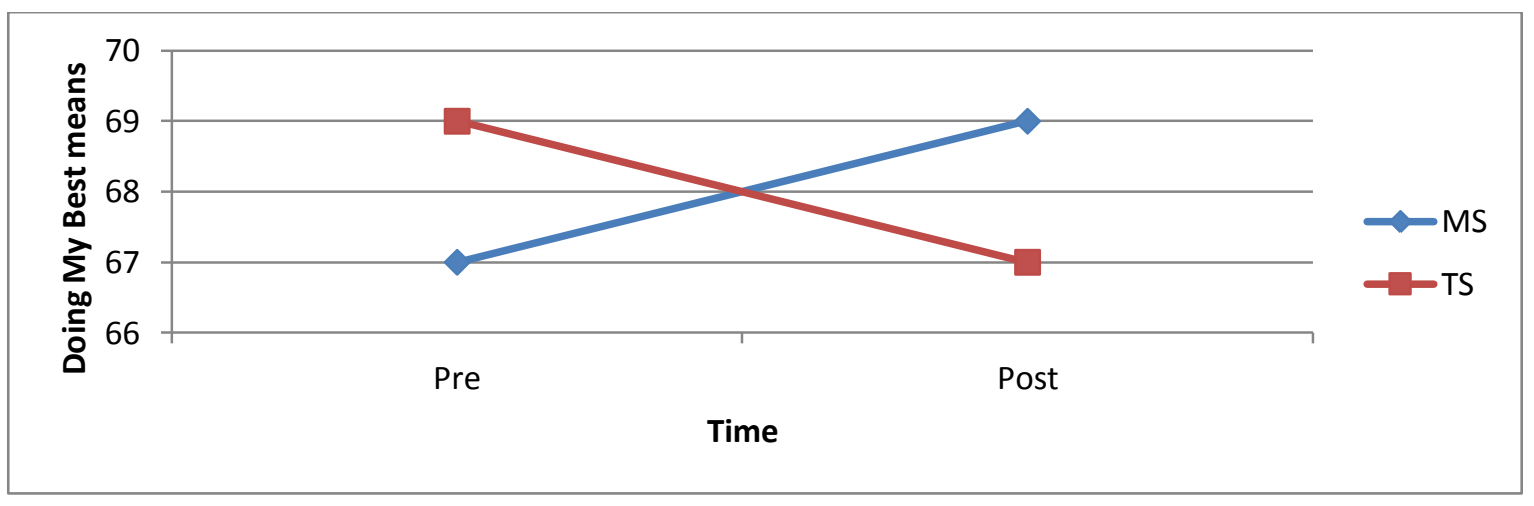

Figure 27. Doing My Best - All students 


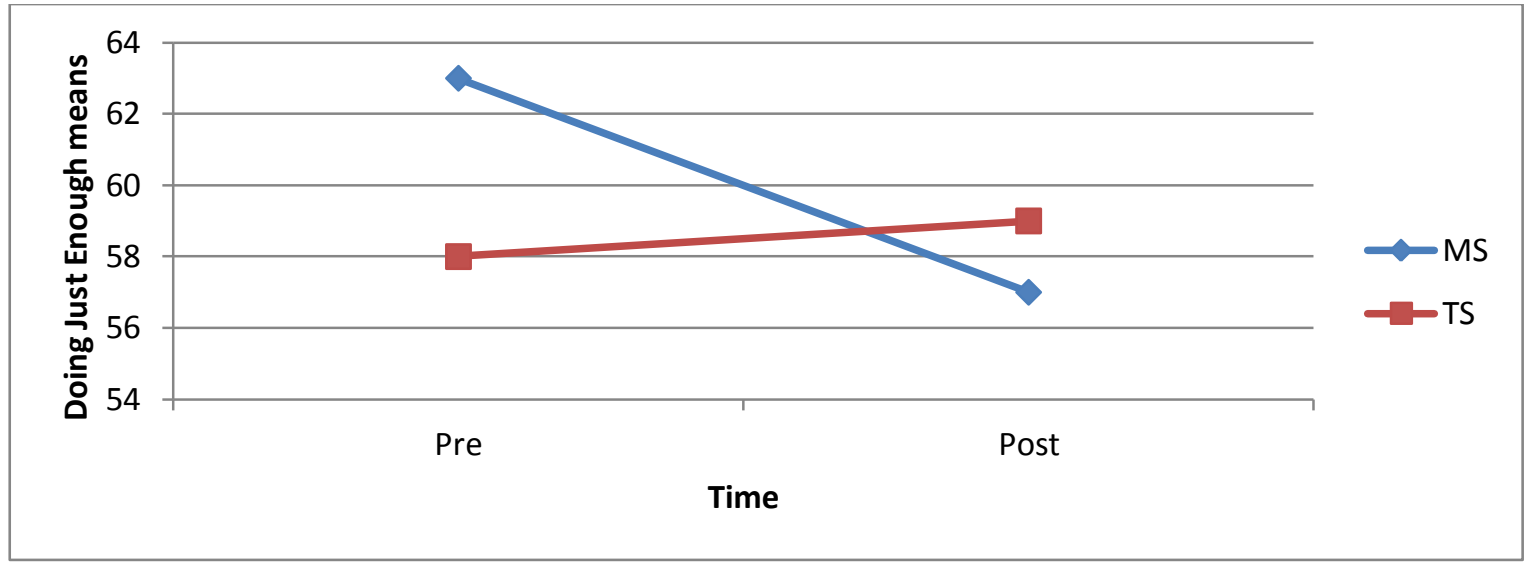

Figure 28. Doing Just Enough — All students

\section{Section Two: Changes in Doing My Best and Doing Just Enough Motivation Orientations for Pasifika Students in the MS and TS Programmes}

The data in tables 19 and 20 below show that there was no difference on the DMB motivation orientation for Pasifika students associated with participation in the MS programme compared with their Pasifika peers participating in the TS programme. On the other hand, there was a medium effect size for larger decreases in DJE self-ratings by Pasifika students in the MS programme compared with those by their peers in the TS programme (see also figures 29 and 30).

\section{Table 19}

Motivation Orientation Means for DMB and DJE for Pasifika Students Participating in the MS and TS Programmes

\begin{tabular}{lcccc}
\hline Variable & Group & $\mathbf{N}$ & $\begin{array}{c}\text { Pre-test } \\
\text { mean (SD) }\end{array}$ & $\begin{array}{c}\text { Post-test } \\
\text { mean (SD) }\end{array}$ \\
\hline Doing My Best & MS & 16 & $71(15)$ & $71(16)$ \\
& TS & 12 & $72(21)$ & $73(22)$ \\
Doing Just Enough & MS & 16 & $63(23)$ & $59(20)$ \\
& TS & 12 & $54(19)$ & $56(20)$ \\
\hline
\end{tabular}




\section{Table 20}

Independent Samples Tests and Effect Size Calculations on Change Scores for the Motivation Factors DMB and DJE for Pasifika Students in the MS versus TS Intervention Programmes

\begin{tabular}{lccccccccc}
\hline Variable & F & Sig & $\mathbf{t}(\mathbf{d f})$ & $\begin{array}{c}\text { Sig } \\
\mathbf{( 2 -} \\
\text { tailed) }\end{array}$ & $\begin{array}{c}\text { Mean } \\
\text { Diff }\end{array}$ & $\begin{array}{c}\text { Std } \\
\text { Error } \\
\text { Diff }\end{array}$ & $\begin{array}{c}95 \% \mathrm{Cl} \\
\text { Lower }\end{array}$ & $\begin{array}{c}95 \% \mathrm{Cl} \\
\text { Upper }\end{array}$ & $\begin{array}{c}\text { Cohen's } \\
\mathbf{d}\end{array}$ \\
\hline Doing My Best & 0.57 & 0.46 & $\begin{array}{c}-0.04 \\
(26)\end{array}$ & 0.97 & -0.21 & 5.25 & -11.01 & 10.59 & -0.02 \\
$\begin{array}{l}\text { Doing Just } \\
\text { Enough }\end{array}$ & 0.89 & 0.35 & $\begin{array}{c}-1.38 \\
(55)\end{array}$ & 0.18 & -6.04 & 4.67 & -15.63 & 3.55 & -0.52 \\
\hline
\end{tabular}

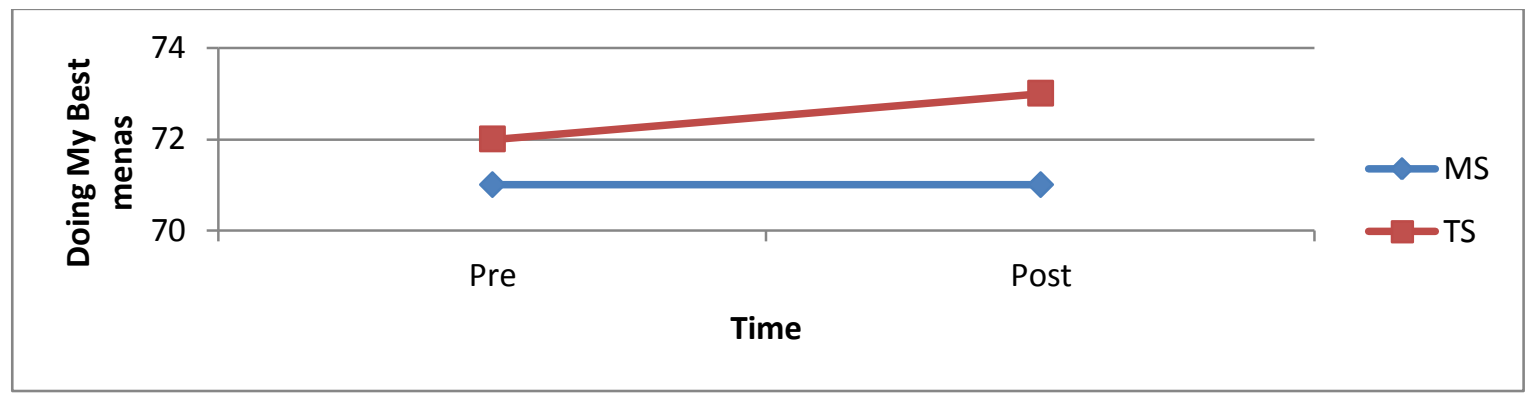

Figure 29. Doing My Best — Pasifika students

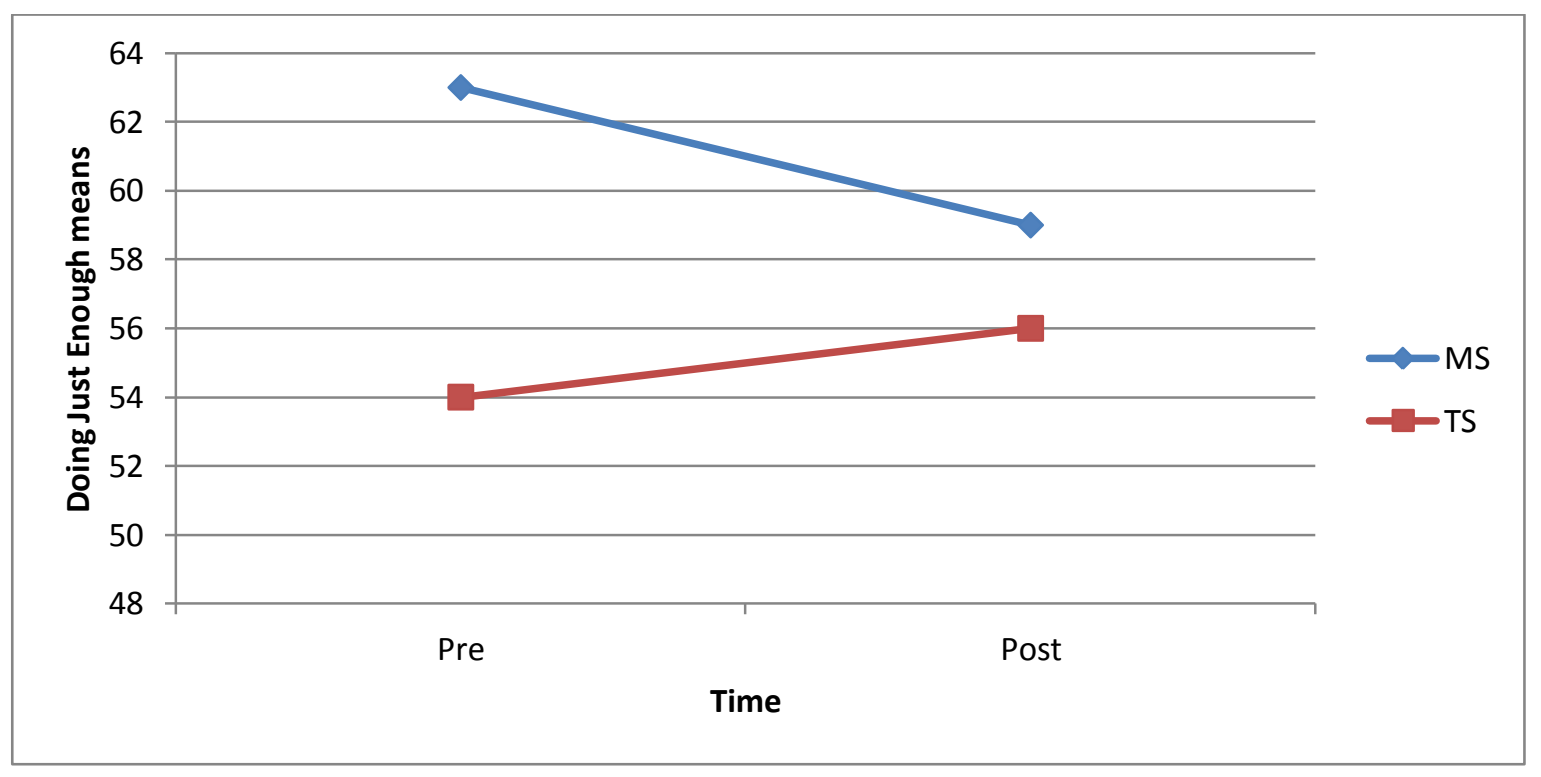

Figure 30. Doing Just Enough — Pasifika students 


\section{Analysis Five: Changes on Inter-personal Motivation Factors}

Changes on the two inter-personal motivation factors peer affiliation and teacher affiliation were also examined as a function of participation in the MS and TS programmes.

\section{Section One: Changes on Inter-personal Motivation Factors for} All Students in the MS and TS Programmes

Table 21 presents the means for the two inter-personal motivation orientation scores peer affiliation and teacher affiliation rated by students before and after participation in the two programmes.

\section{Table 21}

Inter-personal Motivation Factor - Means for All Students Participating in the MS versus TS Programmes

\begin{tabular}{lcccc}
\hline Variable & Group & N & $\begin{array}{c}\text { Pre-test mean } \\
\text { pre-test (SD) }\end{array}$ & $\begin{array}{c}\text { Post-test mean } \\
\text { post-test (SD) }\end{array}$ \\
\hline Peer affiliation & MS & 30 & $66(11)$ & $69(11)$ \\
& TS & 27 & $68(10)$ & $67(12)$ \\
$\begin{array}{l}\text { Teacher } \\
\text { affiliation }\end{array}$ & MS & 30 & $73(13)$ & $74(14)$ \\
& TS & 27 & $71(11)$ & $70(14)$ \\
\hline
\end{tabular}

Table 22 presents the results of the independent samples tests for differences in interpersonal motivation orientations for all students in the MS versus TS programmes. 


\section{Table 22}

Independent Samples Tests and Effect Size Calculations on Change Scores for the Inter-personal Motivation Orientations Peer Affiliation and Teacher Affiliation for All Students in the MS versus TS Programmes

\begin{tabular}{lccccccccc}
\hline Variable & F & Sig & $\mathbf{t}(\mathbf{d f})$ & $\begin{array}{c}\text { Sig } \\
\mathbf{2}- \\
\text { tailed) }\end{array}$ & $\begin{array}{c}\text { Mean } \\
\text { Diff }\end{array}$ & $\begin{array}{c}\text { Std } \\
\text { Error } \\
\text { Diff }\end{array}$ & $\begin{array}{c}95 \% \mathrm{Cl} \\
\text { Lower }\end{array}$ & $\begin{array}{c}95 \% \mathrm{Cl} \\
\text { Upper }\end{array}$ & $\begin{array}{c}\text { Cohen's } \\
\mathbf{d}\end{array}$ \\
\hline Peer affiliation & 0.43 & 0.52 & $\begin{array}{c}1.33 \\
(55)\end{array}$ & 0.19 & 3.80 & 2.83 & -1.88 & 9.48 & $\mathbf{0 . 3 5}$ \\
$\begin{array}{l}\text { Teacher } \\
\text { affiliation }\end{array}$ & 0.92 & 0.34 & $\begin{array}{l}0.61 \\
(55)\end{array}$ & 0.55 & 1.63 & 2.72 & -3.82 & 7.07 & 0.16 \\
\hline
\end{tabular}

None of these differences reached statistical significance, although the higher shift in peer affiliation for the MS group show small effects (see also figures 31 and 32).

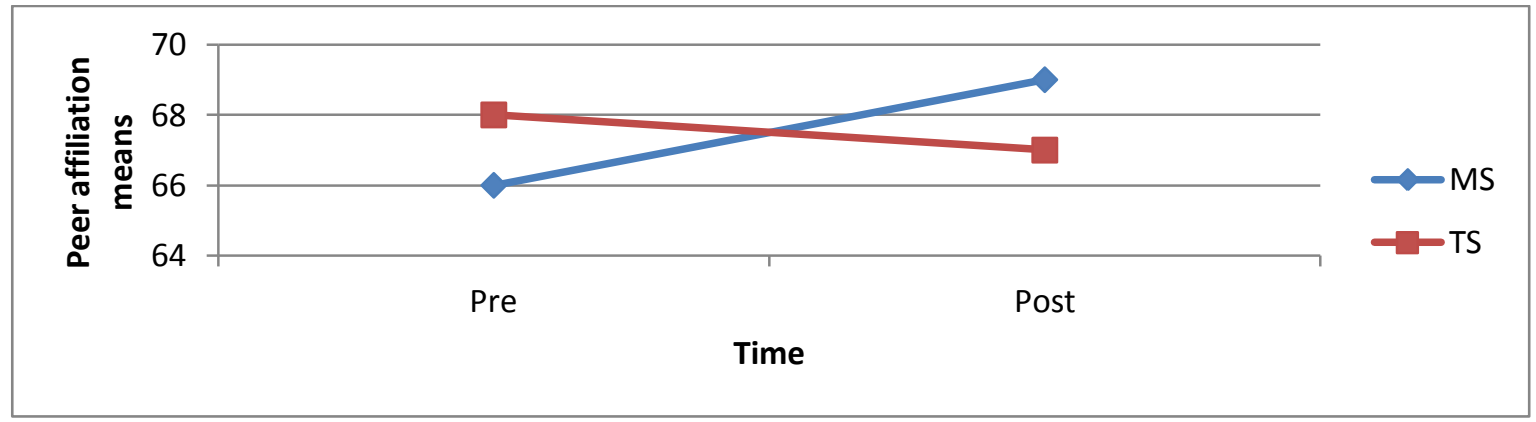

Figure 31. Peer affiliation - All students

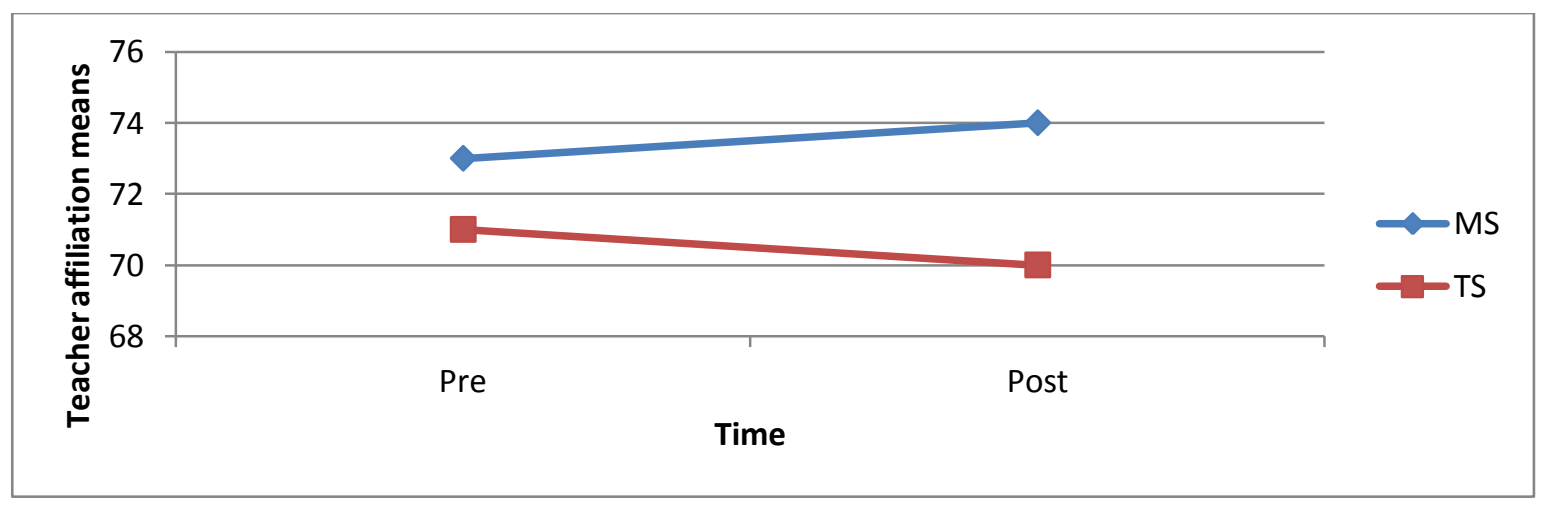

Figure 32. Teacher affiliation - All students 


\section{Section Two: Changes in Inter-personal Motivation Orientations for Pasifika Students in the MS and TS Programmes}

Table 23 presents the means and standard deviations for Pasifika students on peer affiliation and teacher affiliation measured before and after participation in each of the two programmes.

\section{Table 23}

Peer Affiliation and Teacher Affiliation Means for Pasifika Students Participating in the $M S$ versus TS Programmes

\begin{tabular}{lcccc}
\hline Variable & Group & N & Pre-test mean (SD) & Post-test mean (SD) \\
\hline Peer affiliation & MS & 16 & $69(11)$ & $73(9)$ \\
& TS & 12 & $68(11)$ & $67(16)$ \\
Teacher affiliation & MS & 16 & $70(12)$ & $71(12)$ \\
& TS & 12 & $71(9)$ & $69(17)$ \\
\hline
\end{tabular}

Table 24 presents the results of the independent samples tests for differences in these two inter-personal motivation orientations for Pasifika students who participated in the two programmes.

\section{Table 24}

Independent Samples Tests and Effect Size Calculations on Change Scores for the Inter-personal Factors Peer Affiliation and Teacher Affiliation for Pasifika Students in the MS versus TS Programmes

\begin{tabular}{lccccccccc}
\hline Variable & F & Sig & t (df) & $\begin{array}{c}\text { Sig } \\
\text { (2- } \\
\text { tailed) }\end{array}$ & $\begin{array}{c}\text { Mean } \\
\text { Diff }\end{array}$ & $\begin{array}{c}\text { Std } \\
\text { Error } \\
\text { Diff }\end{array}$ & $\begin{array}{c}95 \% \mathrm{Cl} \\
\text { Lower }\end{array}$ & $\begin{array}{c}\text { 95\% Cl } \\
\text { Upper }\end{array}$ & $\begin{array}{c}\text { Cohen's } \\
\mathbf{d}\end{array}$ \\
\hline Peer affiliation & 0.03 & 0.86 & $\begin{array}{l}0.96 \\
(26)\end{array}$ & 0.34 & 4.48 & 4.70 & -5.18 & 14.14 & $\mathbf{0 . 3 7}$ \\
$\begin{array}{l}\text { Teacher } \\
\text { affiliation }\end{array}$ & 5.07 & 0.03 & $\begin{array}{l}0.71 \\
(26)\end{array}$ & 0.48 & 3.40 & 5.13 & -7.14 & 13.94 & $\mathbf{0 . 2 7}$ \\
\hline
\end{tabular}


Figures 33 and 34 also illustrate these pre-test and post-test scores for Pasifika students in the two programmes. The increases tend to favour the MS group, but the effect sizes are small for both the peer affiliation and teacher affiliation variables.

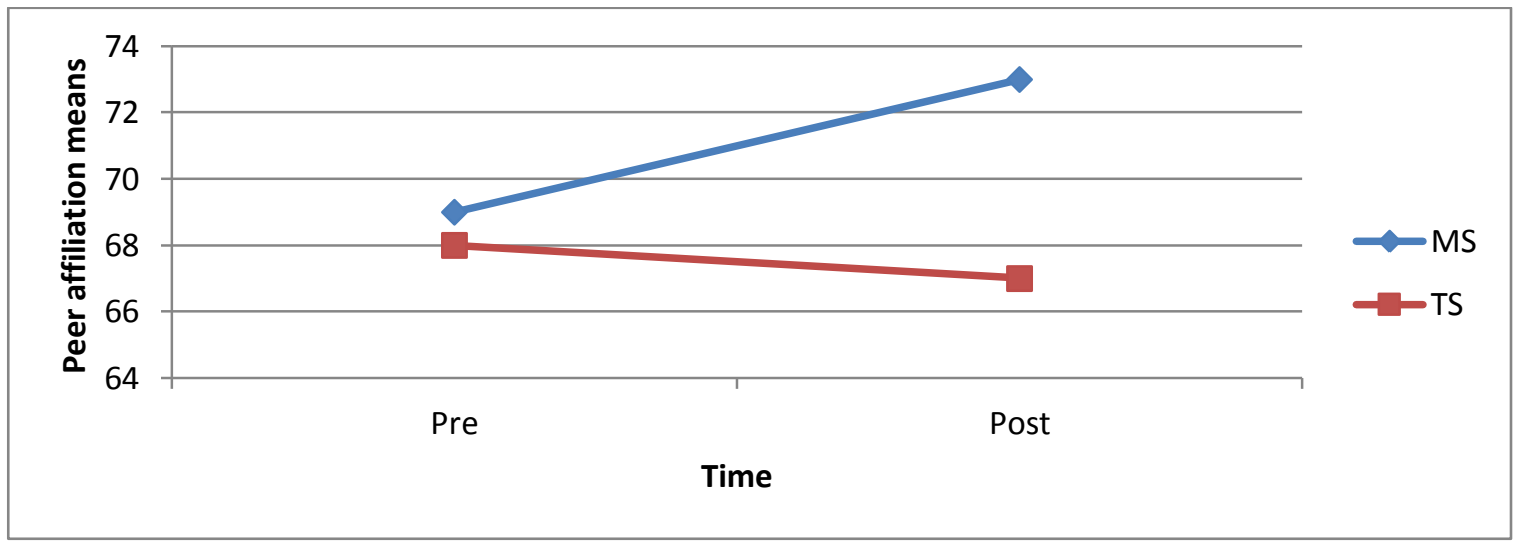

Figure 33. Peer affiliation — Pasifika students

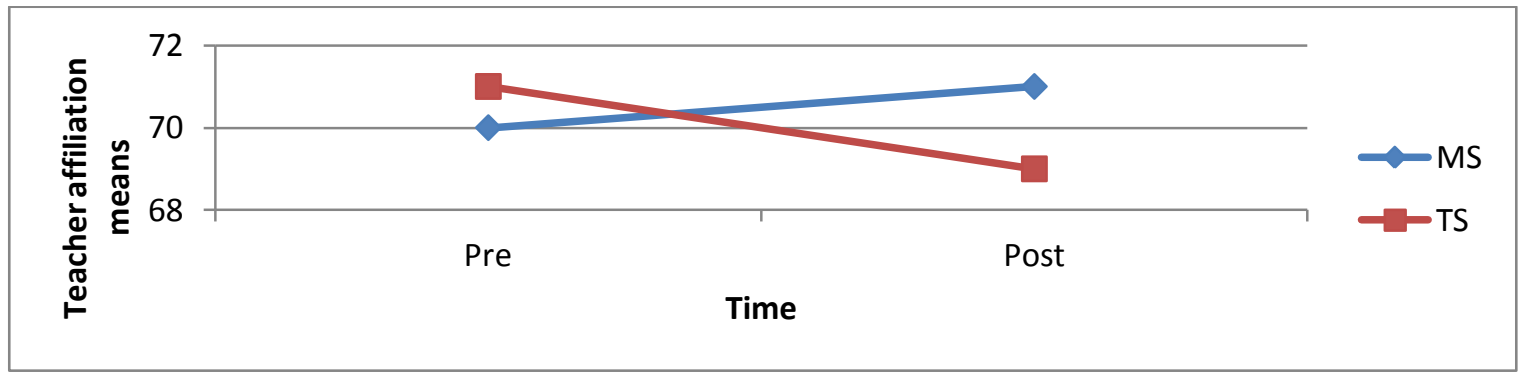

Figure 34. Teacher affiliation - Pasifika students

\section{Analysis Six: Changes in Attributions for Best Marks on Assessments}

As described in the Methods chapter, students rated seven possible attributions or explanations that they considered responsible for their best marks; these factors are ability, effort, good luck, easy assessment, peers, teachers, and family. Section One of 
Analysis Six presents data about changes in attributions for their best marks on assessments from students in both the MS and TS programmes.

\section{Section One: Changes in Attributions for Best Marks}

Table 25 presents the means and standard deviations for attributions for best marks on assessments as rated by all students before and after participation in the two programmes.

\section{Table 25}

Best Mark Attributions Mean Scores by All Students Participating in the MS versus TS Programmes

\begin{tabular}{lcccc}
\hline $\begin{array}{l}\text { Best Mark Attributed } \\
\text { to: }\end{array}$ & Group & N & Pre-test mean (SD) & Post-test mean (SD) \\
\hline My ability & MS & 30 & $81(13)$ & $77(20)$ \\
My effort & TS & 27 & $80(17)$ & $77(18)$ \\
Easy test & MS & 30 & $84(18)$ & $92(14)$ \\
& TS & 27 & $84(19)$ & $81(19)$ \\
Good luck & MS & 30 & $72(22)$ & $68(23)$ \\
& TS & 27 & $68(18)$ & $69(20)$ \\
My family & MS & 30 & $58(27)$ & $51(22)$ \\
& TS & 27 & $62(23)$ & $65(26)$ \\
My teachers & MS & 30 & $78(27)$ & $75(21)$ \\
& TS & 27 & $83(25)$ & $77(24)$ \\
My friends & MS & 30 & $82(17)$ & $84(17)$ \\
& TS & 27 & $78(19)$ & $79(21)$ \\
& MS & 30 & $76(20)$ & $63(21)$ \\
& TS & 27 & $72(22)$ & $71(22)$ \\
\hline
\end{tabular}


Table 26 presents the results of the independent samples tests for differences on change scores for attributions for best marks in assessments as rated by all students in the MS and TS intervention programmes.

\section{Table 26}

Independent Samples Tests and Effect Size Calculations on Change Scores for Student Attributions for Best Marks in Assessments by All Students in the MS versus TS Intervention Programmes

\begin{tabular}{|c|c|c|c|c|c|c|c|c|c|}
\hline $\begin{array}{l}\text { Best mark } \\
\text { attributed to: }\end{array}$ & $\mathbf{F}$ & Sig & $t(d f)$ & $\begin{array}{l}\text { Sig (2- } \\
\text { tailed) }\end{array}$ & $\begin{array}{c}\text { Mean } \\
\text { Diff }\end{array}$ & $\begin{array}{c}\text { Std } \\
\text { Error } \\
\text { Diff }\end{array}$ & $\begin{array}{l}95 \% \mathrm{Cl} \\
\text { Lower }\end{array}$ & $\begin{array}{l}95 \% \mathrm{Cl} \\
\text { Upper }\end{array}$ & $\begin{array}{c}\text { Cohen's } \\
\text { d }\end{array}$ \\
\hline My ability & 6.09 & 0.02 & $\begin{array}{c}-0.30 \\
(55)\end{array}$ & 0.77 & -1.39 & 4.52 & -10.45 & 7.67 & -0.08 \\
\hline My effort & 0.90 & 0.35 & $\begin{array}{l}2.38 \\
(55)\end{array}$ & 0.02 & 11.20 & 4.71 & 1.76 & 20.65 & +0.63 \\
\hline Easy test & 0.00 & 0.95 & $\begin{array}{l}-0.93 \\
(55)\end{array}$ & 0.35 & -5.09 & 5.50 & -16.12 & 5.93 & -0.25 \\
\hline Good luck & 0.01 & 0.93 & $\begin{array}{c}-1.52 \\
(55)\end{array}$ & 0.13 & -10.28 & 6.77 & -23.85 & 3.29 & -0.40 \\
\hline My family & 0.57 & 0.45 & $\begin{array}{l}0.47 \\
(54)\end{array}$ & 0.64 & 2.44 & 5.11 & -7.81 & 12.68 & +0.13 \\
\hline My teachers & 0.49 & 0.49 & $\begin{array}{l}0.30 \\
(55)\end{array}$ & 0.76 & 1.57 & 5.17 & -8.79 & 11.94 & +0.08 \\
\hline My friends & 1.04 & 0.31 & $\begin{array}{l}-1.86 \\
(55)\end{array}$ & 0.07 & -11.57 & 6.20 & -24.00 & 0.85 & -0.49 \\
\hline
\end{tabular}

Attributions for best mark are summarised for two types: traditional attributions and social attributions. Traditional attributions for assessment marks comprised the respective role they thought that ability, effort, luck, and task ease played in their assessment results. These data show that all students in both the MS and TS programmes decreased in attributions of their best marks to ability; although this decrease was statistically significant, the effect size was not (see also figure 35). 


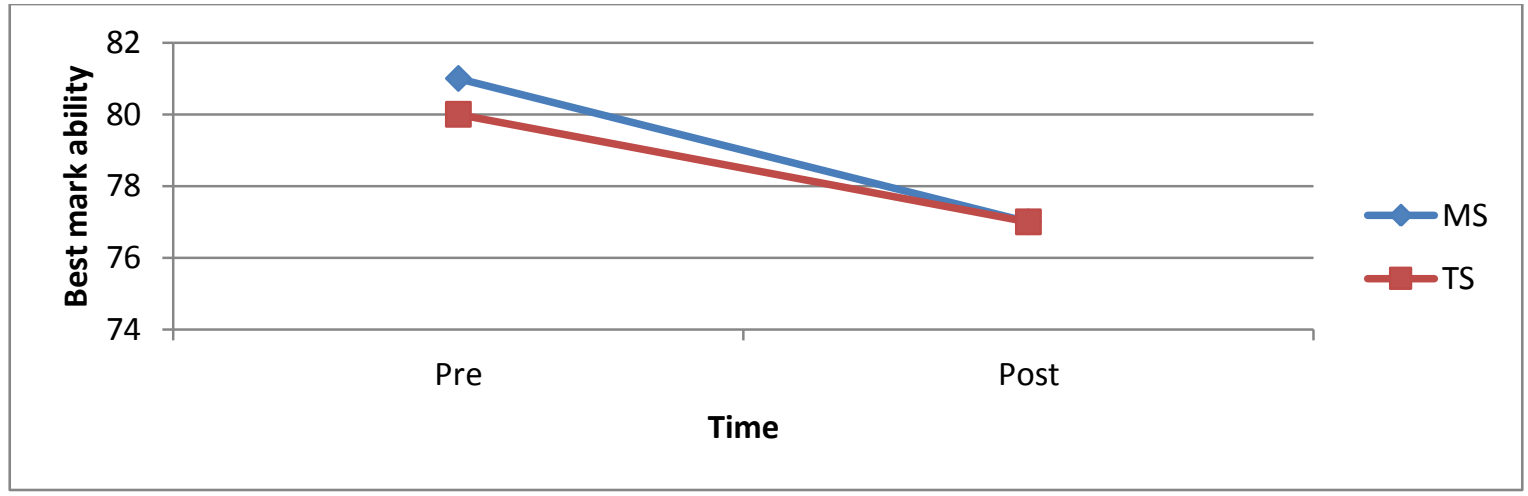

\section{Figure 35. Best mark ability - All students}

Students in the MS programme showed a statistically significant increase in attributing their best marks to effort in comparison to results for the students in the TS programme. This change also fell into the medium effect size range at $d=0.63$ (see also figure 36).

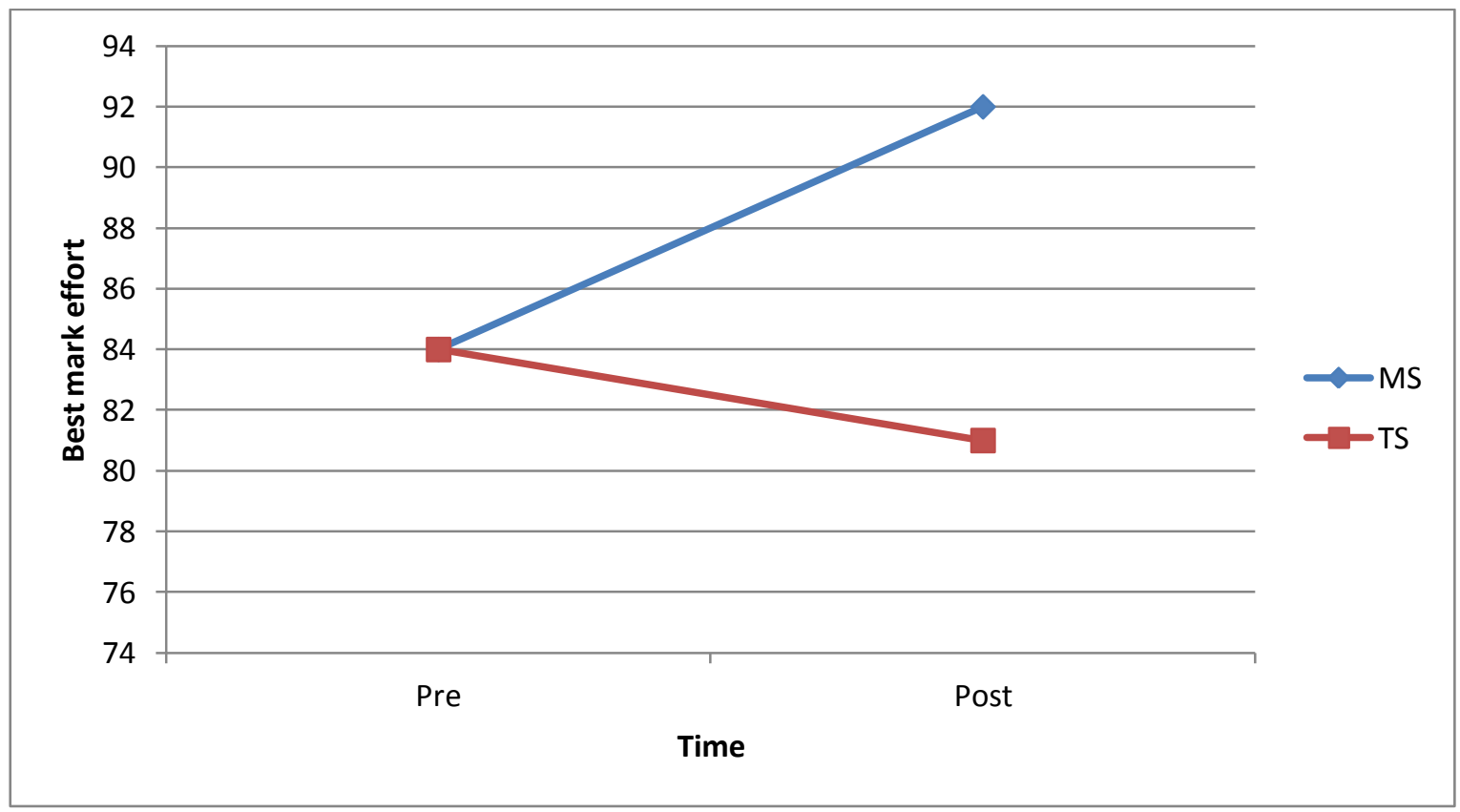

\section{Figure 36. Best mark effort - All students}

Although these differences in change scores are not statistically significant, students in the MS intervention showed a great mean decrease in two negative attributions: attributing best marks to an easy test and to good luck. The tests for effect sizes also 
reveal small effects on both attributions, favouring the MS intervention (see also figures 37 and 38).

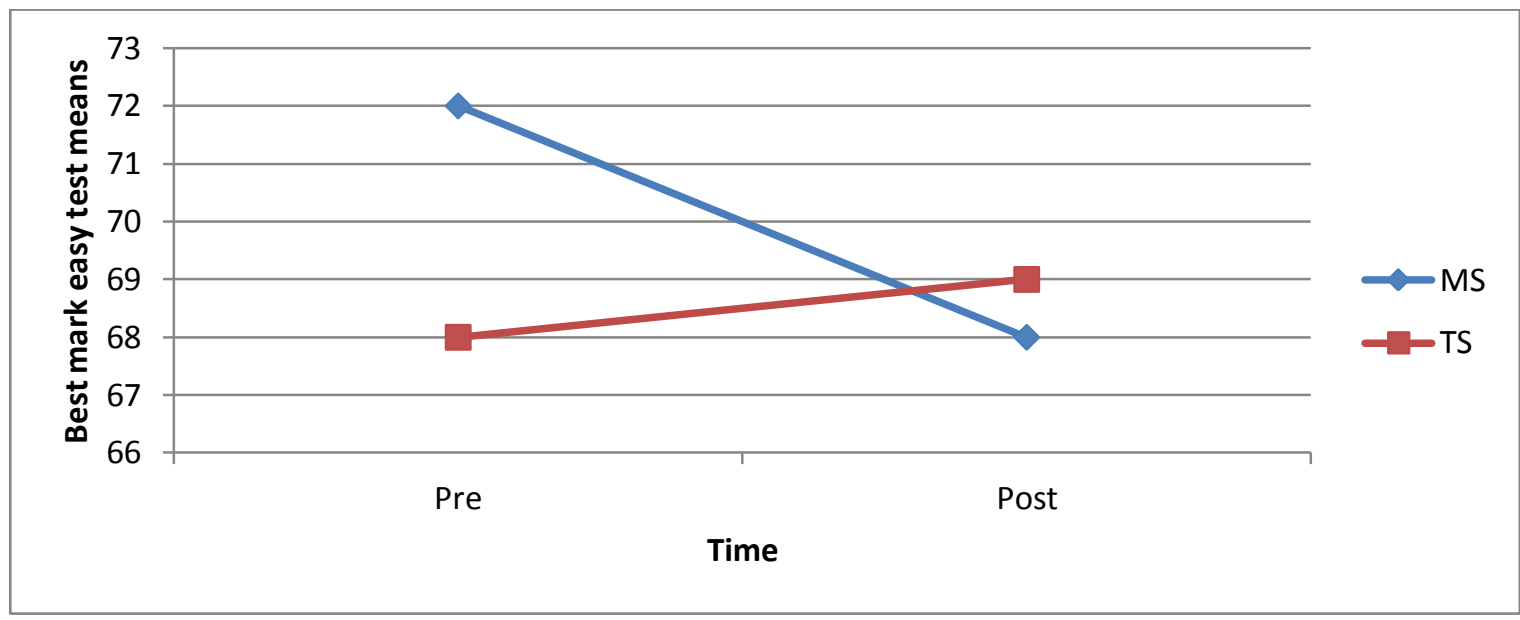

Figure 37. Best mark easy test - All students

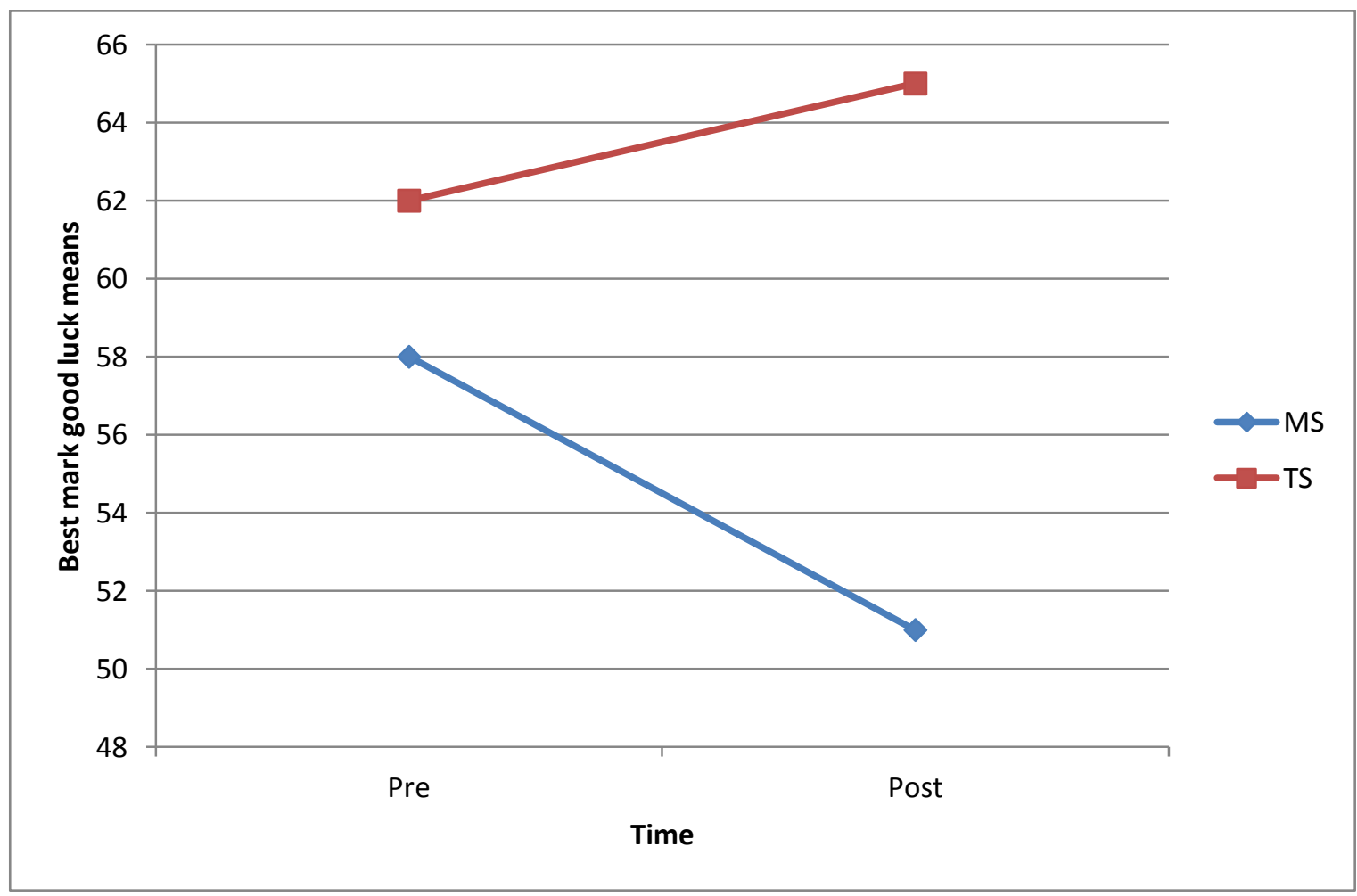

Figure 38. Best mark good luck - All students

Change scores for three social attributions for students' best marks on assessments were also analysed: family, teachers, and friends (see figures 39-41). 


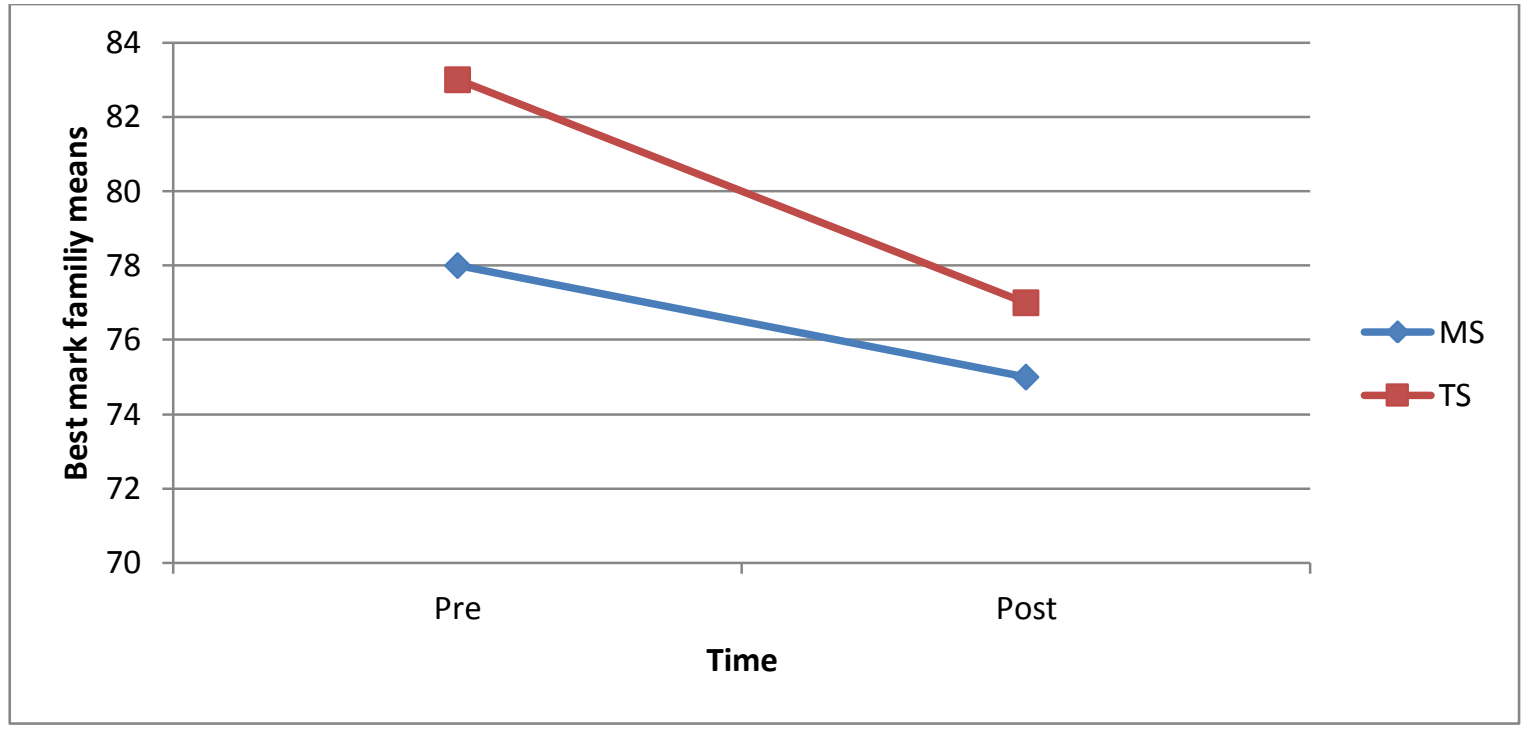

Figure 39. Best mark family - All students

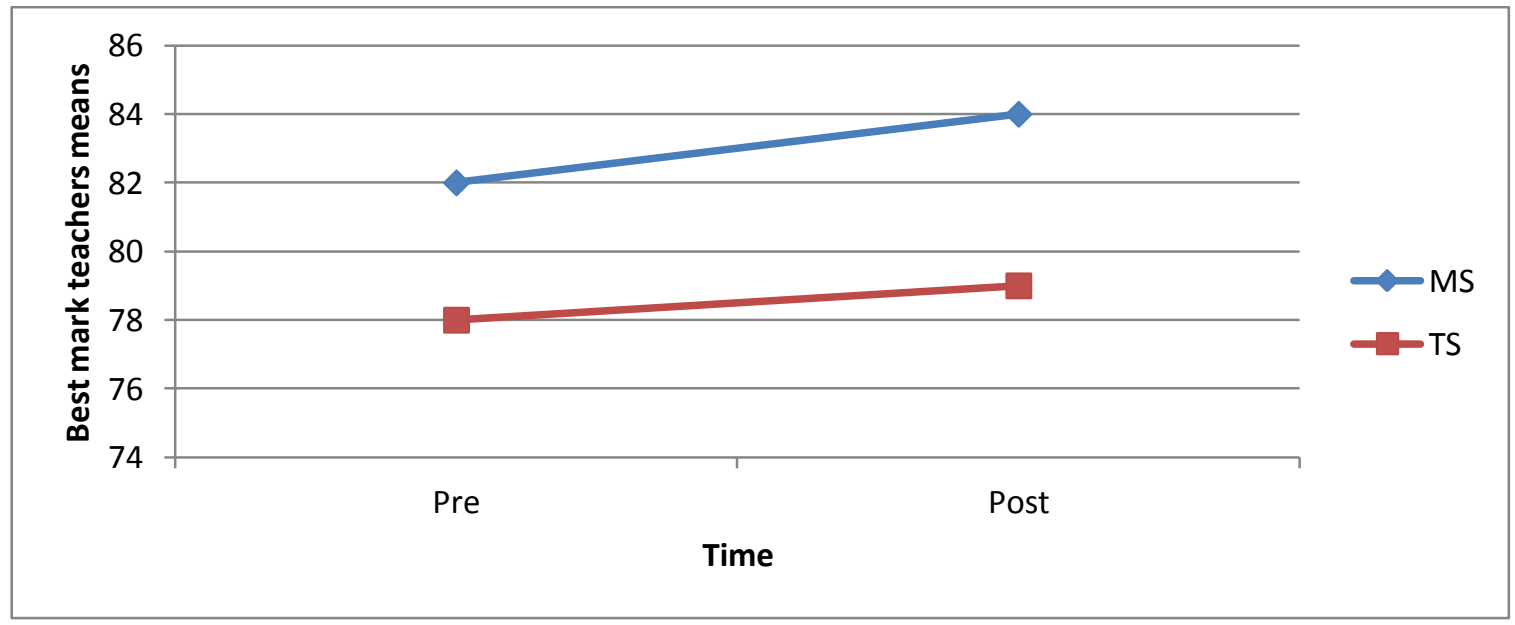

Figure 40. Best mark teachers - All students 


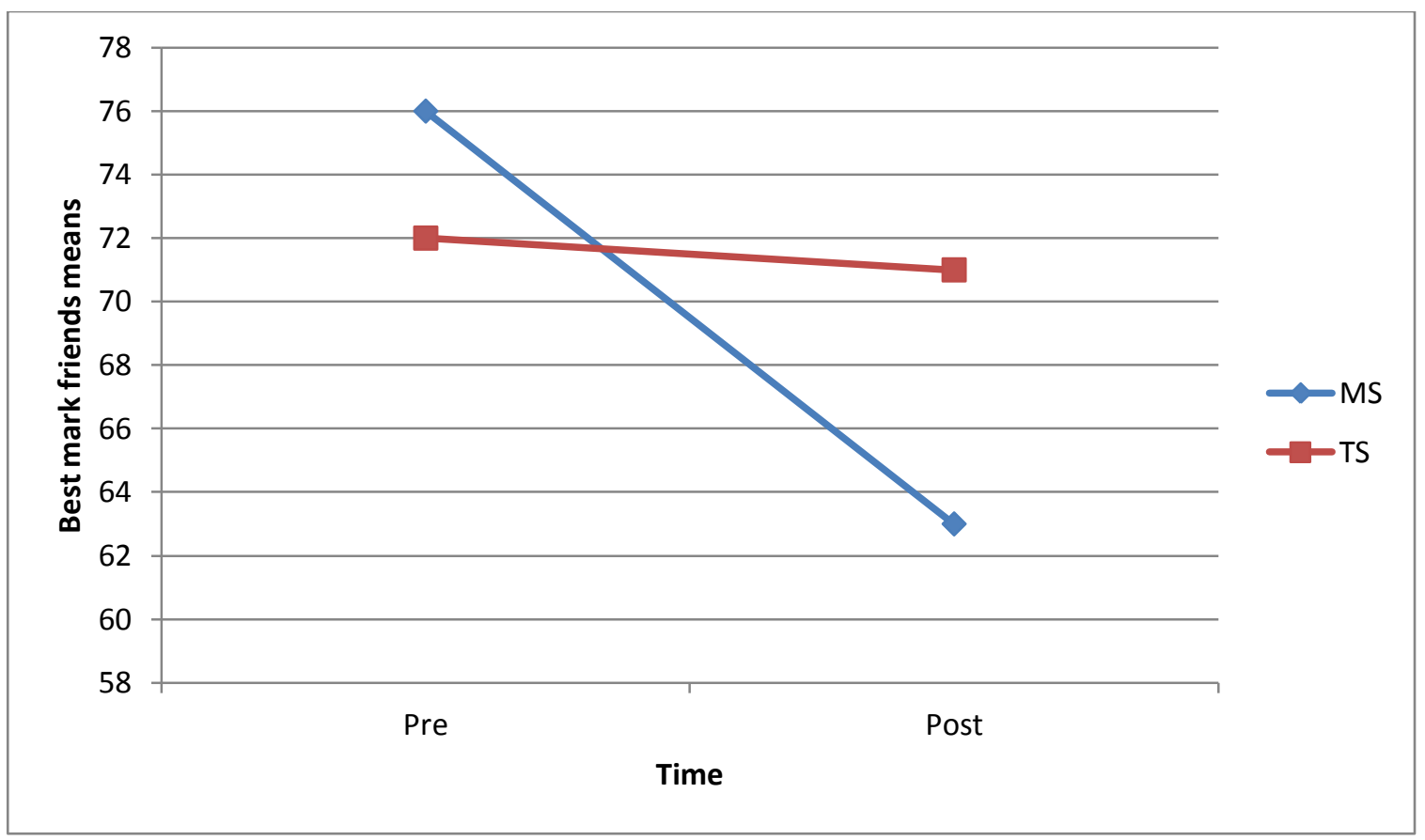

Figure 41. Best mark friends - All students

Findings for these social attributions were not statistically significant. However, there was a medium effect size for a decrease in attributing best marks to friends for the MS group in comparison with the TS group.

\section{Section Two: Changes in Attributions for Best Marks in Assessments for Pasifika Students}

Table 27 presents the means and standard deviations for attribution ratings by Pasifika students who participated in either the MS or TS programme. 


\section{Table 27}

Best Mark Attribution Mean Scores for Pasifika Students Participating in the MS versus TS Programmes

\begin{tabular}{lcccc}
\hline $\begin{array}{l}\text { Best mark attributed } \\
\text { to: }\end{array}$ & Group & N & Pre-test Mean (SD) & $\begin{array}{c}\text { Post-test Mean } \\
\text { (SD) }\end{array}$ \\
\hline My ability & MS & 30 & $77(11)$ & $70(21)$ \\
My effort & TS & 27 & $79(23)$ & $73(25)$ \\
Easy test & MS & 30 & $80(21)$ & $88(16)$ \\
& TS & 27 & $83(16)$ & $79(21)$ \\
Good luck & MS & 30 & $67(24)$ & $66(24)$ \\
& TS & 27 & $69(16)$ & $69(19)$ \\
My family & MS & 30 & $53(26)$ & $48(19)$ \\
& TS & 27 & $63(20)$ & $73(29)$ \\
My teachers & MS & 30 & $78(24)$ & $75920)$ \\
& TS & 27 & $81(26)$ & $73(27)$ \\
My friends & MS & 30 & $80(16)$ & $81(17)$ \\
& TS & 27 & $75(24)$ & $75(26)$ \\
\hline
\end{tabular}

Table 28 presents the results of the independent samples tests for differences on change scores for attributions for best marks in assessments for Pasifika students who participated in the two intervention programmes (see also figures 42-48). 


\section{Table 28}

Independent Samples Tests and Effect Size Calculations on Change Scores for Attributions for Best Marks in Assessments for Pasifika Students in the MS versus TS Intervention Programmes

\begin{tabular}{lccccccccc}
\hline $\begin{array}{l}\text { Best mark } \\
\text { attributed to: }\end{array}$ & F & Sig & $\mathbf{t}$ (df) & $\begin{array}{c}\text { Sig } \\
\text { (2- } \\
\text { tailed) }\end{array}$ & $\begin{array}{c}\text { Mean } \\
\text { Diff }\end{array}$ & $\begin{array}{c}\text { Std } \\
\text { Error } \\
\text { Diff }\end{array}$ & $\begin{array}{c}\text { 95\% Cl } \\
\text { Lower }\end{array}$ & $\begin{array}{c}\mathbf{9 5 \%} \mathrm{Cl} \\
\text { Upper }\end{array}$ & $\begin{array}{c}\text { Cohen's } \\
\mathbf{d}\end{array}$ \\
\hline My ability & 1.43 & 0.24 & $0.00(26)$ & 1.00 & 0.00 & 7.35 & -15.10 & 15.10 & 0.00 \\
My effort & 1.11 & 0.30 & $1.65(26)$ & 0.11 & 11.98 & 7.17 & -2.76 & 26.72 & $\mathbf{+ 0 . 6 3}$ \\
Easy test & 0.69 & 0.41 & $-0.19(26)$ & 0.85 & -1.56 & 8.65 & -19.35 & 16.23 & -0.07 \\
Good luck & 3.13 & 0.09 & $-1.44(26)$ & 0.16 & -15.10 & 11.04 & -37.80 & 7.60 & $-\mathbf{0 . 5 5}$ \\
My family & 0.84 & 0.37 & $0.62(26)$ & 0.54 & 5.21 & 8.11 & -11.66 & 22.08 & $\mathbf{+ 0 . 2 4}$ \\
My teachers & 0.02 & 0.88 & $0.17(26)$ & 0.86 & 1.56 & 9.00 & -16.94 & 20.07 & +0.07 \\
My friends & 0.35 & 0.56 & $-0.47(26)$ & 0.64 & -3.65 & 7.80 & -19.68 & 12.39 & -0.18 \\
\hline
\end{tabular}

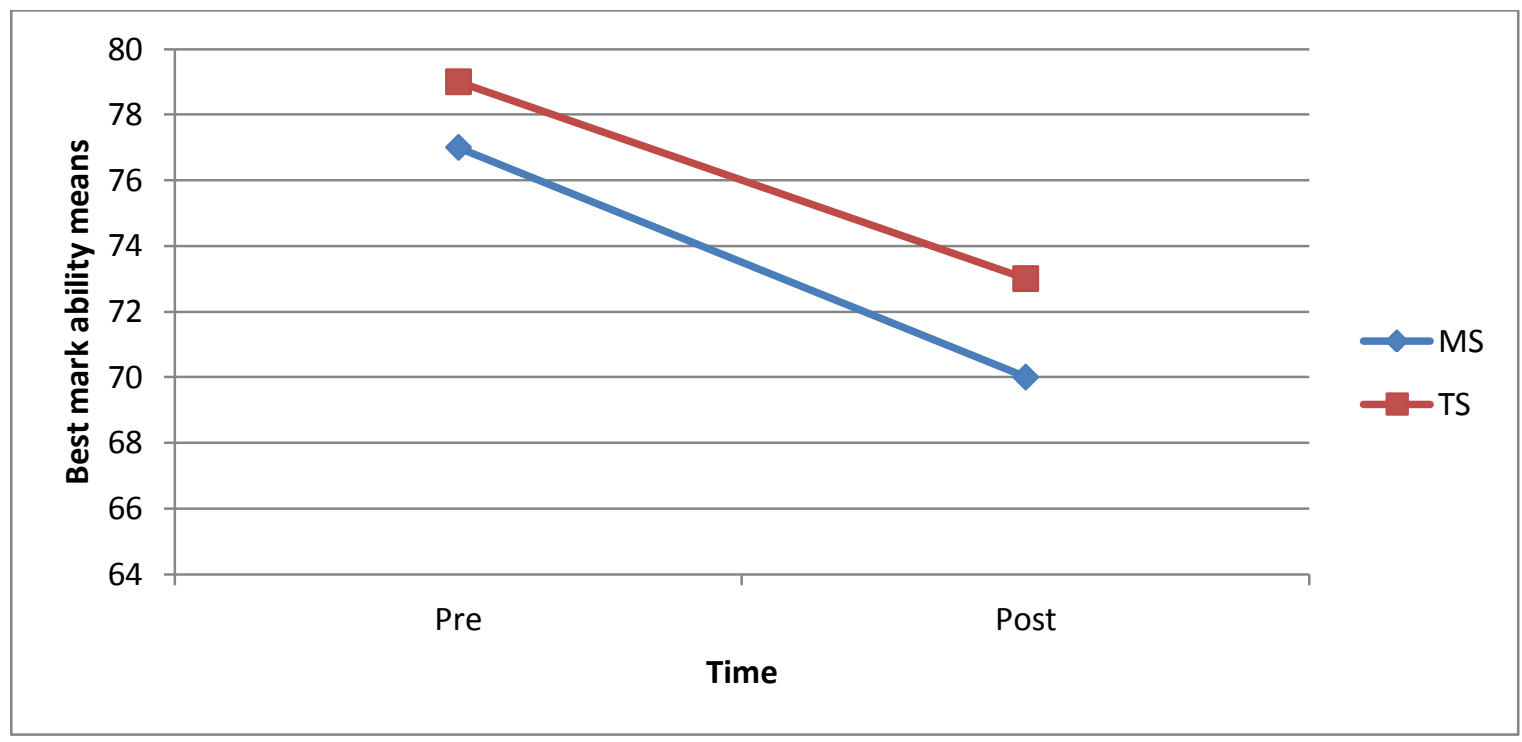

Figure 42. Best mark ability — Pasifika students 


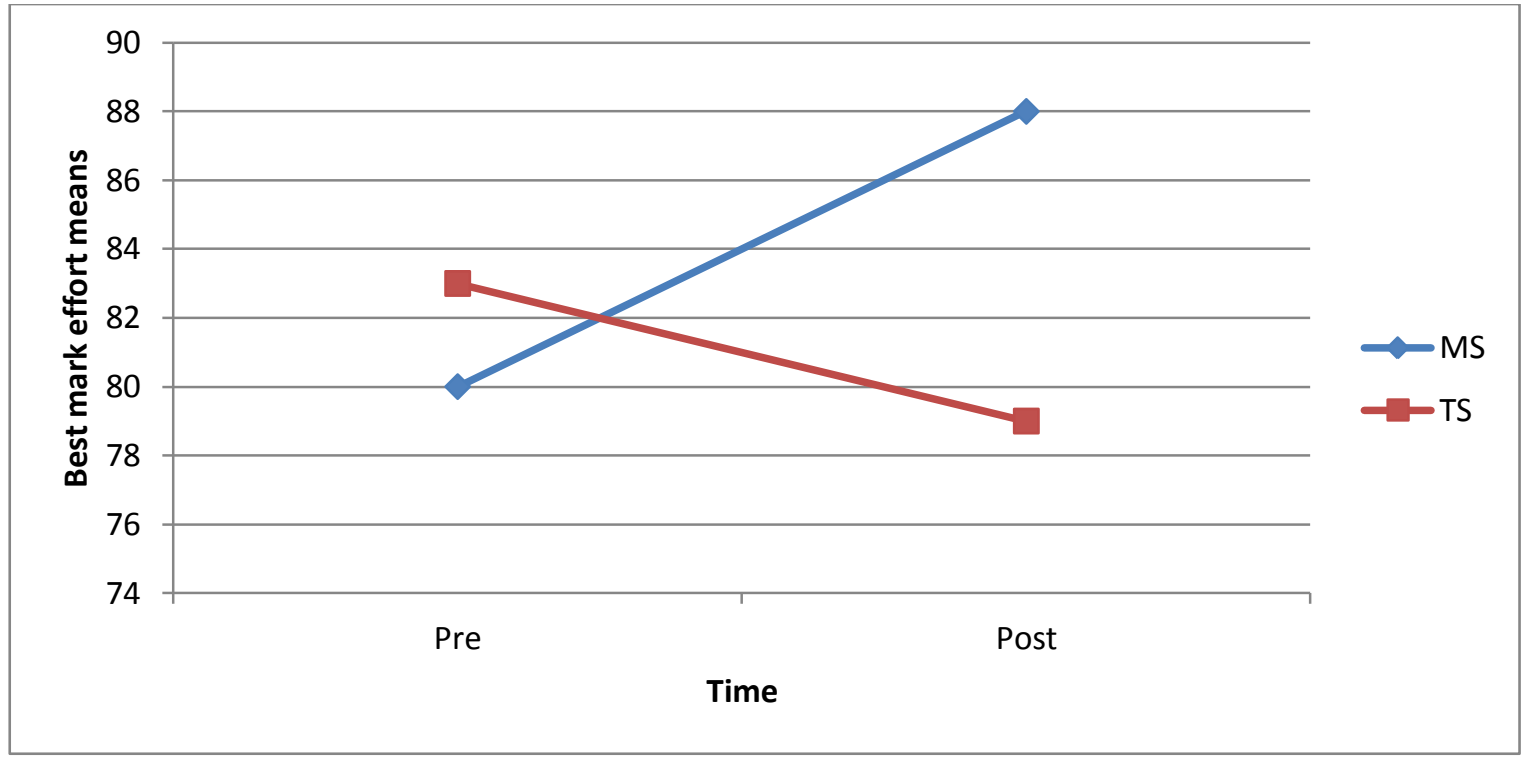

Figure 43. Best mark effort - Pasifika students

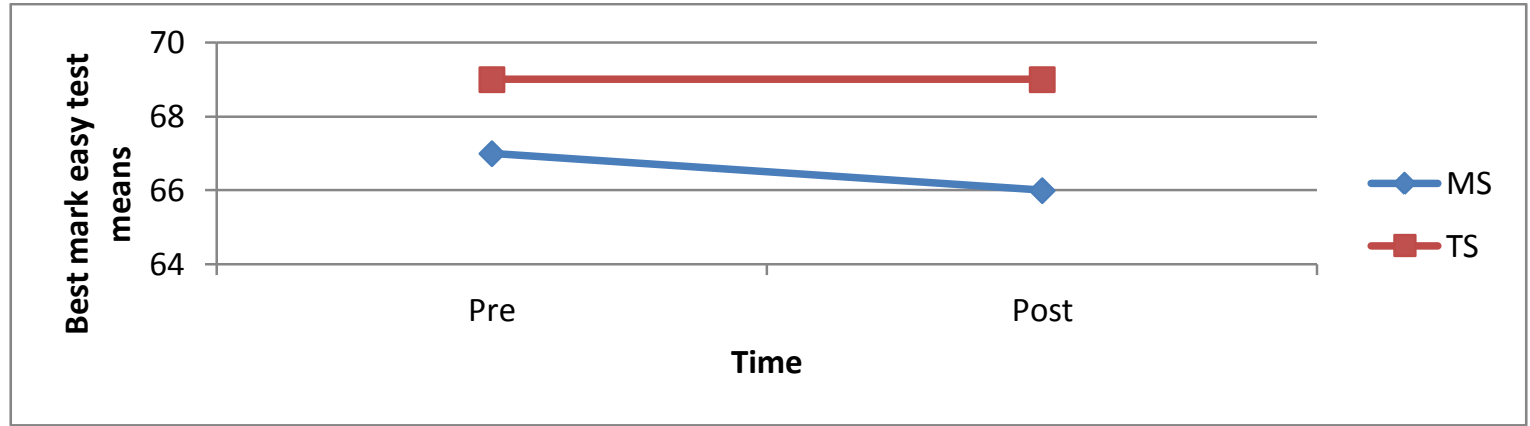

Figure 44. Best mark easy test - Pasifika students 


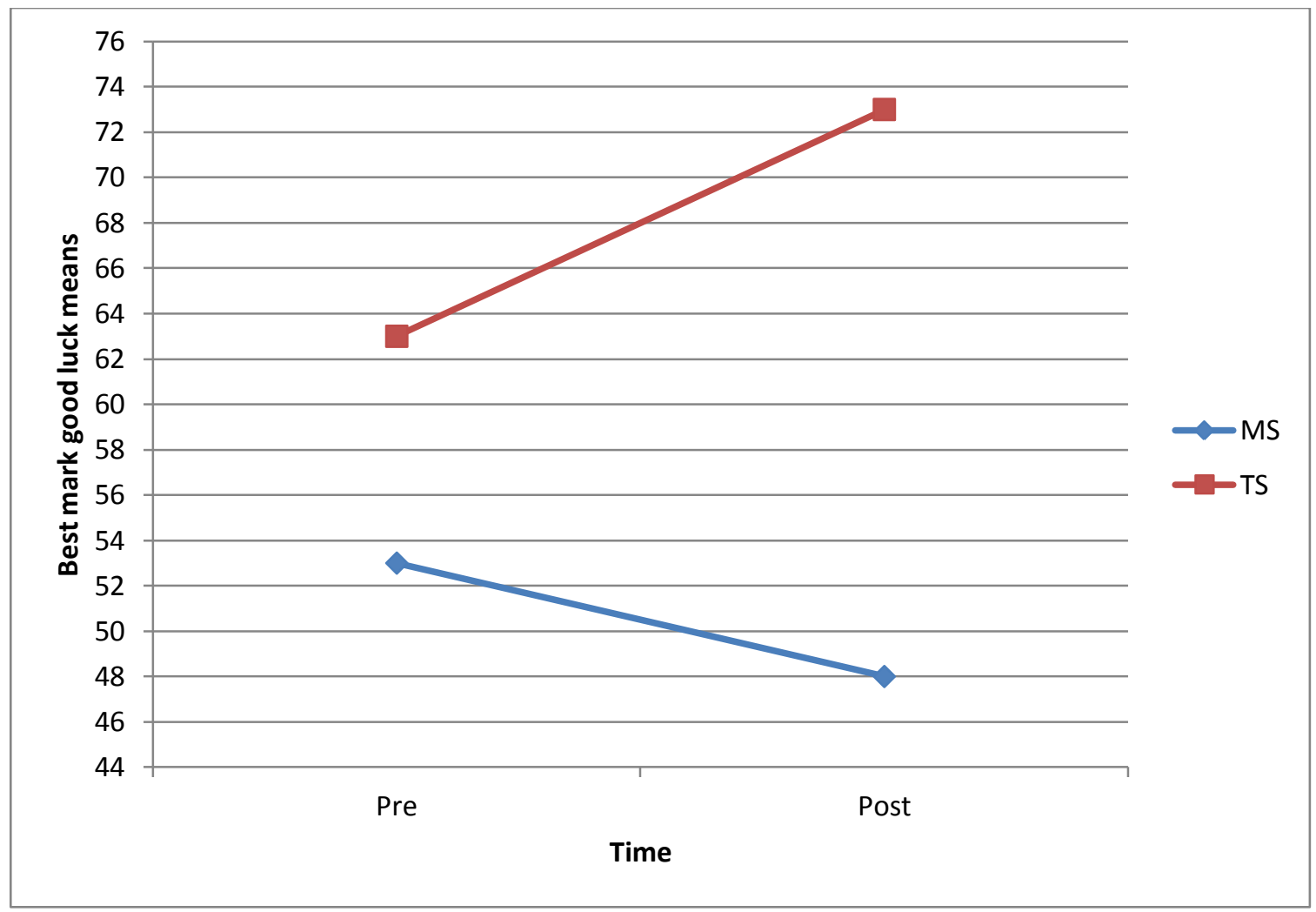

Figure 45. Best mark good luck - Pasifika students

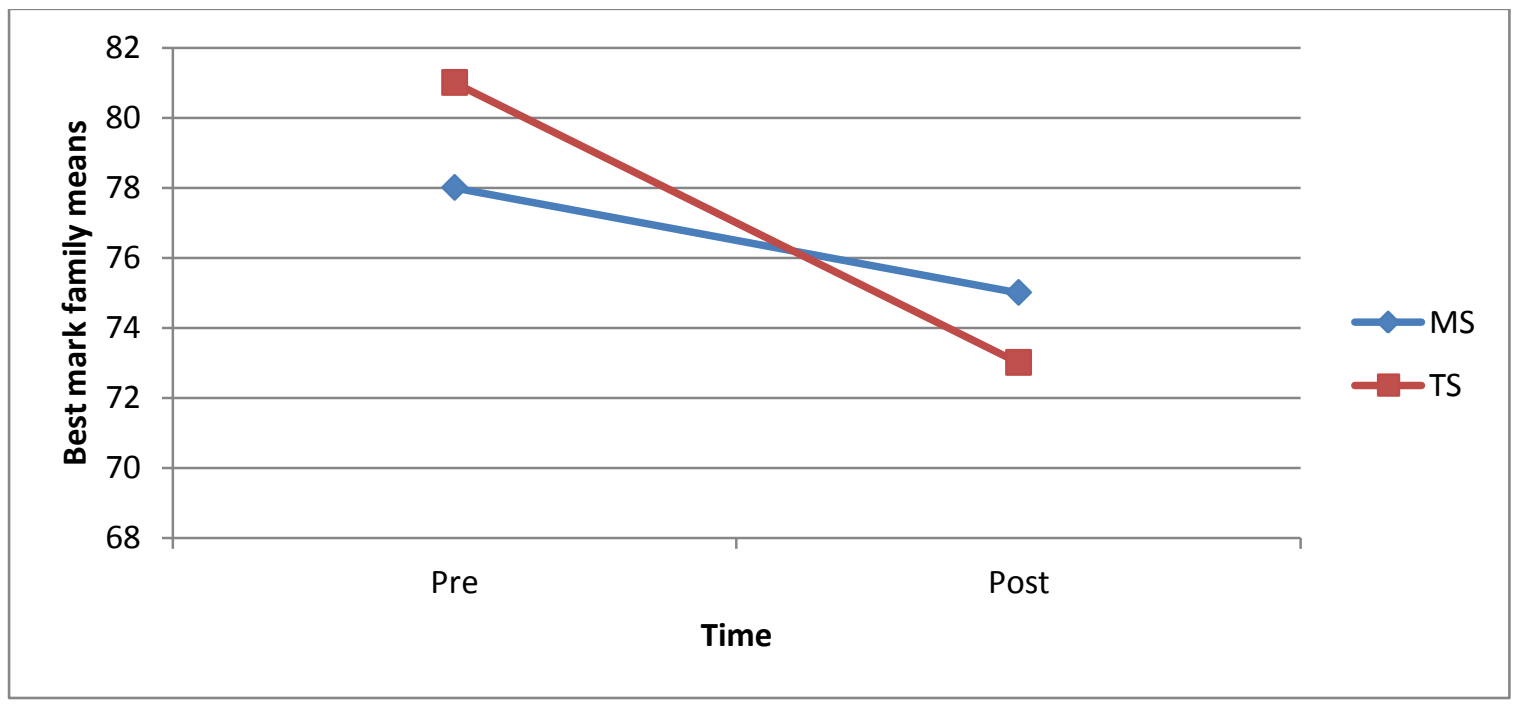

Figure 46. Best mark family — Pasifika students 


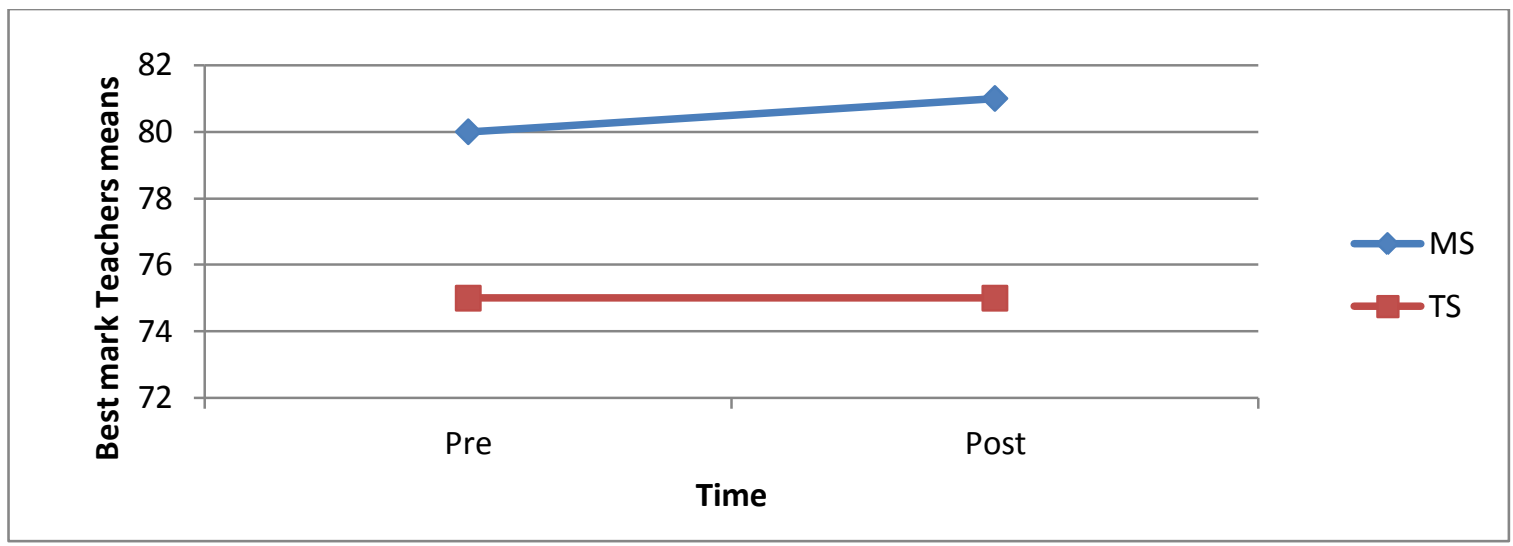

Figure 47. Best mark teacher — Pasifika students

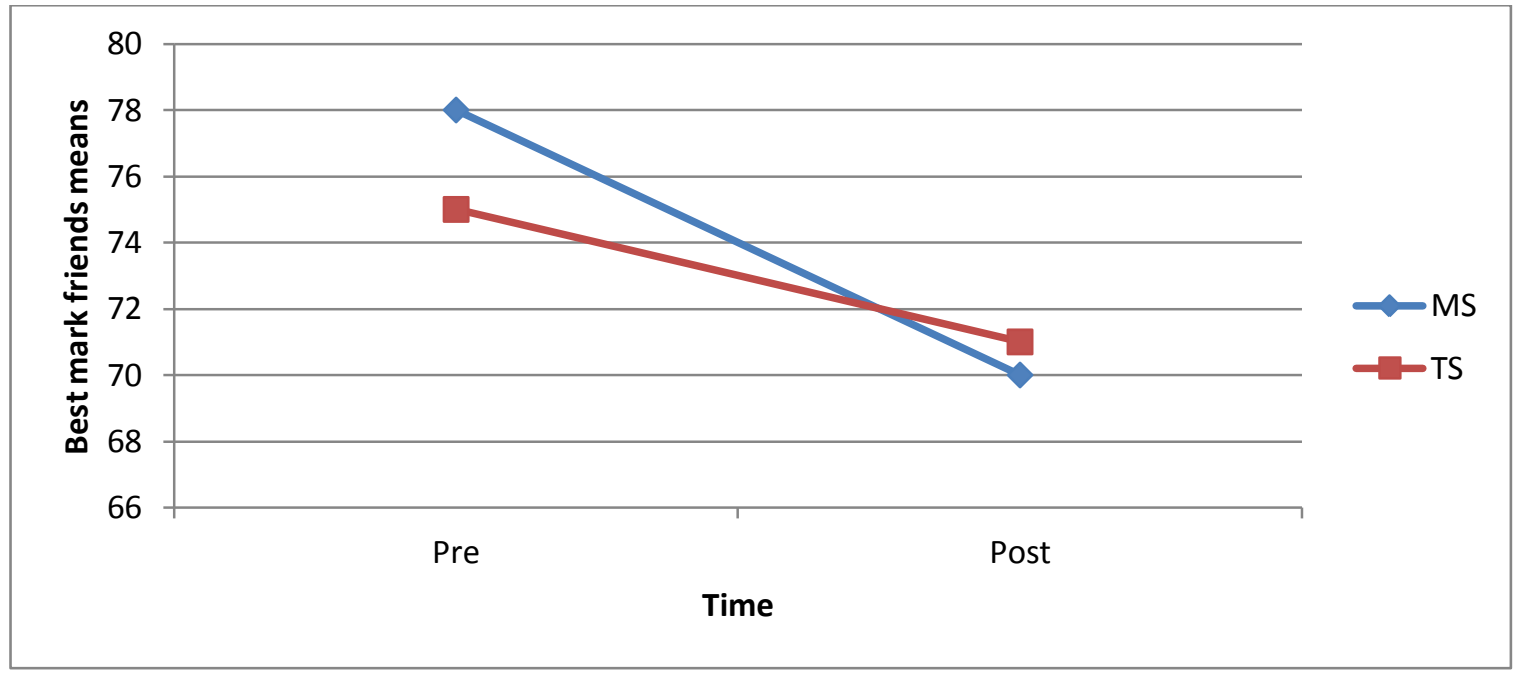

\section{Figure 48. Best mark friends - Pasifika students}

There are a number of contrasting findings about the effects of the MS and TS programmes on attribution made by Pasifika students for their best marks which will be investigated further in the Discussion chapter. The findings provide evidence that the MS intervention was associated with changes as a function of the programme resulting in Pasifika student attributions for their best grade to effort rather than to factors outside the students' control. These include attributions for academic success to ability, good luck, or an assessment that was easy. Medium effect sizes were found for attributions to effort, assessment difficulty, and luck for best marks, all favouring the MS intervention programme. 


\section{Analysis Seven: Changes in Attributions for Worst Marks in Assessments}

This study measured changes in seven attributions for worst marks in assessments, for seven attributions including ability, effort, hard test, bad luck, my family, my teachers, and my friends. Responses from students in the two programmes are compared and reported below.

Section One: Changes in Attributions for Worst Marks in Assessments

Table 29 presents the means and standard deviations for attribution ratings by all students for worst marks in assessments before and after participation in either the MS or TS programme. 


\section{Table 29}

Worst Mark Attributions Mean Scores by All Students Participating in the MS versus TS Programmes

\begin{tabular}{lcccc}
\hline $\begin{array}{l}\text { Worst mark } \\
\text { attributed to: }\end{array}$ & Group & N & Pre-test Mean (SD) & Post-test Mean (SD) \\
\hline My ability & MS & 30 & $63(23)$ & $62(27)$ \\
My effort & TS & 27 & $65(23)$ & $66(23)$ \\
Hard test & MS & 30 & $69(24)$ & $81(22)$ \\
& TS & 27 & $77(25)$ & $82(24)$ \\
Bad luck & MS & 30 & $69(29)$ & $69(23)$ \\
My family & TS & 27 & $79(27)$ & $75(23)$ \\
My teachers & MS & 30 & $49(22)$ & $39(22)$ \\
& TS & 27 & $57(27)$ & $54(27)$ \\
My friends & MS & 30 & $47(25)$ & $45(24)$ \\
& TS & 27 & $49(25)$ & $47(29)$ \\
& MS & 30 & $55(21)$ & $55(25)$ \\
\hline
\end{tabular}

Table 30 presents the results of the independent samples tests for differences on change scores for attributions for worst marks in assessments rated by all students in the two intervention programmes (see also figures 49-55). 


\section{Table 30}

Independent Samples Tests and Effect Size Calculations on Change Scores for Attributions for Worst Marks in Assessments for All Students in the MS versus TS Intervention Programmes

\begin{tabular}{|c|c|c|c|c|c|c|c|c|c|}
\hline $\begin{array}{l}\text { Worst mark } \\
\text { attributed to: }\end{array}$ & $\mathbf{F}$ & Sig & $t(d f)$ & $\begin{array}{c}\text { Sig } \\
(2- \\
\text { tailed) }\end{array}$ & $\begin{array}{c}\text { Mean } \\
\text { Diff }\end{array}$ & $\begin{array}{c}\text { Std } \\
\text { Error } \\
\text { Diff }\end{array}$ & $\begin{array}{l}95 \% \mathrm{Cl} \\
\text { Lower }\end{array}$ & $\begin{array}{l}95 \% \mathrm{Cl} \\
\text { Upper }\end{array}$ & $\begin{array}{c}\text { Cohen's } \\
\text { d }\end{array}$ \\
\hline My ability & 9.12 & 0.00 & $\begin{array}{l}-0.35 \\
(53)\end{array}$ & 0.75 & -2.67 & 8.06 & -18.84 & 13.50 & -0.09 \\
\hline My lack of effort & 2.25 & 0.14 & $\begin{array}{l}0.87 \\
(55)\end{array}$ & 0.39 & 7.04 & 7.98 & -8.96 & 23.04 & 0.23 \\
\hline Hard test & 2.44 & 0.12 & $\begin{array}{l}0.46 \\
(53)\end{array}$ & 0.65 & 3.70 & 7.99 & -12.32 & 19.73 & 0.12 \\
\hline Bad luck & 1.03 & 0.32 & $\begin{array}{c}-1.04 \\
(54)\end{array}$ & 0.30 & -7.57 & 7.38 & -22.36 & 7.22 & -0.28 \\
\hline My family & 1.67 & 0.20 & $\begin{array}{l}0.03 \\
(53)\end{array}$ & 0.98 & 0.20 & 6.92 & -13.67 & 14.07 & 0.01 \\
\hline My teachers & 0.00 & 0.96 & $\begin{array}{l}0.31 \\
(54)\end{array}$ & 0.76 & 1.85 & 6.03 & -10.24 & 13.95 & 0.08 \\
\hline My friends & 0.12 & 0.73 & $\begin{array}{l}-0.93 \\
(55)\end{array}$ & 0.57 & -3.70 & 6.40 & -16.53 & 9.12 & -0.15 \\
\hline
\end{tabular}

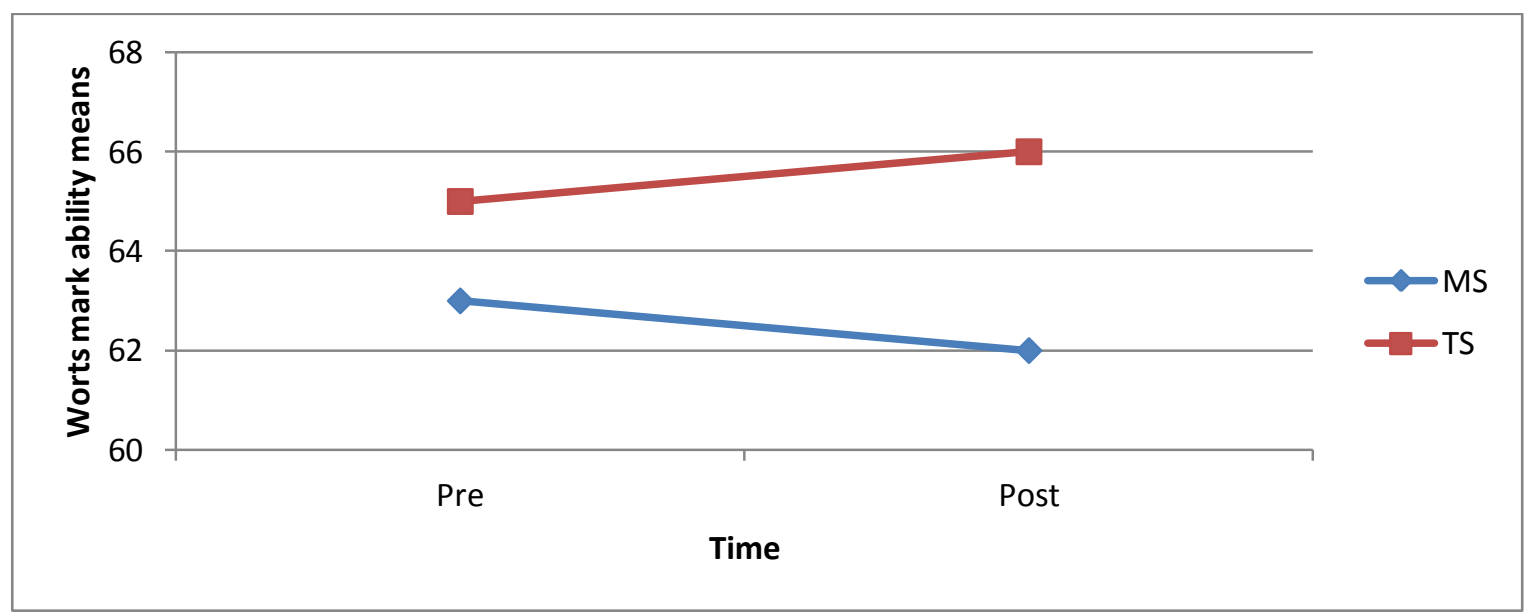

Figure 49. Worst mark ability - All students 


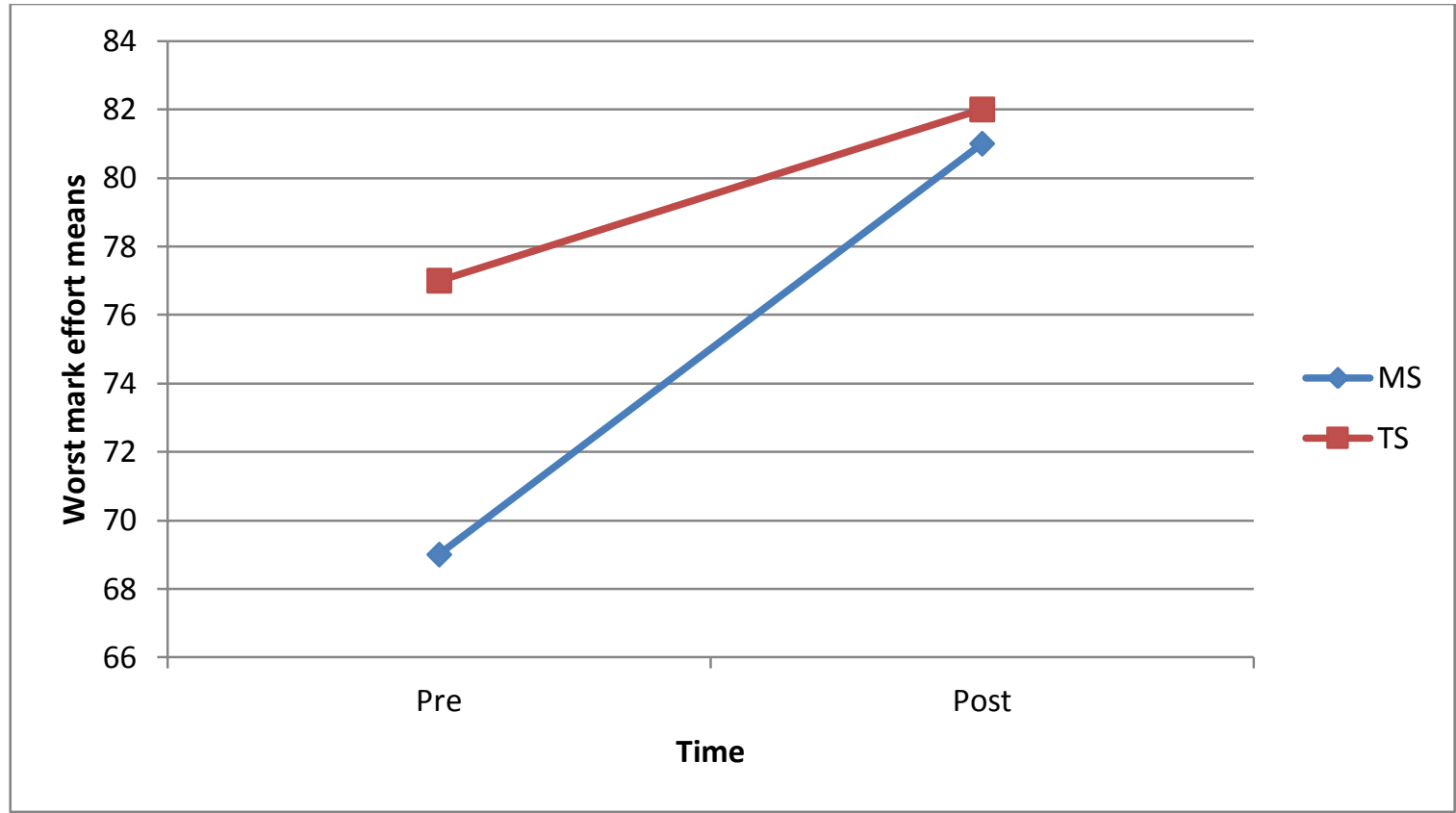

Figure 50. Worst mark effort - All students

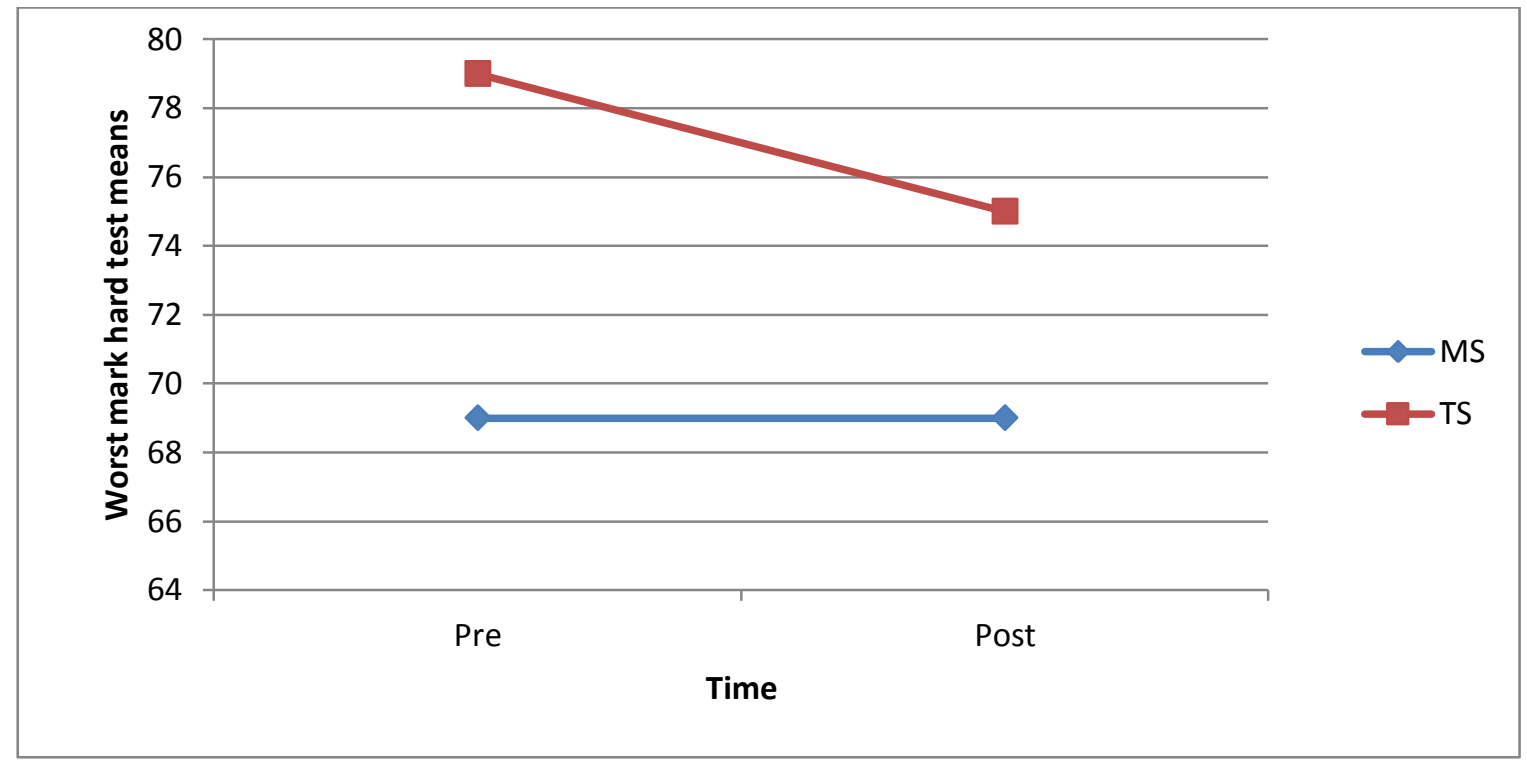

Figure 51. Worst mark hard test - All students 


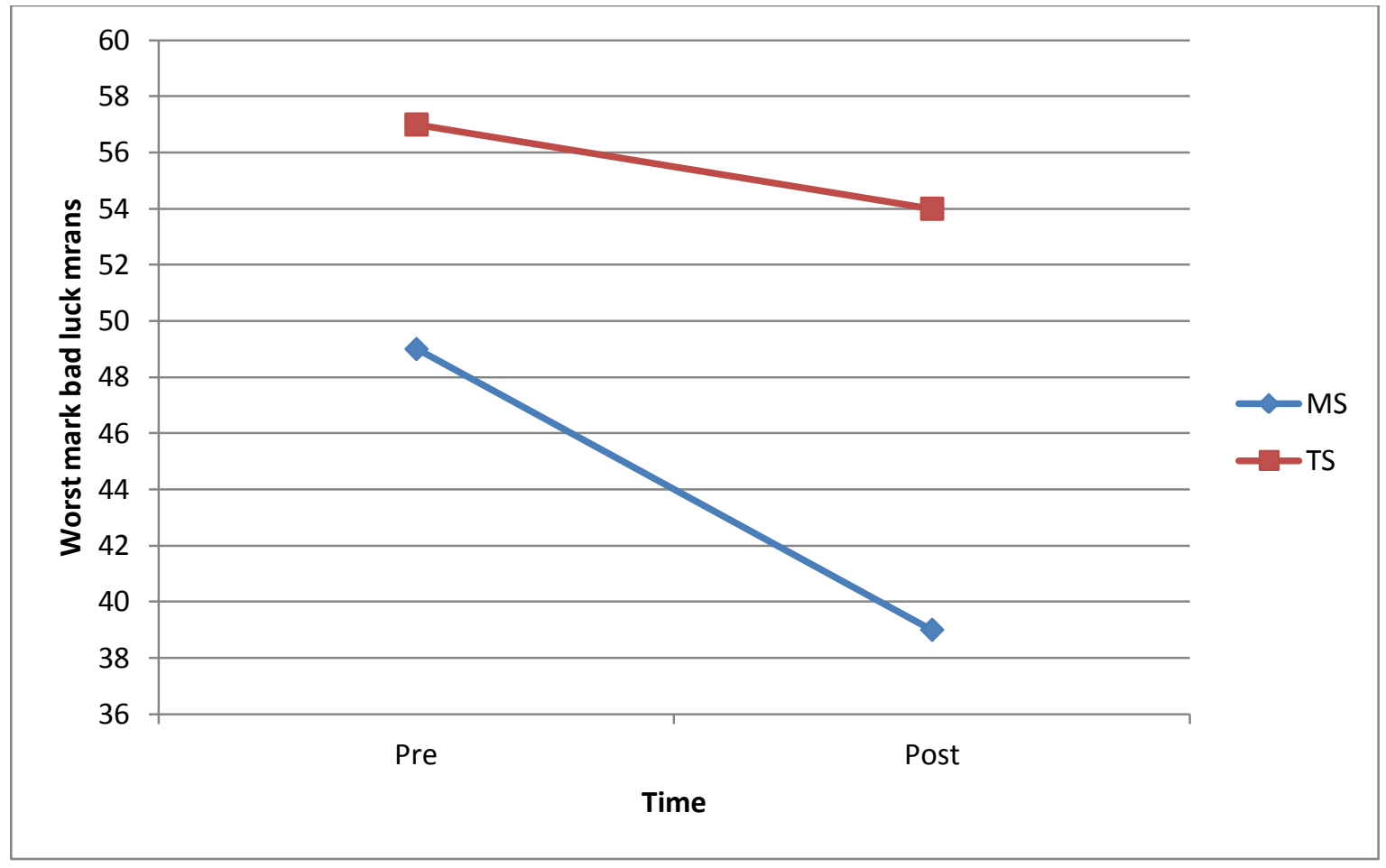

Figure 52. Worst mark bad luck - All students

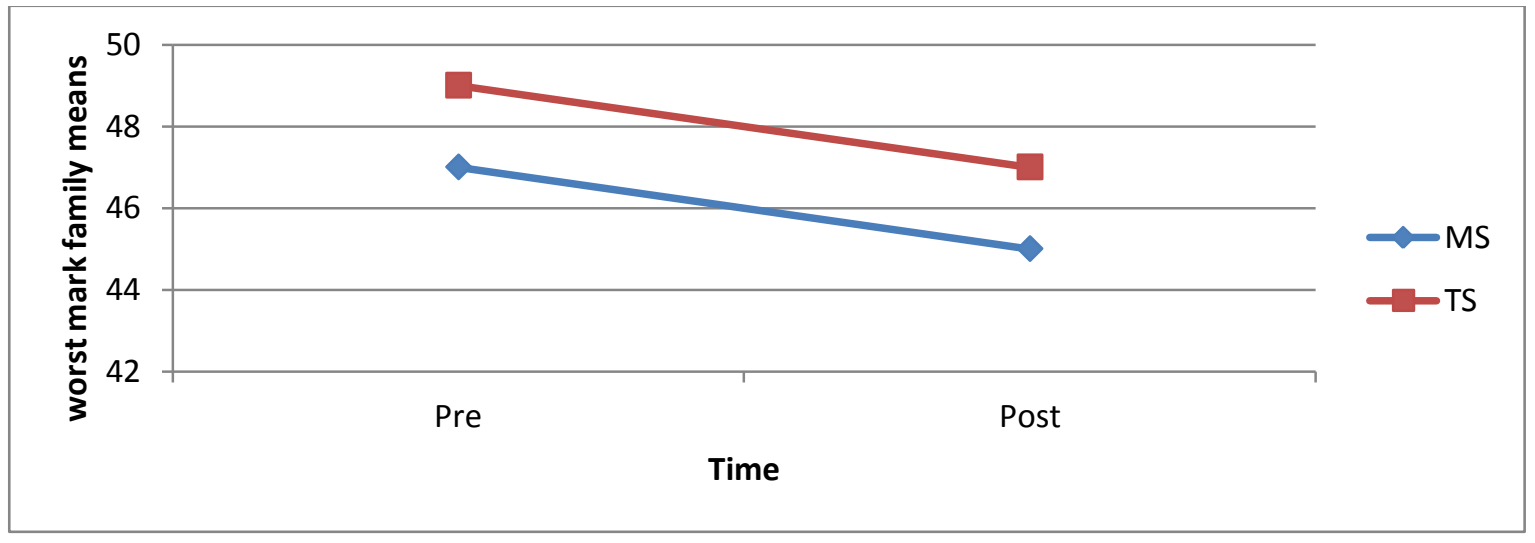

Figure 53. Worst mark family - All students 


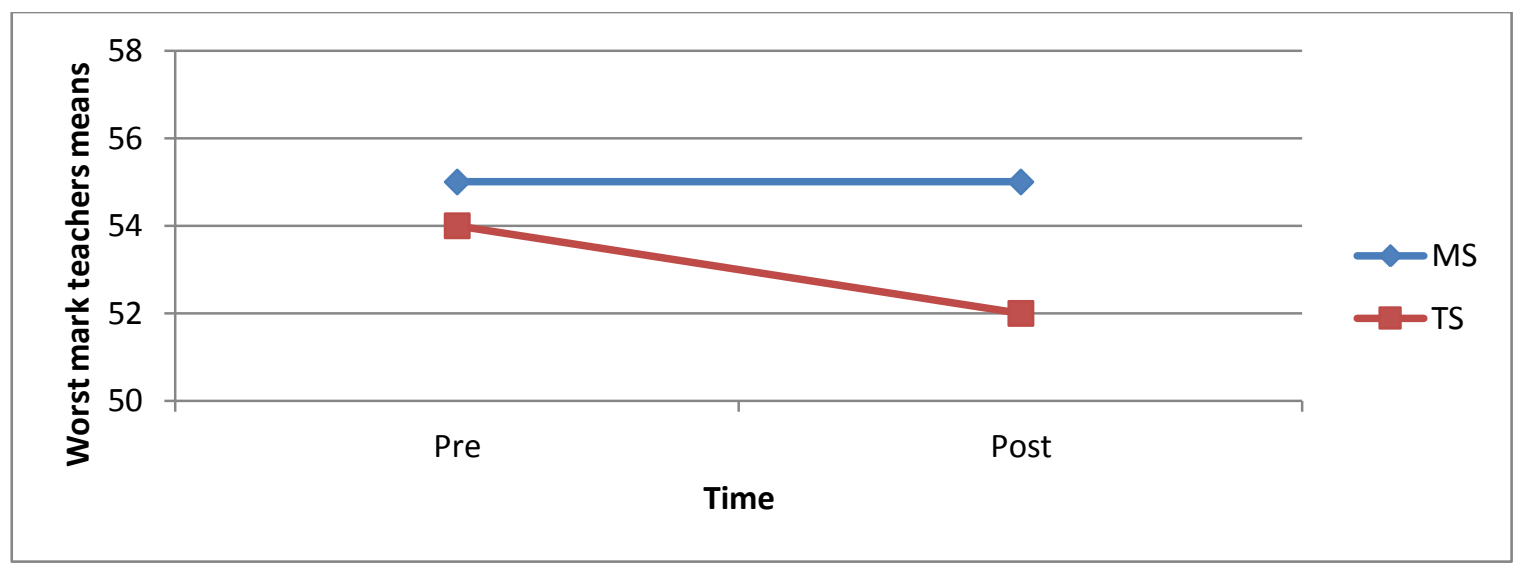

Figure 54. Worst mark teachers - All students

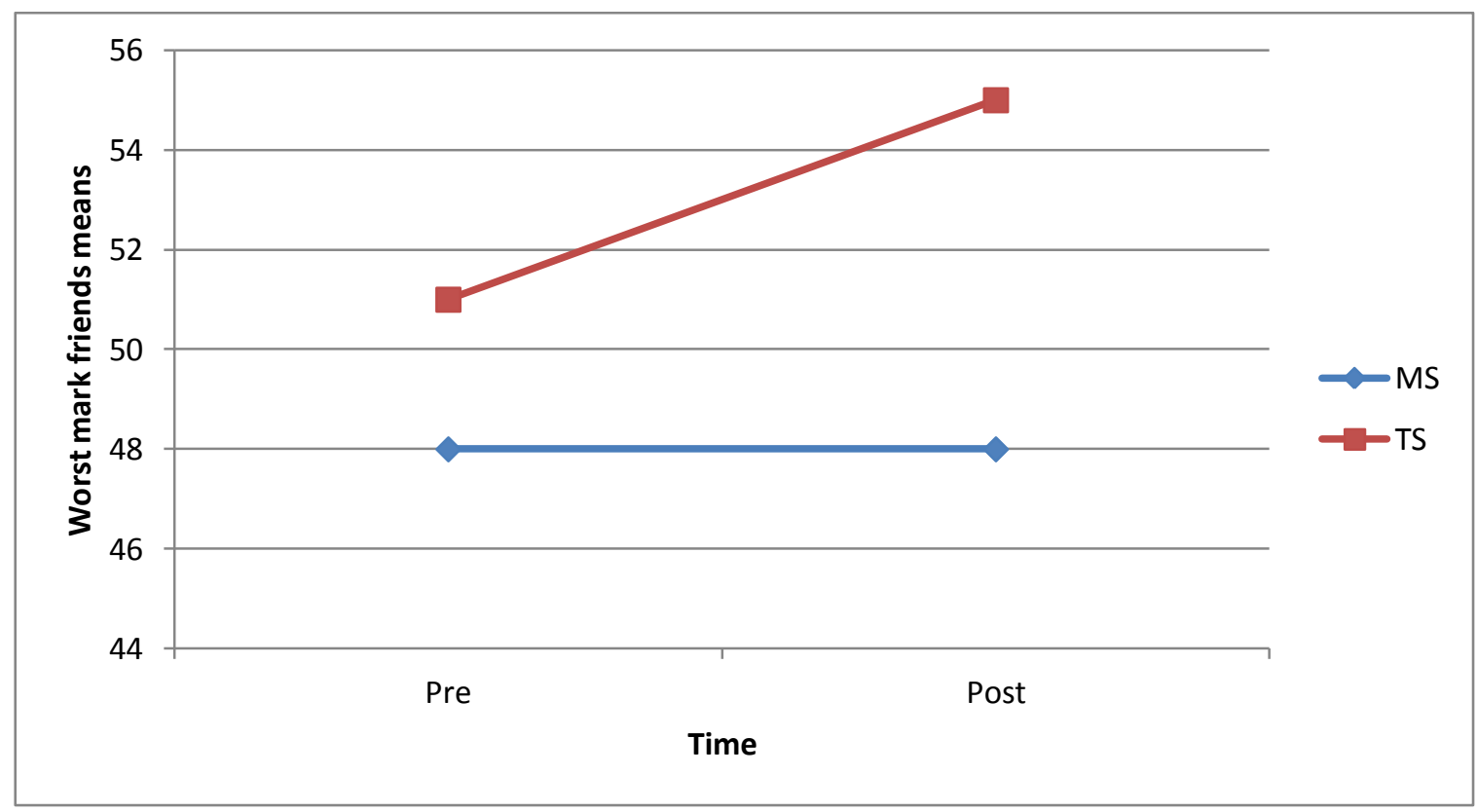

Figure 55. Worst mark friends - All students

Notable is the change in attributions for students in the MS group: students in the MS group overall increased their attribution of worst grades to effort and decreased their attribution of worst grades to luck, with moderate effect sizes evident for both attributions favouring the MS intervention. 


\section{Section Two: Changes in Attributions by Pasifika Students for worst marks in assessments}

Table 31 presents the means and standard deviations data for Pasifika students in each of the programmes and their reported attributions for worst marks in assessments before and after intervention.

\section{Table 31}

Attribution Means for Worst Marks for Pasifika Students Participating in the MS versus TS Programmes

\begin{tabular}{lcccc}
\hline $\begin{array}{l}\text { Worst marks } \\
\text { attributed to: }\end{array}$ & Group & N & Pre-test Mean (SD) & Post-test Mean (SD) \\
\hline My ability & MS & 16 & $64(24)$ & $53(26)$ \\
My lack of effort & TS & 12 & $68(25)$ & $64(23)$ \\
Hard test & MS & 16 & $70(25)$ & $77(27)$ \\
& TS & 12 & $73(25)$ & $83(20)$ \\
Bad luck & MS & 16 & $64(27)$ & $63(24)$ \\
My family & TS & 12 & $79(28)$ & $77(17)$ \\
& MS & 16 & $45(21)$ & $36(16)$ \\
My teachers & TS & 12 & $69(29)$ & $58(31)$ \\
My friends & MS & 16 & $50(26)$ & $48(25)$ \\
& TS & 12 & $54(28)$ & $56(30)$ \\
& MS & 16 & $55(19)$ & $50(24)$ \\
\hline
\end{tabular}

Table 32 presents the results of the independent samples tests for differences in change scores for attributions for worst marks in assessments for Pasifika students in the two intervention programmes. 


\section{Table 32}

Independent Samples Tests and Effect Size Calculations on Change Scores for Attributions for Worst Marks in Assessments for Pasifika Students in the MS versus TS Intervention Programmes

\begin{tabular}{lccccccccc}
\hline $\begin{array}{l}\text { Worst marks } \\
\text { attributed to: }\end{array}$ & F & Sig & t (df) & $\begin{array}{c}\text { Sig } \\
(\mathbf{2}- \\
\text { tailed) }\end{array}$ & $\begin{array}{c}\text { Mean } \\
\text { Diff }\end{array}$ & $\begin{array}{c}\text { Std } \\
\text { Error } \\
\text { Diff }\end{array}$ & $\begin{array}{c}95 \% \mathrm{Cl} \\
\text { Lower }\end{array}$ & $\begin{array}{c}95 \% \mathrm{Cl} \\
\text { Upper }\end{array}$ & $\begin{array}{c}\text { Cohen's } \\
\mathbf{d}\end{array}$ \\
\hline My ability & 4.02 & 0.06 & $\begin{array}{c}-0.46 \\
(25)\end{array}$ & 0.65 & -6.39 & 12.84 & -32.84 & 20.06 & -0.18 \\
My lack of effort & 1.10 & 0.30 & $\begin{array}{c}-0.32 \\
(26)\end{array}$ & 0.75 & -4.17 & 12.51 & -29.89 & 21.55 & -0.13 \\
Hard test & 1.96 & 0.17 & $\begin{array}{c}0.04 \\
(26)\end{array}$ & 0.97 & 0.52 & 11.54 & -23.20 & 24.24 & 0.02 \\
Bad luck & 2.26 & 0.14 & $\begin{array}{c}0.09 \\
(26)\end{array}$ & 0.93 & 1.04 & 11.97 & -23.57 & 25.65 & 0.04 \\
My family & 0.40 & 0.53 & $\begin{array}{c}-0.33 \\
(26)\end{array}$ & 0.74 & -3.65 & 10.56 & -25.34 & 18.05 & 0.13 \\
My teachers & 0.29 & 0.60 & $\begin{array}{c}-1.28 \\
(26)\end{array}$ & 0.21 & -10.94 & 8.20 & -27.79 & 5.91 & -0.54 \\
My friends & 1.53 & 0.23 & $\begin{array}{c}-1.22 \\
(26)\end{array}$ & 0.23 & -10.42 & 8.87 & -28.65 & 7.82 & -0.47 \\
& & & & & & & & & \\
\hline
\end{tabular}

These data show that generally there was little difference between Pasifika students in the kinds of changes to attributions for worst marks in assessment associated with participation in the two intervention programmes. However, medium effect sizes were evident for two of the social attributions for worst marks. On average, Pasifika students in the motivation-enhanced programme decreased attributing their worst marks to their teachers and to their friends following the intervention, whereas those in the traditional study skills programme increased these negative attributions (see also figures 56-62). 


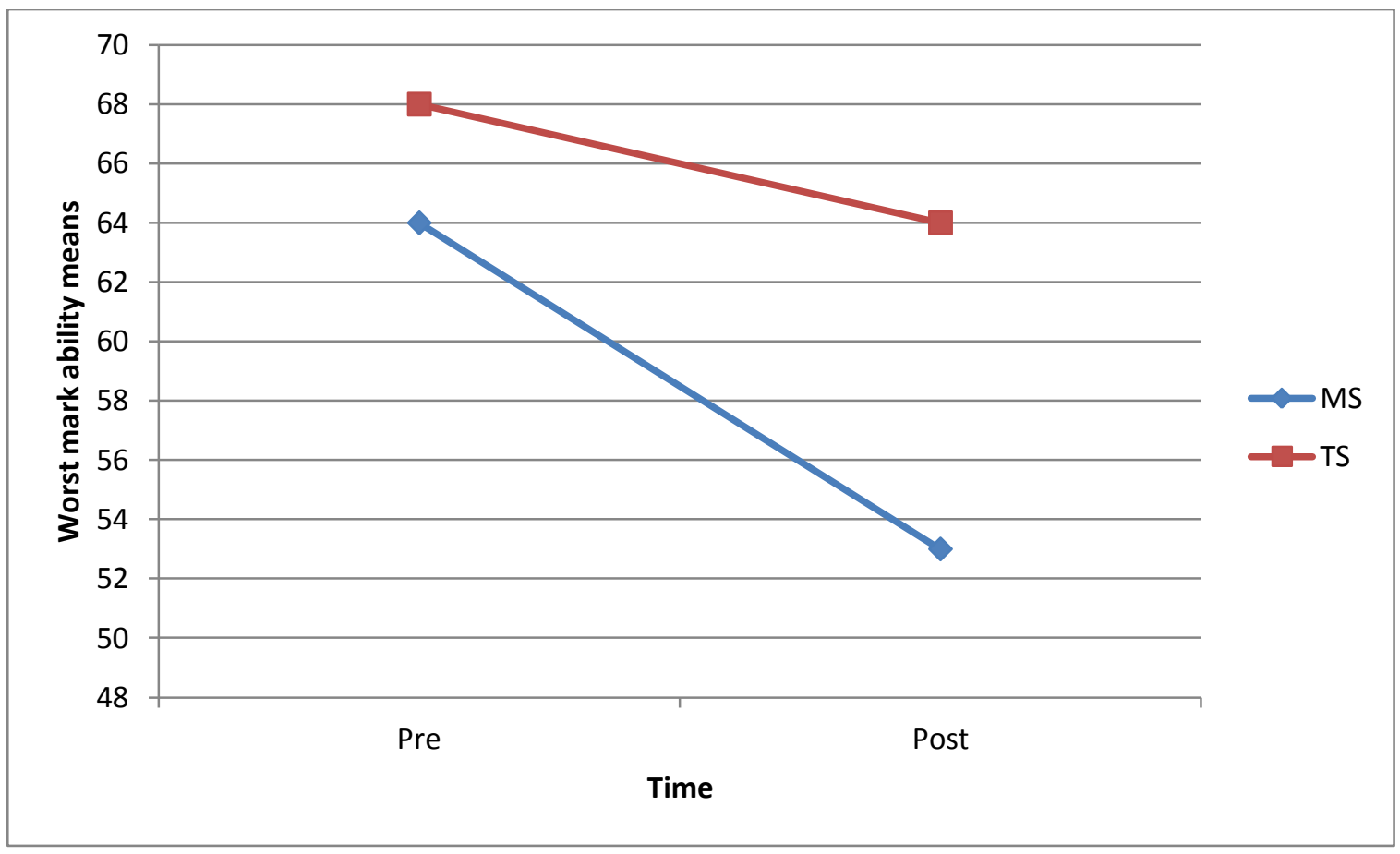

Figure 56. Worst mark ability — Pasifika students

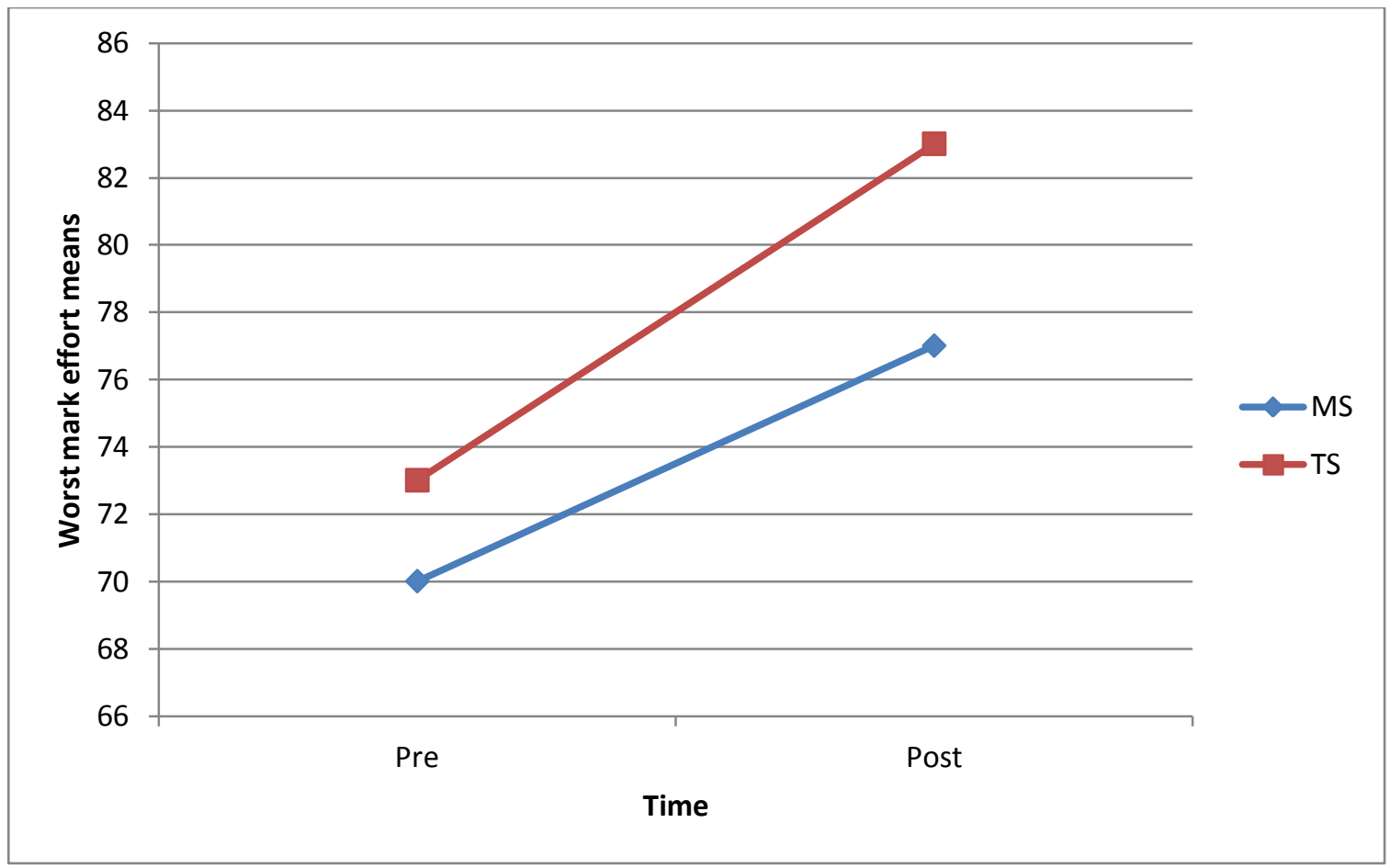

Figure 57. Worst mark effort — Pasifika students 


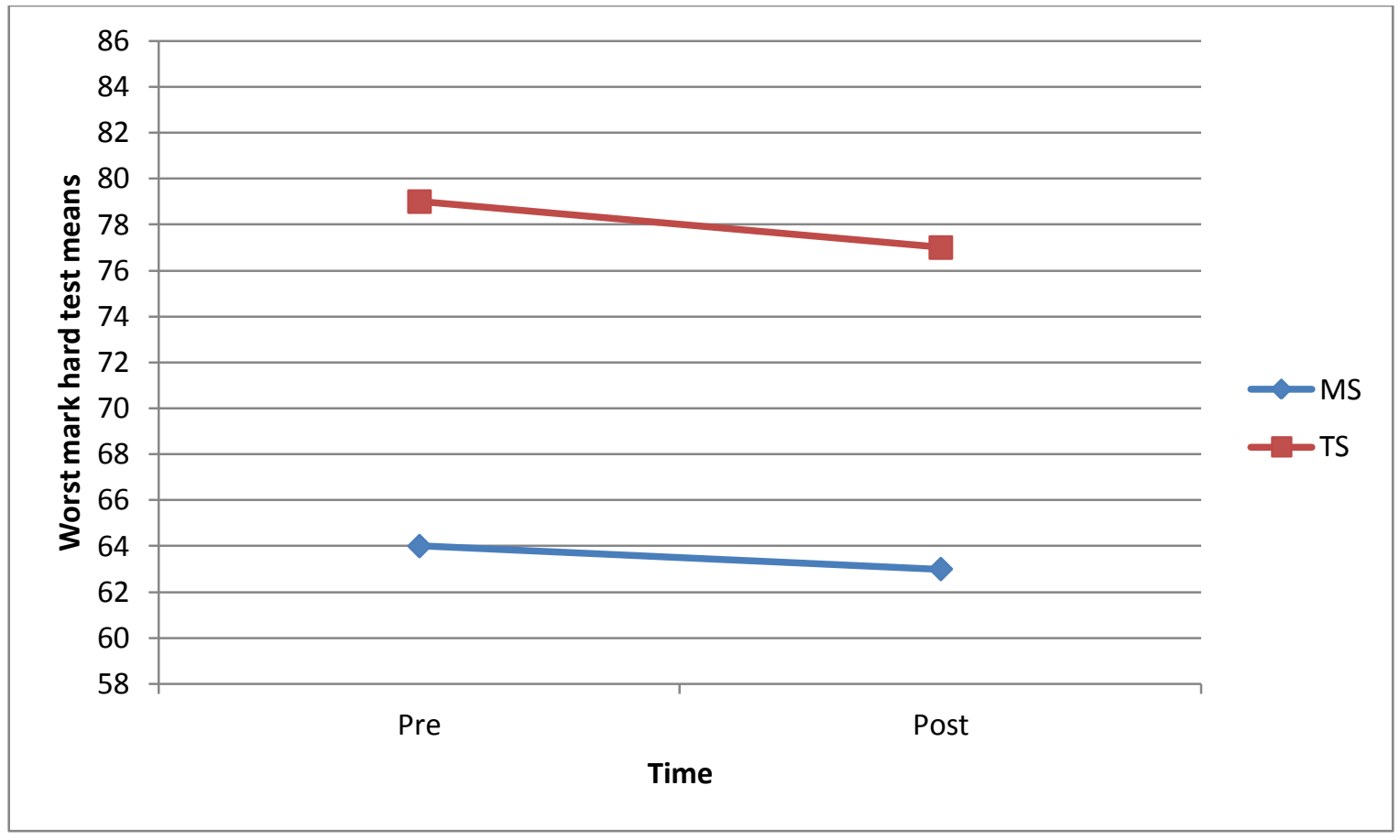

Figure 58. Worst mark hard test - Pasifika students

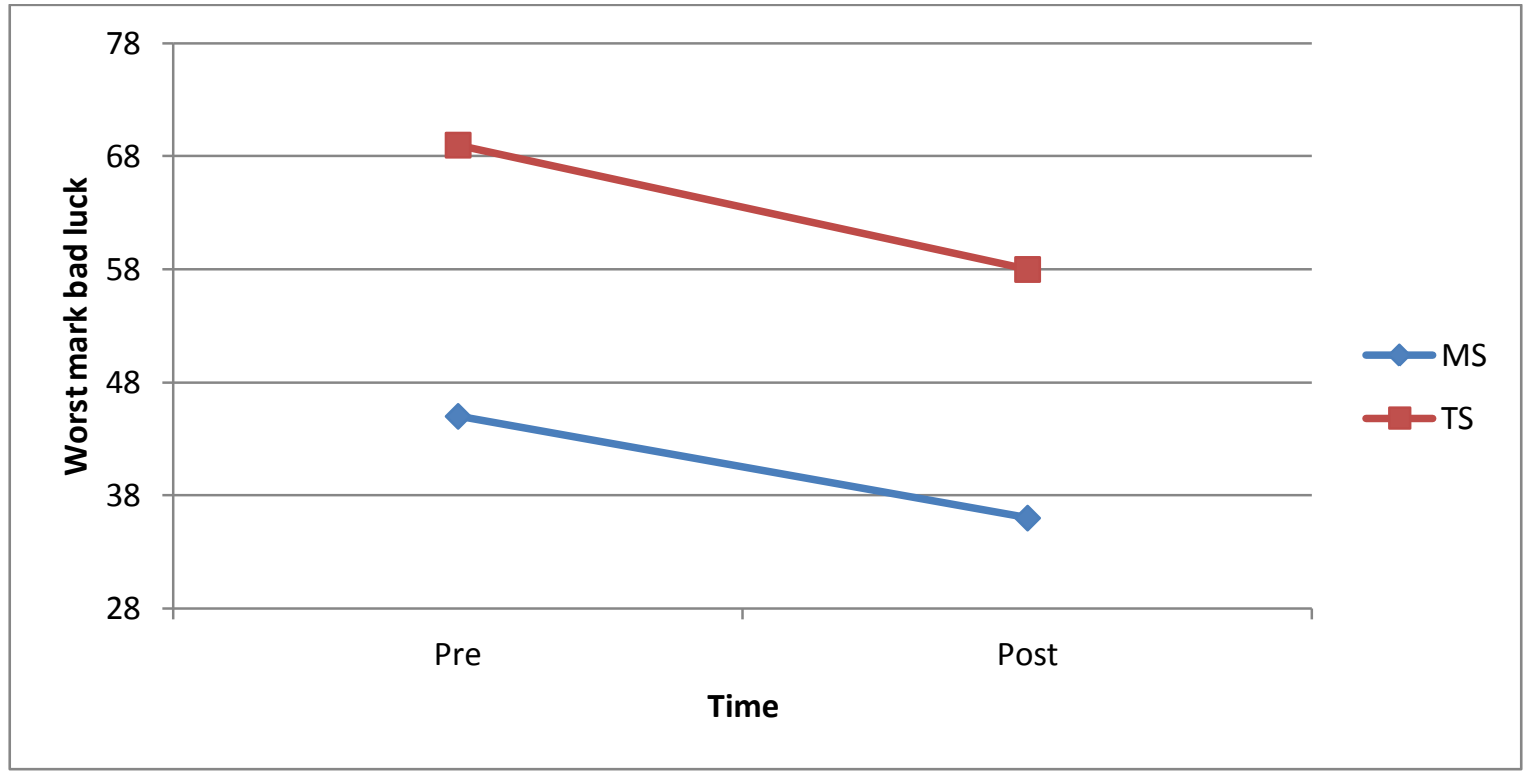

Figure 59. Worst mark bad luck — Pasifika students 


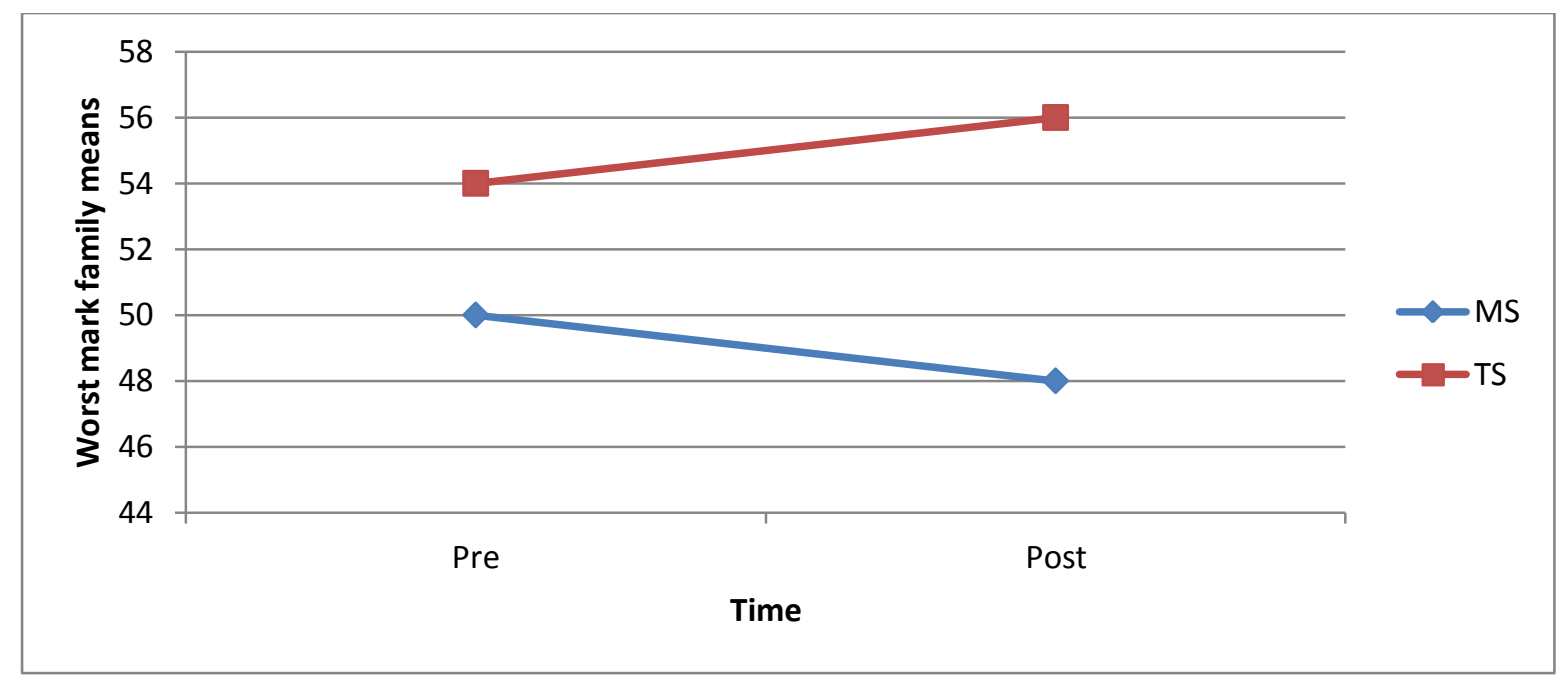

Figure 60. Worst mark family — Pasifika students

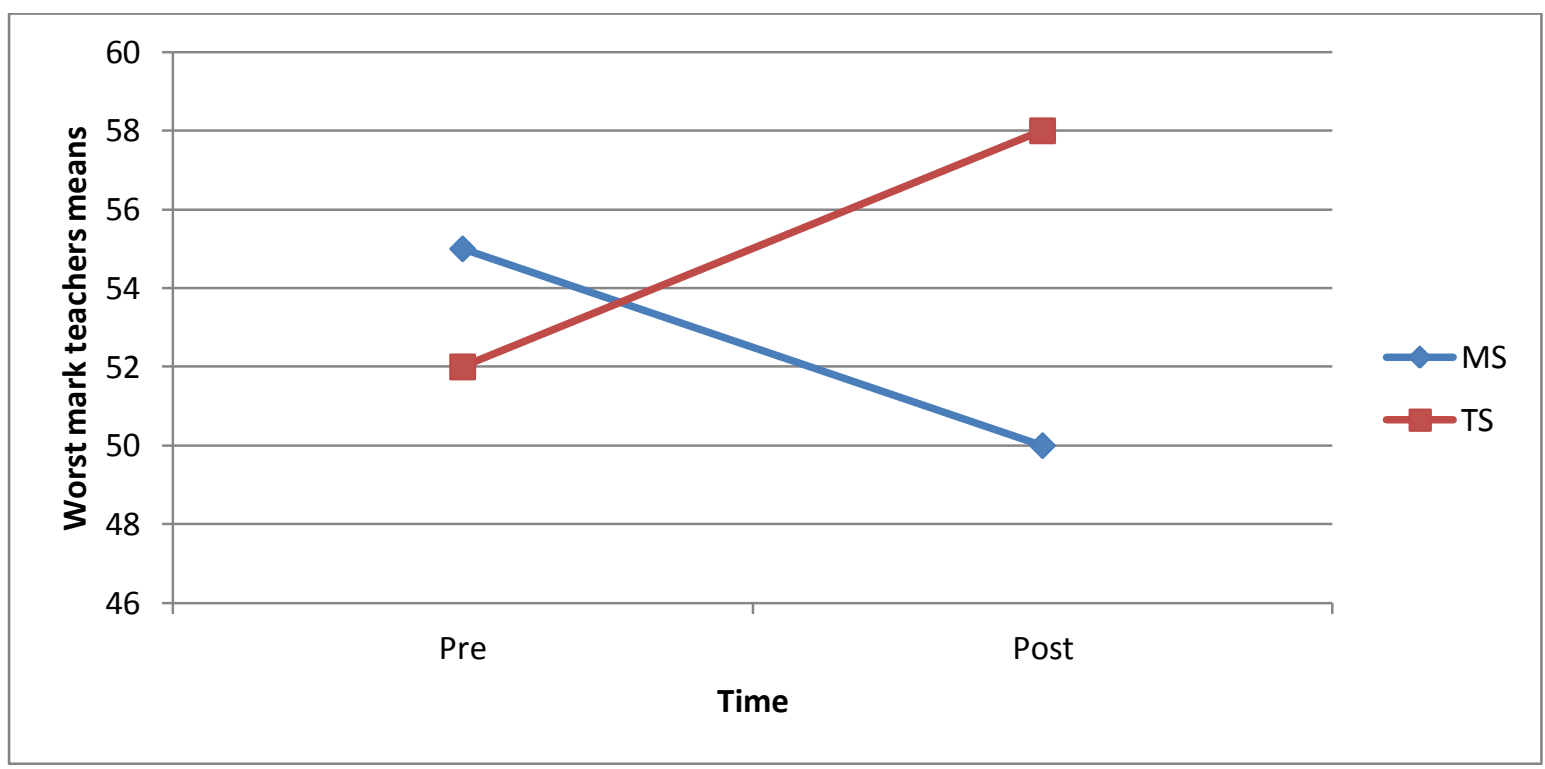

Figure 61. Worst mark teachers - Pasifika students 


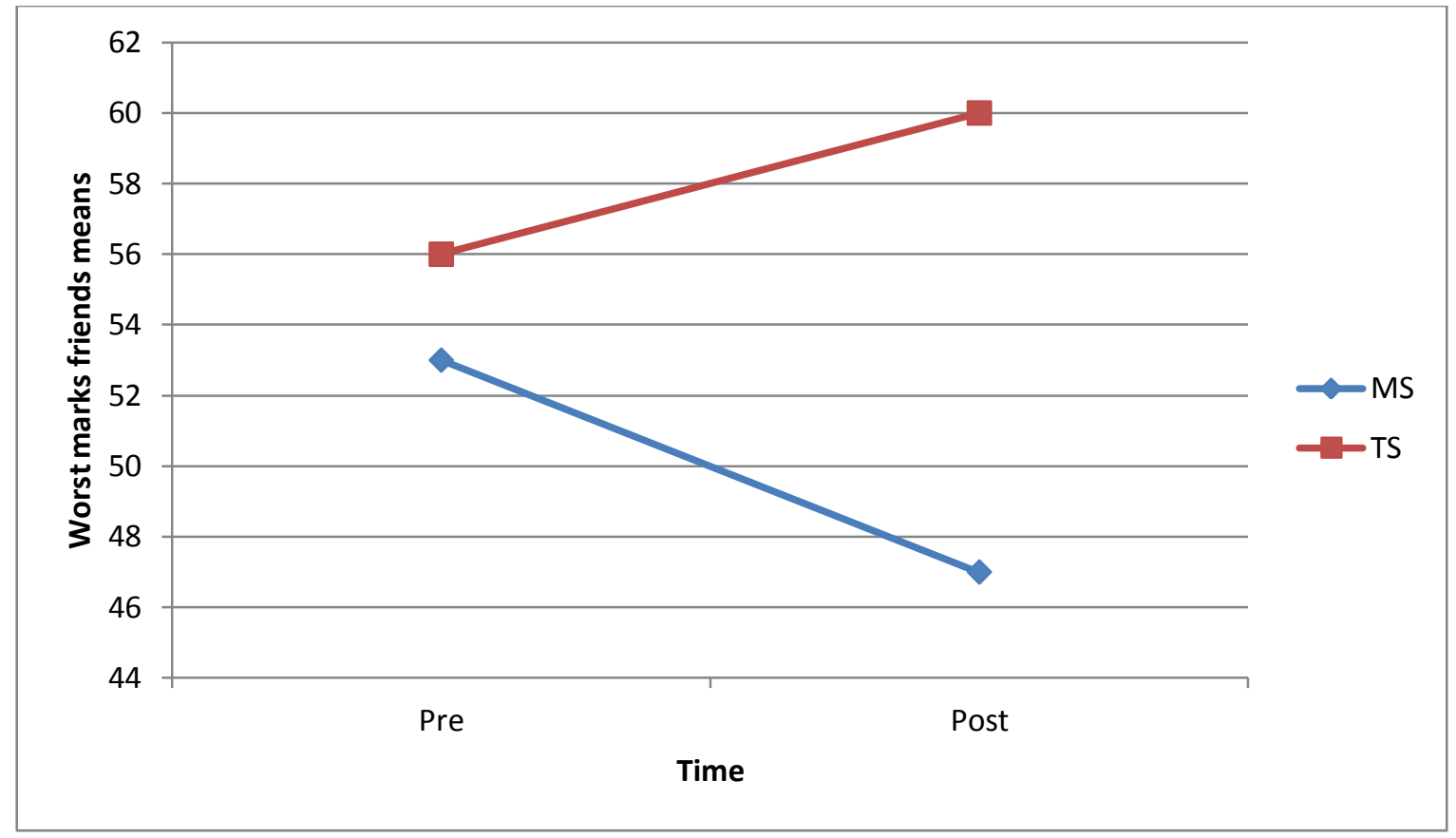

Figure 62. Worst mark friends - Pasifika students

\section{Analysis Eight: Changes in Attendance}

This study measured changes in attendance before and after intervention to see if there were differences in attendance associated with the MS and TS programmes.

\section{Section One: Changes in Attendance for All Students in the MS and TS Programmes}

Table 33 presents the means and standard deviations data on attendance measured before and after participation in the programmes. 
Table 33

Attendance Means for All Students Participating in the MS versus TS Programmes

\begin{tabular}{lcccc}
\hline Variable & Group & N & Pre-test Mean (SD) & Post-test Mean (SD) \\
\hline Attendance & MS & 30 & $83(18)$ & $78(23)$ \\
& TS & 27 & $85(11)$ & $78(20)$ \\
\hline
\end{tabular}

Table 34 presents the results of the independent samples tests for differences in attendance for all students in the two intervention programmes.

\section{Table 34}

Independent Samples Tests and Effect Size Calculations on Change Scores for Attendance for All Students in the MS versus TS Intervention Programmes

\begin{tabular}{lccccccccc}
\hline Variable & F & Sig & t (df) & $\begin{array}{c}\text { Sig (2- } \\
\text { tailed) }\end{array}$ & $\begin{array}{c}\text { Mean } \\
\text { Diff }\end{array}$ & $\begin{array}{c}\text { Std Error } \\
\text { Diff }\end{array}$ & $\begin{array}{c}95 \% \mathrm{Cl} \\
\text { Lower }\end{array}$ & $\begin{array}{c}95 \% \mathrm{Cl} \\
\text { Upper }\end{array}$ & $\begin{array}{c}\text { Cohen's } \\
\mathbf{d}\end{array}$ \\
\hline Attendance & 0.01 & 0.93 & $0.39(55)$ & 0.70 & 1.58 & 4.03 & -6.49 & 9.66 & 0.10 \\
\hline
\end{tabular}

Mean attendance declined similarly for all students regardless of programme, and there was no significant difference between the groups on this factor (see also figure 63).

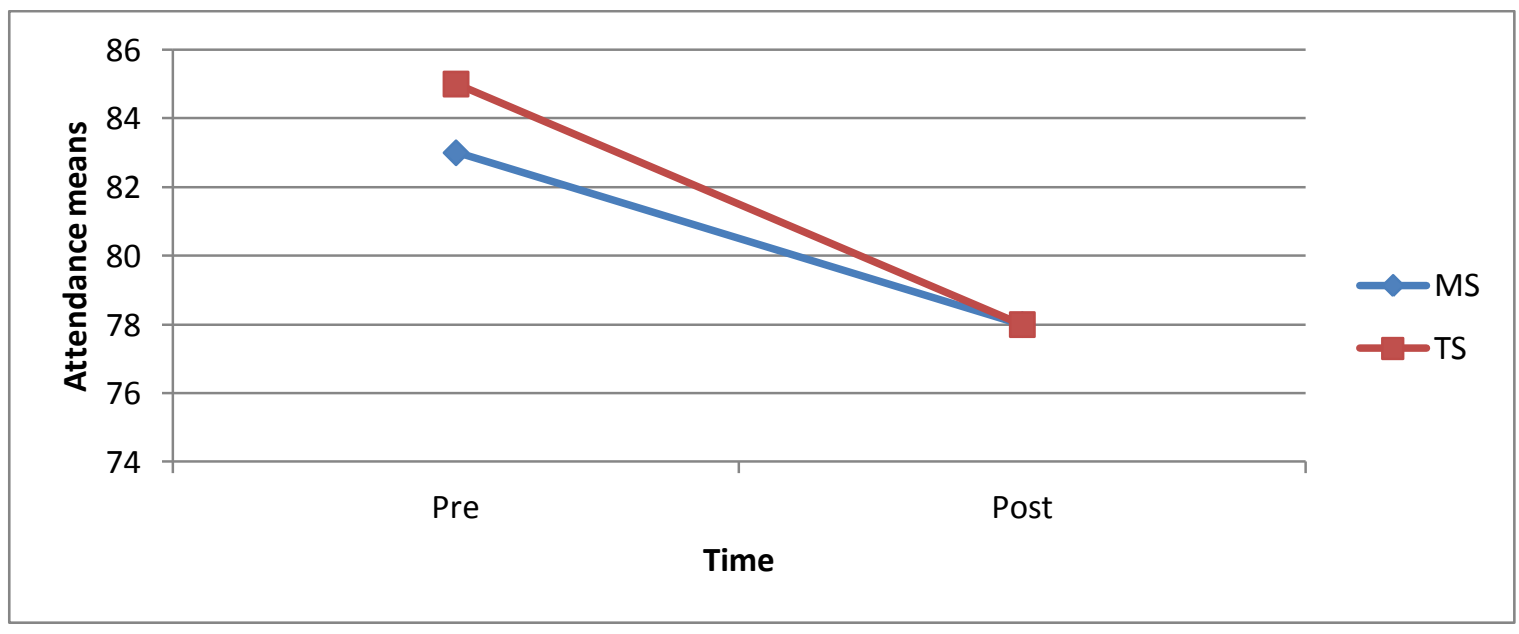

Figure 63. Attendance - All students 


\section{Section Two: Changes in Attendance for Pasifika Students in the MS and TS Programmes}

Table 35 presents the means and standard deviations attendance data for Pasifika students before and after participation in the two programmes.

\section{Table 35}

Attendance Means for Pasifika Students Participating in the MS versus TS Programmes

\begin{tabular}{lcccc}
\hline Variable & Group & N & Pre-test Mean (SD) & Post-test Mean (SD) \\
\hline Attendance & MS & 16 & $80(23)$ & $70(28)$ \\
& TS & 12 & $79(13)$ & $77(19)$ \\
\hline
\end{tabular}

Table 36 presents data from independent samples tests on differences in attendance for Pasifika students in the two intervention programmes.

\section{Table 36}

Independent Samples Tests and Effect Size Calculations on Change Scores for Attendance for Pasifika Students in the MS versus TS Intervention Programmes

\begin{tabular}{lccccccccc}
\hline Variable & F & Sig & t (df) & $\begin{array}{c}\text { Sig } \\
\text { (2-tailed) }\end{array}$ & $\begin{array}{c}\text { Mean } \\
\text { Diff }\end{array}$ & $\begin{array}{c}\text { Std Error } \\
\text { Diff }\end{array}$ & $\begin{array}{c}95 \% \mathrm{Cl} \\
\text { Lower }\end{array}$ & $\begin{array}{c}\mathbf{9 5 \%} \mathrm{Cl} \\
\text { Upper }\end{array}$ & $\begin{array}{c}\text { Cohen's } \\
\mathbf{d}\end{array}$ \\
\hline Attendance & 0.28 & 0.60 & $-1.30(26)$ & 0.20 & -7.23 & 5.38 & -18.28 & 3.82 & -0.50 \\
\hline
\end{tabular}

Mean attendance by Pasifika students pre-intervention was almost equal across the two groups. When measured following participation in the two programmes, attendance decreased very slightly for the TS group but considerably more for the MS group. Although the difference was not statistically significant (affected by the small sample size and consequent lack of statistical power), the medium effect size indicates that Pasifika students in the traditional study skills programme did not decrease attendance as much as those in the motivation-enhanced programme. Indeed, at 
post-test, the comparison group mean attendance was higher than that of the students in the experimental programme (see also figure 64).

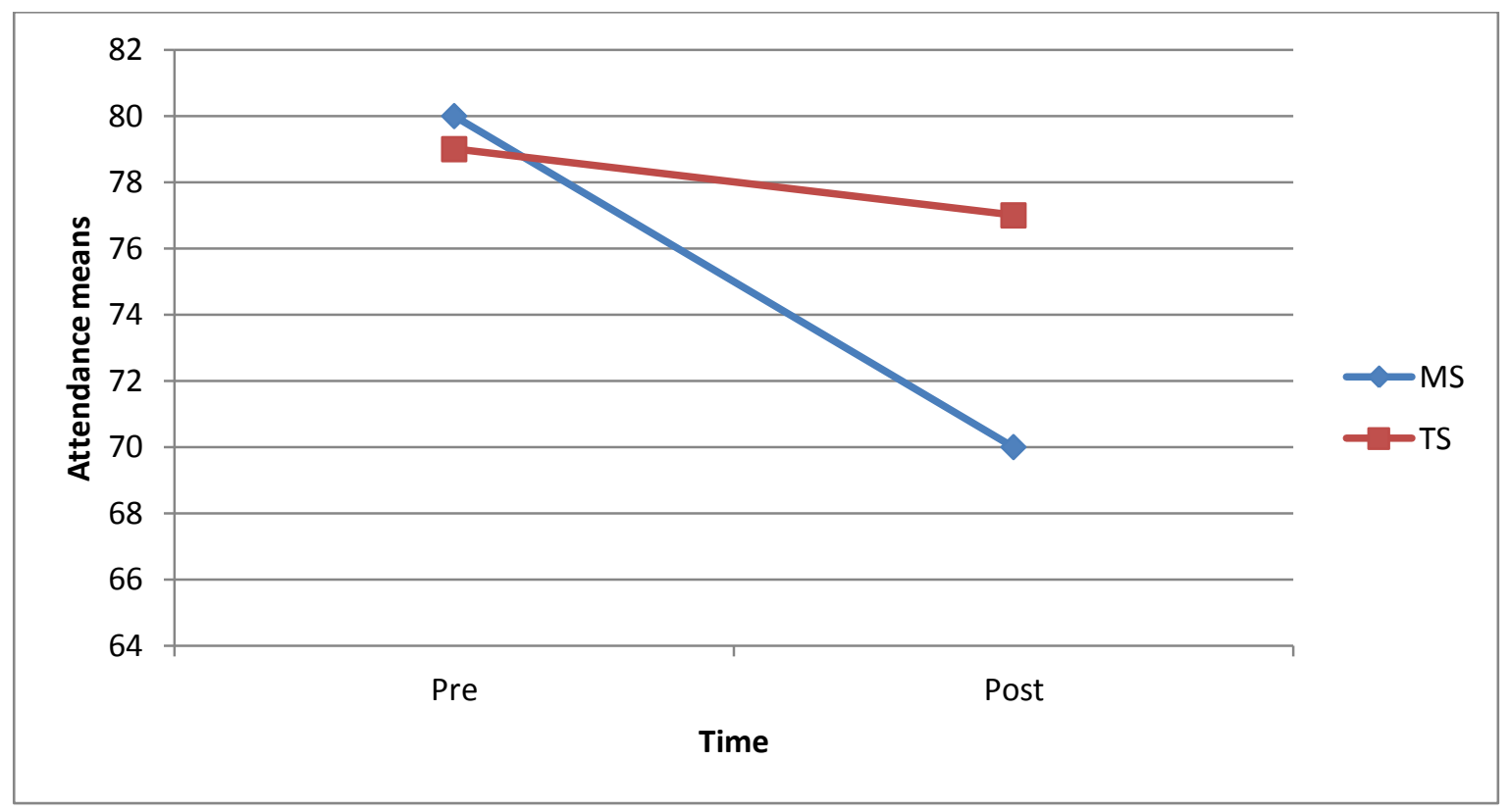

Figure 64. Attendance — Pasifika students

\section{Analysis Nine: Changes in Disengagement}

This study measured changes in student ratings on disengagement before and after intervention to investigate for differences in disengagement by group (see also Appendix C for a copy of the survey questions).

\section{Section One: Changes in Disengagement for All Students in the MS and TS Programmes}

Table 37 presents the means and standard deviations of student ratings for disengagement before and after participation in the two intervention programmes. 


\section{Table 37}

Disengagement Means for All Students Participating in the MS versus TS Programmes

\begin{tabular}{lcccc}
\hline Variable & Group & N & Pre-test Mean (SD) & Post-test Mean (SD) \\
\hline Disengagement & MS & 30 & $35(15)$ & $33(18)$ \\
& TS & 27 & $38(21)$ & $44(24)$ \\
\hline
\end{tabular}

Table 38 presents the results of the independent samples tests for differences in disengagement for all students in the two intervention programmes.

\section{Table 38}

Independent Samples Tests and Effect Size Calculations on Change Scores for Disengagement for All Students in the MS versus TS Intervention Programmes

\begin{tabular}{lccccccccc}
\hline Variable & F & Sig & t (df) & $\begin{array}{c}\text { Sig } \\
\text { (2-tailed) }\end{array}$ & $\begin{array}{c}\text { Mean } \\
\text { Diff }\end{array}$ & $\begin{array}{c}\text { Std } \\
\text { Error } \\
\text { Diff }\end{array}$ & $\begin{array}{c}95 \% \mathrm{Cl} \\
\text { Lower }\end{array}$ & $\begin{array}{c}95 \% \mathrm{Cl} \\
\text { Upper }\end{array}$ & $\begin{array}{c}\text { Cohen's } \\
\mathbf{d}\end{array}$ \\
\hline Disengagement & 0.46 & 0.50 & $-1.66(54)$ & 0.10 & -7.84 & 4.69 & -17.24 & 1.56 & -0.43 \\
\hline
\end{tabular}

These data show that disengagement ratings declined slightly for students in the MS programme but increased for those in the TS programme (see also figure 65).

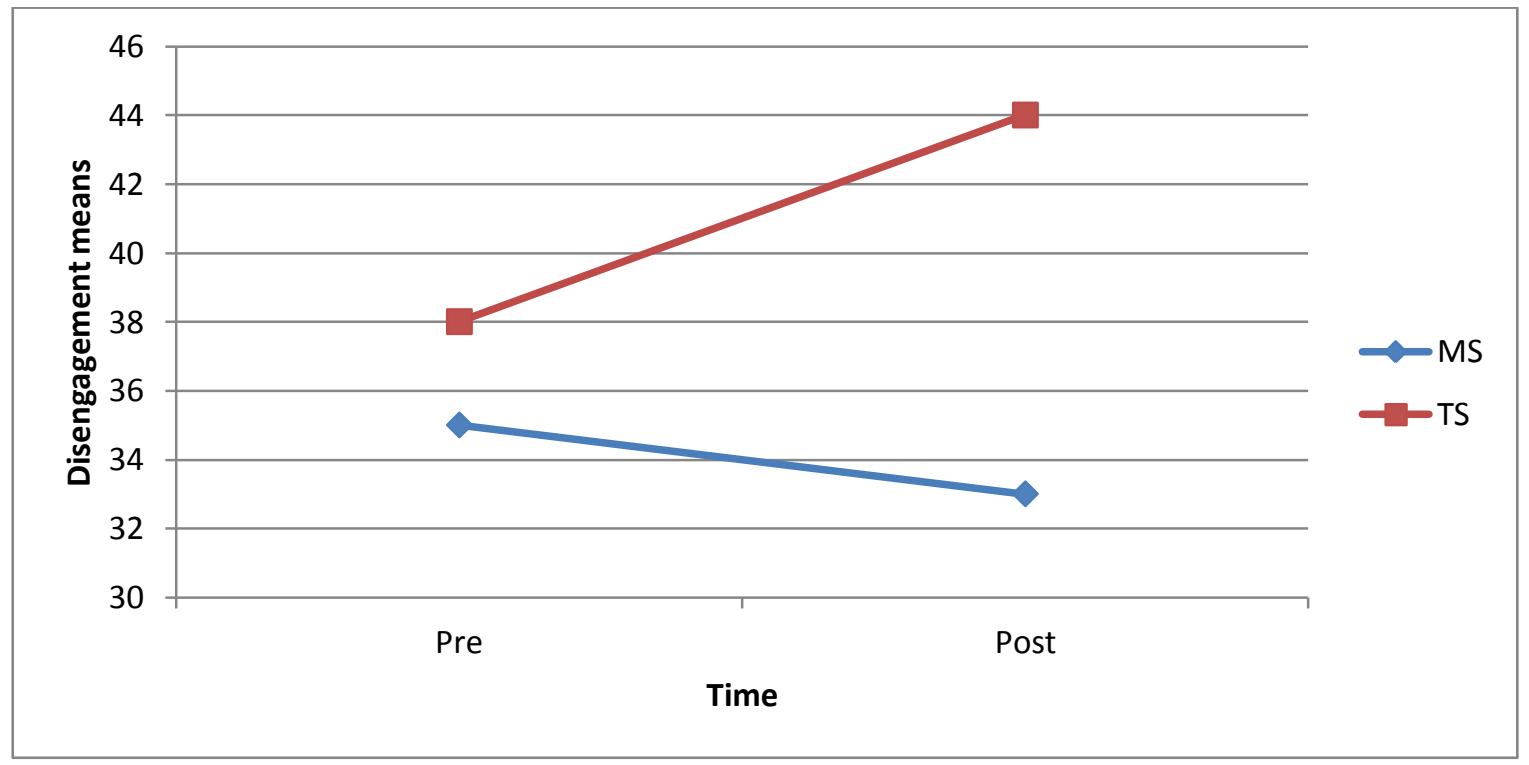

Figure 65. Disengagement - All students 
While the differences were not statistically significant (probably due to the small sample size affecting power), the effect size analysis suggests a small to medium effect indicating that students in the comparison programme were more engaged with school than those in the experimental programme following participation in the intervention.

\section{Section Two: Changes in Disengagement for Pasifika Students in the MS and TS Programmes}

Table 39 presents the means and standard deviations for disengagement ratings for Pasifika students before and after participation in the two programmes.

\section{Table 39}

Disengagement Means for Pasifika Students Participating in the MS versus TS Programmes

\begin{tabular}{lcccc}
\hline Variable & Group & N & Pre-test Mean (SD) & Post-test Mean (SD) \\
\hline Disengagement & MS & 16 & $40(16)$ & $37(23)$ \\
& TS & 12 & $37(19)$ & $39(20)$ \\
\hline
\end{tabular}

Table 40 presents the results of the independent samples tests for differences in disengagement for Pasifika students associated with participation in the two intervention programmes.

\section{Table 40}

Independent Samples Tests and Effect Size Calculations on Change Scores for Disengagement for Pasifika Students in the MS versus TS Intervention Programmes

\begin{tabular}{lccccccccc}
\hline Variable & F & Sig & $\mathbf{t}(\mathbf{d f})$ & $\begin{array}{c}\text { Sig (2- } \\
\text { tailed) }\end{array}$ & $\begin{array}{c}\text { Mean } \\
\text { Diff }\end{array}$ & $\begin{array}{c}\text { Std Error } \\
\text { Diff }\end{array}$ & $\begin{array}{c}\text { 95\% Cl } \\
\text { Lower }\end{array}$ & $\begin{array}{c}\text { 95\% Cl } \\
\text { Upper }\end{array}$ & $\begin{array}{c}\text { Cohen's } \\
\mathbf{d}\end{array}$ \\
\hline $\begin{array}{l}\text { Disengage } \\
\text { ment }\end{array}$ & 1.99 & 0.17 & $\begin{array}{c}-0.63 \\
(25)\end{array}$ & 0.53 & -4.63 & 6.67 & -18.37 & 9.11 & -0.25 \\
\hline
\end{tabular}


The pattern of change in disengagement ratings for Pasifika students before and after intervention was similar to that observed for all students. Pasifika students in the MS programme reported a slight decrease and those in the TS programme a slight increase in disengagement following participation in their respective interventions (see also figure 66). Small effects favouring the TS skills programme were also supported by the effect size analysis.

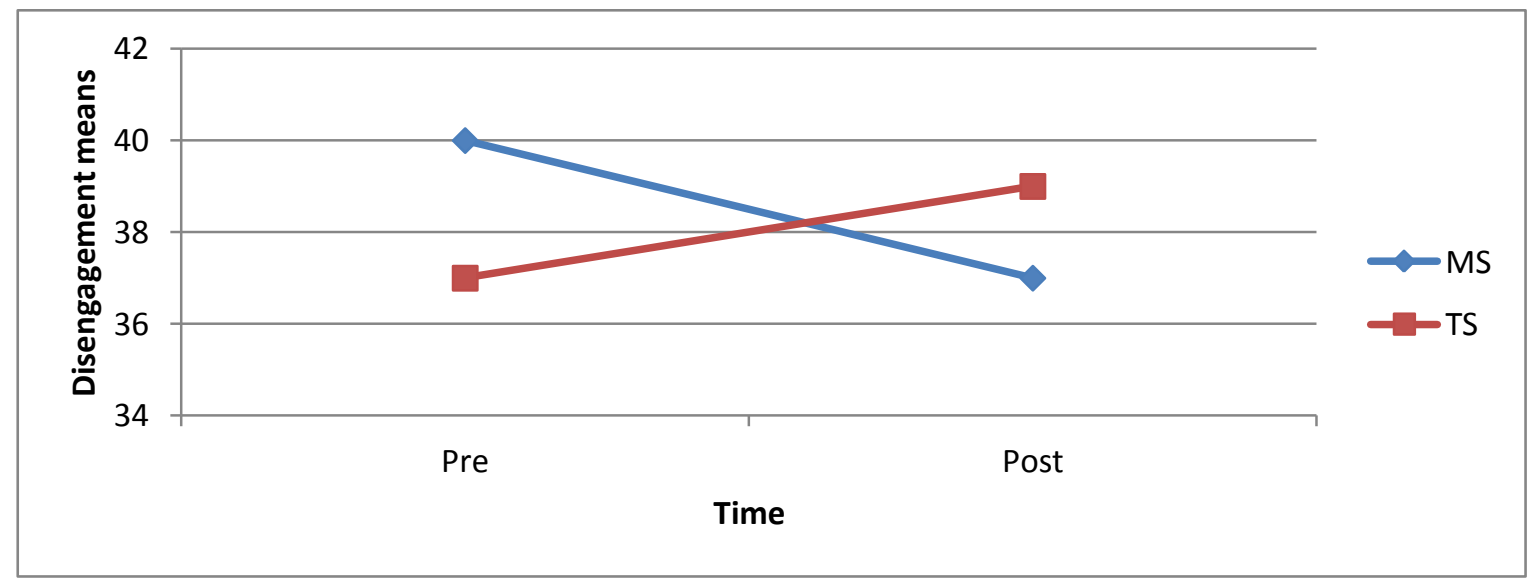

Figure 66. Disengagement - Pasifika students

\section{Analysis Ten: Changes in Aspiration}

This study measured changes in aspiration after intervention compared with selfreported aspiration before intervention to investigate for differences as a function of programme participation (see also Appendix D for a copy of the questions to measure aspiration). Students were asked to indicate the highest level of NCEA certificate they expected to attain, from none to the highest (Level 3). 


\section{Section One: Changes in Aspiration for All Students in the MS and TS Programmes}

Table 41 presents the means and standard deviations for students' aspirations ratings before and after participation in the two programmes.

\section{Table 41}

Aspiration Means for All Students Participating in the MS versus TS Programmes

\begin{tabular}{lcccc}
\hline Variable & Group & $\mathbf{N}$ & Pre-test Mean (SD) & Post-test Mean (SD) \\
\hline Aspiration & MS & 30 & $2.30(0.84)$ & $2.76(0.44)$ \\
& TS & 27 & $2.15(0.86)$ & $2.48(0.51)$ \\
\hline
\end{tabular}

Table 42 presents the results of the independent samples tests for differences in aspirations for all students in the two intervention programmes.

\section{Table 42}

Independent Samples Tests and Effect Size Calculations on Change Scores for Aspirations for all Students in the MS versus TS Intervention Programmes

\begin{tabular}{lccccccccc}
\hline Variable & F & Sig & $\mathbf{t}(\mathbf{d f})$ & $\begin{array}{c}\text { Sig (2- } \\
\text { tailed) }\end{array}$ & $\begin{array}{c}\text { Mean } \\
\text { Diff }\end{array}$ & $\begin{array}{c}\text { Std Error } \\
\text { Diff }\end{array}$ & $\begin{array}{c}\mathbf{9 5 \%} \mathrm{Cl} \\
\text { Lower }\end{array}$ & $\begin{array}{c}\mathbf{9 5 \%} \mathrm{Cl} \\
\text { Upper }\end{array}$ & $\begin{array}{c}\text { Cohen's } \\
\mathbf{d}\end{array}$ \\
\hline Aspiration & 2.86 & 0.10 & 0.95 & 0.35 & 0.17 & 0.18 & -0.20 & 0.53 & $\mathbf{0 . 2 6}$ \\
& & & $(55)$ & & & & & & \\
\hline
\end{tabular}

Both groups increased aspirations for completion of the NCEA following intervention, and, interestingly, the standard deviation in both groups decreased as well indicating less spread within both intervention groups after programme participation (see also figure 67). The differences were not statistically significant, however, and the effect size favouring the MS group was small. 


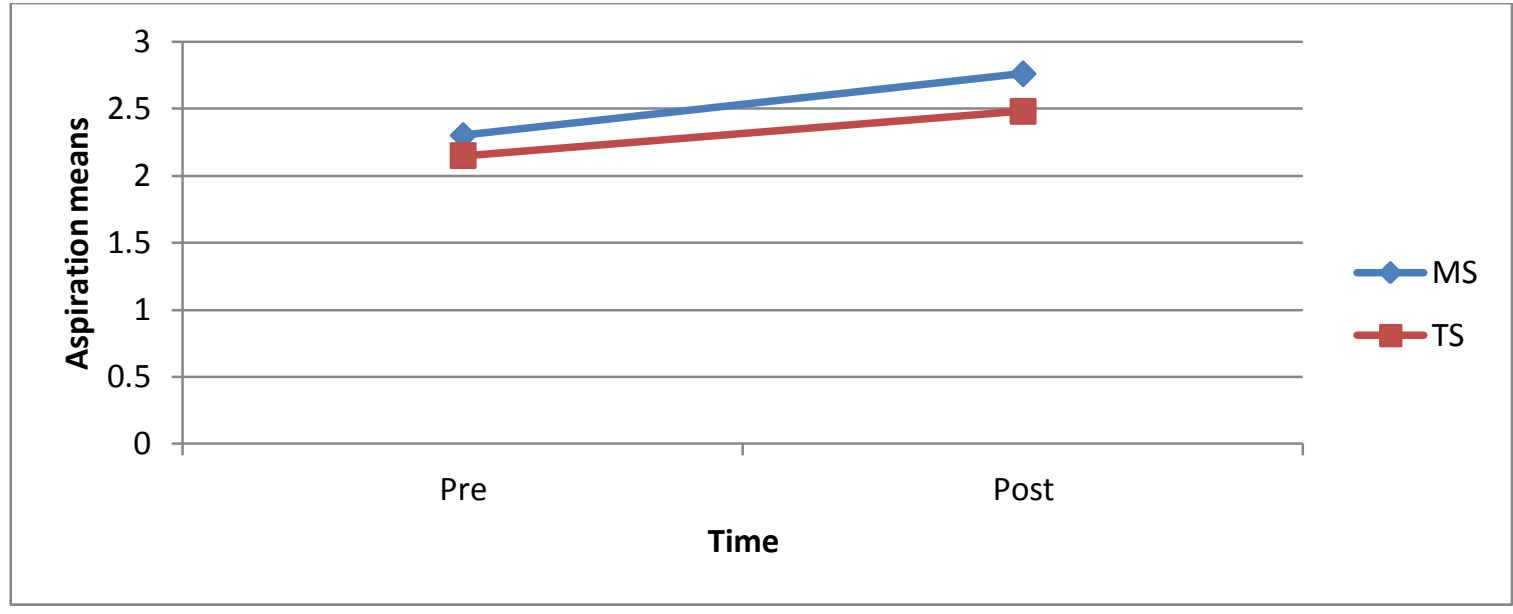

Figure 67. Aspiration - All students

\section{Section Two: Changes in Aspiration for Pasifika Students in the MS and TS Programmes}

Table 43 presents the means and standard deviations aspirations ratings by Pasifika students before and after participation in the two programmes.

\section{Table 43}

Aspiration Means for Pasifika Students Participating in the MS versus TS Programmes

\begin{tabular}{lcccc}
\hline Variable & Group & $\mathbf{N}$ & Pre-test Mean (SD) & Post-test Mean (SD) \\
\hline Aspiration & MS & 16 & $2.44(0.81)$ & $2.85(0.38)$ \\
& TS & 12 & $2.33(0.89)$ & $2.60(0.52)$ \\
\hline
\end{tabular}

Table 44 presents the results of the independent samples tests for differences in aspiration for Pasifika students associated with participation in the two intervention programmes. 


\section{Table 44}

Independent Samples Tests and Effect Size Calculations on Change Scores for Aspirations for Pasifika Students in the MS versus TS Intervention Programmes

\begin{tabular}{lccccccccc}
\hline Variable & F & Sig & t (df) & $\begin{array}{c}\text { Sig } \\
\text { (2-tailed) }\end{array}$ & $\begin{array}{c}\text { Mean } \\
\text { Diff }\end{array}$ & $\begin{array}{c}\text { Std Error } \\
\text { Diff }\end{array}$ & $\begin{array}{c}\text { 95\% Cl } \\
\text { Lower }\end{array}$ & $\begin{array}{c}\text { 95\% Cl } \\
\text { Upper }\end{array}$ & $\begin{array}{c}\text { Cohen's } \\
\text { d }\end{array}$ \\
\hline Aspiration & 4.57 & 0.04 & $0.28(26)$ & 0.78 & 0.06 & 0.25 & -0.46 & 0.58 & $\mathbf{0 . 1 0}$ \\
\hline
\end{tabular}

These data showed that Pasifika students in both groups increased their self-reported aspirations for completion of the NCEA with a narrowing of the standard deviation again (see also figure 68). There was a difference approaching significance favouring the MS group, but the effect size analysis did not support claims that this difference was particularly meaningful.

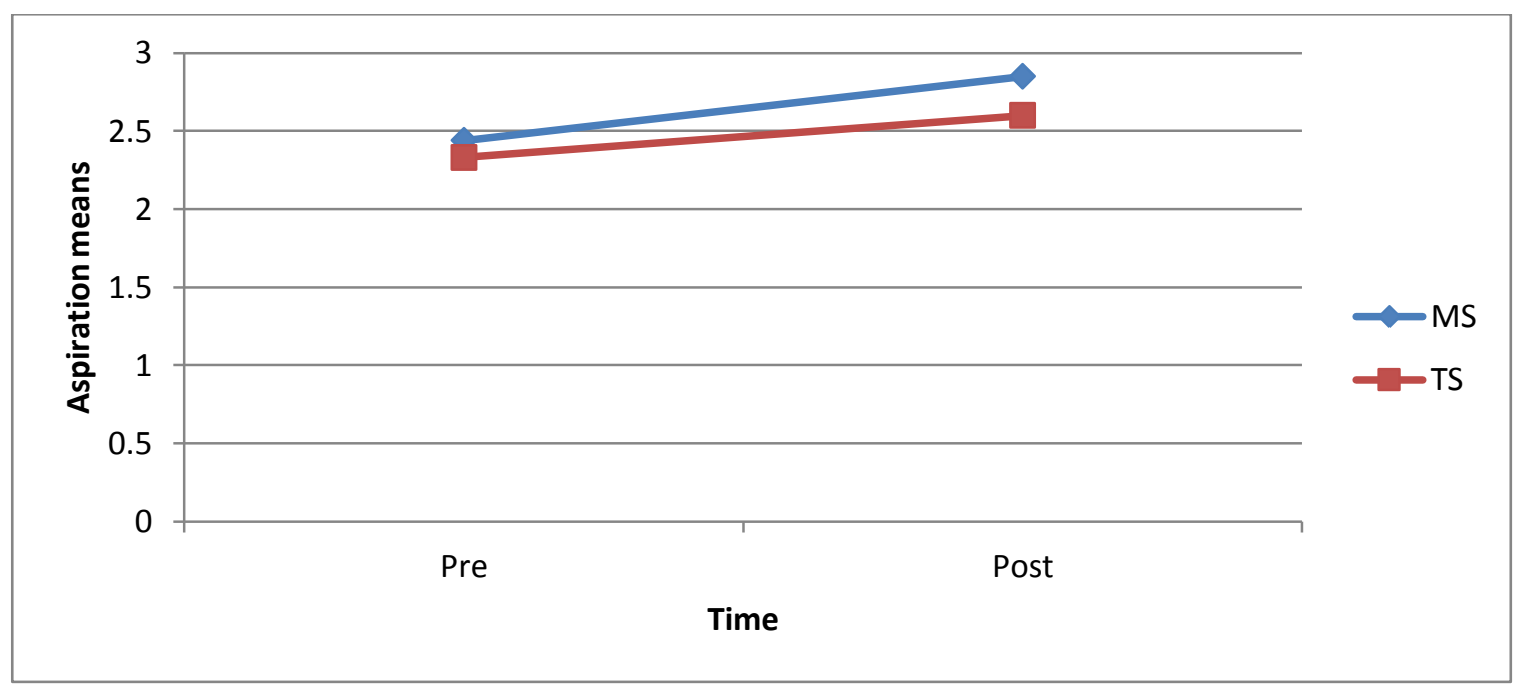

Figure 68. Aspiration - Pasifika students 


\section{Summary}

This chapter reported findings based on ten analyses of the quantitative data for all students who participated in either the motivation-enhanced (MS) programme $(\mathrm{N}=$ 30), compared with all students who participated in the traditional study skills (TS) programme $(N=27)$. These findings addressed research question one which investigated the achievement, motivation, engagement, and attendance outcomes for all students who participated in the two programmes. This chapter also reported the analyses of data for Pasifika students in the MS programme $(\mathrm{N}=16)$ compared with Pasifika students who participated in the TS programme $(N=12)$. These findings addressed research question two which investigated the achievement, motivation, engagement, and attendance outcomes for Pasifika students who participated in either the MS programme ( $N=16)$ compared with Pasifika students who participated in the TS programme $(\mathrm{N}=12)$.

Overall, these data suggested that both programmes were associated with some positive changes for all students and Pasifika students as might be expected if both represented high quality interventions. This is consistent with a basic design feature of this study because it compared the MS group not with a "control" group receiving no intervention, but with a comparison group that also received an intervention - the TS skills programme. These data patterns fall into three major groups. First, there were results which favoured the TS programme, for all and/or for Pasifika. Second there were patterns of results which favoured the MS programme, for all and/or for Pasifika. Finally, there were areas where both MS and TS students, all and/or Pasifika, seemed to benefit. 
There were two main areas of analysis where results favoured the TS programme changes in adaptive intra-personal motivation orientations and changes in attendance. Results about changes in adaptive intra-personal motivation orientations largely favoured the TS skills programme over the MS programme for Pasifika student participants, even more so than for all students. Given the focus on study skills in the TS programme, these results are perhaps consistent with expectations. Indeed, it may be that these factors actually reflect self-assessments regarding study skills. This will be discussed further in the final Discussion chapter. Results about changes in attendance also favoured the TS skills programme over the MS programme particularly for Pasifika student participants.

In comparison there were eight areas of analysis where results favoured the MS programme: NCEA achievement, maladaptive motivation orientations, Doing Just Enough, peer affiliation, attributing their best and worst marks, and disengagement. For example, these data showed that all students and Pasifika students in the MS intervention programme attained more NCEA credits than all students or Pasifika students in the TS skills programme. These data also showed decreases in maladaptive intra-personal motivation orientations associated with the MS programme for Pasifika students that were greater than those occurring for their Pasifika peers in the TS programme. These results were in the same direction as those evident for all students, but the results for Pasifika students in reducing maladaptive motivation factors were more pronounced with larger effect sizes. 
The data also showed all students and Pasifika students in the MS programme decreased on Doing Just Enough compared with their peers in the TS programme. Other data showed that all students and Pasifika students in the MS group showed a higher shift in peer affiliation compared to TS students, and Pasifika MS students only also showed increased teacher affiliation compared to Pasifika TS students. These data also showed all students in the MS programme reported a statistically significant increase in attributing their best marks to effort in comparison to results for the students in the TS programme. All students in the MS intervention also showed a mean decrease in two negative attributions - attributing best marks to an easy test and to good luck. There was also a medium effect size for a decrease in attributing best marks to friends for the MS group in comparison with the TS group.

Other findings provided evidence that the Pasifika MS students attributed their best grade to effort rather than to factors outside the students' control. Pasifika MS students also increased attributions for academic success to ability, good luck, or an assessment that was easy. Medium effect sizes were found for attributions to effort, assessment difficulty, and luck for best marks, all favouring the MS intervention programme. Students in the MS group overall increased their attribution of worst grades to effort and decreased their attributions of worst grades to luck, with moderate effect sizes evident for both attributions favouring the MS intervention. In comparison these data showed that generally there was little difference between Pasifika students in the kinds of changes to attributions for worst marks in assessment associated with participation in the two intervention programmes. However, medium effect sizes were evident for two of the social attributions for worst marks. 
On average, Pasifika students in the MS programme decreased attributing their worst marks to their teachers and to their friends following the intervention, whereas those in the TS skills programme increased these negative attributions.

These data also showed that disengagement ratings declined slightly for students in the MS programme but increased for those in the TS programme. These data suggested that students in the comparison programme were more engaged with school than those in the experimental programme following participation in the intervention. The pattern of change in disengagement ratings for Pasifika students before and after intervention was similar to that observed for all students. All students and Pasifika students increased aspirations for completion of the NCEA following intervention, however the effect size favouring the MS group was small.

However there were two areas of analysis where both MS and TS students, all and/or Pasifika, seemed to benefit. First, the data showed that all students in both the MS and TS programmes decreased in attributions of their best marks to ability. Second, both groups increased aspirations for completion of the NCEA following intervention. In conclusion it is acknowledged that a large number of analyses were conducted to test for statistical significance and effect size, hence some findings might be expected to be significant by chance. However, the findings reported in this chapter also suggest that both interventions produced positive outcomes which support the need for intervention programmes. In addition these data showed an interesting pattern where the MS programme was 
associated with what could be considered important decreases in negative motivations, attributions, and self-sabotaging attitudes.

The increases in positive motivation factors were similar for the MS and TS groups, but the greater gains were made by the MS students overall and for Pasifika on decreasing negative attitudes and motivations that can depress effort and academic performance. These data contest an argument that all the significant results and meaningful effect sizes were simply by chance and suggest instead that the MS programme may have been more effective for increasing motivation and achievement-related outcomes than the TS programme. However, it is also acknowledged that these data also showed there were differences in these patterns for Pasifika students in the MS and the TS programmes, and these results will be discussed fully in the final Discussion chapter.

Table 45 shows a summary of changes on motivation orientations for total student group and Pasifika only student scores following MS and TS. Tables 46 and 47 show a summary of changes on best and worst mark attributions respectively for total student group and Pasifika only student group mean scores following TS and MS. 


\section{Table 45}

Summary of Changes on Motivation Orientations for Total Student Group and Pasifika Only Student Scores following the MS and TS Intervention Programmes

\begin{tabular}{|c|c|c|c|c|}
\hline $\begin{array}{l}\text { Motivation orientation } \\
\text { (+ or - } \\
\text { for desired change) }\end{array}$ & $\begin{array}{l}\text { TS total student } \\
\text { group }\end{array}$ & $\begin{array}{c}\text { MS total } \\
\text { student group }\end{array}$ & $\begin{array}{l}\text { TS Pasifika only } \\
\text { student group }\end{array}$ & $\begin{array}{l}\text { MS Pasifika } \\
\text { only student } \\
\text { group }\end{array}$ \\
\hline Self-efficacy & Increase & Increase & Increase $^{m}$ & Decrease \\
\hline Persistence & Increase & Increase & Increase $^{m}$ & Increase \\
\hline Planning & Increase & Decrease & Increase $^{\mathrm{m}}$ & Decrease \\
\hline Mastery learning & Decrease & Decrease & Decrease & No change \\
\hline Valuing & Increase & Decrease & No change $^{m}$ & Decrease \\
\hline Task management & Increase & Decrease & Increase ${ }^{* 1}$ & Decrease \\
\hline \multicolumn{5}{|l|}{$\begin{array}{l}\text { Maladaptive } \\
\text { intra-personal (-) }\end{array}$} \\
\hline Anxiety & Decrease & Decrease $^{\mathrm{s}}$ & No change & Decrease \\
\hline Failure avoidance & Decrease & Decrease & Decrease & Decrease $^{s}$ \\
\hline Failure avoidance & Decrease & Decrease & Decrease & Decrease $^{s}$ \\
\hline Uncertain control & Decrease & Decrease $^{\mathrm{s}}$ & Increase & Decrease $^{* 1}$ \\
\hline Self-sabotage & Increase & Decrease $e^{s}$ & Increase & Decrease $^{m}$ \\
\hline Doing My Best (+) & Decrease & Increase $^{s}$ & Increase & No change \\
\hline Doing Just Enough (-) & Increase & Decrease $^{\mathrm{s}}$ & Increase & Decrease $^{m}$ \\
\hline Peer affiliation (+) & Decrease & Increase & Decrease & Increase \\
\hline Teacher affiliation (+) & Decrease & Increase & Decrease & Increase \\
\hline
\end{tabular}

\section{Key:}

* $\quad p<0.05$

$s \quad$ small effect size $(0.2<d<0.49)$

$\mathrm{m} \quad$ moderate effect size $(0.5<\mathrm{d}<0.79)$

l large effect size $(0.8<d)$ 


\section{Table 46}

Summary of Changes on Mark Attributions for Total Student Group and Pasifika Only Student Group Mean scores following the MS and TS Intervention Programmes

\begin{tabular}{|c|c|c|c|c|}
\hline $\begin{array}{l}\text { Best mark attributions } \\
\text { (+ or }- \text { for desired } \\
\text { change) }\end{array}$ & $\begin{array}{c}\text { TS total } \\
\text { student group }\end{array}$ & $\begin{array}{c}\text { MS total } \\
\text { student group }\end{array}$ & $\begin{array}{c}\text { TS Pasifika } \\
\text { only student } \\
\text { group }\end{array}$ & $\begin{array}{c}\text { MS Pasifika } \\
\text { only student } \\
\text { group }\end{array}$ \\
\hline My ability (-) & Decrease & Decrease & Decrease & Decrease \\
\hline My effort (+) & Decrease & Increase ${ }^{* m}$ & Decrease & Increase $^{m}$ \\
\hline Easy test (-) & Increase & Decrease $^{s}$ & No Change & Decrease \\
\hline Good luck (-) & Increase & Decrease $^{\mathrm{s}}$ & Increase & Decrease $^{m}$ \\
\hline My family(-) & Decrease & Decrease & Decrease & Decrease $^{s}$ \\
\hline My teachers (+) & Increase & Increase & No Change & Increase \\
\hline My friends(-) & Decrease & Decrease $^{\mathrm{s}}$ & Decrease & Decrease \\
\hline
\end{tabular}

Key:

* $\quad p<0.05$

$s \quad$ small effect size $(0.2<\mathrm{d}<0.49)$

$\mathrm{m} \quad$ moderate effect size $(0.5<\mathrm{d}<0.79)$

large effect size $(0.8<d)$

\section{Table 47}

Summary of Changes on Mark Attributions for Total Student Group and Pasifika Only Student Group Mean scores following the MS and TS Intervention Programmes

\begin{tabular}{|c|c|c|c|c|}
\hline $\begin{array}{l}\text { Worst mark } \\
\text { attributions } \\
\text { (+ or }- \text { for } \\
\text { desired change) }\end{array}$ & $\begin{array}{c}\text { TS total } \\
\text { student group }\end{array}$ & $\begin{array}{c}\text { MS total } \\
\text { student group }\end{array}$ & $\begin{array}{l}\text { TS Pasifika only } \\
\text { student group }\end{array}$ & $\begin{array}{l}\text { MS Pasifika } \\
\text { only student } \\
\text { group }\end{array}$ \\
\hline My ability (-) & Increase & Decrease & Decrease & Decrease \\
\hline My effort (+) & Increase & Increase $^{\mathrm{s}}$ & Increase & Increase \\
\hline Hard test (-) & Decrease & No change & Decrease & Decrease \\
\hline Bad luck (-) & Decrease & Decrease $^{s}$ & Decrease & Decrease \\
\hline My family (-) & Decrease & Decrease & Increase & Decrease \\
\hline My teachers(-) & Decrease & No change & Increase & Decrease $^{m}$ \\
\hline My friends(-) & Increase & No change & Increase & Decrease $^{s}$ \\
\hline
\end{tabular}

\section{Key:}

$$
\begin{aligned}
& \mathrm{p}<0.05 \\
& \text { small effect size }(0.2<\mathrm{d}<0.49) \\
& \text { moderate effect size }(0.5<\mathrm{d}<0.79) \\
& \text { large effect size }(0.8<\mathrm{d})
\end{aligned}
$$




\section{Explanatory note about changes in social attributions for best and worst marks and achievement}

This thesis investigated how AR interventions which focused on traditional attributions and achievement compared to AR interventions which focused on social attributions and achievement. This relates to research about how students perceive teachers, peers, and family to be associated with their attributions for best and worst marks in assessments and how any changes in social attributions may be associated with achievement. Although Weiner's theory views social attributions as being externally located, McClure et al., (2011) noted that "students may construe attributions to the influence of family, friends, and teachers in different ways than the external causes cited by Weiner (task difficulty and luck) (e.g., Liu et al., 2009). For example, whereas people see external causes such as task difficulty as contributing to failure more than success, they may see family as contributing to their success more than their failure (Ng et al., 1995) (p.71). One relevant concept is whether some Pasifika students operate from a collectivist perspective rather than an individualistic view (Duda and Allison, 1989). Previous research about the relationship between changing social attributions for best and worst marks and subsequent achievement shows mixed results (see for example McClure et al., (2011)). Therefore it is not possible to definitively state whether increasing or decreasing social attributions for best and worst marks is associated with improved achievement outcomes. However the data from this study showed that students from both the MS and TS programmes increased on attribution of best marks to their teachers and this finding supports research by McClure et al., (2011) who reported that Vispoel and Austin (1995) found that "attributing success to family influence was linked to higher marks, whereas 
attributing failure to these influences was linked to lower marks" (p.72). Since MS students also had better NCEA outcomes than TS students it is possible that the data in my study support Vispoel and Austin's (1995) research.

However the data in this study do not suggest that an intervention should aim to decrease the other social attributions for best and worst marks, but rather that interventions should aim to decrease family and friend attributions. Research by McClure et al., (2011) supports this view reporting that "according to Weiner's (1985, 2010) theory, attributing achievement to others as an external, uncontrollable attribution ... may decrease a sense of self-efficacy and the expectancy of influencing outcomes. It may also reflect the self-serving bias" (p.72).

The next chapter outlines the qualitative findings of this study following the pragmatic mixed-methods research design. It is hoped that the qualitative data will be enhanced by triangulating it with the interview data. Using multiple sources for data will improve the richness of information from the numeric trends as shown by the quantitative data which can then be compared with the qualitative data (Creswell, 2009). It is hoped that the qualitative data will corroborate, elaborate or initiate new findings (Rossman and Wilson, 1985, p.627). For example the qualitative data may agree with the quantitative data that showed that students in the MS programme reduced in Doing Just Enough. However it is quite possible the qualitative findings will challenge the quantitative findings. It is also hoped that the interview data will elaborate upon findings gained from the quantitative data. For example, the quantitative data showed that students in the MS programme differed to the students in the TS programme in 
Motivation Interventions via Study Programmes for Under-achieving Students

the area of teacher affiliation. It is hoped that the interview data will elaborate upon possible reasons for increased teacher affiliation in a way that the quantitative data can only show as a numeric trend. Finally it is possible the qualitative data will initiate new findings that were not shown by the qualitative data. 


\section{Chapter Five Qualitative Findings}

\section{Introduction}

This chapter reports findings based on interviews with 45 of 57 participants. Of the 57 total participants, 12 students were not interviewed (four from the Motivationenhanced Study (MS) support programme and eight from the Traditional Study (TS) support programme) because these students were repeatedly absent from school including when interviews were scheduled, despite rescheduled interview times being made. These findings address research question three which investigated students' perceptions of the relative value and helpfulness of the TS and MS programmes towards supporting their learning and achievement, including the perceptions of Pasifika students. The material reported here is based on responses from students to the following open-ended questions;

- Tell me about the study programme. Why did you participate? What did you like about it? What didn't you like?

- What part of the programme helped you the most? What part didn't help you or didn't make sense to you?

- Give an example of something you learned in the programme that you used later, in one of your assessments in the classroom? What happened?

- What kinds of things can teachers do to help support you in your classes? 
Motivation Interventions via Study Programmes for Under-achieving Students

- How can your classmates and friends support you in your classes? Outside school?

- Do you find it helpful to bring your own experiences and/or cultural background into your schoolwork? How?

- Are there any barriers that make it hard for you to achieve at school? What are they?

- How do you think the programme could be improved to make it better meet your needs?

- Tell me about how you studied for the external exams for Level 1 NCEA?

- How do you feel about school?

- Tell me what makes you want to work hard at school?

- Tell me about something you are really good at?

The purpose of this chapter is to answer the following questions:

- What did students in the interviews say that supported interpretations based on the quantitative findings?

- What did students say in the interviews that failed to support interpretations based on the quantitative findings?

- How did the interview data help explain and elaborate the quantitative findings?

The interview data were first analysed using NVivo 9, followed by initial line-by-line coding (Charmaz, 2006). This analysis produced five major themes - motivation, teachers, peers, programme, and culture. From these interview data it was possible to 
make direct comparisons with the quantitative data. For example, the quantitative data about effort could be compared directly to the qualitative data on this concept since "effort" was a word commonly used during interviews. However sometimes it was necessary to re-analyse interviews looking for language which may have been more typical of what the 15-year-old New Zealand Secondary School students in this study would have used. For example, one of the analyses investigated changes in aspiration. Initial analysis of the qualitative data found few participants used the actual term "aspiration". To work around this issue, the qualitative data were reanalysed using possible synonyms for "aspire" such as seek, aim, hope, desire, want and wish. This second analysis of the interview data now showed many more possible references to aspiration. For example when one student was asked the question, "Why do you work hard at school?" he answered "Because I want to pass. Like some other people, they don't care... I actually care about my work." This response was coded as indicating higher aspiration. In comparison, the response from the student who answered the same question with "I just can't be bothered because we were like half way through the project and I just gave up" was coded as lower aspiration.

There were eight analyses of the qualitative data which followed a similar structure to the analyses of the quantitative data:

Analysis One: Changes in adaptive intra-personal motivation orientations

Analysis Two: $\quad$ Changes in maladaptive intra-personal motivation orientations 
Analysis Three: $\quad$ Changes in Doing My Best (DMB) and Doing Just Enough

Analysis Four: $\quad$ Changes in inter-personal motivation orientations

Analysis Five: $\quad$ Changes in attributions for best marks in assessments

Analysis Six: $\quad$ Changes in attributions for worst marks in assessments

Analysis Seven: Changes in disengagement

Analysis Eight: Changes in aspiration

\section{Analysis One: Changes in Adaptive Intra-personal Motivation}

The interview data did not provide support for the interpretation based on the quantitative data that suggested the TS programme was more effective than the MS programme on the six adaptive intra-personal motivation orientations measured in this study - self-efficacy, persistence, planning, mastery-learning, valuing, and taskmanagement. This was partly because several MS students recalled receiving messages about adaptive intra-personal motivation factors, whereas none of the students in the TS programme did, but also because the interview data provided a number of possible explanations for the discrepancy between the two data sets. These included: that the messages were not delivered clearly enough by the researcher; that MS students did receive the messages but the effect was very small; that these six adaptive intra-personal motivation factors were not really "intra-personal motivation orientations" at all, but were an indirect measure of whether the student perceived he/she had good study skill attitudes; that students held multiple negative ideas about 
motivation and achievement which may have combined in a particularly unhelpful way; that some students held some positive and negative ideas about motivation and achievement which may have conflicted; and that other motivation variables measured in this study had more impact for students. These explanations will be explored fully in the Discussion chapter but initial evidence for each of these points is outlined briefly below.

The interview data suggest that intra-personal motivation messages may not have been delivered clearly enough by the researcher to have an impact on students. When one MS student was asked "Do you remember any of the messages that I gave you?" he replied "Ah it involved at trying to work hard, trying to be more motivated like selfefficacy." When further questioned, "what does self-efficacy mean?" "Oh self-efficacy (pause) .... I'm not sure."

Again some interview data suggest that MS students had received the intra-personal motivation messages, but the effect was very small. For example one MS Pasifika student programme was asked if he ever stayed right to the end of his exams. He replied "The whole three hours?" "Yes." "No that's too long for me". "Did you ever stay two hours?" "No". "Did you ever stay one hour?" "Yep hour and a half is the longest." This student also reported that one and a half hours in an exam was an improvement for him as he normally stayed only the minimum of 45 minutes.

The interview data also support the point that these six adaptive intra-personal motivation factors may not be "intra-personal motivation orientations" at all, but 
rather an indirect measure of whether the student perceived he/she had good study skill attitudes. Students from both the MS and the TS programmes made comments such as "I was more motivated to do work in your class". These data indicate that both programmes had an impact on students' study skills.

The interview data support the point that students may have held multiple negative ideas about motivation and achievement. Such combinations may have been particularly unhelpful because some MS students reported that they held low selfefficacy perceptions and that they were anxious about examinations. It is possible that these multiple negative goals converged to doubly hinder achievement. For example, one MS Pasifika student was asked "Did you believe you were going to pass your external examinations?" the response was "No, I didn't really think I could because I was more worried. That like I might get a question wrong or I might not know the answer."

The interview data also support the point that students held some positive and negative ideas about motivation and achievement which may have been contradictory, for example reporting a positive goal such as persistence at the same time as being engaged in negative classroom behaviours. One MS Pasifika student said that he understood the need to be more persistent with his schoolwork but that he did not stay the full three hours in an external examination because his friends left the exams early. "Oh it's like a pattern. Like he's finished first so they've done the best they can, then that makes you feel like wanting to go as well." This negative peer-group behaviour was more frequently reported by lower achieving students whereas higher 
achieving students reported that they helped each other. "Like my group of friends if we find something hard like then we'll sit down with them and talk through that particular subject... like you know how that saying two brains are better than one or something." These data appeared to indicate that achieving and under-achieving students held different achievement goal patterns.

Finally, the interview data support the point that certain motivation variables measured in this study may have had the greatest impact on their academic behaviour in comparison with others. Examination of the interview responses suggest that interpersonal motivation factors such as teacher-student affiliation were more important to some MS students' achievement than intra-personal motivation factors. For example when one under-achieving MS Pasifika student was asked "what gets in the way of your learning?" she replied, "Sometimes I try my best to be kind to teachers but they still make me angry so I just don't try anymore." Alternatively, there were also examples in the interview data regarding teachers who supported under-achieving students through positive teacher-student interactions that helped students value school. Another under-achieving MS Pasifika student stated "She's the one that's helping me stay in school - she's fighting with me".

These ideas will be investigated further in the Discussion chapter. 


\section{Analysis Two: Changes in Maladaptive Intra-personal Motivation}

The interview data support the quantitative data which had indicated MS students decreased negative motivation factors including self-sabotage, uncertain control, failure avoidance and anxiety in comparison with the TS students. More MS students recalled hearing these maladaptive intra-personal messages than TS students. The interview data also provide a number of possible explanations about how and why students reduced on three of these factors including giving exemplars of self-sabotage behaviours; reporting failure avoidance behaviours in association with teachers' behaviours; and showing an understanding of the difference between internallylocated and externally-located "control" factors. On the fourth maladaptive intrapersonal factor - anxiety - the interview data were conflicting but indicate that higher levels of anxiety were associated with student perceptions of negative teacherstudent interactions.

The interview data show some evidence of self-sabotage. For example, one MS Pasifika student was quite open about his use of self-sabotage behaviours, reporting that he purposely did not study so that if he failed he could say it was because he did not do any study. "Because it is better to blame it on like on no study than to say that I didn't even pass it." In comparison TS students showed little understanding of selfsabotage. 
The interview data also showed that when any students discussed failure avoidance that it was often in association with teachers. "Like if I don't really get it, she will always help me out. But then I kind of got like stopped I didn't really get it so I won't listen. So she stopped like helping me out so I just stopped then I started to fail exams." These data indicated that students who held negative "failure avoidance" views at the same time as experiencing negative teacher-student interactions may have been at increased risk of lower achievement.

The interview data also showed that many MS students recalled messages about what they could "control" in the learning-teaching process, whereas none of the TS students recalled hearing about messages about "control". Students in the MS programme also showed a better understanding of the differences between internally-located, and externally-located "control" factors compared with TS students. For example, one MS student reported "You taught us, like if you want to achieve you have to try and get there, like it's not just luck or anything". The interview data also showed that many MS students who showed a clearer understanding of what they could "control" were Pasifika students and that MS Pasifika students talked about "control" in association with the level of support they received from their teachers. "You know like you need your teachers to guide to help you." These data suggest that some MS Pasifika students believe that their teachers have a mediating effect on students' levels of control and achievement.

The data about anxiety suggest that both programmes were useful in reducing anxiety. However these data indicate that the MS programme may have been more successful 
in reducing anxiety for Pasifika students than the TS programme; most references to anxiety in the interview data were made by Pasifika rather than non-Pasifika students. These interview data also show that TS Pasifika students appeared to be more resigned to failure compared with MS Pasifika students. For example, one TS Pasifika student reported "I didn't (study) because I was like I'm going to fail, so there's no point". Other TS Pasifika students reported high levels of exam anxiety: "I was like dead scared because I really didn't want to fail". In comparison MS Pasifika students explained that for them, anxiety was associated with achievement. For example, one female Pasifika student said male Pasifika students in her classes were "Starting to worry now since they've become seniors, they've started to worry about school, but before they didn't". Other interview data indicated that some MS Pasifika students associated anxiety with teacher behaviours. For example, one MS Pasifika students reported that "relaxed" teachers did not help students deal with their anxieties about NCEA. "Mr X like, he was like not worried too much of the time, just talking with the girls." In comparison another MS Pasifika student said her teacher did help her deal with her anxiety. "Yeah he's calm... he never worries and he always has these notes to hand out. Yeah. And then he'll have time for our experiments everything's planned... yeah and so we get used to that."

These ideas will be investigated further in the Discussion chapter. 


\section{Analysis Three: Changes in Doing My Best (DMB) and Doing Just Enough (DJE)}

\section{Changes in Doing My Best (DMB)}

The interview data provide partial support for the quantitative finding that all students in the MS group increased on DMB compared with students in the TS group. Some MS students recalled receiving DMB messages, whereas no TS programme students did. On the other hand, the interview data provided more support than the quantitative data with respect to the impact of DMB messages on Pasifika students in particular; whereas, the quantitative data found no differences on DMB between MS Pasifika and TS Pasifika students, but six of the eight MS students who recalled DMB messages were Pasifika students.

The interview data may provide an explanation for this difference. This first analysis was based on students' responses which literally stood for DMB, rather than an analysis which encompassed other words students may have used to describe DMB behaviours. Therefore, the qualitative interview data were reanalysed searching for terms closely related to DMB and associated behaviours, such as work hard, try, learn, effort, excellence, merit, new and different. For example, when one student was asked about why she had come to the MS study-skills programme, she replied "I wanted to find a new way of learning and you said that you had a different way and I wanted to learn something new." This response was coded as a DMB reference.

The reanalysis provides further support for the quantitative finding that $D M B$ increased for all MS students compared with all TS students as MS students made six 
times as many DMB comments as TS students. However this reanalysis failed to explain the quantitative finding that DMB remained the same for MS Pasifika students compared with TS Pasifika students as the interview data showed that MS Pasifika students made four times as many DMB comments as TS Pasifika students. Counting references to $\mathrm{DMB}$ and $\mathrm{DMB}$-related behaviours was only part of the analysis as the interview data also suggest a number of possible explanations about how and why MS students may have increased on DMB compared to TS students. These include how MS students responded to DMB messages; that DMB was a task-specific goal; that while some MS Pasifika students heard the DMB messages this did not necessarily mean application of DMB to schoolwork; that MS Pasifika students held conflicting goals; that DMB lacked specificity as a goal which could have diminished its effect on achievement; and that the behaviours of teachers, parents and friends may have impacted on students' application of DMB goals.

The interview data indicate that MS students who received DMB messages responded differently in comparison to responses by TS students, who of course had not received DMB messages. For example, students from both programmes were asked, "How did you study for the external exams for Level 1 NCEA?" TS group students tended to answer this question in the context of study skills whereas MS students gave responses associated with motivation and achievement. For example, one MS student reported he felt he had higher levels of persistence in external examinations after the MS intervention programme. "Usually in exams I sit there and do nothing but this time I ended up doing stuff so that was good." In comparison, a TS student answered the 
question with "I liked the little booklets you gave us how we have had so many sheets. I found it easy to follow, it was organized".

The interview data also showed evidence that DMB was a task specific goal because many students made comments about DMB in the context of NCEA. For example when one MS student was asked why he worked hard at school, he replied "Because I want to pass. I want my level 1 NCEA in case the Rugby League thing doesn't work out and I can get a job or something like that".

The interview data also support the point that while some MS Pasifika students heard the DMB messages, this did not necessarily mean application of DMB to schoolwork; when one MS Pasifika student was asked if she heard and applied DMB ideas, she replied, "Well with games, yep".

The interview data also support the point that MS Pasifika students may have held conflicting goals. For example in response to the question "Are you a person who does their best or does just enough?", a MS Pasifika student replied "Half and half I reckon, oh it depends on which class". These data may indicate that MS students held multiple goals which may have converged to assist achievement, or conflicted with one another to reduce achievement.

The interview data also supported the point that DMB lacked specificity as a goal, which could have diminished its effect on achievement. In an attempt to overcome this problem, the MS programme taught students to make goals more specific by 
going down the personal best (PB) pathway. The interview data support the view that students heard and may have applied the PB message: several MS students recalled hearing the PB concept, whereas no TS students did so.

Finally the interview data also support the point that the behaviours of teachers, parents and friends may have an impact on students' application of DMB goals. MS responses about $\mathrm{DMB}$ were often made in association with teachers, friends and family, whereas this was not the case for TS students. Four MS students reported "I was more motivated to do work in (Mr X's) class". Why? "Because (Mr X's) really nice." Other MS students reported that the MS programme facilitated DMB goals and behaviours. "I think it was really good how we did the group tests. Yeah because it was like competition and it was like competing with other groups. And class was good like working altogether." Many MS Pasifika students also reported that their main reason for increased DMB behaviours at school was because of, and for, family. However it also appears that while family may have been a reason that MS Pasifika students said they held DMB goals, family expectations may have also led to students favouring performance goals rather than mastery goals. "They just say, oh because they wanted me to go to university but I try hard but I don't know. I don't know just don't want to disappoint them."

These ideas will be investigated further in the Discussion chapter. 


\section{Changes in Doing Just Enough (DJE)}

The interview data support the quantitative findings indicating that MS students decreased on DJE compared to TS students. Some MS students recalled hearing DJE messages, whereas no TS students recalled DJE. These interview data also show that seven of the 10 MS students who recalled DJE messages were MS Pasifika students and that eight were male. This indicates that the MS programme may have provided more opportunities for students to reflect on the effects of DJE and that male MS Pasifika students were particularly receptive to DJE messages.

The interview data also suggest possible explanations for how and why students may have reduced on DJE. These include differences in the quality of explanations of DJErelated behaviours between students in the MS and TS programmes; that DJE was a task-specific goal; that some students held conflicting goals; that DJE was associated with social goals; and that interactions with teachers, parents and friends were positively and negatively associated with DJE.

The interviews revealed that TS students reported more simplistic DJE related behaviours such as "I don't try anymore" and "I don't think I'll be passing NCEA". In comparison, MS students made more reflective DJE-related comments which elaborated on their views about why MS students did not work hard at school. "Some didn't do well because they talked too much, not focusing in class, yep." These data provide further evidence that DJE could be considered a task-specific goal because many MS and TS students made comments about DJE within the context of NCEA. 
However the interview data also show that more MS Pasifika students made DJE comments than TS Pasifika students. These data appear to contradict quantitative findings which had indicated the MS programme was associated with decreased DJE for MS Pasifika students. One explanation for this contradiction could be that some MS Pasifika students heard DJE/work avoidance messages but did not act upon them. The interview data partially support this interpretation, as one MS Pasifika student explained his DJE-related behaviours: "Like I didn't put enough effort that I could have. I didn't pass the biology and physics and that was my fault because I didn't study as much as I could have."

Other interview data appear to indicate that some MS students held conflicting goals, specifically work approach/DMB goals versus work avoidance/DJE goals. Observations of classroom behaviour by the researcher also support this interpretation. When the researcher asked two MS Pasifika students why they had stayed down the back of the classroom talking instead of listening to the teacher, one replied "Oh because there was nothing to do, she was just explaining about how to get Merits". Again these data support the task specificity nature of DMB/DJE as comments made by this MS student about DJE were made in the context of the NCEA.

Finally the interview data indicate that DJE was associated with social goals and that interactions with teachers, parents and friends were positively or negatively associated with achievement. For example, one MS Pasifika student reported that her cousins had not worked hard at school and some had dropped out of school. "Because most of them are into their gangster stuff and into drugs and all of that, they thought 
school was a waste of time." However this MS Pasifika student explained that these behaviours made her want to work harder at school. This point was corroborated by other MS students: "Oh because no one's really finished school in my family, everyone's dropped out and yeah just wanted to, I didn't want to repeat history".

These ideas will be investigated further in the Discussion chapter.

\section{Analysis Four: Changes in Inter-personal Motivation Orientations}

\section{Peer Affiliation}

When the qualitative data were analysed for references to peer affiliation, most student responses could be placed in one of two categories: peer behaviours that helped students learn and peer behaviours that did not help students learn. Some of the positive ways students reported they helped each other learn include explaining how to do schoolwork; deliberate formation of supportive peer groups; facilitation of friendly competition with friends; because their friends knew them better than teachers did; and simply because informal talking with friends helped them learn. In comparison, students reported just one negative peer behaviour that did not help them learn: friends distracting them from their schoolwork.

The qualitative data support interpretation of quantitative findings of increased peer affiliation for MS students compared with TS students. MS students made $60 \%$ of the positive peer affiliation comments, whereas TS students made just $40 \%$ of these 
positive comments. In comparison, TS students made $55 \%$ of the negative peer affiliation comments whereas MS students made $45 \%$ of the negative comments.

The interview data about peer affiliation also show differences by gender, with MS Pasifika female students twice as likely to make positive comments about how classmates and friends supported them in class or outside school than TS Pasifika female students. Pasifika female students in the MS programme were also less likely to make negative comments about their classmates and friends not supporting them in class or outside school. Male MS Pasifika students were nearly three times as likely to make positive comments about how their classmates and friends supported them in class or outside school compared with male TS Pasifika students. However male MS Pasifika students made the same number of negative comments about their classmates and friends not supporting them in class or outside school as male TS Pasifika students.

To investigate these patterns in the interview data for male and female MS Pasifika students, the quantitative data about peer affiliation were reviewed. The quantitative data about male MS Pasifika students were compared with female MS Pasifika students. This reanalysis showed that male MS Pasifika students increased on peer affiliation, whereas female MS Pasifika students decreased slightly on peer affiliation after intervention. These data appear to indicate that the effects of the MS programme on peer affiliation were different for male MS Pasifika students compared with female MS Pasifika students. This interpretation is supported by classroom observation data showing that male MS Pasifika students exhibited more negative 
peer behaviours than female MS Pasifika students which could be one possible reason for this different pattern on peer affiliation. For example, more female MS Pasifika students reported positive peer affiliation behaviours such as "Like for English... we found it hard doing research so we helped each other like we broke the research down and answered the questions". In comparison, male MS Pasifika students admitted less positive peer affiliation behaviours such as "The talking, mucking around and play fighting".

The interview data also suggest several possible explanations about how and why the MS programme may have been associated with increased peer affiliation. These include that increased reflection about peer affiliation by MS students may have been associated with different peer group behaviours compared with TS students; differences in peer affiliation comments were reported by higher achieving students compared with under-achieving students; peer affiliation may have been associated with teacher affiliation; and differences in peer affiliation comments reported by male and female Pasifika students in the MS programme.

The interview data suggest that increased reflection about peer affiliation by MS students may have been associated with different peer group behaviours compared with TS students. For example, when MS students explained why they sat with their friends in the classroom, their reasons were frequently associated with learning. "There's like, there's like rows of computers and you try, well all your mates just sit on like one row so you can just like help each other". Other MS students agreed and said that their learning suffered if they were not in these self-formed supportive peer 
groups. "If we had like the option of sitting together and then got split up then it would be like annoyed and I wouldn't want to be work like just being there with my friends makes me want to do work." In comparison, when TS students explained why they sat with their friends in the classroom they gave more simplistic reasons, often unrelated to teaching and learning. "Because that's my row. Because like it's where we usually sit."

The interview data also show that higher achieving students made different comments when describing negative peer behaviours compared with comments made by underachieving students. Under-achieving students implied there was nothing they could do about their distracting friends claiming "Oh you tell them then they lower their voice down. But a few minutes later it goes high again." "What I don't like about them is sometimes they like always talk loud like real loud so we can't hear what the teacher's saying." In comparison, higher achieving students indicated that they could stop friends from distracting them. "I just acted like I was her parent, I was like her mum like do this, if you don't do well don't do your work you're going to end up as a bum and they laugh and do their work." Because these comments were made by the higher achieving students from both the MS and TS groups, these data suggest that students with prior academic success gained more from either study skills intervention programme compared to students who had not previously experienced as much academic success. These comments may also suggest that under-achieving students de-motivated their peers more than higher achieving students did. 
Other interview data further indicate that peer affiliation was associated with teacher affiliation. Many students reported that distracting students compromised the effectiveness of teachers who were trying to help other students learn. "Sometimes in Science there's a bit of, like the teacher gets frustrated. That's the boys at the back of the class. That's because they're talking amongst themselves." These interview data indicate that more male students exhibited negative peer behaviours in the classroom than female students, again regardless of whether they were in the MS or TS programme. Classroom observation data corroborated evidence that most of the distracting male students were also under-achieving students. These data suggest that under-achieving students had different peer networks and pursued different goals in the classroom than higher achieving students. Related interview data indicate that under-achieving students tended to pursue DJE/work avoidance goals compared to achieving students who tended to pursue DMB/work approach goals. For example, one higher achieving MS Pasifika student reported that her friends divided up a learning task so that everyone did a part and then they combined their answers. In comparison when asked if under-achieving students also formed positive peer groups, the higher achieving MS Pasifika student stated that in her view "They just play around".

These ideas will be investigated further in the Discussion chapter. 


\section{Teacher Affiliation}

Analysis of the interview data indicated that every MS student made comments about teacher affiliation as did every TS student, and that students from both programmes made more responses about teacher affiliation than for any other questions they were asked in interviews. These data indicate the importance these students placed upon teacher-student interactions. The interview data also show that most student responses about teacher affiliation could be placed in one of two categories: teacher strategies or behaviours that supported students' learning, and teacher strategies or behaviours that did not support students' learning.

Students from both groups were quite clear about the positive teaching strategies or behaviours they believed supported their learning. These included feedback from teachers which was prompt and constructive and which showed teachers understood students' learning. They also included teachers' expertise and knowledge of their subject, patient teaching, direct teaching, clarity of teaching, reciprocal teaching, teachers who used humour, teachers who were relaxed, teachers who managed the classroom climate well, teachers who managed the behaviour of disruptive students, and teachers who pushed students to learn.

The qualitative data support the quantitative finding of increased teacher affiliation for MS students compared with TS students; MS students, considered as a whole group, made $60 \%$ of the positive teacher affiliation comments, whereas TS students made just $40 \%$ of the positive teacher affiliation comments. MS Pasifika students made four times as many positive teacher affiliation comments as TS Pasifika students. 
Male MS Pasifika students made twice as many positive comments about teacher affiliation compared to male TS Pasifika students. In comparison, female MS Pasifika students made similar numbers of positive teacher affiliation comments as female TS Pasifika students.

The interview data also suggest a number of possible explanations about how and why the MS programme was associated with an increase in teacher affiliation compared with the TS programme. These include the importance MS students placed on positive teacher-student interactions and that MS students made more comments that associated teacher strategies with learning and achievement compared with TS students. Interview responses also emphasised the importance students placed on positive teacher-student interactions on motivation and achievement: most MS and TS students talked about their teachers in terms of "I like the teacher" and/or "the teacher likes me". For example, students associated warm and friendly teachers with achievement: "She's got a real kind voice and she doesn't put anybody down, like tells you if they're wrong and then helps you fix it up". However the interview data show that MS students made more comments that associated teacher strategies with learning and achievement compared with TS students. For example, one MS Pasifika student's advice for teachers was "break it into parts, learn one part and then make sure we have it in our heads. Then take a little mini test at the end, just so we know, and they know, if we remembered it." In comparison, TS students described helpful teacher strategies in more simplistic terms not necessarily related to teaching and achievement such as, "Get me back on task when I'm not on task, yeah". 
The interview data also show that most students in both programmes reported negative teacher strategies and behaviours that students considered unhelpful. Most of the negative comments that students made about teachers related to student perceptions of the quality of the teaching. Students reported they were de-motivated when teachers appeared to have different expectations of some students, expressed annoyance or "communicated irritation", were impatient, did not push students to achieve, were unsure of their subject, were ineffective, and/or got "off-topic". They also made negative comments about teacher-controlled peer-tutoring, poor classroom management and teacher-directed learning. The interview data also show that many students from both programmes made negative personalised comments about their teachers, suggesting that negative teacher-student relationships may be associated with de-motivation and lack of achievement. These negative student comments about teachers were particularly around the word "not like" and could be generalised as "I don't like the teacher and/or the teacher does not like me".

There were some discrepancies around the quantitative and qualitative data with respect to negative student comments. The interview data show that MS students made more negative comments about their teachers, whereas the quantitative data findings indicated that MS students increased in teacher affiliation. This disparity was similar for MS Pasifika students who made more negative comments about their teachers' strategies at the same time as the quantitative data revealed increased teacher affiliation. Male MS Pasifika students made about the same number of negative personalised comments about their teachers compared with male TS Pasifika students, however female MS Pasifika students were twice as likely to make negative 
personalised comments about their teachers compared with female TS Pasifika students. In sum, the MS programme was associated with increased teacher affiliation for MS students at the same time as the qualitative data showed MS students making more negative comments about their teachers' strategies and behaviours.

One possible argument to explain these findings is that the MS programme provided more opportunities for students to reflect on teacher behaviours. While some of these reflections were negative, the MS programme nevertheless provided more opportunities than the TS programme for students to reflect on teacher-student relationships in a comfortable non-threatening situation. However, this also meant that some MS students felt empowered to report dissatisfaction with teacher behaviours such as the way some teachers used their power in the classroom.

The interview data support this argument, revealing more opportunities in the MS programme for students to reflect on whether their teachers were supportive in the classroom or not. However simply mentioning unhelpful or negative teacher behaviours is not considered the same as acting upon them. In fact it is possible that when MS students reflected upon unhelpful teacher behaviours, this may have led to students reflecting that other teacher behaviours were helpful. There were some data to support this interpretation. For example, one female MS Pasifika under-achieving student initially reported "Teachers just don't influence me at all". "Teachers have no influence?" "They are not even on the list!" The same student later admitted that she "liked" another teacher. "She's the one that's helping me stay in school she's fighting with me - she's cool." More MS students described "not liking the teacher" in terms 
Motivation Interventions via Study Programmes for Under-achieving Students

of teacher behaviours compared with TS students. For example, one MS Pasifika female student explained "He just stands there and looks at your work, he doesn't really talk much. There's no 'hi how's your day?' kind of stuff." She further explained that her achievement may have been affected by this more "distant" teacher behaviour. "I couldn't hand in my assignment... I was like afraid to hand it in... I finished an assignment but I handed it in about a week later because I am not comfortable around the teacher."

The interview data show that the MS programme provided more opportunities for students to reflect on teacher-student relationships in a comfortable non-threatening situation. For example only MS Pasifika students discussed what happened in classrooms when they believed teachers held differential expectations of their achievement: "That's why there are so many fights in his room." Other students took a more resigned approach and muttered "We are all the dumb people." Other MS Pasifika students indicated that it was okay to be defiant when they believed teachers held low expectations of them. "He told me school had run out of options for me, so I punched him." Other data indicated that some Pasifika MS students thought some of their teachers blamed students for lack of achievement rather than looking at their own limited teacher strategies: "He just hands out sheets and like and doesn't make sure you understand he like... he just thinks like because he handed out a sheet that you he thinks that you've learned that part... so once he's put that sheet down that means you've learned it and then he just goes on to the next one and the next one." 
Finally the interview data show that students from both MS and TS programmes reported dissatisfaction with the ways that teachers used their power in the classroom. They expressed frustration about what was happening in their classroom and that they wanted teachers to do something about it. Most students believed that only teachers had the power to change negative teacher-student relationships or a dysfunctional classroom climate. The interview data indicate that MS students reported more pragmatic ideas about how teachers could use their power in the classroom. "Yeah it depends on the teacher." "If they [the teachers] put all the naughty people in together. Then they [the students] don't learn nothing." In comparison, TS students tended to express frustration with the ways some teachers used their power in the classroom rather than providing a solution. "Like walk in, the lesson's just started and then (the teacher) starts yelling... and then that's going to be for the whole lesson, yeah, yelling, you get sore ears, you can't focus, and the only thing you want to do is walk out, out of the classroom - don't want to learn, don't want to learn."

\section{Analysis Five: Changes in Attributions for Best Marks in Assessments}

The interview data show that MS students made more comments about the four traditional attributions for best mark measured in this study - ability, effort, luck and task difficulty — compared to TS students. 


\section{Best Marks Ability}

The interview data seemed to contradict quantitative findings that there were few differences between the two groups on ability attributions for best marks. Several MS students reported that they attributed their best marks to their ability, whereas just one TS student made a positive comment attributing best marks to ability. The interview data also show that MS students provided more explanations about how and why ability attributions were associated with best marks, including that ability is a malleable concept; differences in ability attributions based on students' prior experience with academic success; and that teachers were associated with students' views of their ability.

The interview data show that MS students described ability as "What you know... What you can do" but also agreed that ability could change, "same as sport... you don't just get better... you have to train". Other MS student responses indicated selfpreservation of their ability: "Because I think people of my age like to think of blaming other stuff, then people don't think that they're dumb or anything." In comparison, TS students did not make comments like these about ability. These responses suggest that the MS programme may have been associated with increased ability attributions but that other attributions such as effort may have been more important to MS students.

The interview data also show that higher achieving students had more positive views about their ability than under-achieving students regardless of which programme they were in. For example, one higher achieving student described ability as "What you 
know, what you can do" and "it means you can do it, like you think you can do it". In comparison, another under-achieving student stated that "I'm pretty thick in the head and I don't study". These data may reveal that higher achieving students believed they could do better in the future if they made an effort, as opposed to under-achieving students who may believe they could do slightly better if they worked harder but still held low ability ideas about themselves and doubted they could really do well. These data may also suggest the damage that can be done to achievement when students hold notions such as being "thick in the head" and "stupid".

Finally, the interview data also show that teachers were associated with students' views of their ability. One under-achieving student reported that a teacher asked "if there was something wrong with my brain?" These data indicate that teachers could easily de-motivate students or undermine the ability notions held by some students.

These ideas will be investigated further in the Discussion chapter.

\section{Best Marks Effort}

The interview data support quantitative findings that the MS programme was associated with greater increased effort attributions for best marks compared with the TS programme. All but two of the MS students made positive comments about effort and achievement, whereas no TS students made effort attributions. The interview data also show that only MS students gave detailed descriptions about how 
effort was related to achievement and that many MS students associated effort attributions with teachers.

For example, MS students explained how effort related to achievement: "Well if you don't try... Then obviously you are not going to pass... you've got to try to pass" and "You have to learn how to work if you didn't put effort into it your work would still be like a baby." The interview data also show that many MS students associated effort attributions and achievement with their teachers, which suggests further evidence of the importance students place upon student-teacher interactions. "If she knows we know the answer but are not really thinking or anything then she will get it out of us... it's hard to explain but she has that thing where she can make people talk. So even when you are the quietest person in class she will make you speak and give the answer and stuff." These types of responses were commonly reported by MS students and not at all by TS students, indicating that effort attribution data was very different for the two groups.

These ideas will be investigated further in the Discussion chapter.

\section{Best Marks Easy Test}

The interview data support the finding that the MS programme was associated with decreased attribution of their best mark being due to an easy test. Several MS students commented on test difficulty as an attribution for best marks, whereas no TS students did so. The interview data also show that all MS students who attributed 
their best marks to an easy test were non-Pasifika MS students, indicating that the intervention programme may have been less effective for Pasifika students on decreasing this attribution. The interview data also show that it was higher achieving female and male MS students who dismissed attributions of their best marks to test difficulty compared with under-achieving MS students. "It was quite easy... It could have been harder... It should have been harder... Yeah it was an easy two credits... still credits though." Finally, the low volume of interview data about attribution of best mark to test difficulty may have indicated that the researcher delivered these messages less effectively or that students evaluated task difficulty as a less useful attribution compared to other possible attributions for best marks. These ideas will be investigated further in the Discussion chapter.

\section{Best Marks Good Luck}

The interview data support the findings that the MS programme was associated with decreased good luck attributions for best marks. Many MS students rejected good luck as a viable attribution for their best marks, whereas no TS students made any comments about this attribution. Most MS students who rejected good luck as an attribution for best mark were higher achieving MS students. "You taught us if you want to achieve you have to try and get there, like it's not just luck or anything." However, the interview data also show that despite hearing messages that good luck attributions were negative, four under-achieving MS Pasifika students failed to decrease good luck attributions after intervention. 
These ideas will be investigated further in the Discussion chapter.

\section{Social Attributions for Best Marks}

Analysis of the interview data also show that MS students made more comments about the three social attributions for best mark measured in this study - family, teachers and friends - compared with TS students. The interview data support quantitative findings that students in the MS programme increased on family attributions for best marks compared with TS students, especially for MS Pasifika students. More MS students reported this attribution. MS Pasifika students attributed best mark to family three times as often as TS Pasifika students. The data also show that three-quarters of all MS students who made positive family attributions for their best marks were Pasifika students, whereas just one-third of all TS students who made these family attributions were Pasifika. Female MS students were more likely to positively attribute best mark to their family compared with male MS students.

The interview data also provide a possible explanation about how and why the MS programme may have been associated with increased family attributions for best marks: MS students, especially MS Pasifika students, expressed the desire to reciprocate the effort that they saw their parents had made for them. "An Island family means you see how they have struggled to get forward and it makes you want to work better at school." These data suggest that the MS programme may have more potential to get students thinking about the effects of family on motivation and achievement compared with the TS programme, and that this aspect of the MS 
programme may have been particularly effective for Pasifika students. These interview data also indicate the importance of considering the effects of social attributions on motivation and achievement as well as consideration of the traditional attributions for best marks - ability, effort, luck and task difficulty.

The interview data support quantitative findings of little differences on changes in attributions for best mark to teachers between the MS and TS programmes. MS students made just as many positive attributional comments about their teachers and achievement as did TS students. These data may indicate that both the MS and TS programmes were effective for all students for consideration of the role of teachers on student achievement. However, the interview data about teacher affiliations may be associated with increased attribution for best marks for MS Pasifika students over TS Pasifika students and may also indicate the importance students, especially Pasifika students, place on interactions with teachers.

The interview data support quantitative findings that the MS programme was associated with decreased attribution to peers for best mark. More MS students positively attributed their best mark to peers compared with TS students. The interview data also show that male MS students were more likely to positively attribute best mark to peers compared with female MS students. MS Pasifika students made twice as many positive attributions of best mark to peers compared with TS Pasifika students. Male MS Pasifika made eight times as many positive comments about their peers compared with male TS Pasifika students. These data suggest that the MS programme was more effective in developing students' positive attributions 
about the effects of their peers on motivation and achievement than the TS programme.

The interview data also provide one possible explanation about how and why the MS programme was associated with increased peer attributions for best marks. Some MS Pasifika students reported that friendly competition with friends helped them achieve better marks. "Yeah we made a bet to see who gets the most credits out of us two." "So did that make you work?" "Yeah it made us work". "What's the prize?" "Nothing, just the shame [of losing]". The interview data also suggest that some MS Pasifika students held collectivist attributions alongside individualistic attributions about peers and achievement, providing further evidence of the importance of considering the role of social attributions as well as the traditional attributions of ability, effort, luck and task difficulty on motivation and achievement. These ideas will be investigated further in the Discussion chapter.

\section{Analysis Six: Changes in Attributions for Worst Marks in Assessments}

The interview data show that MS students made more comments about the three social attributions for worst marks measured in this study - family, teachers and friends - compared to TS students. However, the interview data also show that students from both the MS and TS programmes made fewer references to attributions for worst marks in assessments compared with the number of responses about attributions made for best marks in assessments. 


\section{Worst Marks Lack of Ability}

The interview data do not support the quantitative findings that there were few differences between MS and TS programmes on attribution of worst marks to lack of ability. Some MS students reported in interviews that they attributed their worst mark to lack of ability, whereas no TS students reported this attribution. The interview data also provide a number of possible explanations about how and why the MS programme was associated with ability attributions for worst marks compared with the TS programme. These included differences between achieving and underachieving students; conflicting views about lack of ability; and that teachers negatively influenced student perceptions about their lack of ability.

The interview data show that most of the MS students who made lack of ability attributions for worst marks were Pasifika students. The interview data also show most MS Pasifika students who associated lack of ability with under-achievement were under-achieving male MS Pasifika students, whereas higher achieving male MS Pasifika students did not make negative ability attributions about lack of achievement. These data suggest that under-achieving male Pasifika students held more negative ideas about their lack of ability which may in turn relate to school performance. Of particular concern was the finding that only male MS Pasifika students described ability in pejorative terms such as "We are all the dumb people".

Another interview response suggested that MS students held conflicting views about lack of ability. One MS student reported she wanted to learn but did not want to be 
shown up to her classmates as lacking ability. "Well it's embarrassing like putting your hand up, everyone knows that you don't know what to do."

Finally the interview data suggest that teachers negatively influenced student perceptions about their lack of ability. For example, two MS students reported that a teacher repeatedly ignored an under-achieving Pasifika student in class, failed to give this student worksheets and acted as if the student was not there. These data suggest that the MS programme may have had more potential to get students thinking about the nature of ability, effort, intelligence and school performance than the TS programme.

These ideas will be investigated further in the Discussion chapter.

\section{Worst Marks Lack of Effort}

The interview data support the finding for all MS students of attributing worst marks to lack of effort. Several MS students reported lack of effort attributions, whereas no TS students did so. The interview data also show that most of the students who attributed poor achievement to lack of effort were male MS Pasifika students. For example, one male Pasifika MS student explained his poorer than expected NCEA results as "Like I didn't, I didn't put enough effort that I could have". The interview data suggest a possible explanation for this finding: some MS Pasifika students held conflicting goals and attributions such as DJE and effort attributions. For example, a male MS Pasifika student reported "I was thinking oh I wanted to be a cop but like 
everyone is saying it's like hard work and that, but like me I'm, I'm someone who does hard work but only if I want to". These data indicated that the MS programme may have provided more opportunities for students to reflect on goals and attributions because TS students did not make similar comments.

\section{Worst Marks Hard Test}

The interview data support quantitative findings that the MS programme was associated with a small but weak increase in attribution of a hard test for worst marks. Some MS students reported this attribution whereas no TS students did so. However the interview data contradicted quantitative findings that there were no differences in attributions of worst marks to a hard test for Pasifika MS students compared with Pasifika students in the TS programme. Several MS Pasifika students attributed their worst marks to a hard test.

The interview data also show that higher achieving male MS students reported different attributions than under-achieving male MS students. Under-achieving male MS Pasifika students tended to make more frequent comments and more negative comments about how hard tests were affecting their achievement. "It was too hard, no one passed it" and "I know, I tried it out. It was just too hard". In comparison, higher achieving male Pasifika MS students tended to dismiss a hard test as a reason for poor achievement. "It's not based on a hard test, it's based on your work input." These data suggest that higher achieving MS students were already aware that blaming poor marks on a hard test was counterproductive to achievement. These data 
may also indicate that higher achieving students were more receptive to the MS programme messages about useful/less useful attributions for worst marks in assessments. Student interview responses suggest that the MS programme had more potential to get students thinking about the nature of test difficulty and school performance than did the TS programme. However, the interview data may also support the effectiveness of the MS programme in changing the views of higher MS achieving students on this attribution compared with MS under-achieving students. Finally, these data also suggest that the MS programme failed to convince some under-achieving male Pasifika students that an externally located attribution such as test difficulty could be associated with their lack of achievement.

\section{Worst Marks Bad Luck}

The interview data support the finding that the MS programme was associated with a decrease in attributing bad luck to worst marks compared with the TS programme. Some MS students attributed their worst marks to bad luck whereas no TS students did so. However the interview data did not support the quantitative findings that Pasifika MS students showed no difference on attribution of bad luck to their worst marks compared with Pasifika students in the TS programme; many MS Pasifika students made this attribution in their interview responses. The interview data also show that all MS students who reported bad luck as an attribution for worst marks were male. Further, higher achieving MS students tended to dismiss bad luck as an attribution for lack of achievement. For example, one higher achieving male Pasifika 
MS students reported, "Luck? It's got nothing to do with it... maybe if you're tired and not concentrating that could be luck".

In comparison, some under-achieving male MS students made attributions of bad luck to lack of achievement. These data indicate that the MS programme may have been more successful in changing the views of achieving students rather than underachieving students. The data also suggest that the MS programme failed to convince some under-achieving Pasifika students that an externally located attribution such as bad luck could be associated with their lack of achievement.

\section{Worst Marks Family}

The interview data support the quantitative findings that there were no differences on attribution to family for worst marks for all MS students compared to all TS students. Both MS and TS students made negative comments about the role of family in relation to their worst marks in assessments. However, MS Pasifika students made twice as many negative attributions to family compared with TS Pasifika students. Male MS Pasifika students made more negative comments about family and underachievement compared with the MS group of students considered as a whole.

The interview data also provide a possible explanation for family attributions for worst marks. Some MS Pasifika reported that their family members discouraged them from working hard which students then associated with lower achievement. For example, one male MS Pasifika student said that his father had let him choose if he went to 
school or not. "I tell him that I don't want to go to school today and he understands. He just leaves me alone yeah." These data may explain quantitative findings suggesting that MS Pasifika students were slightly more likely to attribute worst marks to family. These data also suggest that while both programmes had potential to get students thinking about the negative effects of family on motivation and achievement, it was the MS programme that had a more marked effect for male MS Pasifika students compared with male TS Pasifika students.

\section{Worst Marks Teachers}

The interview data also did not support quantitative findings of little differences between all MS and all TS students on attribution of worst marks to teachers. MS students made more negative attribution comments about their teachers and worst marks compared with TS students. The interview data does support the stronger quantitative findings that MS Pasifika students reduced in attribution of worst marks to teachers. Some MS Pasifika students explained that lack of achievement was their responsibility as students: "Oh it's not their [teachers'] fault, it's us, we just need to work harder." In comparison, Pasifika TS students did not make these types of comments. These results suggest that the MS programme may have more potential to reduce students' attributions of worst marks to teachers than the TS programme.

\section{Worst Marks Peers}

The interview data support and help explain quantitative findings revealing that MS Pasifika students decreased on the negative attribution of blaming peers for lack of 
achievement. MS Pasifika students made fewer negative comments about this attribution. However the interview indicated differences by gender, as more male MS Pasifika students made negative attribution of worst marks to their peers than female MS Pasifika students. Female TS Pasifika students made more negative attribution of worst marks to their peers than female MS Pasifika students. Male TS Pasifika students made more negative attribution of worst marks to their peers than male MS Pasifika students. These findings also suggest that the MS programme has more potential for increasing student reflection on the effects of peers on their achievement, particularly for Pasifika students. The interview data also reveal that students form peer groups based on similar achievement levels, which means underachieving students may form unhelpful peer groups with other under-achieving students. This could result in further increased under-achievement.

These ideas will be investigated further in the discussion chapter.

\section{Analysis Seven: Changes in Engagement}

The interview data show that equal numbers of MS and TS students exhibited disengagement from school by truancy from class ("wagging"). The interview data also reveal similarities across gender and ethnicity, with equal numbers of male and female students reporting wagging classes as well as similar numbers of Pasifika and nonPasifika students referring to wagging. The interview data also show, unsurprisingly, that higher achieving students attended more classes and that under-achieving students attended fewer classes. Under-achieving students, regardless of group, were 
more likely to report wagging from class. These data are evidence of the damage to achievement when already under-achieving students make poor attendance decisions.

MS students were more responsive than TS students in explaining why students truanted from class. MS students reported that the attendance decisions were influenced by student perceptions of the quality of the teacher-student relationships they experienced. For example, one MS student said her main reason for truanting was poor relationships between her and other students. "Like the rumours and then when girls get jealous because something went down and then everyone changes and turns their back on you and yeah that puts me off school."

MS students reported that the quality of student-teacher relationships affected their decisions to attend class more frequently than TS students. Another MS Pasifika student expressed her disengagement with school; not only was she wagging classes but she said she was probably going to leave school completely and blamed the situation on the deteriorating relationships between her and her teachers. "He said that school is not working and that it would be best if I just leave." In comparison, TS students tended to give more simplistic reasons about why they wagged class: "There was nothing better to do". These data may have indicated that the MS programme has more potential to get students thinking about engagement with school and its effects on achievement compared to the TS programme. These ideas will be investigated further in the Discussion chapter. 


\section{Analysis Eight: Changes in Aspiration}

The interview data support quantitative findings that the MS programme was associated with an increase on aspiration compared with the TS programme. More MS students made references to higher aspirations than TS students. The interview data also show that MS students were more responsive in explaining what affected their aspirations to aim for higher achievement compared with TS students. Most of these aspiration explanations were made in the context of teachers, family and friends.

For example, many MS students said they aspired to higher levels of learning because of positive teacher behaviours. "Like the teacher talked to each of us and stuff and if we needed help he would always come over. Like that motivated me to work." Conversely, negative teacher behaviours appeared to reduce student aspiration. "Like in other classes, like the teacher's always talking to someone and you have to wait. Some of the teachers are just like not very enthusiastic about helping you." MS students also reported that less positive interactions with teachers were associated with lower aspirations. "They hated the teachers and they hated waking up and going to school and other stuff so eventually they just dropped out." In comparison TS students expressed lower aspiration but without explaining why: "I hate school, school sucks".

MS Pasifika students explained that family positively affected aspiration - especially parents. "We're always there for each other and like there for me and like they've always wanted me to do well at school so I can get further in my life." However other MS Pasifika students reported that family could be positively and negatively 
associated with achievement aspirations. "They just say, oh because they wanted me to go to university but I try hard but I don't know." These data suggest that high family aspirations may have encouraged performance rather than mastery goals which in turn may have affected achievement. "So I'm basically doing it mostly for them." In comparison, TS students made low aspiration comments in the context of family in simplistic negative terms, such as "My Dad said if it was legal he'd let me drop out today".

Other MS students explained that the behaviours of brothers, sister and cousins affected aspiration but interestingly negative family behaviours encouraged students to have higher aspirations. One MS Pasifika students reported that her underachieving brothers and sisters who had left school too early tried to encourage her to stay at school. "They're like, oh no, we don't want you turning out like us." In comparison, TS students made more vague low aspiration comments which were associated with family such as "but like my brother dropped out when he was Year 11". These data may indicate that the MS programme is more effective in encouraging students to think about aspirations and their effects on achievement compared with the TS programme.

These ideas will be investigated further in the Discussion chapter.

\section{Summary}

This chapter reported findings based on interviews with 45 participants addressing research question three - students' perceptions of the relative value and helpfulness 
of the TS and MS programmes towards supporting their learning and achievement, with a particular focus on the perceptions of Pasifika students. The findings from these interview data were compared with the previously reported quantitative data. The summary of this chapter is arranged in three sections. Section one covers areas where qualitative and quantitative findings agree, for all students and for Pasifika students. Section two shows where the quantitative analyses were challenged by the qualitative analyses of student interviews for all students and for Pasifika students' results. Section three outlines where the quantitative findings were elaborated by the qualitative findings for all students and Pasifika students. The summary shows that the interview data generally support the quantitative data and there were few instances where the interview data did not align with the quantitative findings. However, the analyses of the interview data provided some common findings that were not as apparent from the quantitative data analysis alone. Finally the qualitative data also provided many explanations which elaborated how and why and for whom the MS programme, in particular, may have affected motivation and achievement.

\section{Section One: Where Qualitative and Quantitative Findings Agreed}

In most areas the qualitative findings supported the quantitative findings. These included that the MS programme was associated with reduced maladaptive motivation factors and decreases on DJE compared with their peers in the TS programme. The interview data also supported the quantitative data that showed that all students and Pasifika students in the MS group increased in peer affiliation and teacher affiliation compared to TS students. The interview data also supported the 
quantitative data about traditional attributions for best marks especially easy test, good luck and friends. The interview data also supported the quantitative findings about worst mark social attributions, especially the decreased attribution of worst marks to peers. Finally, the interview data supported the quantitative findings about reduced disengagement ratings and increased aspiration for MS students compared to TS students.

\section{Section Two: Where Qualitative Findings Challenged Quantitative Findings}

There was just one main area where differences in quantitative analyses were challenged by the qualitative analyses of student interviews. The quantitative findings showed that changes in adaptive intra-personal motivation orientations largely favoured the TS skills programme over the MS programme especially for Pasifika student participants. In comparison the student interview responses revealed that several MS students recalled receiving messages about adaptive intra-personal motivation factors whereas none of the students in the TS programme did.

However the interview data also suggested new findings about similarities between the MS and TS programmes whereas the quantitative data had indicated differences. These included: that higher achieving students made different comments when describing negative peer behaviours compared to under-achieving students; more male students exhibited negative peer behaviours in the classroom than female students, regardless of whether they were in the MS or TS programme; that every MS student made comments about teacher affiliation as did every TS student and that 
students from both programmes made more responses about teacher affiliation than any other questions they were asked in interviews; most MS and TS students talked about their teachers in terms of "I like the teacher" and/or "the teacher likes me"; that students from both MS and TS programmes reported dissatisfaction with the way that some teachers used their power in the classroom; others expressed frustration about what was happening in their classroom and that they wanted teachers to do something about it; and that higher achieving students had more positive views about their ability than under-achieving students regardless of which programme they were in.

\section{Section Three: Where the Quantitative Findings were Elaborated by the Qualitative Findings}

It was encouraging to see how often the qualitative data elaborated upon the quantitative findings. For example, the interview findings support the quantitative data that showed all students and Pasifika students in the MS programme decreased on DJE compared with their peers in the TS programme. However the interview data also indicate that male MS Pasifika students were particularly receptive to DJE messages than other sub-groups in this study. Another example was where the qualitative analysis of student interviews supports the quantitative findings that showed that all students, and particularly Pasifika students, in the MS group increased in teacher affiliation compared with TS students, both for all students and for Pasifika students. However the interview data gave additional detail showing that male MS Pasifika students made twice as many positive comments about their teachers and achievement as male TS Pasifika students. In comparison, female MS Pasifika students 
made similar numbers of positive comments about their teachers as female TS Pasifika students.

The interview data also provided new insight into best mark attributions to good luck because they showed that four MS students continued to attribute their best marks to good luck after intervention. These four students were mostly under-achieving students and all were Pasifika students. The interview data also show that all MS students who attributed their best marks to an easy test were non-Pasifika MS students indicating that the intervention programme may have been less effective for Pasifika students on this factor.

The interview data also show that higher achieving MS students dismissed attribution of their best marks to test difficulty whereas under-achieving MS students did not. The interview data supported these findings and also showed that all MS students who attributed the worst marks to bad luck attribution were male. The interview data also showed higher achieving MS students dismissed bad luck as an attribution for lack of achievement.

The interview data showed that more male MS Pasifika students made negative attribution of worst marks to their peers than female MS Pasifika students; more female TS Pasifika students made negative attribution of worst marks to their peers than female MS Pasifika students; and more male TS Pasifika students made more negative attribution of worst marks to their peers than male MS Pasifika students. The 
interview data also showed that MS under-achieving students made more negative attributions to their worst marks to peers than MS higher achieving students.

In conclusion, the findings reported in this chapter suggest that both interventions produced positive outcomes which support the need for intervention programmes. In addition these interview data confirmed the interesting pattern where the MS programme was associated with what could be considered important decreases in negative motivations, attributions, and self-sabotaging attitudes. The increases in positive motivation factors were similar for the MS and TS groups. However the greater gains were made by the MS students overall and for Pasifika students on decreasing negative attitudes and motivations that can depress effort and academic performance. The interview data often indicated that interactions with teachers, parents and friends were positively and negatively associated with motivation and achievement.

Again these data contest an argument that these results occurred simply by chance and suggested instead that the MS programme may have been more effective for increasing motivation and achievement related outcomes than the TS programme. However it is also acknowledged that these data also show there were differences in these patterns for Pasifika students in the MS and the TS programmes and these conflicts will be discussed fully in the next chapter, the Discussion chapter. 
Motivation Interventions via Study Programmes for Under-achieving Students 


\section{Chapter Six Discussion}

\section{Introduction}

This chapter discusses findings from this study which extend research on the effects of intervention programmes in three areas of motivation and achievement attributions, goals and intra-personal motivation orientations. As both intervention programmes had a focus on outcomes for Pasifika students in New Zealand Secondary Schools, these findings may also extend research about ethnicity and motivation and achievement. The effects of the two programmes on achievement outcomes are discussed, and one overarching idea is that the primary impact of the Motivationenhanced Study (MS) support intervention programme was to decrease a "cluster" of negative motivation-related behaviours that may affect achievement more than the Traditional Study (TS) support programme. Martin, Marsh and Debus (2001) explained that these negative motivation-related behaviours can lead students to adopt a performance orientation, make external attributions for success and failure, hold entity views of ability, exhibit uncertain personal control, and reinforce negative views of teachers. These data suggest that both study skills programmes were useful but that the MS programme was generally more successful in encouraging students towards more positive motivation-related behaviours compared with the TS programme. For example, MS students increased on making internal attributions for 
success and failure, moved from entity views of intelligence to incremental views, decreased in external attributions for success and failure, decreased in uncertain control, adopted a work approach orientation rather than a work avoidance orientation, reduced in stereotype threat, increased in a sense of belonging and experienced an interruption to the "recursive cycle" of negative motivation related behaviours that may have previously affected achievement. I will explain how the data in this study are consistent with attribution theory, helplessness theory, goal theory, and mastery theory. I will also discuss possible mechanisms for how the MS programme may have impacted on achievement including ideas from social psychological intervention theory. These include an explanation of a major difference between the two intervention programmes - that the MS intervention programme may have interrupted negative recursive cycles, which in turn may have affected motivation and achievement. In comparison, the TS programme offered traditional study skills but was not designed to change motivation concepts which may explain why TS student achievement was lower than MS student achievement.

There are three sections to this chapter:

- Section One: Attributions and control

- Section Two: Goals

- Section Three: Intra-personal motivation orientations

\section{Section One: Attributions and Control}

This study measured the effects of two intervention programmes on seven attributions - ability, effort, luck, task difficulty, teachers, friends and family. 
Attribution theory has three dimensions - locus, control and stability (Weiner, 1985, 2010), and this discussion focuses on a comparison of changes in attributions following intervention on two of those dimensions - stability and control. The stability dimension of attributions is important because if a student who is underachieving believes that their ability is stable or fixed it is likely that the student could adopt a fatalistic approach to test situations and come to believe that there is nothing they can do to prevent failure. If a student believes that effort is unstable, then it is more likely that they could also believe that with more effort they could have achieved better marks in an assessment (Blackwell, Trzesniewski and Dweck, 2007). A student's beliefs about the control dimension when attributing causality for best and worst marks is important: if a student believes they have some control over the reasons why they may have done well or badly in an assessment situation, there is a greater chance that they may engage in study behaviour to do better on future tests.

A comparison of the effects of the MS and TS programmes on these seven attributions for best marks for all students show that there were differences on four of the seven attributions for best marks with at least an effect size of greater than 0.2. Hattie (2009) explains that this level is rather small because one year of regular classroom teaching should produce an effect size of 0.4 on learning outcomes. In comparison, the two intervention programmes in this study were relatively short (6-8 hours over a period of four weeks). It could be argued that outcomes associated with two alternative interventions of such short duration can be compared with a full year of regular classroom teaching merit, even where the effect sizes are small (0.2). The four attributions for best marks show an effect size difference between the two 
intervention programmes above 0.2 were effort, easy test, good luck and friends. Each of these more significant findings will be discussed in this section.

\section{Effort}

The details of students' pre-test and post-test data were outlined in the qualitative findings chapter and also have been further analysed, especially for changes in ranking of attributions. The most noticeable finding from the quantitative data was that MS (all) students increased on effort attributions for best marks whereas TS (all) students decreased on effort attributions for best marks following intervention. This was a statistically significant result and the effect size favoured the MS programme (0.63). These findings suggest that the motivation-enhanced MS programme had a greater effect on increasing effort attributions for best marks than the TS intervention programme. One possible explanation of these data is that because MS students received direct messages about the relationship between effort and achievement whereas TS students did not, MS students increased on attribution of best marks to effort while TS students decreased. However a closer examination of the data show that both MS (all) and TS (all) students ranked effort as their number one attribution for best marks at both pre-test and post-test, so it is not possible to state that the MS programme improved the overall ranking of the effort attribution for MS or TS students. These data suggest that students from both programmes continued to rank effort high on their list of possible attributions for best marks in assessments. However there were discernible differences by programme because the data show MS (all) students ranked this effort attribution eight percentage points higher than the 
second ranked attribution (teachers) after intervention. In comparison TS (all) students ranked the effort attribution just two percentage points ahead of the second ranked best mark attribution (which was also to teachers).

MS (Pasifika) students also increased on effort attributions for best marks whereas TS (Pasifika) students decreased following intervention. Again the medium effect size difference favoured the MS programme (0.63). These findings suggest that the motivation-enhanced MS programme had a greater effect on increasing effort attributions for best marks after intervention for all students and for Pasifika students and that the effects of the two programmes on effort attributions for best marks did not vary by ethnicity. The data show that effort was the highest ranked attribution for best marks by both MS and TS Pasifika students before and after intervention, so again it is not possible to state that either programme improved the overall ranking of the effort attribution for best marks. However these data also show that, following intervention, MS Pasifika students increased on effort attribution for best marks by eight percentage points whereas TS Pasifika students reduced on effort attribution by four percentage points (see appendixes).

These findings about differences between the effects of the two intervention programmes on effort attributions could be evidence that MS students adopted a mastery learning approach rather than a performance approach. This is because effort is considered to reflect a mastery orientation where students focus on learning new skills (Grant and Dweck, 2003; McClure et al., 2011). An alternative approach that students can take to mastery learning is the performance approach "which is generally 
Motivation Interventions via Study Programmes for Under-achieving Students

associated with attributing outcomes to stable causes such as ability", and McClure et al. explain that "People with a performance orientation avoid new learning opportunities for fear of performing poorly and appearing incompetent" (p.72). It could be argued that the MS programme was more effective in encouraging students to adopt a mastery learning approach rather than a performance learning approach because there were no differences between the two programmes on ability attributions.

\section{Ability}

The data about ability attributions for best marks show that all students in both programmes reduced on attribution of best marks to ability following intervention and that the effect size difference between the two groups was negligible (0.08). Further analysis shows that students in both programmes continue to rate ability high on their attribution list for best marks following intervention. Prior to intervention, ability was ranked by MS (all) and TS (all) as the third highest attribution for best marks. In comparison, effort attribution was ranked number one and teacher attribution was ranked number two by all students in both groups. After intervention, ability was still ranked third highest attribution for best marks by students in both groups. This means it is not possible to say that either programme changed the overall ranking of the ability attribution for best marks. However, these findings may indicate that students in both programmes perceived ability as an unstable construct and that both programmes may have been effective in reducing ability attributions for best marks. 
These findings also indicate that students regarded effort attributions for best marks as more important than ability attributions regardless of intervention programme.

MS and TS Pasifika students also both reduced on attribution of best mark to ability with no discernable effect size difference between the two groups (0.00). There was one slight difference in ranking of the ability attribution for best marks by MS Pasifika students: the ability attribution for best marks was ranked fifth by MS (Pasifika) students before and after intervention. In comparison the ability attribution for best marks was ranked third by MS (all), TS (all) and TS (Pasifika) both before and after intervention. While this discrepancy may simply have been due to the relatively small number of students in this study, it is possible that these data indicated that some Pasifika students rank the internally located ability attribution for best marks lower than other students. The data also show that TS Pasifika students ranked ability as third in the attribution list, below effort and family but above friends and teachers. This pattern was more like the MS (all) and TS (all) arrangement, whereas the MS (Pasifika) pattern was slightly different to the TS (Pasifika) pattern which again may have been due to the small number of students in the study. However this finding may have indicated that some Pasifika students place social attributions as explanations for best marks above traditional attributions. This point will be discussed more fully later in this chapter.

The data show that MS (all) students reduced in attributing their worst mark to lack of ability. In comparison, TS (all) students increased on this attribution. However, the effect size difference between the two groups was negligible (0.09). Students in both 
programmes continued to rate lack of ability high on their attribution list for worst marks after intervention. The pre-test data on the lack of ability attribution for worst marks show very similar scores for MS (all) and TS (all) students prior to intervention as both MS (all) and TS (all) ranked lack of ability as the third most important reason for worst marks. After intervention students from both programmes continued to rank lack of ability as the third most important reason for worst marks. These data may indicate that regardless of intervention, many students continued to hold to negative views of their ability. However these data also indicate that because MS students received messages about the incremental nature of ability and achievement, and TS students did not, the MS programme may have been more effective in assisting students to view ability as an unstable rather than a stable construct.

This point is strengthened by the data that showed that both MS (Pasifika) and TS (Pasifika) students decreased on attribution of worst marks to lack of ability after intervention. The effect size difference favoured MS (Pasifika) students (0.18). These data also indicate that both intervention programmes may have been particularly effective in reducing students' negative perceptions of their ability for Pasifika students compared with results for all students. The pre-test data also show that MS (Pasifika) and TS (Pasifika) students ranked lack of ability as the third most important reason for best marks. This position was relatively unchanged after intervention which again illustrates the deeply held beliefs that some students have about their lack of ability. 
McClure et al. (2011:72) reported that "Few studies of attributions have examined the relationship between the internally located attributions of effort and ability and actual achievement in school or other settings. Those studies that have been performed have shown mixed findings" (p.72). They reported three patterns - effort attributions were the stronger predictors of achievement, ability attributions were stronger predictors of achievement, and ability attributions were equally predictive of achievement. Because the data showed that the MS programme had more effect on effort attributions than ability attributions, these findings may have been associated with the differences in achievement outcomes for the two programmes (details are provided in the Qualitative Findings chapter). The data also suggested that effort attributions were stronger predictors of achievement than ability attributions.

These patterns support the findings from Liu et al. (2009) who investigated the effects of aspiration and attributions on academic achievement. They reported that "students with high educational expectations and effort attribution exhibited higher growth rates in their academic achievements" (p.911). Liu et al. also reported that ability attributions were not significant in their effect on learning rates.

The findings that show that both intervention programmes were successful on reducing ability attributions for best marks suggests that both programmes successfully signalled incremental rather than entity views to students (Vispoel and Austin, 1995). These findings held regardless of ethnicity, for both MS all students and MS Pasifika students. This may indicate that these findings also support the idea that interventions that can affect ability and effort attributions are useful - see for 
example McClure et al. (2011) who reported that "Effort and ability may operate in synergy rather than being competing factors. The finding that students' attribute their high marks to both effort and ability is consistent with this view" (p.79).

These findings support the idea that internally located attributions were more closely associated with changes in achievement (McClure et al., 2011). However the study also tries to explain the differences in achievement between the two groups. As both groups decreased on attribution of best marks to ability but only the MS group increased on attribution of best marks to effort, it could be argued that the MS programme may be more closely associated with increased National Certificate of Educational Achievement (NCEA) achievement.

\section{Control}

The link between students who made effort attributions compared with students who made ability attributions could be due to differences in control dimension of attribution theory. As explained earlier in this chapter, if students believe they have some control over the reasons as to why they may have done well or badly in an assessment situation, there is a greater chance that they may engage in the necessary study behaviour to do better on future assessments. McClure et al. (2011) explain that "Attributing outcomes to stable, uncontrollable causes such as ability weakens motivation and in extreme cases leads to learned helplessness" (p.71). Control is associated with mastery and hopefulness, and lack of control is associated with 
helplessness. These ideas are relevant to the findings in this study about changes in effort and ability attributions and achievement as Perry et al. (1993) noted that:

This stability/controllability difference between ability and effort lies at the heart of helpless and mastery orientations to academic achievement... helplessness is more likely to result from a lack of ability attribution (stable/uncontrollable factor) for failure, whereas mastery is more probable from a lack of effort attribution (unstable/controllable factor) for failure (p.690).

McClure (1985) and McClure et al. (2011) also showed that effort attributions were consistent with helplessness theory as did Liu et al. (2009). Because MS students showed both increased effort attributions and increased control after intervention compared to TS students, it is possible that the MS programme had positive effects on both the control and stability dimensions of attributions and helplessness.

The MS programme was associated with decreased uncertain control. As shown in the Quantitative Findings chapter, both MS (all) students and TS (all) students reduced in uncertain control after intervention programmes; further, there was a small effect size difference on decreased uncertain control which favours the MS programme (0.21). These quantitative findings may indicate that both intervention programmes have the potential to affect uncertain control positively. Gains were made as a function of both interventions, which is a positive finding as this supports the worth of intervention programmes. However, because control was overtly part of the MS programme and 
Motivation Interventions via Study Programmes for Under-achieving Students

only covertly part of the TS program, it appears that overt messages about control were more effective than covert messages about control. The interview data supported this interpretation: many MS students recalled messages about what they could "control" in the learning-teaching process whereas none of the TS students recalled hearing about messages about "control".

In comparison, the data about MS Pasifika students show decreased uncertain control after intervention whereas TS Pasifika students increased on uncertain control with a medium effect size which favoured MS Pasifika students (0.78). This result indicates that the MS programme may have been particularly effective in reducing uncertain control for Pasifika students. It is further argued that control is related to the idea that people whom students care about demonstrate they value the outcome and ideas about non-contingent or inconsistent feedback (Azjen, Walkey et al., 2013).

This means that it was not just the control messages that were important here but also how the messages were delivered. Some MS Pasifika students believed that teachers had a mediating effect on students' levels of control and achievement. In addition, some MS Pasifika students talked about "control" in association with the level of support they received from their teachers. Such as "You know like you need your teachers to guide to help you". It is likely that a student who fails enough times will simply stop trying as they may believe that they lack the control to do well in tests. I will also argue that teachers must realise that they are central to enhancing students' motivation because students may develop learned helplessness. Teachers may set up the learned helplessness situation in the first place if they are the agents of 
assessment and gatekeepers of success and failure. How does a particular teacher, especially in a Secondary School situation, where a student may have up to ten teachers, know what effect the award of a failed grade will be if the student has received that same message repeatedly?

The concept that teachers have a mediating effect on students' perception of control may also be extended to teachers having a mediating effect on students' perceptions of effort and ability attributions. The interview data suggest that teachers can negatively influence student perceptions about their lack of ability. For example, two MS students reported that a teacher repeatedly ignored an under-achieving Pasifika student in class and failed to give worksheets to this student. Another under-achieving student reported that a teacher made disparaging remarks about his ability. Perry et al. (1993) suggested how teachers might make positive attribution comments during regular teaching classes:

During and after class students often make statements such as: “I'm not smart enough to pass," "I was just lucky to do well on the test," or "The material is too difficult." Faced with such attributional statements, the instructor has an ideal opportunity to encourage the student to think differently about the event, by suggesting a more suitable explanation: "You do have the ability; otherwise you would not be here," "Luck has less to do with your success than your approach (strategy) to the course," or "This may be a difficult course, but you can master the material if you study harder" (p.718). 
The findings discussed so far about effort, ability and control support the development of a possible mechanism to explain how the observed differences between the two intervention programmes may also be associated with changes in achievement. The proposed mechanism so far is an intervention that promotes increased effort attributions for best marks and decreased uncertain control may be associated with increased achievement. The mechanism also indicates that teachers may have a mediating effect on students' perceived levels of control over their achievement and ability to succeed at the achievement task.

This mechanism will be developed further in this chapter in the discussion of other aspects of motivation and achievement such as goals and inter-personal and intrapersonal motivation orientations. First, other findings with effect size differences greater than 0.2 are discussed, including luck, friends, family and teachers.

\section{Luck}

The quantitative data show that MS (all) students ranked the good luck attribution for best marks as the lowest out of seven attributions from which they could choose (see appendixes). These data also showed that following intervention, MS (all) students reduced on assigning good luck attribution for their best marks. In comparison, TS (all) students also ranked good luck as the lowest out of seven choices as an attribution for their best marks. However, following intervention, TS (all) students increased slightly on this attribution although the overall ranking did not change. The small to medium effect size difference favoured the MS (all) students following intervention (0.40). 
The data for Pasifika students was slightly stronger. MS (Pasifika) students ranked good luck as the lowest out of seven possible attributions for their best marks both before and after intervention. However, the quantitative findings also show that MS (Pasifika) students decreased on this attribution following intervention. In comparison, TS (Pasifika) students initially ranked good luck lowest out of seven in attribution for their best marks before intervention. Following intervention, TS (Pasifika) students raised the ranking of the good luck attribution for best marks to third equal alongside ability and family. The qualitative data also show that TS (Pasifika) students increased markedly for percentage terms on the good luck attribution for best marks following intervention. Not surprisingly it was a medium sized effect difference between MS (Pasifika) and TS (Pasifika) students which favoured MS (Pasifika) students (0.55).

The quantitative data showed that MS (all) students initially ranked bad luck as fifth out of seven attributions for worst marks. Following intervention this ranking had dropped to seven out of seven on the self-rating students gave to the worst mark attribution. In comparison, TS (all) students ranked bad luck as number four out of seven attributions for their worst marks. This ranking remained relatively unchanged following intervention, shifting to fifth out of seven attributions. The quantitative data also show a small effect size difference favouring MS (all) students compared to TS (all) students (0.28).

Results for Pasifika students showed that MS (Pasifika) students ranked bad luck as the lowest out of seven possible attributions for their worst marks following 
intervention. In comparison, TS (Pasifika) students ranked bad luck as third out of seven attributions for their worst marks. Following intervention, this ranking had dropped to fifth equal out of seven, and the overall self-rating TS (Pasifika) students gave also dropped. Not surprisingly since both groups of students reduced on their attributions of bad luck for their worst marks, the effect size difference between the two groups following intervention was null (0.04).

These findings support the usefulness of further research about attributional retraining interventions. The MS programme was partially based on the principles of attributional retraining and Perry et al. (1993) explained how AR interventions are designed:

"Attributional retraining comprises a set of procedures generally intended to restructure a person's explanations about events in his/her surrounding environment... For success outcomes, external, unstable attributions, such as good luck, must be replaced with internal, more stable attributions, such as high ability, thereby encouraging expectations of continued success" (p.691).

Attributional retraining has also been associated with increased achievement. For example McClure et al. (2011) reported that "research has shown that attribution training can improve academic performance, by training students to make controllable attributions for success and failure, to encourage persistence" (p.72).

These findings also support previous research findings that intervention programmes can be more effective on changing luck attributions compared with changing task 
difficulty attributions. This is generally considered to be because luck is regarded as being external, uncontrollable, and unstable. In comparison, task difficulty is considered external, uncontrollable, and stable (McClure et al., 2011).

It is likely that the MS programme encouraged changes in luck attributions because MS students (all) received messages about the futility of luck as an attribution for best marks whereas TS (all) students did not receive these messages. MS students decreased on the good luck attribution, whereas TS students increased suggesting that the good luck attribution messages were delivered differently to the two groups and possibly acted upon differently. For Pasifika students, the result was similar but even more marked which may have indicated that Pasifika students were more receptive to the luck attribution messages. The data do not indicate that Pasifika students rated luck highly as an attribution compared with all students: regardless of programme, both MS all and Pasifika as well as TS all and Pasifika students rated luck as the lowest possible attribution for best marks prior to intervention. It was what happened after intervention that is more interesting. MS Pasifika students continued to rank luck as the seventh of seven attributions whereas TS Pasifika students ranked luck as an attribution for best marks at third-equal after intervention. These findings support the idea that reducing good luck attributions for best marks can be associated with higher achievement. For example Meyer et al. (2007) reported that "Attributing one's best mark to good luck was associated with gaining slightly more unit standard credits, fewer achievement standard credits, and fewer achievement standard credits with Merit and Excellence" (p.47). 
These data also indicate the simplicity of the luck attribution message and receptivity of students of this age to ideas that luck is a poor attribution for best marks. MS students rejected good luck as a viable attribution for their best marks - "You taught us if you want to achieve you have to try and get there, like it's not just luck or anything" - whereas no TS students made any comments on this attribution. These data also add to the further development of the motivation mechanisms by which the MS programme may have affected achievement. These data appear to indicate that decreased good luck attributions for best marks can be associated with higher achievement

\section{Family}

The study also investigated the effects of programmes on the social attributions of family for best marks. The quantitative data show no difference between MS (all) and TS (all) students (0.13) on this point. In comparison, the quantitative data show that both MS and TS Pasifika students reduced on attribution to family for best marks, but MS (Pasifika) students showed a smaller decrease with a small effect size difference of 0.24. The interview data support the finding that MS students increased on family attributions for best marks compared with the TS students, especially for MS Pasifika students, as more MS students reported this attribution. MS Pasifika students attributed family to best marks three times as often as TS Pasifika students. The data also show that three-quarters of all MS students who made positive family attributions for their best marks were Pasifika students whereas just one-third of all TS students who made these family attributions were Pasifika. Female MS students were 
more likely to positively attribute best mark to their family compared to male MS students. These findings support research that associates family attributions with achievement (McClure et al., 2011; Vispoel and Austin, 1995).

These data may also indicate that family has a mediating effect on students' attributions for best marks. MS Pasifika students explained they wanted to reciprocate the effort they saw their parents had made for them. These data suggest that the MS programme may have had greater potential for encouraging students to think about the effects of family on motivation and achievement compared with the TS programme, and that this aspect of the MS programme may have been particularly effective for Pasifika students. The quantitative data about the effects of the two programmes on worst mark attributions to family show no difference between the groups, for all students and Pasifika students. This finding may support research by Ng et al. (1995) that students may see family as contributing to their success more than to their failure. These data also indicate the importance of considering the effects of social attributions on motivation and achievement as well as consideration of the traditional attributions for best marks such as ability, effort, and luck.

\section{Friends}

The study also investigated the effects of programmes on the social attributions of friends for best marks. The quantitative data about all students showed that MS (all) decreased on attribution of best marks to my friends following intervention. In comparison, TS (all) stayed about the same on this factor following intervention. There 
was a medium effect size for a decrease in attributing best marks to friends in the MS group in comparison with the TS group (-0.49).

The quantitative data about Pasifika students show that both groups decreased on attribution of best marks to friends following intervention. There was an effect size approaching the small level (-0.18) which favoured MS Pasifika students.

Vispoel and Austin (1995) did not categorise friends as a best mark attribution as they have done with family and teachers. However, assuming they had followed the same pattern, the dimensions of best mark attributions to friends would be external, stable, and uncontrollable. McClure et al. (2011) reported that "Research has not shown a consistent relation between teacher attributions and achievement" (Kurtz-Costes and Schneider, 1994; O’Sullivan and Howe, 1996; Vispoel and Austin, 1995). Liu et al. (2009) found that attributing one's achievement to others (teacher instruction, parental discipline, or help from friends) was linked with "lower achievement outcomes over time" (p.72).

The quantitative data in this study support this view. A reduction in best mark attributions to friends could be part of the mechanism of how the MS programme was associated with some higher NCEA achievement outcomes compared to the TS programme. The larger reductions in best mark attributions to friends between MS (all) and TS (all) (-0.49) compared to smaller reduction on best mark attributions to friends between MS (Pasifika) and TS (Pasifika) (-0.18) may also be associated with the larger effect size increases in some NCEA achievement outcomes between MS (all) and 
TS (all). For example, the effect size difference for total credits at Achieved level for MS (all) compared with TS (all) students was (0.35) compared to the effect size difference for total credits at the Achieved level for MS (Pasifika) compared with TS (Pasifika) students of (0.28). McClure et al. (2011) reported that one reason to explain how this mechanism may work is that "according to Weiner's $(1985,2010)$ theory, attributing achievement to others is an external, uncontrollable attribution, which may decrease a sense of self-efficacy and the expectancy of influencing outcomes. It may also reflect the self-serving bias" (p.72).

\section{Teachers}

The quantitative data about Pasifika students on worst mark attributions to teachers showed that MS (Pasifika) students decreased on this attribution whereas TS (Pasifika) students increased on this attribution. The effect size difference favoured MS (Pasifika) students (0.54). These data could be interpreted as showing that MS (Pasifika) students blamed their teachers less than TS (Pasifika) students following intervention. Some MS (Pasifika) students explained that lack of achievement was their responsibility as students: "Oh it's not their [teachers'] fault, it's us, we just need to work harder". In comparison, TS (Pasifika) students did not make these types of comments. This finding may have indicated that the MS programme may have had more potential to reduce students' attributions of worst marks to teachers than the TS programme. These data may also indicate that teachers had a mediating effect on students' attributions for worst marks. This finding will be discussed later in this 
chapter alongside the increased teacher affiliation differences between these two groups of students.

From the findings discussed so far about effort, ability and control and now luck, family, friends and teachers, it may be possible to begin to further develop a possible mechanism that helps to explain how the observed differences between the two intervention programmes may also be associated with changes in achievement. The proposed mechanism could now be extended to include an intervention that promotes increased effort attributions for best marks and decreased uncertain control associated with increased achievement. The mechanism also indicates that teachers, family and friends may have a mediating effect on students' perceived levels of control over their achievement and ability to succeed at the achievement task. These data appear to indicate that decreased good luck attributions to best marks can be associated with higher achievement

However, attribution motivation theory is only part of the picture. Other relevant theoretical frameworks include goal theory and self-views (intra-personal) motivation. For example, Perry et al. (1993) noted that "a further limitation of current research is the exclusive focus on changing attributions only, even though other aspects of attribution theory lend themselves to interventions" (p.713). McClure et al. (2011) investigated whether attributions are better predictors of achievement than other motivational factors and these and other ideas are discussed in section two of this chapter on goals, motivation and achievement. 


\section{Section Two: Goals}

Section two of this discussion chapter considers how achievement goal theory is also associated with changes in motivation orientations found in this study. In the findings chapters, changes in two motivation orientations called Doing My Best (DMB) and Doing Just Enough (DJE) were reported. DMB and DJE may be considered achievement goals. Martin and Dowson (2009) explained that goal motivation theory is related to achievement through the meanings and goals students attached to assessments. They explain that goal motivation theory is useful in the educational context because it "located" where a student was on an "approach-avoidance" continuum. For example, a student who willingly chooses to participate in a classroom activity would be more positively motivated than a student who avoids taking an assessment because they think they will fail (p.335). Hodis et al. (2011) reported that "DMB is considered to resemble the "performance-approach" achievement goal whereas DJE shares features with the "performance-avoidance" achievement goal (p.2). Because these DMB and DJE motivation orientations are associated with effort, the previously discussed findings about changes in effort attributions which support the MS programme can be considered to enhance the argument that increased DMB and reduced DJE levels following the MS and TS intervention programmes may also be associated with increased achievement.

A key question for this study is a comparison of the effects of the MS programme on effort attributions compared with motivation orientations. The data in this study showed that effect size changes for MS (all) students on effort attributions were similar to effect size changes in some motivation orientations, especially reductions in 
DJE compared to TS (all) students. This finding holds for ethnicity, as the data also showed that for MS (Pasifika) students the effect size differences on decreased DJE and increased effort attributions for best marks were comparable to MS (all) students. These findings suggest that the strongest effects of the MS programme, for all students and Pasifika students, were on increasing effort attributions for best marks and reducing DJE. But which has the stronger effect?

Related research in New Zealand Secondary Schools compared the effects of various attributions for best and worst marks alongside DMB and DJE, peer affiliation and teacher affiliation, as predictors of achievement (McClure et al., 2011). Using regression analysis, they showed that all of these combined factors accounted for $38 \%$ of the variance in grade point averages (GPA). However this research also showed that DMB and DJE were four times as predictive of achievement compared to effort attributions for best and worst marks. In comparison, my study shows that the effect size difference between the MS and TS groups for DJE and effort attributions were similar to each other, but greater than DMB. However the data that showed that the MS programme had an equal effect on effort attributions and DJE do not necessarily mean that this implies that these factors had equal effect on changes in achievement. It is possible that the MS programme was able to influence effort attributions just as strongly as affecting DJE because the effort attribution message was a very simple and direct message which was readily picked up by students. This finding may also indicate that levels of effort are an implicit part of both effort attributions and the DMB/DJE motivation orientations. 
Since I do not directly report on changes in GPA in this study, it is useful to compare my findings with another achievement indicator - total credits in NCEA, which my study and the McClure et al. (2011) research both measure, so this means a more direct comparison can be made between the two pieces of research. McClure et al. (2011) showed that DJE was the strongest predictor of NCEA total credits; DJE was twice as strong a predictor compared to effort attributions for best marks; and DJE was four times as strong a predictor of NCEA total credits compared with DMB. This research showed that DJE may be the strongest predictor of total NCEA credits and that $\mathrm{DMB}$ is much less predictive of future total NCEA credits. These findings are relevant to my study because MS (Pasifika) students reduced on DJE but showed no change on DMB relative to TS (Pasifika) students. This indicates that one of the most important effects of the MS programme could be a reduction in DJE, especially for Pasifika student achievement.

This research also provides a possible quantification of the relative effects of increasing effort attributions compared to decreasing DJE, and suggests that reducing DJE may have twice the effect on prediction of total NCEA credits compared to increasing effort attributions for best marks. One other useful point that arises from a comparison of my study with this research is that McClure et al. (2011) showed that teacher affiliation was also a strong predictor of total number of credits in NCEA, almost as strong a predictor as attributions for best marks. The relevance of this point will be discussed later in this chapter. 
The body of research from Meyer and her colleagues (e.g., Meyer et al., 2006, 2007, 2009) in New Zealand Secondary Schools in the context of the NCEA is relevant to this study. For example, Meyer et al. (2006) reported that "the strongest predictors of high academic achievement and higher grades were a high motivation orientation towards Doing My Best and a low motivation orientation towards Doing Just Enough" (p.2). The findings in this study may be compared to this body of research. Meyer et al. (2009) found that "The Doing My Best orientation in 2005 is significantly related to more total credits, internal standards with Excellence and externally assessed standards at all levels of achievement in 2007. The Doing Just Enough orientation is significantly related to fewer total credits, internal standards with Excellence, and externally assessed standards at all levels; Doing Just Enough also is significantly related to higher total unit standard credits" (p.22). The findings in this study support this research, however it is possible to quantify the effect in increased DMB and decreased DJE. Related research by Hodis et al. (2011) quantified changes in DMB and DJE as they proposed that for every DMB percentage point increase a 1.10 credit increase could be expected, and for every DJE percentage point reduction a 1.13 NCEA credit increase may occur. For the purposes of this research this will be referred to as the "Hodis model," and it is possible to apply this model to the data in this study, as changes in DMB and DJE were measured by percentage points.

MS (all) students increased by two percentage points on DMB and decreased by six percentage points on DJE compared to TS (all) students. Using the Hodis model this suggests that MS (all) students in this study should gain 8.98 more total NCEA credits after intervention. In comparison TS (all) decreased two percentage points on DMB 
and also increased in DJE by one percentage point suggesting a total expected decrease of 3.33 NCEA credits after intervention. The Hodis model suggests that changes in DMB and DJE could lead to a 12.33 total NCEA credit difference between MS (all) and TS (all) students following intervention. A comparison with the data in this study showed that MS (all) students gained nine more total NCEA credits than TS (all) students. These data support the direction of the Hodis model although the number of credits gained is not as much as the 12.33 credits predicted. This difference could be expected, however, as other motivation factors may also have impacted upon this achievement outcome, for example changes in effort attributions for best marks, a factor which this research, about the effects of a motivation-enhanced study skills intervention, argues impacted on future achievement outcomes.

A further test of the Hodis model on data about Pasifika student changes in DMB and DJE after intervention is useful because these data about Pasifika students were different than the data about all students. MS (Pasifika) decreased by four percentage points on DJE but showed no change on DMB following intervention. In comparison TS (Pasifika) increased on DMB by one percentage point and also increased on DJE by two percentage points after intervention. Applying the Hodis model to these data suggests that MS (Pasifika) students could be expected to gain 5.78 more total NCEA credits than TS (Pasifika) students. The actual data showed that MS (Pasifika) students gained 7.65 more NCEA credits than TS (Pasifika) students. Again these data support the direction of the Hodis model, with the number of credits gained slightly exceeding the number of credits predicted. 
This comparison means that application of the Hodis model to the data about all and Pasifika students in this study showed the model correctly predicts the direction of achievement. However these changes in DMB and DJE and achievement also suggest that decreased DJE may be a stronger predictor of total NCEA credits than DMB. This argument is strengthened by other data which showed MS (Pasifika) students had no change in DMB but a four percentage point decrease in DJE which suggests that decreased DJE by itself is capable of predicting changes in achievement for Pasifika students. This supports research from Meyer et al. (2009) who reported that while "both the Doing My Best and Doing Just Enough orientations were significantly related to future achievement for New Zealand European and Asian students, the Doing Just Enough orientation was related to achievement for all ethnic groups" (p.9).

There is further evidence of the importance of DJE compared to DMB from Hodis and his colleagues (2011) who suggested that the impact of reduced DJE on achievement as measured by total NCEA credits is greater than a combination of increased DMB and decreased DJE. This is because changes in DMB and DJE have been associated with the formation of two groups of students who have different achievement outcomes. Hodis et al. (2011) named these two groups the "high slight" and "low steep" groups which refer to initial achievement levels of students and how these achievement levels change over the latter years of secondary education. "High slight students start with relatively high numbers of credits but the rate of accumulation of credits decreased slowly over time whereas low steep students begin with lower numbers of credits but the rate of accumulation of credits decreased more markedly than the high slight group" (p.7). Clearly it would be preferable for students to be part 
of the "high slight" group, and Hodis and his colleagues (2011) further showed that students' chances of allocation to one of these two groups was predicted by changes in their levels of DMB and DJE. "A one-unit increase on the DJE was associated with a $20 \%$ reduction in odds of belonging to the high slight class and the odds of belonging to the high slight class increased 5.7\% for each 1-point increase in Doing My Best" (p.6). Here Hodis et al. (2011) suggest that the impact of reducing DJE has more than 3.5 times the effect of increasing DMB. Therefore the findings in this study support the chances that both MS (all) and MS (Pasifika) students have of "high slight" group membership after intervention compared to TS (all) and TS (Pasifika) students. In the first section of this discussion chapter, I also outlined a possible mechanism from the findings discussed so far which proposed that an intervention that promotes increased effort attributions for best marks and decreased good luck attributions with best marks could be associated with higher achievement. This mechanism can now be extended to include a statement that increased DMB and decreased DJE may also be associated with changes in achievement. In addition, the effect of the decreased DJE appears to be greater than increased DMB.

Clearly, the quality of the design content and delivery of the MS intervention programme is critical to any claims that can be made about the effectiveness of such an intervention when compared to a TS skills programme. One key question still needs to be answered: how exactly did the MS programme increase DMB and reduce DJE? One explanation is that the MS study skills programme operated within the context of a task-focused, standards-based assessment system - the NCEA - which gives integrity to the MS programme. Meyer et al. (2006) explained that "unlike with the 
norm-referenced and scaled examinations of the previous system, the standardsbased assessments for today's students do not focus on comparisons across students but on how well the student performs in relationship to a standard, that is, a particular learning outcome" (p.7). Understanding how the MS programme tried to increase $\mathrm{DMB}$ and reduce DJE via mechanisms can be better understood by comparison with the body of research about DMB and DJE (such as Hodis et al., 2011; McClure et al., 2011; Meyer et al., 2006, 2007, 2009). This research is situated within the context of the qualification New Zealand Secondary School students seek to achieve - NCEA. Hodis et al. (2011) explained that DMB and DJE "are context specific, relating students' motivation to students' specific academic context, in this case the NCEA system, rather than to how other students perform" (p.2). Meyer et al. (2009) further suggested that "shifting student motivations away from the more negative Doing Just Enough to the more positive Doing My Best orientation may require focused academic tasks and activities where students receive support to achieve positive outcomes through their own endeavours" (p.9).

In this study, motivation concepts were discussed with MS students during conventional lessons while students were also studying for their NCEA. The researcher would take opportunities to seamlessly place motivation messages alongside teaching algebra or chemistry concepts. For example, "Now we have just learned how to factorise equations and next week we will have an assessment opportunity. How will you prepare for the test? Perhaps getting a higher grade than your friend is important to you? But remember when you focus on competing with others, you pay less attention to your own work. While competition can be motivating, it is better if you 
focus on your own effort. This is called a mastery goal. Try to improve on your last test result in each subject. If you failed the last Maths test, try to get Achieved this time. If you passed the last test in English, try to get a Merit in the next one. You can be competitive with other students, which is called a performance goal, but it is better if you try to improve on your own performance rather than just trying to beat your friends. It is also good to consider the needs of others, these are called social goals, but try focusing on your own Personal Best (PB). Remember that a PB refers to the best you have ever done in something. Try to do the best you can each time you take a test in NCEA." (These ideas were adapted from a variety of sources including material from Martin (2008) Lifelong Achievement Group.) The interview data provide evidence that only MS students received these motivation concepts such as PB messages. For example, one MS student recalled: “PB? That mastery thing... like what goals you want to set for yourself. Yeah... like Doing My Best Leads to Success, that's stuck in my head." None of the TS students recalled PB.

DMB and DJE can be categorised as target goals which have been shown to predict academic achievement, especially when combined with broader aspirational goals (Corker and Donnellan, 2012: 148). In the New Zealand context, Walkey et al. (2013) also reported that DMB and DJE are "Motivation orientations... specifically referenced to NCEA assessment, incorporating meaningful goal orientations for performance against standards, rather than norm-referenced assessments where grades are influenced not solely by the student's performance but also by how other students perform" (p.307). 
The MS and TS programmes were both delivered within this task-focused context of NCEA achievement. Because students were offered the opportunity to get NCEA credits alongside instruction in study skills, they had opportunity to gain credits at the end of the study skills programme. Three credits were available; however, the topic was assessed using unit standards so that students could only receive Achieved/Not Achieved grades and not earn Merit or Excellence credits towards endorsements. Meyer et al. (2009) explained that the endorsement concept was introduced into the NCEA framework to "provide incentive to students to continue striving beyond attaining the required minimum number of credits" (p.13). Because this option was not available to these students in this study, DMB messages may have been affected since it was not possible to work towards Merit or Excellence grades during the study skills programme. In comparison, the DJE message may have been enhanced because of the unit standards focus of the study skills programme. The DJE messages were certainly firmly contextualised in the study skills programme which supports the view that the MS study skills programme may have reduced DJE and increased DMB because MS students had a "focused academic task and activities" and "students receive[d] support to achieve positive outcomes through their own endeavours" (Meyer et al., 2009:9).

This concept of delivering the motivation messages in the MS intervention within a context of a task-focused NCEA study skills programme suggests another reason why the MS intervention programme may have led to changes in achievement. The MS programme adopted what has been referred to as a persuasive but stealthy approach in social-psychological intervention research. For example, Cohen (2011) reported that 
high-pressure messages to teenagers about the risks of ideas such as poor nutrition do not work as well as getting them to participate in fun activities that had hidden but beneficial side-effects for education. It is possible that the MS intervention programme may have worked (in part) because while students learned Mathematics and study skills they were also introduced to, and affected by, well-directed motivation messages which were subtly embedded within the programme, and were based upon sound motivation and achievement research.

The context, task-focused argument is further enhanced by the delivery mechanism of the MS and TS intervention programmes. In both schools the researcher was fortunate to have access to regular classroom teaching time and students were able to gain credits towards NCEA at the same time as receiving study skills. Generous, collegial educators allowed the researcher to teach alongside them which enhanced the credibility of both the programmes and the researcher. This meant study skills, whether traditional or motivation-enhanced, were incorporated within the taskspecific situation of gaining credits in NCEA in Year 11 Mathematics or Science. Students came to Mathematics or Science class and classroom content was delivered but in a compulsory classroom subject-based situation. For example, messages about $\mathrm{DMB}$ and DJE were focused on the academic task of gaining Mathematics and Science credits towards NCEA. This probably addressed one problem associated with generalised DMB goals that was raised by Hattie (2009) - that "Do your best goals are easily attained" (p.164). Meyer et al. (2009) agreed stating that "connecting motivations to specific tasks would contrast with traditional admonitions to young people, telling them simply to do your best without linking a vague generality such as 
this to specific tasks and approaches" (p.9). This means the context or task issue is addressed by placing the DMB and DJE messages within regular classroom tasks of gaining NCEA achievement in any subject for which credits are available. Although this study used Mathematics and Science as the task context, it seems reasonable to suggest that any curriculum subject in which students can gain credits towards NCEA could be a suitable context in which to base DMB/DJE/effort messages.

Previously reported data showed that the MS programme was particularly successful in reducing DJE. It is argued that the MS programme focused strongly on reducing the DJE motivation orientation by encouraging students to move from the passive approach that many under-achieving students take, to more active participation in their own learning. The idea here was to encourage students to take a small but achievable step from doing little preparation for a test and instead make enough effort and just get the credits. "Why don't you put in a bit more effort and get credits". It appears that this concept may have been particularly important to underachieving students. The researcher worked alongside MS students as they worked on their Mathematics or Science, providing encouraging messages such as "you can do it with more effort" and "three more credits here, three more credits there, they all add up". It is clear that MS students reduced on DJE and it could be argued that one reason is because what researchers call "DJE", students call "getting credits".

T: Yeah at the beginning of the year I mucked around. I didn't care about credits.

PS: And now?

T: $\quad$ Now I do! Because I didn't think it was important... 
Other students associated DJE with behaviours such as truanting (wagging) and less NCEA credits:
PS: $\quad$ Are you a wagger?
T: I used to... In the first half of the year.
D: (Another student advises T) Lowest credits!

In comparison, it could be argued that students associate DMB with getting NCEA with Merit and Excellence endorsements. However, Merit and Excellence endorsements may not have been an immediate aim for many of the under-achieving students in this study, who may instead have been thinking more about the possibility of just passing rather than the failure to which they may have become accustomed. For these students, prior to the intervention programmes, not passing NCEA may have seemed more likely. "I haven't passed everything. It's too hard. Yeah the exam's like... no one passed it, even the top students." Comments like this showed that for many students in this study, the DJE message, just getting credits and passing, was more relevant. Context may also contribute to this mind set. If under-achieving students are likely to be encouraged to enroll in courses offering only unit standards, this may communicate strong messages to them from their teachers and schools that Merit and Excellence are not realistic goals, therefore achievement standards are irrelevant.

The researcher had the opportunity to re-interview some students, and it was interesting to note how MS students' effort remained months after the MS 
Motivation Interventions via Study Programmes for Under-achieving Students

intervention. Students who moved from Year 11 (the year the MS intervention was delivered) and into Year 12 continued to show reduced DJE.

PS: How much did you try for your exams?

P: I like half way between didn't try much at all and tried a little. Yep. Like I didn't, I didn't put enough effort that I could have.

PS: Do you regret that you were low?

P: $\quad$ Yep. Like this year I'm starting to study more I guess. Oh because this year I've actually been doing my work and not getting too distracted. So yeah because I'm taking biology again.

PS: In what year?

P: $\quad$ Year 12. Yeah with Miss X but I had to beg her to be in her class and do Biology because at first she said no. So I started begging and she said alright then but I've got to do my work, so if I don't do my work then she's going to kick me out of the class. So l've been doing my work so far.

These findings support research that showed that increased achievement associated with changes in $\mathrm{DMB}$ and DJE can be enduring in the short to medium term. For example Meyer et al. (2009) found relationships between these two motivation orientations over a two-year period. "Doing My Best in 2005 was generally associated with higher achievement two years later, and Doing Just Enough was generally associated with lower achievement across two years" (p.22). 
A final comment on DMB and DJE and credits and the contextual nature of NCEA was the credits count back feature. This aspect of NCEA as a standards-based assessment was apparent when under-achieving students realised that even though they had failed Level 1 NCEA in Year 11, they were able to count any Level 2 credits that they gained in Year 12 back towards gaining Level 1. Many students seemed unaware of this feature of the NCEA however, when they were told about it, this appeared to be motivating. The point here is that DJE may have worked because of the structure of NCEA as a standards-based assessment system. Students are given second chances which increases their focus on the task of getting more NCEA credits.

PS: $\quad$ But you know the level two credits count back don't you?

T: Yeah.

S: $\quad$ Yeah but they add on.

PS: $\quad$ They add on to level one.

T: $\quad$ Oh I didn't know that, I thought that they just stay as level two.

S: $\quad$ No, yeah that's why I had 69 because I had 65 at first.

T: $\quad$ But I passed my Tourism tests last week. It was worth three [credits]. But does it still go on to your level two?

PS: Yes.

T: $\quad$ (smiles) I need a pen.

PS: Here's a pen. You going to work out your credits?

T: Yeah.

PS: $\quad$ Alright. (So now S and T are trying to work out their credits).

$\mathrm{T}$ : (Talking to $\mathrm{S}$, almost oblivious to the researcher) Got my maths test on Friday — that's worth four and six credits for foods.... 
So far this section of the Discussion chapter has considered how achievement goal theory as exemplified by DMB and DJE may be associated with changes in achievement. However, previous research has shown that DMB and DJE motivation orientations may vary as predictors of future achievement by ethnicity. For example, Meyer et al. (2009) reported that while DMB was associated with future achievement for New Zealand European and Asian students, the effects were not as strong for Pasifika students. They suggested that one possible reason for this variation was that DMB and DJE "reflect individualistic, more typically 'Western' values and approaches" (p.10). They further consider that the role of social motivation goals on motivation and achievement should be considered alongside the traditional goals such as DMB and DJE. Social goals may reflect collectivist and non-Western values and approaches. Changes in two social goals, peer affiliation and teacher affiliation, were supported by effect size differences favouring the MS programmes for both all students and Pasifika students.

The changes in teacher affiliation would seem to be more important than changes in peer affiliation to the extent that changes in teacher affiliation are associated more closely with achievement compared with changes in peer affiliation. For example, McClure et al. (2011) showed that teacher affiliation was a strong positive predictor of total number of credits in NCEA, almost as strong a predictor as effort attributions for best marks, which in turn was half as predictive as reduced DJE. In comparison, peer affiliation was negatively associated with changes in achievement. 
The data about increased teacher affiliation in this study showed there was some effect size difference which favoured MS (all) students compared to TS (all) students. However this did not reach the 0.20 threshold until MS (Pasifika) students were compared to TS (Pasifika) students. Here the larger effect size difference on increased teacher affiliation (0.27) favoured MS (Pasifika) students. Perhaps this social goal is more important to Pasifika students than it is to the general student population participating in this study. The relevance of this finding is that the MS programme was designed and delivered around the principle that teachers can promote motivation and achievement. One mechanism that the MS programme used to encourage effort was feedback and the role teachers play in giving or with-holding feedback. Locke (1995) explained how feedback, effort and achievement are associated, stating that "goal setting is most effective when there is feedback showing progress in relation to the goal, feedback is a moderator of the goal performance, and effort is roughly proportional to the judged difficulty of the goal" (p.120). It could be argued that the differential effects of the two study skills programmes on achievement outcomes were partly because MS students received feedback about teacher behaviours that was not available to TS students.

Making teacher affiliation an overt aim of the MS programme acknowledges the view that changing students' subjective experiences at school are important. Cohen et al. (2006) stated that "it can be as important to change people's 'construals' - their interpretations of the social world and their place in it - as it is to change the objective environment" (p.1252). Following this principle, the MS programme design was focused on social goals such as teacher and peer affiliation as well as more 
objective effort-related goals such as DMB and DJE. Cohen and his colleagues' research in the field of social-psychological interventions is relevant to this study because it provides alternative explanations about how changes in social goals may impact on achievement. For example, the data that show that students in the MS programme increased on teacher affiliation could be because the MS programme was based on concepts from other brief social-psychological education interventions which have been shown to positively affect motivation and achievement, such as teacher expectation, stereotype threat and dis-identification.

For example, Cohen et al. (2006) reported that a social-psychological intervention based on reducing negative ideas students may have about stereotype threat "significantly improved the grades of African American students and reduced the racial achievement gap by $40 \% "$ (2006:1307). Stereotype threat is associated with minority-group students who may be affected by negative views others hold of their ability. Stereotype threat is relevant to this study because "bad news" stories about the under-achievement of some Pasifika students may lead all Pasifika students to hold some level of stereotype threat. Paunesku (2013) explains that brief socialpsychological education interventions "try to open students to existing learning opportunities by removing psychological barriers that may otherwise inhibit them" (p.7). There has been some scepticism about how simple social-psychological interventions of short duration such as the MS programme could have any effect on achievement. However Cohen et al. (2006) believed that "what appear to be small or brief events in isolation may in reality be the last element required to set in motion a 
process whose other necessary conditions already lay, not fully realized, in the situation" (p.1309).

Another relevant brief social-psychological education intervention was reported by Cohen et al. (2009). This was a follow-up of their 2006 study, which showed that when students reflected on the importance of personal values, such as relationships with friends and family through a series of structured writing tasks, that writing selfaffirmations reduced psychological threat stress and improved performance. Walton and Cohen (2011) also reported an intervention which addressed "social-belonging" issues of African-American students, as stereotyped and socially marginalised compared to European-American students. The results of this intervention showed that African-American students in the treatment programme increased on GPA compared to African-American students in the control programme. These ideas have similarities to the research from Meyer and her colleagues; for example Meyer et al. (2009) reported that there was "a relationship between whether students believed their teachers were interested in their learning and their actual NCEA achievement" (p.65).

The research about social-psychological interventions is relevant to this study because MS students received the opportunity to discuss how teacher behaviours may have affected their teaching and learning, whereas TS students did not. For example, many students in both programmes made comments such as "the teacher does not like me" or "I do not like the teacher". Because of the difference in design between the two programmes, only students in the MS programme had the opportunity to discuss what 
these "like/not like teacher" comments could mean and to receive feedback on how these teacher comments could be contextualised. For example MS students discussed with the researcher how student behaviours such as not completing work or arriving late to class may annoy the teacher but that this was not the same as the teacher having a personal dislike for the student. In comparison, students in the TS programme were not given this opportunity. These researcher-student interactions may have contributed to increased teacher affiliation for MS students, particularly for MS (Pasifika) students.

For this argument to hold there would need to be compelling evidence from the qualitative data about differences on teacher affiliation between the two intervention programmes. The MS programme was designed to promote teacher affiliation whereas the TS programme was not. It is argued that the MS programme followed the principles of social-psychological education interventions by seeking to lower the psychological barriers of negative teacher behaviours and low teacher expectation in three ways. First, students in the MS programme received opportunities to rationalise positive and negative teacher behaviours that TS students did not receive. Second, MS students received opportunities to discuss differential teacher expectation and stereotype threat, and TS students did not. Third, MS students received opportunities to discuss dis-identification and disengagement while TS students did not.

MS programme students received opportunities to rationalise positive and negative teacher behaviours that TS students did not receive. When MS students presented ideas about the positive and negative teacher behaviours they experienced every day 
in their classrooms, the researcher discussed these positive and negative teacher behaviours openly. This approach was based on the concept of allowing student voice to be legitimised and showing students that what they think about teachers is just as important as what teachers think about students. These ideas are based on coconstruction of teacher behaviours within a model of culturally responsive teaching as outlined by Bishop and his colleagues in the Te Kotahitanga research carried out in New Zealand secondary schools (Sleeter, 2011). Teachers can be categorised as low, moderate or high implementers of what is called the "effective teacher profile" (ETP). There are four dimensions of the ETP: to care for students as culturally located individuals; to adopt discursive teaching and learning interaction and use of a range of strategies to facilitate learning interactions; to have high expectations for student learning and promoting, monitoring and reflecting learning outcomes with students; and finally to manage the classroom to promote learning (p.126). Savage and Hindle (2011) advise teachers that their repositioning behaviours towards becoming higher implementers of the ETP could include moving away from being "the traditional teacher who did not smile until Easter" (p.129) because teachers who become higher implementers of the ETP could expect higher achievement.

Both the MS and TS programmes were designed to be delivered with high implementation of the ETP, and the researcher delivered both intervention programmes with these principles in mind. This meant that the researcher attempted to be a high implementer of ETP for all students in both programmes. For example, one of the ETP dimensions is to care for students as culturally located individuals. This involved greeting students as they entered class, and trying to get to know individual 
students by, for example, asking them about family, sports, their life. Using Māori and Pasifika greetings were appropriate, and while talking individually to all students during class. The difference between the MS and TS programmes was that the coconstruction of teacher-student behaviours was only explicitly carried out with MS students. The teacher affiliation comments from students from both programmes suggested that the MS programme did result in more student voice from MS students than TS students. It is possible that these open discussions about teacher behaviours may also be associated with changes in teacher affiliation. MS students certainly had the opportunity to discuss how their teachers' behaviours may have impacted upon their achievement in a way that TS students did not have. For example S, a high achieving Pasifika female MS student, was able to describe differences between teacher behaviours and how these behaviours may have impacted on her learning. $S$ begins with Teacher A:

PS: What kinds of things can teachers do to help support you in your classes?

S: $\quad$ Helps us learn (reflects)... You remember our maths teacher... Oh yeah well he's like one of us he's funny and not just serious all the time.

E: $\quad$ Strict.

S: $\quad$ Yeah... yeah he's not strict. He's like a little child.

PS: What is it that you like that he does?

S: It's like... because he's like one of us he's there for all the students you can ask him questions.

PS: What do you mean he's like one of us? 
Motivation Interventions via Study Programmes for Under-achieving Students

S: $\quad$ He's... (Laughs) As I said before he's not like serious, so umm he jokes around with us so we just see him as another friend who teaches us... you just talk to him.

PS: $\quad$ But he's quite strict as well?

S: $\quad$ Yeah when he wants you to do something and learn he becomes strict but all the rest of the time he's funny.

In comparison, two MS Pasifika students, $\mathrm{S}$ and her friend $\mathrm{E}$, describe the behaviour of Teacher B.

S: $\quad$ Teacher B, yep. He is quite, I don't know about you but I can't really talk to him much, that's why I don't get the work done.

E: And you've got to greet him like really nicely.

S: Yeah.

PS: Can you explain why you can't talk to him?

S: Yep, because I'm not sure, compared to our maths teacher [teacher A] is all open and funny and stuff, [teacher B] is just, he just stands there and looks at your work, he just looks round the class doesn't really talk, talk much.

E: Yeah.

S: $\quad$ Like with our computer studies and stuff we just walk into class, get our folder and do our work. There's no hi how's your day kind of stuff. You don't do any class discussions. 
Motivation Interventions via Study Programmes for Under-achieving Students

Next these two students were asked to think about the impact these two teachers, teacher A (a higher implementer of ETP) and teacher B (a lower implementer of ETP), may have had on their achievement.

PS: Do you think the way that they taught... do you think that affected your learning?

S: $\quad$ Probably... because I spoke to you before about how I couldn't hand in my assignment... I was like afraid to hand it in... I finished an assignment, about a week later I handed it in because I am not comfortable around the computer teacher [teacher B] ... but if it was the Maths teacher [teacher A] I would just hand it in straight away.

PS: $\quad$ So you finished this assignment and didn't hand it in?

S: $\quad$ Yeah, for a week.

PS: What did you do for with it... just carry it in your bag?

S: $\quad$ Yeah... oh no l left it in the folder inside the room.

PS: Did you know you hadn't handed it in?

S: $\quad$ Yeah I knew... every day that we had computers I thought shall I hand it in today?

PS: Why didn't you hand it in on say the Monday?

S: I have no idea... I feel kind of stupid now... because if I had handed it in earlier I could have got the other assignment and started on that... I think it's just that I didn't... like because he's a closed off teacher and I didn't want to hand it in at all and see what his reaction would be like. 
Here teacher A could be categorised as a high implementer of ETP because the teacher relates well to students and manages classroom behaviour skilfully. Teacher B could be categorised as a lower implementer of ETP because the teacher is distant with students and uses a limited range of strategies to facilitate classroom interactions. The discussion situation that the MS programme facilitated, "Do you think the way that they taught... do you think that affected your learning?", is an example of what Sleeter et al. (2011) described where student voice can "allow teachers to hear students' desire to learn and be respected and they will learn what their students know and care about" (p.165). The good news from S's experiences with teacher B came later in the interview as teacher B (classified as a lower implementer of ETP) appeared to also sometimes exhibit higher implementation ETP behaviours as well as the lower implementation behaviours. Suga continued with her description of teacher $B$ and the assignment:

PS: In the end you got to the final deadline and had to hand it in? Was it the last day?

S: No, I just wanted to start something new.

PS: So you couldn't start the next one until you handed it in?

S: $\quad$ No.

PS: Think back to when you handed it in, can you remember?

S: $\quad$ Yeah, he was laughing... he was smiling he was happy I'd finished it and he actually gave me a smiley face thing... yeah... for doing good work.

PS: Were you surprised?

S: $\quad$ Yes I was... So that was why when I finished the last assignment I handed it in straight away. 
These ideas support research by Allen et al. (2011) about the My Teaching PartnerSecondary Program (MTP-S) intervention which reported increased student achievement which was "mediated by changes in teacher-student interaction" (p.1034). They concluded that "Although it is obviously necessary to know math to teach math, in secondary school classrooms teaching math skilfully also involves successfully relating to and interacting with students so as to enhance their academic motivation" (p.1034). These ideas also support research by Paunesku (2013) who found that "Students who perceive their teachers to be more relatable and emotionally supportive feel a stronger sense of belonging in school, pursue more adaptive classroom goals, hold higher achievement expectations, and earn better course grades" (p.5).

The MS programme also provided students with opportunities to rationalise teacher behaviours regarding teachers who did not know their subject or had classroom control issues or arguments with students. Again there were differences between the two programmes because MS students had the opportunity to express how their interactions with confrontational teachers impacted on their learning whereas TS students did not. For example, two MS Pasifika students, $\mathrm{P}$ and $\mathrm{S}$, explained the teaching and learning situation with teacher D.

PS: So just think back, what's it like with [teacher D], what's the good things about [teacher D]?

P: He's nice. 
Motivation Interventions via Study Programmes for Under-achieving Students

S: $\quad$ Yeah, I like him as a person I think he's really good, he is a nice person isn't he.

P: $\quad$ Sometimes he shouts but not, it's not really his fault. Just when the class gets a bit stringy.

PS: Does everybody listen or do they talk over him?

P: $\quad$ Oh sometimes.

S: $\quad$ Yeah

P: I think they treat him like a pushover.

S: $\quad$ Because they know he's kind

In this school, the ineffective teacher situation became so bad that teacher $D$ was replaced by teacher $\mathrm{E}$. The $\mathrm{MS}$ programme and subsequent interviews gave MS students the opportunity to comment on the changes and provides an interesting example of how students are very aware of the effects of teacher behaviours on their learning.

PS: How did that affect you?

P: I was kind of glad that I got [teacher E] because how it was like the crunch time for us. And because [teacher D], he was like not worried too much of the time, just talking with the girls and then with teacher $E$ she like, she tells us to be quiet and stuff and we just do our work, there's hardly any mucking around now.

P: $\quad$ Yeah because like we've got exams coming up.

P: Yes, and we've got to study hard.

P: Well [teacher E], she's also cool like because it's cool she's teaching us 
Motivation Interventions via Study Programmes for Under-achieving Students

because we actually learn stuff

P: $\quad$ Yeah and she gives us some good examples

Savage and Hindle (2011) explained that low implementers of the ETP tend to be passive and ignore progressively challenging behaviour in the classroom. Although many of these low implementing teachers may interact with students in a positive way individually, they did not manage the task of classroom learning well. The examples given above suggest that students in the MS programme were able to evaluate how teacher behaviours related to their learning. In comparison, TS students did not make these sorts of evaluations about teaching and learning and these differences between the MS and TS programmes may be associated with differences in achievement.

The MS programme also provided students with opportunities to discuss differential teacher expectations of students and stereotype threat that TS students did not. Differential teacher expectations by ethnicity is well-known but is particularly disturbing in the New Zealand educational context. This is because research has shown that New Zealand teachers expected Māori students to achieve at a lower level than students of other ethnicities even though pre-achievement data showed no differences by ethnicity (Rubie-Davies et al., 2003). It could be hoped that this situation would have improved by 2014 , but very recent research by Turner (2014) showed that some teachers still had negative opinions about Māori students, including low expectations and deficit views of Māori students. 
Unfortunately these ideas were supported in the study where many MS Pasifika students reported teachers held low expectations of some students. For example, a high achieving MS Pasifika student, D, described a situation: "Well there is this teacher, she is only mean to one kid, S, this islander. It's not racist or anything because she's nice to all the other Islander kids; but just him, misses out. Like she doesn't give him sheets and that... She just walks past him and starts nutting on at him for no reason... She gave him a detention for giving someone his calculator, like letting him borrow his calculator... He got a detention for it... She always tells stuff like that to him."

While D was quick to state that this teacher behaviour "was not racist or anything", other under-achieving MS Pasifika students reported what they called teacher racism. For example I and $\mathrm{O}$ said:

I: $\quad$ Yeah that's what I don't like - because some teachers here ... I think it's because they are racist (lowers the tone of her voice then - more defiantly - names teachers). Mr. $\mathrm{X}$ is.

O: $\quad$ Mr. X and Mr. Y.

I: $\quad$ Yeah Mr. Y (I agrees).

O: $\quad$ (Adds) Mr. Z.

I: $\quad$ Yeah (I agrees).

These two Pasifika students appear to have strong feelings about what they call racist teachers and list them in a way that showed they feel angry but may feel empowered at the same time because they have the opportunity to tell a neutral person - the 
researcher - how they feel. Both of these students were part of the MS programme. They continued:

I: I punched his head one time.

PS: You punched his head?

At this point the researcher was not quite sure what to do with this information and just asked another question.

PS: Do you students talk about racist teachers amongst yourselves?

I: No, we just keep it to ourselves and stuff.

PS: $\quad$ But you know it.

O: $\quad \mathrm{Mmm}$.

PS: Does it bother you going to class with a teacher who has that reputation?

I: Yes.

PS: Have you ever tried to do anything about it?

I: No, we just like... we have teachers... like.... and we just say is it... (doesn't finish the sentence, laughs)... oh I don't say it (laughs).

O: (Finishes the sentence) Is it because I'm black?

PS: You say that to the teacher? And what happens?

I: $\quad$ And then they just kick us out.

PS: What does the teacher say when you say that?

O: $\quad$ Oh you get suspended. 
While this is disturbing to hear these student accounts of what is happening inside New Zealand classrooms, it is also positive that the MS programme may have provided some opportunity for students to have their views legitimised and this in turn may have reduced stereotype threat. The MS programme may have had some impact on MS student achievement because they could discuss differential teacher expectations of and stereotype threat. This supports research by Hattie and Timperley (2007) about negative and positive feedback loops and the impact of feedback on achievement. The perception held by some students that some of their teachers had low teacher expectations of them and held racist attitudes may have been evidence of stereotype threat which in turn affected Pasifika student achievement. Aronson, Fried and Good (2002) explained that stereotype threat "is a perceived negative racial inferiority in the eyes of others, and one's own eyes, or both at the same time. Importantly, it is not necessary that a student believes the stereotype to fill this burden, he/she need only be aware of the stereotype" (p.114). This is similar to research by Cohen $(2006,2009)$ which showed what happens when you have negative feedback and how to interrupt a feedback cycle or a recursive cycle. It is possible that the MS programme provided opportunities to interrupt the negative recursive cycle around stereotype threat. For example the researcher asked one higher achieving Pasifika student, P. "Can you tell me that something you are really good at?" The researcher expected the usual "to-anfro" of comments between the student and researcher, and P started that way but then spontaneously burst into recalling a speech:

P: I like English.

PS: Tell me about that? 
Motivation Interventions via Study Programmes for Under-achieving Students

P: $\quad$ Well, we had to memorise a speech right now and we are doing about poetry and we had to memorise quite a scene from the Merchant of Venice - have you read that?

PS: $\quad$ Mmm - Shylock or something.

P: We had to memorise a speech and it goes something like - you have disgraced me and hindered me half a million times, laughed at my losses and mocked at my gains, scorned my nation, scorned my nation, thwarted my bargains, killed my friends, hated my enemies; and what's his reason? I am a Jew. Have not a Jew eyes? Have not a Jew hands, organs, dimensions, senses, affections, passions, fed with the same food, hurt with the same weapons, subject to the same diseases, healed by the same means, warmed and cooled by the same winter and summer as a Christian is? If you prick us, do we not bleed? If you tickle us, do we not laugh? If you poison us, do we not die? And if you wrong us, shall we not revenge?

(P paused, looked at the researcher for a moment, and continued.)

P: $\quad$ You can relate that to anything - like you can replace Jew with black.

The researcher gained the distinct impression that $P$ was trying to get a message across about racism. This may be evidence of how the MS programme may have interrupted negative recursive cycles especially addressing stereotype threat. This student had high achievement outcomes not only just after intervention in Year 11, but over a longer time period including becoming academic head boy at his college in Year 13. 
During a later interview $\mathrm{P}$ was part of a group of MS Pasifika students with whom the researcher had the last interview opportunity for this study. The researcher asked these students what they wanted from their teachers. Many of their comments were associated with racism which may be evidence that the MS programme addressed stereotype threat, if only by legitimising racism as a topic which students could discuss:

"Yeah don't be a 'dick'" (note this term was later associated with a student's description of racism).

"Don't put yourself out there."

"A teacher told a joke - that was a bit too far - the Samoan and Tongan joke - his jokes are not funny. Don't say racist jokes."

“Don't be too overboard with your jokes yeah and you're the only one laughing - maybe no jokes about culture at all."

Finally, MS students received opportunities to discuss dis-identification and disengagement that TS students did not. Many MS students reported that they did not like it when teachers were impatient or got angry. Again there were differences between the comments of MS and TS students because MS students had the opportunity to express how their interactions with confrontational teachers made them want to leave school, and how this impacted on their learning. For example, one 
Motivation Interventions via Study Programmes for Under-achieving Students

under-achieving MS Pasifika student, I, explained how the interaction with teacher C made her dis-identify with school.

PS: If there are three groups who influence you - parents teachers and friends - can you rate their influence on you?

I: $\quad$ Teachers don't influence me in any way!

PS: Okay back to the list.

I: $\quad$ Parents then friends.

PS: Teachers?

I: $\quad$ Teachers just don't influence me at all!

PS: Teachers have no influence?

I: $\quad$ They are not even on the list! Sometimes I try my best to be kind to teachers but they still make me angry so I just don't try anymore. They want me kicked out of school so we're looking for a course.

PS: Who wants you kicked out of school?

I: $\quad[$ Teacher $\mathrm{C}]$ because of my absences. He said that (names school) has ran out of options for me and it's not working and that it would be best if I just leave.

PS: When did he say that to you?

I: This term, at the beginning of this term.

PS: $\quad$ And he just left you alone since then?

I: $\quad$ He is, because I don't listen to him.

PS: Did he put you on daily report or anything?

I: $\quad$ Yes, but I threw it away.

PS: What happened then? 


\section{I: Nothing (laughs).}

From a student's perspective, this sort of student behaviour could be classified as disidentification. Wentzel and Wigfield (2007) explained that "disidentification helps to explain the under-achievement of African American students. To protect their selfesteem, they may disidentify with academic achievement leading to both a lowering of the value they attach to intellectual accomplishments and a detachment of their self-esteem from both positive and the negative academic experiences" (p.264). Savage and Hindle (2011) explained that impatient teacher behaviours can also be an indication of low implementation of ETP where teachers displayed relationships with students that were under significant tension and stress.

From a teacher's perspective this sort of teacher behaviour could be classified as low ETP implementation. Savage and Hindle (2011) reported that approximately half of the low implementers demonstrated confrontational behaviour, threatening students with detention in relation to appearance or how they behaved. Teacher voice is often raised, and the language used (you and I) tended to separate the students from teachers (p.136).

However, the MS programme was able to provide an opportunity to allow students to express their opinions about teaching and learning. It could be argued that intervening like this could be associated with student achievement even if just because students stay at school rather than leaving. Wentzel and Wigfield (2007) reported that another reason why ethnic minority children might benefit from more effective interventions 
such as the MS programme was that it would address disidentification which "might help explain the underachievement of African-American students" (p.264). The MS programme provided opportunities for the researcher to intervene and discuss with students possible dis-identification which emerged as outlined in the previous encounter with teacher $\mathrm{C}$. This could then be addressed, whereas the TS programme could not provide these type of opportunities. For example, the researcher was able to follow up the poor teacher-student interaction previously described by MS student I, with a short, more positive intervention (here student I is with student 0 ):

PS: $\quad$ You know you only have to feel one teacher is looking out for you and treating you fairly - you told me about one teacher that you liked. I forgot [her name - I think it was Miss X]

O: $\quad$ My one is... (names teacher and laughs).

PS: $\quad$ You just need one.

O: $\quad$ Mmm (agrees).

I: Was it at a lady or a man (I is trying to find out who she talked about).

PS: A woman - I think she was a counsellor.

O: $\quad$ Ms. X (O offers help).

I: $\quad$ Yeah, Ms. X (I agrees with O). She's the one that's helping me stay in school. She's fighting with me (I uses "fighting" in a positive way).

PS: You like her?

I: $\quad$ Yeah she's cool.

Student I could be described as a partially dis-engaged student however the MS programme gave these students an opportunity to compare their situation with fully 
disengaged students - students who no longer attended school at all. There was some evidence that the MS programme provided students with the opportunity to compare their present situation before becoming completely disengaged from school. These opportunities were not available to TS students. It is possible that by legitimising disengagement as a topic, the MS programme provided opportunities for students that were in some way associated with greater identification with school:

E: Oh my sister, she's like a year older, two years older than me. Oh yeah, she just got into the whole like drinking alcohol stuff and she dropped out of school and yeah she's been like looking for a job but because she doesn't have her levels yet, her NCEA, she can't do anything. So she's just like being a bum at home doing nothing, yeah.

PS: $\quad$ Does she ever talk about going back to school maybe?

E: $\quad$ No. Talks about doing courses but she doesn't end up doing it.

PS: What do you think?

E: It made me want to do better than her, yeah.

It could be argued that the MS programme helped partially disengaged students to report the stories of fully disengaged students. It is possible that the MS programme facilitating student voice about dis-identification and disengagement could be associated with increased achievement. This is particularly important in the context of this study where there were a number of students who could not be interviewed because they were rarely at school. For example, when trying to locate one particularly dis-engaged student, the researcher was advised to come back in the afternoon as that student was "not good at mornings". 
From the findings discussed so far about goals and achievement, it may be possible to begin to further develop the possible mechanism that helps to explain how the observed differences between the two intervention programmes may also be associated with changes in achievement. The proposed mechanism outlined in section one may now be extended to include that an intervention that is able to decrease the Doing Just Enough motivation orientation may be associated with increased achievement. This reduction in DJE appears to have had more impact on achievement than increasing a related motivation orientation, Doing My Best. These DMB and DJE messages may have been more effective because they were delivered within the taskfocused context of NCEA achievement. Increased teacher affiliation may also be associated with achievement because the MS programme provided opportunities for students to tell teachers how negative teacher behaviours and differential teacher expectation affected their teaching and learning.

However attribution and achievement goal motivation theory is only part of the picture - one final relevant theoretical framework is self-view (intra-personal) motivation. Martin $(2005,2008)$ investigated how intra-personal motivation may be associated with achievement and these and other ideas are discussed in section three of this chapter - intra-personal motivation and achievement. 


\section{Section Three: Intra-personal Motivation Orientations}

Section three of this Discussion chapter considers the effects of the two intervention programmes on intra-personal motivation orientations. Martin (2002) conceptualised achievement motivation by amalgamating the key theories of academic motivation into a multi-dimensional model called "The Student Motivation Wheel". While Martin $(2002,2005,2007)$ considered that this model incorporated all the major motivation achievement theories, it is probably more accurate to say that this model represents all of the major intra-personal motivation theories. A comparison with Martin's (2005, 2008) studies is useful because they are intervention research with which data from this study can be compared.

Martin (2005) investigated the impact of an intervention programme on participants' academic motivation over two sessions of programme delivery and again after 6-8 weeks (p.184). Martin (2005) used a pre-test/post-test design with 53 Year 10 male and female high school students. He found that the levels of some adaptive/booster motivation constructs were higher, both immediately after the intervention, and 6-8 weeks later (p.194). Martin (2005) believed the results of this study were significant because they showed that even a brief, but well-targeted intervention could yield significant positive changes in motivation. Martin also concluded that these results showed that it was possible to embed a motivation programme into a larger youth enrichment programme. 
Previous studies from the field of intervention research reported that motivation orientations can be positively affected by intervention. For example, Martin (2005, 2008) investigated the effects of an intervention programme on intra-personal motivation orientations and reported increases on adaptive motivation orientations such as persistence and task-management and decreases on maladaptive motivation orientations such as uncertain control and self-sabotage. However, Martin's (2008) research was not able to show that these changes in motivation were associated with improved achievement outcomes. Martin (2008) concluded that "A more powerful test of the effectiveness of the intervention would be to assess the link between these results and later academic achievement" (p.263). This is one area where this research can add to our understanding of the effects of intervention on intra-personal motivation orientations because this study also measured changes in achievement. So what are the similarities and differences between my research and Martin's (2005, 2008) research?

This research is similar to Martin's $(2005,2008)$ studies because it investigated changes in the same adaptive and maladaptive intra-personal motivation orientations. Both this study and Martin's $(2005,2008)$ used the same measuring instrument - the MES-HS, and both Martin's $(2005,2008)$ study and this study had participants of a similar age ( $N=15$ years) with all interventions being aimed at students in Secondary Schools in Australia and New Zealand. In 2008, Martin made changes to the way his motivation intervention was delivered and reported that the motivation programme could be delivered in a more flexible way with less reliance on an expert facilitator than the workshop approach situation which the 2005 study followed. Martin (2008) 
explained that this meant delivering the motivation intervention programmes individually, in small groups, or in a classroom situation. This way of delivering motivation interventions is relevant to this study because the MS skills programme also took place with students in their regular classroom context. This method of delivery is based on the idea that educators can try the motivation programme in their own classrooms without the need to artificially create a treatment situation.

Martin (2005) reported that students increased on all six adaptive intra-personal factors measured in his study - self efficacy, mastery orientation, valuing of school, planning, study management and persistence. Martin concluded that in a workshop format, motivation and engagement could be enhanced (p.244). In the 2008 research, Martin reported that students increased on most of the six adaptive intra-personal factors and he again concluded that both motivation and engagement could be enhanced by intervention programmes (p.239).

However, when the results of this study are compared with Martin's (2005) research on changes in adaptive intra-personal motivation orientations following similar intervention programmes, the data do not correlate. For example students in the MS programme decreased on all six intra-personal motivation factors when compared to students in the control programme. While all of the effect size changes were very small (ranging from -0.04 to -0.18 ) they are still quite unlike the increases that Martin $(2005,2008)$ reported. For example the students in the treatment programme in Martin's (2005) study increased on three intra-personal motivation factors - selfefficacy, persistence and mastery learning. These three effect sizes were all small but 
positive $(+0.20$ to +0.28$)$. The comparison with my data and Martin's (2008) study is even more different. He reported an increase on five of the six intra-personal motivation factors - persistence, planning, mastery learning, valuing and task management $(+0.38$ to +0.64$)$.

Martin (2008) noted that one limitation of his study was that participating students were selected from students who had shown lower motivation and engagement so there was a potential for a state of readiness prior to intervention. This may explain some of the differences in changes in adaptive intra-personal motivation orientations, because in contrast the students in this study were not necessarily lower in motivation and engagement as they were drawn from the general Secondary School population of the classrooms from their schools. Another possible reason could be ethnicity differences between the students in Martin's studies and this study.

Analysis of Martin's $(2005,2008)$ studies showed that ethnicity of participants was not reported. The researcher asked Martin, in a personal communication, to clarify any associations between interventions which sought to modify adaptive intra-personal motivation orientations and ethnicity: The question was asked; "Can you tell me the ethnicities of the participants in each study or if that is too time-consuming can you please answer this question: Did any of the 53 participants in your 2005 and 2008 studies identify their ethnicity as Pacific Island - particularly Samoa, Tonga or the Cook Islands?" Martin replied: "I've just looked back into the datasets and no ethnicity data were collected. Given the nature of the contexts in which data were collected, if 
any Samoans, Tongans, or Cook Islanders were involved, there would only be a couple/few at most".

This information led the researcher to re-investigate the data, looking for any association between ethnicity and changes in intra-personal motivation orientations. As previously noted, when all students in the treatment programme were compared to all students in the control programme on differences in the six adaptive intrapersonal motivation orientations before and after intervention, students in the treatment programme increased on these desirable outcomes compared to students in the control programme. The data were split by ethnicity into Pasifika versus nonPasifika students in each of the MS and TS programmes and analysed for differences in the six adaptive intra-personal motivation orientations before and after intervention. This analysis showed that MS (non-Pasifika) students increased on five of the six adaptive intrapersonal motivation orientations, whereas MS (Pasifika) students decreased on all six of the adaptive intra-personal motivation orientations. These data may indicate that ethnicity may be associated with changes in adaptive intra-personal motivation orientations. This strengthens the argument that the culture of students may be associated with the increases in Martin's intervention studies $(2005,2008)$ because the students in his studies were largely non-Pasifika and they also increased on the adaptive intra-personal motivation factors.

This study next investigated the association between ethnicity and changes in intrapersonal motivation orientations and changes in achievement. These data showed that there is a conflict in the data by culture. These data showed that Pasifika students 
in the treatment programme did not respond positively to the intra-personal motivation orientations in the intervention programme yet still increased on achievement. However, non-Pasifika students in the treatment programme did respond positively to the intra-personal motivation orientations messages in the intervention programme and increased on achievement.

Martin (2005) also investigated changes in four maladaptive intra-personal motivation orientations - anxiety, failure avoidance, uncertain control and self-sabotage. This study also investigated changes in these four maladaptive factors. Comparison of the data in this study with Martin's $(2005,2008)$ correlated better on these maladaptive factors. For example when MS (all) students were compared to TS (all) students, MS (all) students decreased on three out of four maladaptive intra-personal motivation factors. The effect size differences ranged from small to medium $(-0.14$ to -0.42$)$. The students in the treatment programme in Martin's (2005) study also decreased on three maladaptive intra-personal motivation factors - anxiety, failure-avoidance, and uncertain control - with similar effect size changes $(-0.25$ to -0.38$)$. The comparison data in this study and Martin's (2008) study also correlated well. Students in the treatment programme in Martin's (2008) study showed a decrease on three maladaptive intra-personal motivation factors - failure avoidance, uncertain control and self-sabotage - with medium effect size differences $(-0.31$ to -0.59$)$.

There are at least two reasons - demotivation and deficit views - why the data about students in this study does not correlate with Martin's $(2005,2008)$ research on adaptive intra-personal motivation orientations and yet the data about students in 
this study does correlate with Martin's $(2005,2008)$ research on maladaptive intrapersonal motivation.

Hattie (2009) showed that demotivation can be powerful: "for many (students) demotivation has more impact than motivation. Such demotivation can directly affect commitment to the goals of learning, turn off the wish for and power of feedback, and decrease involvement" (p.48). It could be argued that Martin's $(2005,2008)$ programmes may be based on a deficit-oriented model. Sleeter et al. (2011) reported that "deficit-approaches, while the most common, are the least helpful, while emancipatory approaches that include culturally responsive pedagogy, while the least common, have the most power to bring about lasting change" (p.4). These ideas are linked to the low teacher expectation concept discussed earlier. This preoccupation may be reflected in the idea that if only educators could improve intra-personal motivation orientations that under-achieving students "possess" then achievement would improve. These ideas are also associated with study skills because some of the intra-personal motivation orientations that Martin $(2005,2008)$ reported are also part of general study skills programmes - for example persistence, planning, and task management. In summary, these results largely favour the TS skills programme TS over the MS programme for Pasifika student participants, even more so than for all students. Given the focus on study skills in the TS programme, these results are perhaps consistent with expectations. Indeed, it may be that these factors actually reflect self-assessments regarding study skills. These findings support the need for high quality interventions, whether motivation-based or study-skills based. 
However, the data in this study which suggests that maladaptive intra-personal motivation factors may be more susceptible to intervention, especially for Pasifika students, may be relevant to the New Zealand Ministry of Education initiative called Power up to NCEA (pasifikapowerup.co.nz). This is described as "a study programme that uses the power of our communities and channels for a good cause - education". The Power up to NCEA programme operates for eight weeks and brings Pasifika families and secondary school-aged students together to prepare and learn about NCEA exams. The programme consists of a series of workshops for community volunteers focusing on study skills and is promoted as including examination and study tips, time management and inspirational success stories. The design of this programme supports research which shows the importance of family as a social motivation factor, especially for Pasifika students, which may be associated with achievement (see for example Fletcher, Parkhill, Fa'afoi, Taleni and O’Regan, 2009). However evidence from this study suggests that these factors are part of traditional study skills programmes and my data showed that intervention programmes that focus on traditional study skills such as study tips and time management are less successful than metacognitive study skills programmes. Hattie (2009) explains that metacognitive study skills programmes include the type of motivation-enhanced study skills programme such as this study. Data from my study showed that students in the MS study skills programme had higher achievement outcomes than students in the TS skills programme. Therefore it is possible to conclude that if the Power up to NCEA programme also addressed motivation orientations, especially maladaptive motivation orientations and inter-personal motivation orientations, then the Power up to NCEA programme could be even more effective than current anecdotal evidence suggests. 
Another possible reason that Pasifika students in the treatment programme did not increase on the six adaptive intra-personal motivation factors and yet still increased on achievement may be because other aspects of motivation are also involved in the observed achievement. Meyer et al. (2009) reported that "one possible reason is that intra-personal motivation orientations such as self-efficacy, value of schooling, mastery orientation, planning, study management and persistence may be regarded as traditional "Western" views of academic motivation and that we need to consider other theoretical frameworks that include less traditional "non-Western" views of motivation and achievement. These include areas which have been "traditionally less researched such as social goals and motivation and achievement" (p.10). They further reported that: "This is because we have argued that traditional motivation orientations including our own Doing My Best and Doing Just Enough reflect individualistic, more typically 'Western' values and approaches” (p.10).

It is possible that Pasifika students in this study did not respond as well as non-Pasifika students to messages that suggested they behave as individuals, because they may have preferred collectivist culture ideas. Conversely this data could be interpreted that non-Pasifika students responded more positively to the individualistically oriented intra-personal motivation messages than Pasifika students. It is also possible that intervention programmes that deliver messages about failure avoidance and selfsabotage may be particularly effective for Pasifika students. 
Part of the mechanism to explain the effects of the MS programme on student achievement could be that the MS programme addressed deep-seated "failure" ideas in all students and Pasifika students. Martin (2007) explained that "based on a need achievement and self-worth models of motivation, students can be characterized in terms of three typologies: the success-oriented student, the failure-avoidant student and the failure-accepting student" (p.417). Failure avoidance can be considered a "treatable" condition which schools should address before they become failureaccepting which may then be harder to address. Failure-acceptance can be associated with helplessness theory in a similar way that control is associated with mastery and hopefulness and lack of control with helplessness. Martin (2007) explains that "Failure-avoidant students tend to be anxious, and motivated by a fear of failure and may even actively handicap their chances of success (e.g., procrastinate, leave study until the last minute or not study at all) so that they have an excuse if they do not do so well" (p.417). Martin (2002) also reported that "every quiz, every assignment, and every exam becomes a test of their worth as a person" (p.76). The MS programme may have addressed these issues as evidenced by reduced failure avoidance and reduced self-sabotage behaviours. One important aim of motivation interventions should be to address helplessness; it is possible that findings that MS students, in particular MS (Pasifika) students, reduced on anxiety, failure avoidance, and selfsabotage may be evidence that the MS programme halted failure avoidance and prevented students from becoming failure-accepting students. The MS programme provided opportunities for sensitive topics such as failure to be openly discussed in a way that the TS programme did not. Consider the following exchange with two MS Pasifika students - P and T: 
Motivation Interventions via Study Programmes for Under-achieving Students

PS: $\quad$ Do you think that you purposely didn't study so that if you failed you could say oh it's because I didn't do any study?

P: $\quad$ Oh. Oh.

T: $\quad$ That's harsh.

P: $\quad$ No, it's just like a good question, because for me, ah, that might have been, yeah.

PS: $\quad$ Tell me about that?

P: $\quad$ Because better to blame it on like study than to say that I didn't even pass it.

PS: What does that mean?

P: $\quad$ Then that would just mean that I'm stupid, oh because I think people our age like to think of blaming other stuff then people don't think that they're dumb or anything.

While this exchange is a bit disturbing, even as the researcher recalls this conversation, particularly rehearing $\mathrm{T}$ saying that this was a harsh question, it is also positive that the MS programme may have provided opportunities to discuss issues that are not normally raised regular classroom interactions. Even though the term selfsabotage is not directly mentioned in this exchange, it had been mentioned during the MS programme delivery and both $\mathrm{P}$ and $\mathrm{T}$ would have been familiar with the term selfsabotage. It is possible that the MS programme may have had some impact on MS student achievement because of discussion about motivation orientations around failure, whereas TS students did not have these opportunities. P passed Level 1 NCEA, and T gained 137 credits and almost a Merit endorsement. 
In contrast TS (Pasifika) students may have slipped from failure avoidance into failure acceptance; as Martin explained, "failure-accepting students (sometimes referred to as learned helpless) have given up to the point of not even trying to avoid failure. These students may be generally disengaged from their studies and display a helpless pattern of motivation" (p.417). Consider S - an under-achieving TS Pasifika student who gained a very low number of level NCEA credits and did not pass Level 1 NCEA:

S: I started to fail exams. Most of the exams I failed. I didn't really get the subject at all. So then throughout like the whole class period I was just sitting there drawing, texts or just play games.

PS: $\quad$ And what did the teacher do?

S: $\quad$ He will just tell me but then I would just look at him and I'd just start drawing again.

PS: $\quad$ And who were you sitting with when you were doing this?

S: I just sit by myself. Just because I don't want to pull other people to like, to my way so I can just do my own thing and they can do their own things.

Student S was however still at school because, and he had recounted this to the researcher, other under-achieving students had just quietly slipped away and left school.

S: $\quad$ Oh, I kind of know people, so I just didn't want to be like them so I just tried my hardest.

PS: $\quad$ Can you tell me about them, how they dropped out from school? 
S: I'm not sure but like I think that they hated the teachers and they hated waking up and going to school and other stuff so eventually they just dropped out.

\section{Summary}

From the findings discussed so far in all three sections of this Discussion chapter it may be possible to begin to finally develop a mechanism, which is explained more fully in the Conclusion chapter, that helps to explain how the observed differences between the MS and TS intervention programmes may also have been associated with changes in achievement.

From section one - an intervention that promotes increased effort attributions for best marks and decreased uncertain control may be associated with increased achievement. The mechanism also indicates that teachers, family and friends may have a mediating effect on students' perceived levels of control over their achievement and ability to succeed at the achievement task. These data appear to indicate that decreased good luck attributions to best marks can be associated with higher achievement.

From section two - an intervention that is able to decrease the Doing Just Enough motivation orientation may be associated with increased achievement. This reduction in DJE appears to have more impact on achievement than increasing a related motivation orientation, Doing My Best. These DMB and DJE messages may have been more effective because they were delivered within the task-focused context of NCEA 
achievement. Increased teacher affiliation may also be associated with achievement because the MS programme provided opportunities for students to tell the researcher how negative teacher behaviours and how differential teacher expectation may have affected their teaching and learning.

Finally from section three - an intervention that focuses on reducing maladaptive rather than increasing adaptive intra-personal motivation factors may be associated with improved achievement outcomes, especially for Pasifika students. These data suggest that it is possible to treat failure avoidance behaviours before failure acceptance or learned helplessness occurs.

In the final chapter, the Conclusion, the findings and the discussion about these findings, from this study are drawn together to explain how the effects of MS and TS intervention programmes may have been associated with changes in achievement. 


\section{Chapter Seven Conclusion}

\section{Introduction}

This chapter begins with an overall summary of this study and then outlines the research outcomes. The chapter then outlines the strengths and limitations of the study. The chapter concludes with implications for practice in schools, education policy and for future research.

\section{Summary of the Study}

The under-achievement of some students in New Zealand secondary schools is of concern to educators, academics and policy-makers in the Ministry of Education. Of particular concern are ethnic patterns that show that Pasifika students have lower achievement outcomes than students from other ethnic groups. Research about the effects of intervention programmes to help improve teaching practice and raise achievement could be useful (Robinson and Timperley, 2004; Chu et al., 2013) and so this study reports the effects of two study skills programmes - a traditional study (TS) skills programme and a motivation-enhanced (MS) study skills programme. This research builds on international and New Zealand research on the impact of motivation on achievement via culturally responsive teacher-student relationships. These intervention programmes were aimed at improving the academic achievement 
of under-achieving students, with a focus on Pasifika students, in New Zealand Secondary Schools as measured by achievement-related outcomes including NCEA achievement, motivation, engagement and attendance. It was reasonable to expect there could be improved achievement outcomes for Pasifika students from both the MS programme and the TS programme since both programmes provided teaching and learning opportunities. Both programmes offered a regular place for students to complete study, a programme of general study skills, and one-on-one assistance to students, particularly with literacy activities and in other subject areas. However the MS programme included all these components plus motivation-focused elements. This research was designed to make comparisons about the effectiveness of each of the programmes on student achievement, motivation, engagement, and attendance outcomes.

This thesis aimed to address three research questions:

1. Were there differences in achievement, motivation, engagement and attendance outcomes for students who participated in a TS support programme compared to students who participated in a MS support programme?

2. Were there differences in the achievement, motivation, engagement and attendance outcomes of Pasifika students who participated in a TS support programme compared to Pasifika students who participated in a MS support programme?

3. How did students perceive the relative value and helpfulness of the TS support programme and the MS support programme towards supporting their learning 
Motivation Interventions via Study Programmes for Under-achieving Students

and achievement? What were the perceptions of Pasifika students regarding programme components?

This was a two-phase, sequential, explanatory, mixed-methods study. In phase one, quantitative data were gathered from a two-group pre-test/post-test randomized experiment that aimed to determine whether achievement-related outcomes of the two intervention programmes were different. These data informed research questions one and two. Two main instruments were used in this study. The first was Martin's (2001, 2005, 2008) Student Motivation and Engagement Scale (MES-HS) and the second was the Survey of NCEA Goals Year 10 and Year 11 Students (2008) designed and tested by Meyer and her colleagues. The first instrument gathered data about intra-personal motivation factors such as self-efficacy and persistence. The second instrument gathered further data about intra-personal goal motivation orientations such as DMB and DJE as well as inter-personal goal motivation orientations such as peer and teacher affiliation, aspirations, and attributions for best and worst marks. These quantitative data were analysed using the Statistical Package for the Social Sciences (SPSS). A basic design feature of this study was a comparison of the MS group not with a "control" group receiving no intervention, but with a comparison group that also received an intervention - the TS skills programme. In phase two, qualitative data were gathered from participants. The qualitative data were analysed using a grounded theory approach and addressed research question three. 


\section{Research Outcomes}

The quantitative data patterns fell into three major groups. First, there were results which favoured the TS programme, for all and/or for Pasifika, for example changes in adaptive intra-personal motivation orientations and changes in attendance. Given the focus on study skills in the TS programme, these results were perhaps consistent with expectations. Indeed, it may be that these factors actually reflected self-assessments regarding study skills. Second there were patterns of results which favoured the MS programme, for all and/or for Pasifika, such as NCEA achievement, maladaptive motivation orientations, Doing Just Enough, peer affiliation, attributing their best and worst marks, and disengagement. For example, these data show that all students and Pasifika students in the MS intervention programme attained more NCEA credits than all students or Pasifika students in the TS skills programme. These data also showed decreases in maladaptive intra-personal motivation orientations associated with the MS programme for Pasifika students that were greater than those occurring for their Pasifika peers in the TS programme. These results were in the same direction as those evident for all students, but the results for Pasifika students in reducing maladaptive motivation factors were more pronounced with larger effect sizes. The quantitative data also show that all students and Pasifika students in the MS programme decreased on Doing Just Enough compared with their peers in the TS programme. All students and Pasifika students in the MS group showed a higher shift in peer affiliation compared with TS students, and Pasifika MS students only also showed increased teacher affiliation compared with Pasifika TS students. These data also showed all students in the MS programme reported a statistically significant increase in attributing their best marks to effort in comparison to results for the students in the 
TS programme. All students in the MS intervention also showed a mean decrease in two negative attributions - attributing best marks to an easy test and to good luck. There was also a medium effect size for a decrease in attributing best marks to friends for the MS group in comparison with the TS group.

Other findings provide evidence that the Pasifika MS students attributed their best grade to effort rather than to factors outside the students' control. Pasifika MS students also increased attributions for academic success to ability, good luck, or an assessment that was easy. Medium effect sizes were found for attributions to effort, assessment difficulty, and luck for best marks, all favouring the MS intervention programme. Students in the MS group overall increased their attribution of worst marks to effort and decreased their attributions of worst marks to luck, with moderate effect sizes evident for both attributions favouring the MS intervention. In comparison these data showed that generally there was little difference between Pasifika students in the kinds of changes to attributions for worst marks in an assessment associated with participation in the two intervention programmes. However, medium effect sizes were evident for two of the social attributions for worst marks. On average, Pasifika students in the MS programme decreased attributing their worst marks to their teachers and to their friends following the intervention, whereas those in the TS skills programme increased these negative attributions. These quantitative data also show that disengagement ratings declined slightly for students in the MS programme but increased for those in the TS programme. These findings suggest that students in the comparison programme were more engaged with school than those in the experimental programme following participation in the intervention. The pattern of 
change in disengagement ratings for Pasifika students before and after intervention was similar to that observed for all students.

Finally the quantitative data showed there were areas where both MS and TS students, all and/or Pasifika, seemed to benefit. For example, the data showed that all students in both the MS and TS programmes decreased in attributions of their best marks to ability. Second, both groups increased aspirations for completion of the NCEA following intervention. In conclusion, it is acknowledged that a large number of analyses were conducted to test for statistical significance and effect size, hence some findings might be expected to be significant by chance. However these quantitative findings also suggested that both interventions produced positive outcomes which support the effectiveness of intervention programmes. In addition, these data showed an interesting pattern where the MS programme was associated with what could be considered important decreases in negative motivations, attributions, and selfsabotaging attitudes. The increases in positive motivation factors were similar for the MS and TS groups, but the greater gains were made by the MS students overall and for Pasifika on decreasing negative attitudes and motivations that can depress effort and academic performance. The pattern of findings contest an argument that all the significant results and meaningful effect sizes were simply by chance and suggest instead that the MS programme may have been more effective for increasing motivation and achievement-related outcomes than the TS programme. However it is also acknowledged that there were differences in these patterns for Pasifika students in the MS and the TS programmes, and these differences are highlighted later in this 
chapter in the implications for practice in schools, education policy and for future research.

The qualitative data were compared with the quantitative data and show that the interview data findings generally support the quantitative data findings. For example, the qualitative data showed that the MS programme was associated with reduced maladaptive motivation factors and decreases on Doing Just Enough compared with their peers in the TS programme. The interview data also support the quantitative data that showed that all students and Pasifika students in the MS group increased in peer affiliation and teacher affiliation compared to TS students. The interview data also support the quantitative data about traditional attributions for best marks especially easy test, good luck and friends. The interview data also support the quantitative findings about worst mark social attributions, especially the decreased attribution of worst mark to peers. Finally the interview data support the quantitative findings about reduced disengagement ratings and increased aspiration for MS students compared to TS students.

However there were a few instances where the interview data did not align with the quantitative findings. One example is that the quantitative findings showed that changes in adaptive intra-personal motivation orientations largely favour the TS skills programme over the MS programme especially for Pasifika students. In comparison, the student interview responses revealed that several MS students recalled receiving messages about adaptive intra-personal motivation factors whereas none of the students in the TS programme did. 
The interview data also suggest new findings about similarities between the MS and TS programmes whereas the quantitative data had indicated differences. These include: that achieving students made different comments when describing negative peer behaviours compared to under-achieving students; more male students exhibited negative peer behaviours in the classroom than female students, regardless of whether they were in the MS or TS programme; that every MS student made comments about teacher affiliation as did every TS student and that students from both programmes made more responses about teacher affiliation than any other questions they were asked in interviews; most MS and TS students talked about their teachers in terms of "I like the teacher" and/or "the teacher likes me"; that students from both MS and TS programmes reported dissatisfaction with the way that some teachers used their power in the classroom; others expressed frustration about what was happening in their classroom and that they wanted teachers to do something about it; and that higher achieving students had more positive views about their ability than under-achieving students regardless of which programme they were in.

However it was encouraging to see how often the qualitative data elaborated upon the quantitative findings. For example, the interview findings support the quantitative data that showed all students and Pasifika students in the MS programme decreased on Doing Just Enough compared with their peers in the TS programme. However the interview data also indicate that male MS Pasifika students were particularly receptive to DJE messages compared to other sub-groups in this study. Another example was that all students and particularly Pasifika students in the MS group increased in 
teacher affiliation compared with TS students. However the interview data provided additional detail showing that male MS Pasifika students made twice as many positive comments about their teachers and achievement as male TS Pasifika students. In comparison, female MS Pasifika students made similar numbers of positive comments about their teachers as female TS Pasifika students.

The interview data also provide new insight into best mark attributions to good luck and test difficulty. For example, four MS students continued to attribute their best marks to good luck after intervention and these four students were mostly underachieving students and all were Pasifika students. The interview data also showed that all MS students who attributed their best marks to an easy test were non-Pasifika MS students indicating that the intervention programme may have been less effective for Pasifika students on this factor.

The interview data also showed that higher achieving MS students dismissed attribution of their best marks to test difficulty whereas under-achieving MS students did not. The interview data support these findings and also show that all MS students who attributed the worst marks to bad luck attribution were male. The interview data also showed higher achieving MS students dismissed bad luck as an attribution for lack of achievement.

The interview data show that more male MS Pasifika students made negative attribution of worst mark to their peers than female MS Pasifika students; more female TS Pasifika students made negative attribution of worst mark to their peers 
Motivation Interventions via Study Programmes for Under-achieving Students

than female MS Pasifika students; more male TS Pasifika students made more negative attribution of worst mark to their peers than male MS Pasifika students. The interview data also showed that MS under-achieving students made more negative attributions of their worst marks to peers than MS achieving students.

In conclusion the findings reported in this chapter suggest that both interventions produced positive outcomes which support the effectiveness of intervention programmes. In addition, these interview data reveal an interesting pattern whereby the MS programme was associated with what could be considered important decreases in negative motivations, attributions, and self-sabotaging attitudes. The increases in positive motivation factors were similar for the MS and TS groups. However, greater gains were made by the MS students overall and for Pasifika in decreasing negative attitudes and motivations that can depress effort and academic performance. The interview data often indicate that interactions with teachers, family and friends were positively and negatively associated with motivation and achievement.

Again, the clear pattern of these findings contests an argument that significant results occurred simply by chance and suggest instead that the MS programme may have been more effective for increasing motivation and achievement-related outcomes than the TS programme. However it is also acknowledged that these data showed there were differences in these patterns for Pasifika students in the MS and the TS programmes. These differences are highlighted later in this chapter where 
implications for practice in schools, education policy and for future research are outlined.

\section{Strengths of this Study}

This study could be considered sound motivation intervention research because it is based upon clear theoretical foundations and constructs, considers motivation and achievement from an ethnic minority student perspective, and utilises two psychometrically validated survey measures in a mixed-methods research design (Wentzel and Wigfield, 2007). This study may contribute to our understanding of the effects of social-psychological interventions and how these interventions may be associated with achievement (Paunesku, 2013).

The theoretical framework of this study is situated within six seminal motivation theories - self-efficacy, expectancy-value, goal, self-determination, self-worth and attribution motivation theory. However, this study is particularly based on an intervention informed by attribution, goal and intra-personal motivation theories and how these may be associated with changes in achievement.

This study considers motivation and achievement from an ethnic minority student perspective. Some research shows that some Pasifika students may be operating from a collectivist rather than an individualistic view. These ideas are relevant to the theoretical framework of this study because as McClure et al. (2011) explained, some Pasifika students may hold ideas that are described as collectivist, such as associating achievement outcomes with family. This supports claims made by Markus and 
Kitayama (1991) that "participants from more collectivist societies attribute their outcomes to social influences more than people from individualistic cultures" (p.72).

The MS intervention programme in this study is located in the field of socialpsychological interventions. Cohen (2006) noted that "what these interventions share is that they are grounded in science, found effective in randomized experiments, have surprisingly large and durable effects" (p.178). These ideas are also relevant to the MS intervention as the research design of this study was based on a stratified random assignment of student participants to the two groups - the MS and TS study skills programmes. There is a comprehensive body of social-psychology research including Cohen, Garcia, Apfel and Master (2006) and Cohen, Garcia, Purdie-Vaughns, Apfel, and Brzustoski (2009) who investigated stereotype threat interventions. For example Harackiewicz, Rozek, Hulleman, and Hyde (2012) reported on an intervention that was designed to encourage a greater uptake of Mathematics and Science courses in high school. They reported that "this relatively simple intervention led students whose parents were in the experimental group to take, on average, nearly one semester more of science and mathematics in the last 2 years of high school, compared with the control group" (p.899). The "small nudge" concept that Cohen (2011) refers to is important here because the MS programme fits this view that an apparently short intervention can have effects on achievement. It is possible to locate the MS intervention in this social-psychological intervention field as explained by Paunesku (2013) who reported that "over the last several decades, a handful of seemingly small psychological field interventions, lasting hours or even minutes, have affected students' achievement over periods of months or years" (p.7). 
This study may add to our understanding of the effects of social-psychological interventions and how these interventions may be associated with achievement because this motivation-enhanced study skills programme was based on retraining in three areas of motivation and achievement - attributions, goals and intra-personal motivation orientations. Attribution retraining (AR) is a well-researched area about the effects of interventions on motivation and achievement, including the possible effects of AR on achievement (e.g., Robertson, 2000). However this study adds to research in the area of goal retraining (GR) where interventions which seek to change intra-personal and inter-personal goals are investigated for possible subsequent effects on achievement. This is particularly so in New Zealand research about motivation and achievement as this study may be considered, in part, to be a practical implementation of some of the ideas from Meyer and her colleagues $(2006,2007$, 2009). There is some research about interventions which aim to change intra-personal motivation orientations, for example intra-personal motivation retraining (IPMR), such as Martin $(2005,2008)$. However, Martin's research focuses on IPMR and not directly on subsequent achievement. This study builds on Martin's research because it attempts to associate changes in motivation with changes in achievement.

\section{Limitations and Validity of the Study}

To support the integrity of this study, the researcher designed and delivered both the MS and TS interventions. It was important to establish confidence in the integrity of the programmes and to ensure they were delivered according to the planned variations of TS and MS emphases. Careful plans were developed for each study 
programme and these were strictly adhered to so that students in the TS programme did not receive the motivational messages that the students in the MS programme received. Both thesis supervisors independently observed one TS or one MS session to check the integrity of programme delivery. Other potential threats to internal and external validity for this proposed research included possible diffusion effects, potential ready state, self-reported data and small sample size.

Campbell (1979) explained that the diffusion effect can occur when direct or indirect interaction between treatment and control groups invalidate comparisons between them. This can happen when the control group becomes aware that the treatment group is receiving an intervention that they are not receiving and they become resentful and give up, stop trying or otherwise negatively react to the benefits of the intervention being denied to them. To overcome this limitation, both groups were offered interventions where the treatment group received a motivation intervention MS, and the control group a remediation intervention TS. The literature shows that the design of both study-skills intervention programmes may be helpful to academic achievement, and so both groups should have been satisfied that they were receiving something useful from their intervention programme (Hattie, 2009:189-191). To further overcome any possible diffusion effects, two schools were involved in the study and all students in all groups received an intervention, therefore no student should have had reason to "become resentful".

Another possible limitation of this study was potential ready state. This could be because participating students may have had variable levels of motivation, 
engagement, achievement, and attendance prior to intervention and may have therefore been in a potentially ready state to make changes in their lives. Martin (2008) noted that it was unclear to what extent change would occur with students who were less ready to change and future research needed to explore this. However Martin (2008) also reported that it was possible that one benefit of a motivation intervention was fast-tracking of a student's readiness to change (p.262). Potential ready state remains a relevant limitation of this proposed study given that students voluntarily participated in this study. However, because the MS and TS programmes operated in school time, attendance issues were ameliorated, and students in the MS and TS programmes should not have differed from other students who did not participate in the programmes.

Another possible limitation was that some data in this study were self-reported. Martin (2008) noted that it was important to conduct research that examines data derived from additional sources (p.263). To enhance the validity of this study, students were asked to give their perceptions of the interventions and their ideas about motivation and achievement in an attempt to triangulate data.

Both the TS and MS intervention programmes were delivered by the researcher, following scripts that were carefully designed to ensure the presence of the distinctive components in each of the two different approaches to intervention. In addition to this a priori intervention design and documents review, steps were taken to reinforce further the integrity of delivery of the two programmes as planned. The two PhD supervisors independently observed the researcher delivering two sessions (one MS 
and one TS) in the schools; the supervisors did not know which session was being observed in advance, but checked the researcher's teaching messages against the two scripts and confirmed which approach had been delivered following the individual sessions. These observations were not entirely random but were scheduled according to convenience across the existing programme schedules and that of the two supervisors.

Two main instruments were used in this study. The first was Martin's (2001, 2005, 2008) Student Motivation and Engagement Scale (MES-HS) and the second was the Survey of NCEA Goals Year 10 and Year 11 Students (2008) designed and tested by Meyer and her colleagues. Any issues about validity and reliability of instruments were addressed by Martin (2005) who stated that the MES-HS was based on valid and reliable psychometric principles, as outlined previously in the methodology chapter. Similarly, Meyer et al. (2007) described the Survey of NCEA Goals Year 10 and Year 11 Students (2008) as "a brief screening tool for student motivation [that] not only correlates with the longer motivation survey developed by Meyer et al. (2006), but has high reliability and generates highly predictive results" (p.4).

It is acknowledged that the sample for this study is not large. Martin (2008) noted that intervention research typically does not involve large numbers of participants, so the sample is not unusually small in this context (p.263). To a certain extent the size (and power) of this study has a natural constraint because this study was designed to operate in the regular New Zealand classroom context where the class sizes range from 19-25 students. This may be important for further research if replication studies 
are carried out because these are typical class-sizes other researchers would probably find in secondary schools. Size and validity issues in this study were enhanced because of the additional qualitative interview data which were gathered and analysed.

Finally it is acknowledged that there two main issues related to the t-tests used in this study - the large number of t-tests carried out and the level of significance reported. There were ten analyses of the quantitative data, using t-tests; however within each of these 10 analyses further sub-analyses were also made. For example, t-tests were conducted on the mean differences between all students in the MS program and all students in the TS program before and after intervention. There were further t-tests on the mean differences between Pasifika students in the MS program and Pasifika students in the TS programme before and after intervention. This means that in total there were 76 separate t-tests carried out. It is acknowledged that conducting so many t-tests could create a potential problem where the significance of reported findings could be called into question because of capitalising on chance. This problem is compounded because the level of significance used in the study was 0.05 rather than a more conservative cut-off of 0.01, It is acknowledged that another limitation of the study is the level of significance used to report the differences between the two means of the MS and TS groups. The level of significance reported in the study was at the $5 \%$ level, which means there is a possibility that the data in this study showed a difference between the two means that was purely due to chance ( $\mathrm{Ha}$ and $\mathrm{Ha}$, 2012:164). To improve confidence in the results of this study, a lower significance level $(1 \%)$ could have been used. 
While there were many t-tests in this study there were also many significant differences, all of which would not be expected by chance. This means that something was going on, although it is acknowledged that it is almost impossible to state with any confidence which ones in particular were "real" and which were those "chance" variations. This means that analysis and discussion of the results in the study must be interpreted in a circumspect manner to avoid claiming "real" differences overall, and this study is therefore cautious in claiming significant results at this stage of investigation about differences in the effects of the two study skills programs. While it is good that both interventions had positive outcomes it is acknowledged that a larger scale, well-controlled intervention study is really needed to follow up this thesis which could be regarded as a "pilot" study.

\section{Implications for Practice in Schools}

The main implications for teaching practice and for teacher educators from this study focus upon the extra gain in achievement outcomes that educators could expect by implementing motivation-enhanced study skills programmes rather than following more traditional study skills programmes. This section on implications for practice in schools outlines specific aspects of the motivation enhanced programme and which parts of the programme may have been more effective in producing possible better achievement outcomes for all students and/or for Pasifika students. 
This MS skills programme was based on retraining in three areas of motivation and achievement - attributions, goals and intra-personal motivation orientations. Attribution retraining (AR) is a well-researched area about the effects of interventions on motivation and achievement, including the possible effects of AR on achievement (for example Robertson, 2000). Perhaps less well researched is the area of goal retraining $(G R)$ where interventions which seek to change intra-personal and interpersonal goals are investigated for possible subsequent effects on achievement. Finally there is some research about interventions which aims to change intrapersonal motivation orientations, intra-personal motivation retraining (IPMR) (e.g., Martin, 2005, 2008). However, Martin's research focuses on IPMR and not directly on subsequent achievement.

\section{Attribution Retraining (AR)}

This study showed that attribution retraining appeared to be particularly effective in two areas for all students and Pasifika students. The MS programme showed consistent increases on best mark attributions for effort and decreased on best mark attributions for good luck. This means that educators considering implementing an AR programme could usefully focus on these two attributions for all students in New Zealand Secondary Schools. However the study also showed differences by ethnicity. The MS programme was associated with reducing best mark attributions for an easy test and to friends which appeared to be effective for all students, but less effective for Pasifika students. However the study also showed that a motivation-enhanced study skills programme may be more effective for Pasifika students on increasing best 
mark attributions for family, but less so for all students. This study showed that AR aspects of the MS programme were less effective on changing worst mark attributions especially for Pasifika students. There appeared to be two areas worth focusing on for all students - increasing atttributions for worst marks to lack of effort and decreasing those for bad luck. This study also showed that AR aspects of the MS programme appeared to be more effective for Pasifika students compared to all students decreasing worst mark attributions for teachers and friends. Educators could note that these reduced worst mark attributions to teachers may have indicated that teachers had a mediating effect on students' attributions for worst marks.

\section{Goal Retraining (GR)}

This study showed that results about goal retraining can be divided into two sections - intra-personal goal retraining (DMB and DJE) and inter-personal goal retraining (PA and TA). This study appeared to be particularly effective in one particular area of intrapersonal goals for all students and Pasifika students - reducing DJE. While the MS skills programme showed increases on another intra-personal goal (DMB) for all students, this did not occur for Pasifika students. This suggests that educators who are interested in GR should focus on reducing negative work-avoidance behaviour patterns in under-achieving students in their classrooms. This study also showed that the MS programme may have been more effective in the area of goal retraining because DMB and DJE are target goals, as this study operated in a regular classroom context alongside the gaining of NCEA credits. Educators may also be interested to know that the MS programme operated in two curriculum areas - Science and 
Mathematics - which indicated that goal retraining aspects of the MS programme could work in more than one curriculum subject area. Educators may be further interested to observe that the MS skills programme appeared to be effective beyond the year level in which they were delivered (Year 11) and the benefits continued into Year 12. This finding occurred because the researcher interviewed some students when they were Year 11 and again in follow-up interviews when students were in Year 12.

This study also showed that GR appeared to be particularly effective in one particular area of inter-personal goals for all students and Pasifika students - increasing peer affiliation. However the MS programme was also associated with increased teacher affiliation, but this effect was evident only for Pasifika students. Increased teacher affiliation has been more closely associated with improved achievement outcomes than peer affiliation (McClure et al., 2011). This study concludes that because the MS skills programme appeared to be associated with increased teacher affiliation, particularly for Pasifika students, this is evidence of the importance of teacher relationships for Pasifika students in New Zealand Secondary Schools.

Educators, including teacher educators, may be interested to hear specific examples from MS and TS students about how they perceived teachers helped them learn. Students want feedback from teachers that is prompt and constructive and shows that teachers understand students' learning. Students also appreciate teachers' expertise and knowledge of their subject, patient teaching, direct teaching, clarity of teaching, reciprocal teaching, teachers who use humour, teachers who are relaxed, teachers 
who create a positive classroom climate, teachers who manage the behaviour of disruptive students, and teachers who encourage students to learn.

Educators may also be interested to hear specific examples from MS students about how they perceived teachers liked or did not like them. The design of the MS intervention meant that students in the MS programme had the opportunity to rationalise and contextualise personalised teacher comments and to discuss perceptions of differential teacher-expectation with the researcher, whereas TS students did not. This provided students with the opportunity to co-construct teacher behaviours within a model of culturally responsive teaching (Sleeter, 2011) and the Effective Teaching Profile (ETP) (Bishop et al., 2009). Students want warm and friendly teachers to support their achievement. This study also suggests that negative teacherstudent relationships may be associated with de-motivation and lack of achievement. Negative student comments about teachers used the phrase "not like" and could be generalised as "I don't like the teacher" and/or "the teacher does not like me". MS students reported they were de-motivated by teachers who appear to have different expectations of some students, express annoyance or "communicated irritation", are impatient, do not push students to achieve, are unsure of their subject, are ineffective, and/or get "off-topic". They also made negative comments about teacher-controlled peer-tutoring, poor classroom management and teacher-directed learning. 


\section{Intra-Personal Motivation Retraining (IPMR)}

This study showed that Intra-Personal Motivation Retraining (IPMR) can be divided into two sections - adaptive (such as self-efficacy and persistence) and maladaptive (such as failure-avoidance and self-sabotage). Educators may be interested to know that the MS programme showed differences by ethnicity in changing adaptive intrapersonal motivation orientations. For example, all MS students increased slightly on adaptive factors whereas MS Pasifika students decreased on adaptive intra-personal motivation factors. The MS programme was effective in reducing maladaptive intrapersonal motivation orientations for all students but was particularly effective for MS Pasifika students. This finding suggests that educators who are interested in implementing motivation enhanced study skills programmes should focus on reducing maladaptive intra-personal features rather than increasing adaptive aspects of intrapersonal motivation. One possible reason for this finding is that it may be easier for teachers to demotivate students than to motivate them (Hattie, 2009).

\section{Implications for Education Policy}

This study was based on the effects of a motivation-enhanced study skills programme compared to a traditional study skills programme outcome with a focus on Pasifika students. The motivation enhanced study skills programme was associated with higher NCEA achievement outcomes for all students and for Pasifika students. This may indicate that operational policy changes which facilitate replication of this intervention programme as a pilot study in a larger number of schools could be worthwhile. 
This study showed that the MS programme which was based on retraining in three areas of motivation and achievement - attributions, goals and intra-personal motivation orientations - had a common theme: teacher relationships are important to all students and particularly Pasifika students in New Zealand secondary schools. Policy-makers may also be interested to know that the MS programme did not appear to be curriculum specific, which indicated that goal retraining aspects of the MS programme could work in several curriculum subject areas. Policy-makers may be further interested to observe that the MS skills programme appeared to be effective beyond the year level in which it was delivered (Year 11) and that benefits continued into Year 12.

\section{Implications for Future Research}

This study showed that while all students and Pasifika students reduced on the intrapersonal goal of Doing Just Enough, Pasifika students did not increase on the related intra-personal goal of Doing My Best. Future research could also usefully investigate ideas of Western versus non-Western motivation concepts within the context of motivation-enhanced study skills programmes.

The findings of this study suggest that an intervention that focuses on reducing maladaptive rather than increasing adaptive intra-personal motivation factors may be associated with improved achievement outcomes, especially for Pasifika students. It may be possible to treat failure avoidance behaviours before failure acceptance or learned helplessness occurs. Future research could investigate these ideas in replicated intervention programmes. 
This study showed that the MS skills programme appeared to be effective beyond the year level in which they were delivered (Year 11) and the benefits continued into Year 12. The longitudinal effects of motivation-enhanced skills programmes could be investigated in future studies.

Finally this study demonstrates that a relatively small scale motivation-enhanced study skills programme produced some interesting results. This may indicate that replication of this intervention programme as a pilot study in a larger number of schools could be worthwhile to investigate issues of scalability of motivationenhanced study skills intervention programmes for all students and in particular Pasifika students in New Zealand Secondary Schools. 
Motivation Interventions via Study Programmes for Under-achieving Students 


\section{References}

Abrahamson, Seligman and Teasdale (1978). Learned Helplessness in Humans: Critique and Reformulation Journal of Abnormal Psychology, 87, 49-74.

Airini, Anae, M., Mila-Schaef, K.M., with Coxon, E., Mara, D. \& Sanga, K. (2010). Teu Le $\mathrm{Va}-$ Relationships across research and policy in Pasifika education A collective approach to knowledge generation \& policy development for action towards Pasifika education success. Report to the Ministry of Education, NZ.

Allen,J.P., Pianta, R.C., Gregory, A., Mikami, A.Y., Lun, J. (2011). An Interaction-Based Approach to Enhancing Secondary School Instruction and Student Achievement. Science, Vol. 333.

Alton-Lee, A. (2003). Quality Teaching for Diverse Students in Schooling: Best Evidence Synthesis. Wellington, Ministry of Education.

Ames, C. (1992). Classrooms: Goals, structures, and student motivation. Journal of Educational Psychology, 84, 261-271.

Ames, C. \& Ames, R. (1984). Systems of Student and Teacher Motivation: Qualitative Definition Toward a Qualitative Definition. Journal of Educational Psychology, 76, 4, 536-556.

Anae, M., Coxon, E., Mara, D., Wendt-Samu, T., \& Finau, C. (2001). Pasifika Education Research Guidelines Final Report. Wellington: Ministry of Education.

Aronsen, Fried and Good (2002). Reducing the Effects of Stereotype Threat on African American College Students by Shaping Theories of IntelligenceJournal of Experimental Social Psychology 38, 113-125 (2002).

Atkinson, J.W., (1957). Motivational determinants of risk - taking Behavior. Psychological review, 64, 6, 359-372.

Averill, R.M. (2009). Teacher-student Relationships in Diverse New Zealand Year 10 Mathematics Classrooms: Teacher Care. Thesis submitted in fulfilment of the requirements for the degree of Doctor of Philosophy Victoria University of Wellington.

Ajzen, I. (2011). The theory of planned behaviour: Reactions and reflections, Psychology \& Health, 26:9, 1113-1127. 
Bandura, A., (2007). Much ado over a faulty conception of perceived self-efficacy grounded in faulty experimentation. Journal of social and clinical psychology, 26, 6, 641-658.

Bergman, M. (2010). On Concepts and Paradigms in Mixed Methods Research. Journal of Mixed Methods Research 4(3) 171-175.

Bernardi, L., Keim,S. \& von der Lippe, H. (2007). Social Influences on Fertility: A Comparative Mixed Methods Study in Eastern and Western Germany Journal of Mixed Methods Research, 1: 23.

Biddulph, F., Biddulph, J., \& Biddulph, C. (2003). The complexity of community and family influences on children's achievement in New Zealand: Best evidence synthesis. Wellington: Ministry of Education.

Bishop, R., Berryman, M., Tiakiwai, S., \& Richardson, C. (2003). Te Kotahitanga: The experiences of Year 9 and 10 Māori Students in Mainstream Classrooms. Report to the Ministry of Education. Wellington, NZ.

Bishop, R., Berryman, M., Powell, A., \& Teddy, L. (2005). Te Kotahitanga Phase 2: Towards a whole school approach. Wellington, New Zealand: Ministry of Education.

Bishop, R., Berryman, M., Cavanagh, T., \& Teddy, L. (2007). Te Kotahitanga phase III whanaungatanga: Establishing a culturally responsive pedagogy of relations in mainstream secondary school classrooms. Wellington New Zealand: New Zealand Ministry of Education.

Bishop, R., Berryman, M., Cavanagh, T., \& Teddy, L. (2009). Te Kotahitanga: Addressing educational disparities facing Māori students in New Zealand. Teaching and Teacher Education, 25, 734-742.

Blackwell, L.S., Trzesniewski, K.H., and Dweck, C.S. (2007). Implicit Theories of Intelligence Predict Achievement Across an Adolescent Transition: A Longitudinal Study and an Intervention. Child Development, January/February 2007, Volume 78, Number 1, pages 246-263.

Blumenfeld, P. C. (1992). Classroom learning and motivation: Clarifying and expanding goal theory. Journal of Experimental Psychology, 84, 272-281.

Bong, M. (2004). Academic Motivation in Self-Efficacy, Task Value, Achievement Goal Orientations, and Attributional Beliefs. The Journal of Educational Research. Vol. 97, Iss. 6.

Bong, M. (2006). Problems in Academic Motivation Research and Advantages and Disadvantages of Their Solutions. Contemporary Educational Psychology 21, 149-165. 
Bryman, A. (2007). Barriers to Integrating Quantitative and Qualitative Research Journal of Mixed Methods Research, 1: 8.

Campbell, D.T. (1979). Experimental and quasi-experimental designs for research. Chicago, R. McNally.

Casserly, A. M. (2013). The socio-emotional needs of children with dyslexia in different educational settings in Ireland. Journal of Research in Special Educational Needs, 13(1), 79-91.

Chamaz, K. (2006). Constructing grounded theory: A practical guide through qualitative analysis. London: Sage.

Chodkiewicz, A. R., \& Boyle, C. (2014). Exploring the contribution of attribution retraining to student perceptions and the learning process. Educational Psychology in Practice, 30(1), 78-87.

Chu, C., Glasgow, A., Rimoni, F., Hodis, M., \& Meyer, L. H. (2013). An analysis of recent Pasifika education research literature to inform improved outcomes for Pasifika learners.An analysis of recent Pasifika education research literature to inform improved outcomes for Pasifika learners.

Cohen G. L. (2011) Social Psychology and Social Change. Science, 334, 178-179.

Cohen, G. L., \& Sherman, D. K. (2014). The psychology of change: Self-affirmation and social psychological intervention. Annual review of psychology, 65, 333-371.

Cohen, G. L., Garcia, J., Apfel, N., \& Master, A. (2006). Reducing the racial achievement gap: A social-psychological intervention. Science, 313(5791), 1307-1310. Cohen, Garcia, Purdie-Vaughns, Apfel, and Brzustoski (2009).

Corker, K. S., \& Donnellan, M. B. (2012). Setting lower limits high: The role of boundary goals in achievement motivation. Journal of Educational Psychology, 104(1), 138.

Covington, M. \& Omelich, C. (1980). Ability and Effort Valuation Among FailureAvoiding and Failure-Accepting Students. Journal of Educational Psychology, 77, 4, 446-159.

Coxon, E., Anae, M., Mara, D., Wendt-Samu, T., \& Finau, C. (2002). Literature review on Pacific education issues. Auckland: University of Auckland.

Creswell, J.W. (2009). Research Design. Qualitative, Quantitative and Mixed Method approaches. Sage. 
Dickie, J.G. (2008). An Investigation of Sites, Uses and Practices for Literacy in the Lives of Pasifika Students. Thesis submitted in fulfillment of the requirements of the degree of Doctor of Philosophy in Education Victoria University of Wellington.

Dowson, M., \& Mclnerney, D. M. (2003). What do students say about their motivational goals?: Towards a more complex and dynamic perspective on student motivation. Contemporary educational psychology, 28(1), 91-113.

Duda, J. L., \& Allison, M. T. (1989). The attributional theory of achievement motivation: Cross-cultural considerations. International Journal of intercultural relations, 13(1), 37-55.

Education Counts http://www.educationcounts.govt.nz

Elliot, A.J. (2005). A conceptual history of the achievement goal construct. In A.J. Elliot \& C.S. Dweck (Eds.), Handbook of competence and motivation (pp.52-72). New York: Guilford Press.

Field, T., Diego, M., Sanders, C. (2002). Adolescents' parent and peer relationships. Adolescence; Spring 2002; 37, 145, 121-130.

Fletcher, J., Parkhill, F., Taleni, T., Fa'afoi, A., \& O’Regan, B. (2009). Pasifika students: Teachers and parents voice their perceptions of what impacts on Pasifika students' achievement in literacy, language and learning. Teaching and Teacher Education: An International Journal of Research and Studies, 25, 24-33. (2009).

Försterling, F. (1985). Attributional retraining: A review. Psychological Bulletin, 98(3), 495.

Fusitu'a, L., \& Coxon, E. (1998). Ko e'ulungaanga faka-tonga mo e ako lelei: Tongan culture and academic achievement. New Zealand Journal of Educational Studies. Fyrsten, Nurmi, and Lyytinen (2006).

Gall, M.D. (1990) Tools for learning: A guide to teaching study skills. Association for Supervision and Curriculum Development. Alexandria, Va.

Gorinski, R. (2005). Pasifika Islands School-Parent-Community Liaison Project: Case study. New Zealand Ministry of Education, Wellington.

Graham, J., Meyer, L. H., McKenzie, L., McClure, J., \& Weir, K. F. (2010). Maori and Pacific secondary student and parent perspectives on achievement, motivation and the NCEA. Assessment Matters, 2, 132-157.

Grant, H., \& Dweck, C. S. (2003). Clarifying achievement goals and their impact. Journal of personality and social psychology, 85(3), 541. 
Greene, J.C., Caracelli, V.J. \& Graham. W.F. (1989). Toward a Conceptual Framework for Mixed-Method Evaluation Designs Educational Evaluation and Policy Analysis, Vol. 11, No. 3, pp. 255-274.

Harackiewicz, J. M., Rozek, C. S., Hulleman, C. S., \& Hyde, J. S. (2012). Helping Parents to Motivate Adolescents in Mathematics and Science An Experimental Test of a Utility-Value Intervention. Psychological Science, 0956797611435530.

Harvey, V.S. \& Chickie-Wolfe, L.A. (2007) Fostering independent learning : practical strategies to promote student success. New York, Guilford Press.

Hattie, J. (2003). New Zealand Education Snapshot. Paper presented at the Knowledge Wave Forum, Auckland, New Zealand.

Hattie, J. (2009). Visual Learning - Visible Learning: A Synthesis of Over 800 MetaAnalyses Relating to Achievement, Routledge.

Hattie, J., Biggs, J., \& Purdie, N (1996). Effects of Learning Skills Interventions on Student Learning: A Meta-Analysis. Review of Educational Research, Vol. 66, No. 2, pp. 99-136.

Hattie, J., \& Timperley, H. (2007). The power of feedback. Review of educational research, 77(1), 81-112.

Hawk, K., and Hill, J., (with Foliaki, L., Seabourne, T., Tanielu, L. and Williams, T.) (1996). Towards Making Achievement Cool: Achievement in Multi-cultural High Schools. Wellington: Ministry of Education.

Hawk, K., Hill, J., (1998). Aiming for Student Achievement: How teachers can understand and better meet the needs of Pacific Island and Maori students, SET: Research Information for Teachers, 2 (Item 4).

Hawk, K., Hill, J., (1999), 'AlMHI' - Achievement in Multicultural High Schools, Paper presented at the Educating Pasifika Positively Conference, 10-15 April 1999, Auckland.

Hindmarsh, J. H., Hohepa, M., \& Murphy, W. (1995). The Maori and Pacific Islands school retention policy 1990-1991: Lessons learned. New Zealand Journal of Educational Studies, 30(2), 119-133.

Hodis, F. A., Meyer, L. H., McClure, J., Weir, K. F., \& Walkey, F. H. (2011). A longitudinal investigation of motivation and secondary school achievement using growth mixture modeling. Journal of educational psychology, 103(2), 312.

Horner, S. L., \& Gaither, S. M. (2004). Attribution retraining instruction with a secondgrade class. Early Childhood Education Journal, 31(3), 165-170. 
Ivankova, N.V., Creswell, J.W. \& Stick, S.L. (2006). Using Mixed-Methods Sequential Explanatory Design: From Theory to Practice. Field Methods, 18: 3.

Jick, T. D. (1979). Mixing qualitative and quantitative methods: Triangulation in action. Administrative Science Quarterly, 24, 602-611.

Jones, A. (1991). At School I've Got a Chance: Culture/Privilege: Pasifika Islands and Pakeha girls at school. Palmerston North: Dunmore Press.

Manu'atu, L., \& Kepa, M. (2006). Talanoa malie: Social and education empowerment for Tongans by Tongans in the "Pasifika" educational proposal. Indigenous education and empowerment. International perspectives, 169-177.

Kurtz-Costes, B. E., \& Schneider, W. (1994). Self-concept, attributional beliefs, and school achievement: A longitudinal analysis. Contemporary Educational Psychology, 19(2), 199-216.

Latu, M. (2009). Talonga: A contribution to the teaching and learning of Tongan primary school children in New Zealand (Unpublished Master's thesis). Auckland. University of Technology, New Zealand.

LEAP (2009). Retrieved on 28.01.10 from http://leap.tki.org.nz

Leech, N., Dellinger, A.B., Brannagan, K.B. \& Tanaka, H (2010). Evaluating Mixed Research Studies: A Mixed Methods Approach. Journal of Mixed Methods Research 4(1) 17-31.

Liu, K., Cheng, Y., Chen, Y., \& Wu, Y. (2009). Longitudinal effects of educational expectations and achievement attributions on adolescents' academic achievements. Adolescence, 44, 911-924.

Lomax, R. G. (2007). An introduction to statistical concepts (2nd eds.).

Markus, H. R., \& Kitayama, S. (1991). Culture and the self: Implications for cognition, emotion, and motivation. Psychological review, 98(2), 224.

Martin, A. J. (2001). The Student Motivation Scale: A tool for measuring and enhancing motivation. Australian Journal of Guidance and Counselling, 11, 1-20.

Martin, A. J. (2002). Motivation and academic resilience: Developing a model of student enhancement. Australian Journal of Education, 46, 34-49.

Martin, A. J. (2005). Exploring the effects of a youth enrichment program on academic motivation and engagement. Social Psychology of Education, 6, 179-206.

Martin, A. J. (2006). A motivational psychology for the education of indigenous students. Australian Journal of Indigenous Education, 35, 30-43. 
Martin, A. J. (2007). Examining a multidimensional model of student motivation and engagement using a construct validation approach. British Journal of Educational Psychology, 77(2), 413-440.

Martin, A. J. (2008). Enhancing student motivation and engagement: The effects of a multidimensional intervention. Contemporary Educational Psychology, 33 (2008) 239-269.

Martin, A. J. (2008). Motivation and Engagement Scale High School (MES-HS). Lifelong Achievement Group Pty Ltd. Summer Hill, NSW 2130, Australia.

Martin, A. J., Marsh, H. W., Mclnerney, D. M., Green, J. \& Dowson, M. (2007). Getting along with teachers and parents: The yields of good relationships for students' achievement motivation and self-esteem. Australian Journal of Guidance and Counselling, 17(02), 109-125.

Martin, A. J., \& Dowson, M. (2009). Interpersonal relationships, motivation, engagement, and achievement: Yields for theory, current issues, and educational practice. Review of Educational Research, 79, 327-365.

McClure, J. (1985). The social parameter of "learned" helplessness: Its recognition and implications. Journal of Personality and Social Psychology, 48(6), 1534.

McClure, J., Meyer, L. H., Garisch, J., Fischer, R., Weir, K. F., \& Walkey, F. H. (2011). Students' attributions for their best and worst marks: Do they relate to achievement? Contemporary Educational Psychology, 36, 71-81.

Meyer, L.H., McClure, J., Walkey, F., McKenzie, L., \& Weir, K. (2006). The impact of the NCEA on student motivation: Final Report to the Ministry of Education. Wellington: Ministry of Education and Victoria University.

Meyer, L.H., Weir, K., McClure, J., Walkey, F., \& McKenzie, L. (2007). Longitudinal research on the relationship between the NCEA and student motivation and achievement: Final Report to the Ministry of Education. Wellington: Ministry of Education and Victoria University.

Meyer, L.H., McClure, J., Walkey, F., Weir, K.F., McKenzie, L. (2008). Survey of NCEA goals: Year 10 and Year 11 students. Victoria University of Wellington College of Education, New Zealand

Meyer, L.H., Weir, K.F., McClure, J., Walkey, F., McKenzie, L. (2009). Motivation and Achievement at Secondary School The relationship between NCEA design and student motivation and achievement: A Three-Year Follow-Up. Wellington: Ministry of Education and Victoria University. 
Millward, P., Neal, R., Kofoed, W., Parr, J., Lai, M. K., Robinson, V., \& Lai, M. (2001). Schools' learning journeys: Evaluating a literacy intervention at Dawson Road Primary School. Journal issue, (2).

Molina-Azorín, J.F. (2011). The Use and Added Value of Mixed Methods in Management Research. Journal of Mixed Methods Research, 5(1) 7-24.

Morgan, D.L. (2007). Paradigms Lost and Pragmatism Regained. Methodological Implications of Combining Qualitative and Quantitative Methods. Journal of Mixed Methods Research. Volume 1, Number 1, 48-76.

NZARE. http://www.nzare.org.nz

NEMP (2008). Ministry of Education. Retrieved on 12.12 .09 from http://www.educationcounts.govt.nz/statistics/schooling

New Zealand Ministry of Education (2010a). Downloaded on 10.04.12 from http://www.minedu.govt.nz/NZEducation/EducationPolicies/Schools/SchoolOpe rations/Resourcing/ResourcingHandbook/Chapter1/DecileRatings.aspx

New Zealand Ministry of Education (2010b). Downloaded on 10.04.12 from http://www.minedu.govt.nz/Parents/YourTeen/ProgressAndAchievement/Unde rstandingNCEA.aspx

New Zealand Ministry of Education (NZMoE) website (2012a). www.minedu.govt.nz

New Zealand Ministry of Education initiative called Power up to NCEA http://pasifikapowerup.co.nz

NZMoE website (2012b). www.minedu.govt.nz

New Zealand Qualifications Authority (2012a). Science and the Car (US 18976). Teaching Context for Group One - The car, force and motion. Downloaded on 11.04.12 from http://www.nzqa.govt.nz/ncea/assessment/search.do?query=Science++ Core\&view=all\&level=01

New Zealand Qualifications Authority (2012b). Demonstrate basic algebra skills (US 20659). Teaching context for Group Two. Downloaded on 11.04 .12 from http://www.nzqa.govt.nz/ncea/assessment/search.do?query=math\&view=all\&l evel=01

New Zealand Qualifications Authority (2012c). Describe Aspects of Chemistry (AS 90189). Teaching context for Group Three. Downloaded on 11.07.10 from http://www.nzqa.govt.nz/ncea/assessment/search.do?query=Science\&view=all \&level=01 
Ng, D., Mcclure, J., Walkey, F., \& Hunt, M. (1995). New Zealand and Singaporean attributions and achievement perceptions. Journal of cross-cultural psychology, 26(3), 276-297.

O'Mara, A. J., Marsh, H. W., Craven, R. G., \& Debus, R. L. (2006). Do self-concept interventions make a difference? A synergistic blend of construct validation and meta-analysis. Educational Psychologist, 41(3), 181-206.

Okolo, C. (1992). The effects of computer-based attribution retraining on the attributions,persistence, and mathematics computation of students with learning disabilities. Journal of Learning Disabilities, 25(5), 327-334.

O'Sullivan, J. T., \& Howe, M. L. (1996). Causal attributions and reading achievement: Individual differences in low-income families. Contemporary educational psychology, 21(4), 363-387.

Pasifika Education Plan: Monitoring Report (2010). Downloaded on 03.08.14 from http://www.educationcounts.govt.nz/publications/series/22967/pasifikaeducation-plan-monitoring-report-2010

Pasikale, A., (1999). Skills Pasefika: Contributions to Educating Pasefika Positively, Paper presented at Educating Pasefika Positively Conference, 10-12 April 2001, Auckland.

Paunesku, D. (2013). Scaled-up social psychology: Intervening wisely and broadly in education (Doctoral dissertation, Stanford University).

Perry, R. P., Hechter, F. J., Menec, V. H., \& Weinberg, L. E. (1993). Enhancing achievement motivation and performance in college students: An attributional retraining perspective. Research in Higher Education, 34(6), 687-723.

Perry, R. P., Stupnisky, R. H., Hall, N. C., Chipperfield, J. G., \& Weiner, B. (2010). Bad starts and better finishes: Attributional retraining and initial performance in competitive achievement settings. Journal of Social and Clinical Psychology, 29(6), 668-700.

Phillips, G., McNaughton, S., \& MacDonald, S. (2001). Picking up the pace: Effective literacy interventions for accelerated progress over the transition into decile 1 schools. Wellington: Ministry of Education.

Phillips, G., McNaughton, S., \& MacDonald, S. (2002). Picking up the pace: A summary. Wellington: Ministry of Education.

Richer, K., Godfrey, J., Partington, G., Harslett, M. \& Harrison, B. (1998). Attitudes of aboriginal students to further education: An overview of a questionnaire survey. Paper presented at Australian Association for Research in Education Annual Conference, Adelaide, Australia. 
Robertson, J. (2000). Is attribution training a worthwhile classroom intervention for K12 students with learning difficulties? Educational Psychology Review, 12(1), 111-134.

Robinson, V., \& Timperley H. (2004). Strengthening Education in Mangere and Otara; Final Evaluation Report. Ministry of Education, Wellington, New Zealand.

Rossman, G.B., \& Wilson, B.L. (1985). Numbers and Words : Combining Quantitative and Qualitative Methods in a Single Large-Scale Evaluation Study. Evaluation Review, 9: 627.

Rubie-Davies, C., Hattie, J., Hamilton, J. (2003). Great Expectations: Implications for New Zealand students. Paper presented at NZARE Conference. Auckland, New Zealand.

Rubie-Davies, C., Hattie, J., \& Hamilton, R. (2006). Expecting the best for students: Teacher expectations and academic outcomes. British Journal of Educational Psychology, 76(3), 429-444.

Savage and Hindle (2011) in Sleeter, C.E., (Ed.) (2011). Professional development of culturally responsive and relationship-based pedagogy. New York: Peter Lang.

Schuster, E. (2008). Who are the best teachers of Pasifika children? Kairaranga, 9(2), 10-13.

Shmulsky, S., \& Gobbo, K. (2007). Explanatory style and college students with ADHD and LD. Journal of Attention Disorders, 10(3), 299-305.

Siope, A. (2011). The schooling experiences of Pasifika students. Set 3, 10-16.

Sleeter, C.E., (Ed.) (2011). Professional development of culturally responsive and relationship-based pedagogy. New York: Peter Lang.

Slonim-Nevo \& Nevo (2009). Conflicting Findings in Mixed Methods Research, Journal of Mixed Methods Research Volume 3 Number 2.

Taleni, L. T., Parkhill, F., Fa'afoi, A., \& Fletcher, J. (2007). Pasifika students: What supports them to become effective readers. Pacific-Asian Education: The Journal of the Pacific Circle Consortium for Education, 19(2), 57-71.

Tashakkori, A. \& Creswell, J.W. (2007). Editorial: The New Era of Mixed Methods Journal of Mixed Methods Research 2007 1: 3.

Te Ava, A., Airini, \& Rubie-Davies, C. (2011). Akarakara akaouanga i te kite pakari o te kuki airani: Culturally responsive pedagogy. Pacific-Asian Education, 23(2), 117128. 
Toland, J., \& Boyle, C. (2008). Applying cognitive behavioural methods to retrain children's attributions for success and failure in learning. School Psychology International, 29(3), 286-302.

Turner, H. (2014).

http://www.nzherald.co.nz/nz/news/article.cfm?c_id=1\&objectid=11249785

Urdan, T. C., \& Maehr, M. L. (1995). Beyond a two-goal theory of motivation and achievement: A case for social goals. Review of educational research, 65(3), 213243.

Overwalle, F., \& Metsenaere, M. (1990). The effects of attribution-based intervention and study strategy training on academic achievement in college freshmen. British Journal of Educational Psychology, 60(3), 299-311.

Vispoel, W. P., \& Austin, J. R. (1995). Success and failure in junior high school: A critical incident approach to understanding students' attributional beliefs. American Educational Research Journal, 32(2), 377-412.

Walkey, F., McClure, J., Meyer, L.H., \& Weir, K.F. (2013). Low expectations equal no expectations: Aspirations, motivation, and achievement in secondary school. Contemporary Educational Psychology, 38, 306-315.

Walton, G. M., \& Cohen, G. L. (2011). A brief social-belonging intervention improves academic and health outcomes of minority students. Science, 331(6023), 14471451.

Watkins, D., \& Gutierrez, M. (2001). Causal relationships among self-concept, attributions, and achievement in Filipino students. The Journal of Social Psychology, 130, 625-631.

Weiner, B. (1979). A theory of motivation for some classroom experiences. Journal of educational psychology, 71(1), 3.

Weiner, B. (1985). An attributional theory of achievement motivation and emotion. Psychological Review, 92, 548-573.

Weiner, B. (2010). The development of an attribution-based theory of motivation: A history of ideas. Educational Psychologist, 45, 28-36.

Wentzel, K.R. (1999). Social-motivational processes and interpersonal relationships: Implications for understanding motivation at school. Journal of Educational Psychology, 91, 76-97. 
Wentzel, K. R., Battle, A., Russell, S. L., \& Looney, L. B. (2010). Social supports from teachers and peers as predictors of academic and social motivation. Contemporary Educational Psychology, 35(3), 193-202.

Wentzel, K.R., \& Caldwell, K. (1997). Friendships, peer acceptance, and group membership: Relations to academic achievement in middle school. Child Development, 68, 1198-1209.

Wentzel, K. R., \& Wigfield, A. (2007). Motivational interventions that work: Themes and remaining issues. Educational Psychologist, 42(4), 261-271.

Wigfield, A., Galper, A., Denton, K., \& Seefeldt, C. (1999). Teachers' beliefs about former Head Start and non-Head Start first-grade children's motivation, performance, and future educational prospects. Journal of Educational Psychology, 91(No.1), 98-104.

Wigfield, A. \& Wentzel, K.R. (2011). Introduction to Motivation at School: Interventions That Work. Educational Psychologist, 42(4), 191-196.

Wosnitza, M. \& Volet, S. (2012). Editorial Introduction: Multiple Goals in Learning Contexts. Applied Psychology: An International Review, 61 (4), 513-519.

Yasutake, D., Bryan, T., \& Dohrn, E. (1996). The effects of combining peer tutoring and attribution training on students' perceived self-competence. Remedial and Special Education, 17(2), 83-91.

Ziegler, A., \& Heller, K. A. (2000). Effect of an attribution retraining with female students gifted in physics. Journal of the Education of the Gifted, 23(2), 217-243. 


\section{Appendixes \\ Appendix A Glossary of Key Terms}

$\begin{array}{ll}\text { AIMHI } & \text { The Achievement in Multicultural High Schools project } \\ \text { AR } & \text { Attribution Retraining } \\ \text { AS } & \text { Achievement Standards } \\ \text { DJE } & \text { Doing Just Enough motivation orientation } \\ \text { DMB } & \text { Doing My Best motivation orientation } \\ \text { ECPL } & \text { The Early Childhood Primary Links via Literacy Project } \\ \text { ESOL } & \text { English Speakers of Other Languages } \\ \text { ETP } & \text { The Effective Teacher Profile } \\ \text { GPA } & \text { Grade Point Averages } \\ \text { GR } & \text { Goal Retraining } \\ \text { IEA } & \text { The International Association for the Evaluation of Educational } \\ \text { NE } & \text { The New } \\ \text { NCEA } & \text { The Student Motivation and Engagement Scale - High Schools } \\ \text { IPMR } & \text { Intra-Personal Motivation Retraining } \\ \text { LEAP } & \text { The Literacy Environments for Accelerated Progress Programme } \\ \text { MES } & \text { The }\end{array}$


Motivation Interventions via Study Programmes for Under-achieving Students

NZMoE The New Zealand Ministry of Education

NZQA The New Zealand Qualifications Authority

PA Peer Affiliation motivation orientation

PB Personal Best

PISA The Programme for International Student Assessment

PISPCL The Pacific Island School-Parent-Community Liaison Programme

SEA The School Entry Assessment for Year 1 students

SEMO The Strengthening Education in Mangere and Otara iniative

ST The Screening Tool - the informal title of the Survey of NCEA Goals for Year 10 and Year 11 Students

TA Teacher Affiliation motivation orientation

TIMSS Third International Mathematics and Science Study

TS The Traditional Study support programme

UE University Entrance

US Unit Standards 


\title{
Appendix B The Traditional Study (TS) and Motivation-enhanced Study (MS) Support Programmes
}

\author{
The TS support programme \\ Module One: Introductions, explanations and pre-testing \\ Modules Two and Three: Organising my study and managing myself \\ Module Four and Five: $\quad$ Classwork and reading skills \\ Module Six and Seven: Doing assignments and preparing for tests \\ Module Eight: $\quad$ Assessment and post-testing
}

The MS support programme

Students in the MS support programme received the same programme the TS students received as well as the following motivation and achievement concepts:

MS \#1 Goals and motivation

MS \#2 Personal best (PB) approach to goals

MS \#3 Doing My Best and Doing Just Enough

MS \#4 Adaptive intra-personal motivation orientations and achievement

MS \#5 Maladaptive intra-personal motivation orientations and achievement

MS \#6 Inter-personal motivation orientations and achievement

MS \#7 Attributions and control and motivation 


\section{The TS support programme}

Module One: Introductions, explanations and pre-testing

Introductions

Organisation and explanation of how this programme will run and the foci of the TS programme including:

- How to study more effectively

- How to take the opportunity to gain extra credits towards NCEA

- How to better understand how NCEA works

- The distributing folders and journals

- Pre-testing of motivation orientations

\section{Modules Two and Three: Organising my study and managing myself}

Students in both the MS and TS programmes discussed goals in relation to achievement at school as well as personal goals. During modules two and three, each lesson had three parts: part one was a discussion about study skills covering the items below, usually as a discussion, accompanied with a worksheet which the students could put inside their plastic folders. Part two was teaching the relevant material from US/AS context or a particular class, and during each lesson there was time for food and drink.

Study skills items for modules two and three:

- Discuss setting academic and personal goals

- Organising myself at school

- Organising myself at home

- Thinking about my study conditions

- Thinking about my study style

- How do you know when you have studied well?

- Time management

- Organising a study schedule: Monthly Planner

- Organising a study schedule: Weekly Schedule 
Motivation Interventions via Study Programmes for Under-achieving Students

- Teach concepts from the relevant US/AS context

- Food and drink

\section{Goals Sheet}

Name:

Date:

\begin{tabular}{|l|l|}
\hline Statement & Goal \\
\hline My academic goal this year is & \\
\hline My career goal is & \\
\hline My personal goal is & \\
\hline What things stop you achieving these goals & \\
\hline What things help you achieve these goals & \\
\hline
\end{tabular}




\section{Organising myself at school}

- Using a ring-binder and dividers (model this)

- What are your options when the folder gets full?

- How do you file the stuff the teacher gives you in class, such as handouts and notes?

- Carrying the folder to and from school

- Do you have a locker at school, and do you use it?

\section{Organising myself at home}

- Where is your place at home to put your notes/books/timetable?

- What does your study space look like?

- How could you improve it?

- Do you have all the equipment you need?

- Where do you put your bag when you get home?

- When and how do you pack your bag for school?

- What do you do with the work you did at school each day?

\section{Thinking about my study conditions}

- Do you have a quiet place to study?

- Where else could you study?

- Do you have all the books and equipment you need?

- If not what can you do about it?

- What do you do about missing notes?

- Who are you with when you study?

- If you study in a group, is this positive for all study-group members?

- Where is your place at home to put your notes/books/timetable?

- What does your study space look like? Draw it.

- How could you improve it?

- Do you have all the equipment you need?

- Where do you put your bag when you get home? 
- When and how do you pack your bag for school?

- What do you do with the work you did at school each day?

- Using a ring-binder and dividers

- What are your options when the folder gets full?

- How do you file the stuff the teacher gives you in class, such as handouts and notes?

- Carrying the folder to and from school

- Do you have a locker at school, and do you use it?

Thinking about my study style

- Where are you when you study?

- Describe the environment

- Draw it

\section{How do you know when you have studied well?}

- How much time should you study each day?

- Quantity versus quality of study

- Setting priorities

- Rewarding yourself - study now, do something fun later

- Keeping track of assignments

\section{Time management}

Discussion using ideas from Harvey and Chickie-Wolfe (2007: 140-142) 
Motivation Interventions via Study Programmes for Under-achieving Students

Organising a study schedule: Monthly Planner

Month of: $\quad$ Year: $\quad$ Name:

\begin{tabular}{|l|l|l|l|l|l|l|}
\hline Sunday & Monday & Tuesday & Wednesday & Thursday & Friday & Saturday \\
\hline & & & & & & \\
\hline \\
\hline
\end{tabular}


Organising a study schedule: Weekly Schedule

Week of:

Name:

\begin{tabular}{|c|c|c|c|c|c|c|c|}
\hline Time & Sun & Mon & Tue & Wed & Thur & Fri & Sat \\
\hline $7.00 a$ & & & & & & & \\
\hline 8.00 & & & & & & & \\
\hline 9.00 & & & & & & & \\
\hline 10.00 & & & & & & & \\
\hline 11.00 & & & & & & & \\
\hline 12.00 & & & & & & & \\
\hline 1.00 & & & & & & & \\
\hline 2.00 & & & & & & & \\
\hline 3.00 & & & & & & & \\
\hline 4.00 & & & & & & & \\
\hline 5.00 & & & & & & & \\
\hline 6.00 & & & & & & & \\
\hline 7.00 & & & & & & & \\
\hline 8.00 & & & & & & & \\
\hline 9.00 & & & & & & & \\
\hline 10.00 & & & & & & & \\
\hline
\end{tabular}




\section{Modules Four and Five: Classwork and reading skills}

Students in both the MS and TS programmes discussed how to work effectively in class and also focused on reading skills. Again, during modules Four and Five, each lesson had three parts: part one was a discussion about the relevant study skills for these modules as outlined below. This was usually as a discussion, sometimes accompanied with a worksheet which the students could put inside their plastic folders. Part two was teaching the relevant material from US/AS context or a particular class, and during each lesson there was time for food and drink.

- Attending, preparing and participating in class

- How to take notes in class

- Storing, revising and reviewing notes

- Pre-reading, note-taking and underlining

- Comprehension, monitoring and enhancing

- Reading strategies

- How to read and study written material with headings

- How to read and study written material without headings

- Teach relevant concepts from the relevant US/AS context

- Food and drink

\section{Classwork}

Attending preparing and participating in class

- Maintaining regular class attendance

- Positive attitudes

- Reading assignments before class

- Staying alert in class

- Following the rules of good listeners

- Attempting to answer all teacher questions

- Asking questions when unsure

- Using class time well 


\section{How to take notes in class}

- Taking notes when it is important to remember what the teacher is saying

- Using teacher cues to guide note taking

- Taking notes on definitions and examples

- Taking notes on assignments and test dates

- Taking paraphrase notes

- Using abbreviations and symbols

- Writing legible notes

- Maintaining alertness at the end of class

\section{Storing, revising and reviewing notes}

- Storing notes

- Labelling and dating notes

- Revising notes after class

- Periodically reviewing notes

Reference: Gall (1990: 86-109)

\section{Reading Skills}

Pre-reading, note-taking and underlining

- Allocating time for deep processing

- Analysing the structure of the text

- Determining the nature of the task

- Underlining important information

- Taking paraphrase notes

- Making an outline and graphic organisers

- Summarising a reading passage 


\section{Comprehension, monitoring and enhancing}

- Monitoring comprehension while reading

- Generating and answering questions about the text

- Reading at an appropriate speed

\section{Reading strategies}

- Using the SQ3R reading strategy

\section{References}

Gall (1990: 110-142)

Harvey and Chickie-Wolfe (2007: 181-185)

How to read and study written material with headings - Part A

Survey Question Read Recite Review (SQ3R) - Template

Step 1: Survey the material

- What is the title?

- What are the main subheadings?

Step 2: Question yourself about this material by turning the main subheadings into questions. Use who, what, where, when and why questions. Aim to get three questions from each subheading.

Steps 3 and 4: Read and Recite the answers to the questions above.

Step 5: Review the reading by going back over the pages and making the main points. 


\section{How to read and study written material without headings - Part B}

\section{Key Question Answer (KQA)}

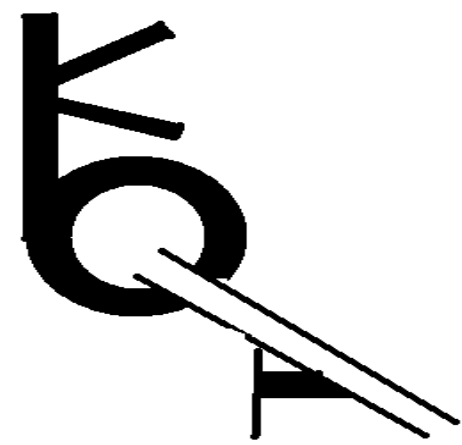

Step 1: Key sentence the material

- This is what to do when there are no subheadings. You use the key sentence.

- The key sentence is the first sentence of each paragraph and tells you what the paragraph is about without giving a heading.

Step 2: Question yourself about this material by turning the key sentence and the rest of the sentences in each paragraph into questions. Use who, what, where, when and why questions. Aim to get one to three questions from each paragraph.

Step 3: Answer the questions from Step 2.

\section{Modules Six and Seven: Doing assignments and tests}

Students in both the MS and TS programmes discussed how to do assignments and take tests. Again, during modules Six and Seven, each lesson had three parts: part one was a discussion about the relevant study skills for these modules as outlined below. This was usually as a discussion, sometimes accompanied with a worksheet which the students could put inside their plastic folders. Part two was teaching the relevant material from US/AS context or a particular class, and during each lesson there was time for food and drink.

- Preparation and planning to write assignments

- Draft writing 
- Final copy

- The test is coming up

- Time management skills

- Test wise skills

- Preparing for tests

- Taking tests

- Predicting test questions

- Teach concepts from the relevant US/AS context

- Food and drink

\section{Preparation and planning to write assignments}

- Defining the writing task

- Specifying the topic

- Developing a writing plan

- Generating ideas

- Collecting information

- Organising ideas into a plan for the essay

\section{Draft writing}

- Drafting the essay

- Getting feedback on the essay

- Revising the essay

\section{Final copy}

- Editing and producing a neat final copy

- Publishing the paper

- Using the computer

\section{References}

Gall (1990: 143-175)

Harvey and Chickie-Wolfe (2007: 197-208) 


\section{The test is coming up}

- Review assigned readings

- Review class notes

- Testing yourself

- Using mnemonic techniques

- Forming a study group

Time management skills

- Recording test dates

- Planning time for test preparation

- Avoiding cramming

- Planning to arrive early

- Keeping track of time in the test

\section{Test wise skills}

- What will the test cover?

- Question format

- Importance of the test

- What gear do I need for the test?

- Sitting in a good location

- How to read test instructions

- Answering easy questions first

- Using appropriate answering techniques

- Avoiding stress and anxiety techniques

- Positive thinking

\section{References}

Gall (1990: 176-204)

Harvey and Chickie-Wolfe (2007: 233-234) 


\section{Preparing for tests}

Students who are well prepared for tests tend to be less anxious leading up to them, and also less anxious while they are doing them. Too often students don't prepare effectively for tests. This has the effect of increasing their anxiety leading up to the test. There are lots of ways to prepare, such as study, looking at papers, a healthy diet, and relaxation. In this exercise you will look at ways you can better prepare for tests. In the table below, tick the boxes you feel you need to pay particular attention to. Put this checklist on your wall at home, in your diary, or somewhere you will see it leading up to a test or exam. (Adapted from 2009 Lifelong Achievement Group.)

\section{Tick which items you need to pay special attention to - then add three more}

- Start your study early in the term and do it regularly - but remember that late study is better than no study.

- As the detail of this material is copyright, the reader is referred to Martin, A. J. (2014). The Motivation and Engagement Workbook (14th Edition). Sydney, Australia: Lifelong Achievement Group (www.lifelongachievement.com).

\section{Taking tests}

Test taking is a skill that can be learnt. This skill significantly reduces anxiety you feel leading up to the test and while you are doing the test. In this exercise you will look at ways you can improve your test taking skills. In the table below, tick the boxes you feel you need to pay particular attention to. Put this checklist on your wall at home, in your dairy, or somewhere you will see it the night before a test or exam. At the end of this list add three items (Adapted from 2009 Lifelong Achievement Group).

Tick which ones you need to pay special attention to - then add three more

- If you're a heavy sleeper, set two alarm clocks (out of reach from your bed) the night before the exam.

- As the detail of this material is copyright, the reader is referred to Martin, A. J. (2014). The Motivation and Engagement Workbook (14th Edition). Sydney, Australia: Lifelong Achievement Group (www.lifelongachievement.com). 
Motivation Interventions via Study Programmes for Under-achieving Students

\section{Predicting test questions}

Students were taught the skills of how to predict the sort of questions that might come up in the test by learning how to access selected questions from previous NCEA papers: http://www.nzqa.govt.nz/.

\section{Module Eight: Assessment and post-testing}

During this final session, students attempted an assessment in order to gain NCEA credits. The students were post-tested using the same two measuring instruments that were used in pre-testing. 


\section{The MS Support Programme}

Students in the MS support programme received the same programme the TS students received as well as the following ideas about motivation and achievement:

MS \#1 Goals and motivation

MS \#2 Personal Best (PB) approach to goals

MS \#3 Doing My Best (DMB) and Doing Just Enough (DJE)

MS \#4 Adaptive intra-personal motivation orientations and achievement

MS \#5 Maladaptive intra-personal motivation orientations and achievement

MS \#6 Inter-personal motivation orientations and achievement

MS \#7 Attributions and control and motivation

\section{MS \#1: Goals and motivation}

During the MS programme the researcher led discussion about goals and motivation and achievement. MS students were introduced to ideas about types of goals that students may hold and associated behaviours including mastery goals, performance goals, work approach/avoidance goals and social goals. The types of goals discussed were mastery goals (I am most motivated when I see my work improving), work approach goals (DMB) and work-avoidance goals (DJE), performance goals (I am most motivated when I am doing better than others), and inter-personal goals (I am most motivated when I work with others). Students were given information about how goals are associated with motivation and achievement, and learned that goals may converge, complement or conflict (Dowson and Mclnerney, 2003). This section of the MS programme focused on:

- Personal Best (PB) approach to goals (Martin, 2006)

- Detail about DMB and DJE (Meyer et al., 2006, 2007, 2009)

- The task specific nature of DMB and NCEA 


\section{MS \#2: Personal Best (PB) approach to goals}

When you focus on competing with others, you pay less attention to your own work. On the other hand, competition can be motivating to students. You can, however, pay attention to own work (mastery goals) and be competitive (performance goals) and consider the needs of others (social goals). You do this by focusing on Personal Bests (PBs). A PB refers to the best you have ever done in something.

\begin{tabular}{|l|l|l|}
\hline Personal Best Goal Sheet: Name: & PB & Date \\
\hline What is your current PB in NCEA overall? (A, M, E?) & & \\
\hline What PB are you aiming for in NCEA overall? (A, M, E?) & & \\
\hline Describe the steps you will take to reach this PB & & \\
1. & & \\
2. & & \\
\hline 3. & & \\
\hline
\end{tabular}

(Adapted from 2009 Lifelong Achievement Group) 


\section{MS \#3: Doing My Best and Doing Just Enough}

The theory behind DMB and DJE has been outlined in the thesis. The details of the intervention are expanded upon here as an appendix for use in any replication of the study. The researcher led discussion about work approach goals (DMB) and workavoidance goals (DJE) incorporating the theory as appropriate for Year 11 (15-year-old students). Meyer et al $(2006,2007,2009)$ reported these ideas about DMB and DJE which would be useful for researchers to read more closely when considering intervention studies about motivation and achievement:

- Atkinson and Raynor (1974) considered that two of the basic concepts in achievement motivation theory are the "motive to achieve success and motive to avoid failure" (Meyer et al., 2006:10).

- There were two motivation orientations to learning and learning tasks that were related to achievement as measured by the NCEA, which were labelled Doing My Best and Doing Just Enough (Meyer et al., 2007:2).

- These two orientations were the strongest predictors of subsequent school achievement in NCEA a year later and were also stable across a two-year period (Meyer et al., 2007:2).

- Students with a Doing My Best orientation recorded more total credits overall, more achievement standard credits, and more credits achieved with Merit and with Excellence (Meyer et al., 2007:2).

- Students with a Doing Just Enough orientation recorded fewer credits overall, fewer achievement standards credits, fewer credits with Merit and with Excellence, more unit standard credits and more Not Attempted standards (Meyer et al., 2007:2).

- Student self-ratings of Doing My Best and Doing Just Enough were particularly strong positive and negative predictors, respectively, of how well students would perform on selected NCEA achievement outcomes in future years (Meyer et al., 2007:9; Hodis, Meyer, McClure, Weir, \& Walkey, 2009).

- Shifting student motivations away from the more negative Doing Just Enough to the more positive Doing My Best orientation may require focused academic 
tasks and activities where students receive support to achieve positive outcomes through their own endeavours (O'Mara, Marsh, Craven \& Debus, 2006) (Meyer et al., 2007:9).

\section{How MS students were encouraged to do their best}

The discussion about encouraging $\mathrm{DMB}$ attitudes focused on ideas about trying for Merit or Excellence, rather than just Achieved, as well as striving for Merit or Excellence even when students didn't need this to achieve their goals. Students were taught practical strategies about how to do their best. There is some crossover between adaptive intra-personal motivation ideas and DMB, and the Lifelong Achievement Group have prepared useful material which can be used here. This includes (1) the $30 \times 2$ plan, (2) Thinking about previous success, and (3) What to do when things get difficult and (4) You choose to do your best. As the detail of this material is copyright, the reader is referred to Martin, A. J. (2014). The Motivation and Engagement Workbook (14th Edition). Sydney, Australia: Lifelong Achievement Group (www.lifelongachievement.com).

\begin{tabular}{|c|c|}
\hline \multicolumn{2}{|c|}{ I am looking forward to my mark in this test because: } \\
\hline If I do well & If I don't do as well \\
\hline I know I worked hard & I know I need to work harder \\
\hline I put in the effort & I will put in more effort \\
\hline \multicolumn{2}{|c|}{ Because Doing My Best } \\
\hline
\end{tabular}




\section{How MS students were challenged about doing just enough}

The discussion about challenging DJE attitudes focused on the limiting nature of a student's goal to get, for example, just NCEA Level 1 or possibly NCEA Level 2 before leaving school, and how finishing Level 3 and getting UE gives better options for future careers. Discussion challenged the notion of being satisfied with 80 credits and working for the minimum number of credits needed at each level, as well as examined the different pathways that choosing credits for life skills and vocational job-related skills leads to compared to choosing credits related to further academic study. Students were taught practical strategies about how to challenge DJE. Again there is some crossover between maladaptive intra-personal motivation ideas and DJE some steps associated with how to challenge DJE include steps adapted from the 2009 Lifelong Achievement Group. For example, students who are low in self-belief tend to think negatively about themselves and what they do. Students were encouraged to identify negative thinking, look at evidence that they could challenge these negative thoughts and replace them with new positive thoughts. Students were shown how to consider what distracts them from study, ways they get in the way of their own success, why they may do this, and what distracts them from study. Discussion looked at how to replace negative strategies with ideas such as "If I study effectively, I'm more likely to do OK - and then there's no need for an excuse." As the detail of this material is copyright, the reader is referred to Martin, A. J. (2014). The Motivation and Engagement Workbook (14th Edition). Sydney, Australia: Lifelong Achievement Group (www.lifelongachievement.com).

\section{MS \#4: Adaptive intra-personal motivation orientations and achievement}

Student responses on six adaptive intra-personal motivation orientations were measured before and after the two intervention programmes: self-efficacy, mastery learning, valuing of school, persistence, planning, and task management. (See Appendix $D$ to review specific items for each construct). Responses from students in the MS programme were compared with those from students in the TS programme (see Appendix $C$ for a copy of the measure and items). Meyer and her colleagues 
$(2006,2007,2009)$ reported that intra-personal motivation concepts are a major component of motivational theory, for example self-efficacy:

Self-perception of ability and ideas of self-efficacy are major components of motivational theory (Meece, Eccles \& Wigfield, 1999). If students think they can do something-even if it requires hard work-they are more likely to persist in learning activities, and their own self-esteem will be enhanced even further when they do succeed. Consider again the teacher who tells a child to persist because the task is indeed difficult versus the teacher who says something is easy. Children who've heard the first message have reason to be pleased with themselves if they succeed. Children who've heard the second message have no reason to value success - after all, the task is easy-and their self-esteem is jeopardised if they cannot succeed.

MS students were introduced to adaptive intra-personal motivation concepts such as self-efficacy and why a mastery learning focus can be useful. MS students also learned how to use the strategies of planning, task management and persistence. For example, Martin (2009) reported that students should:

Break assignments into parts, outline what you need to do for each part,and think carefully about each part; keep a record of what you do with your study time in a week. Record details about where you study, with whom, at what times and under what conditions; be as clear as you can about what you want to achieve in a test or assignment and why you want to achieve it. This is called goal setting. Goal setting increases your persistence". One way to build your self-belief is to be fully aware of your talents. To build or maintain self-belief it is important to recognise that we often do not give ourselves credit for all the successes in our lives. For example we don't recognise that in doing an assignment we achieve many successes along the way. By doing this, you immediately build success into your life even before you get the mark for that assignment or test. When you recognise these successes you have every reason to feel good about yourself ( $p .82$ ).

As the detail of this material is copyright, the reader is referred to Martin, A. J. (2014). The Motivation and Engagement Workbook (14th Edition). Sydney, Australia: Lifelong Achievement Group (www.lifelongachievement.com). 


\section{MS \#5: Maladaptive intra-personal motivation orientations and achievement}

Four maladaptive intra-personal motivation factors were measured including anxiety, failure avoidance, uncertain control, and self-sabotage. MS students were introduced to reasons why negative ideas about intra-personal motivation can drag their achievement down. For example, MS students were asked to identify some negative thinking, look at evidence that you can challenge these negative thoughts and replace it with a new positive thought. Martin (2009) reported that students should:

Think about a project, assignment or test that is coming up for you soon and complete the following table: Self-sabotage, Failure avoidance and Distractions - "I often put assignments off until the last minute". "I tend to waste time the night before tests and exams". "If I don't do so well, I've got an excuse". "If I study effectively, I'm more likely to do OK - and then there's no need for an excuse (p.83).

Again, as the detail of this material is copyright, the reader is referred to Martin, A. J. (2014). The Motivation and Engagement Workbook (14th Edition). Sydney, Australia: Lifelong Achievement Group (www.lifelongachievement.com).

\section{MS \#6: Inter-personal motivation orientations and achievement}

Changes on the two inter-personal motivation factors peer affiliation and teacher affiliation were also examined as a function of participation in the MS and TS programmes. So far this section of the Discussion chapter has considered how achievement goal theory as exemplified by DMB and DJE may be associated with changes in achievement. However, previous research has shown that DMB and DJE motivation orientations may vary as predictors of future achievement by ethnicity. For example, Meyer et al., (2009) reported that while DMB was associated with future achievement for New Zealand European and Asian students, the effects were not as strong for Pasifika students. They suggested that one possible reason for this variation was that DMB and DJE "reflect individualistic, more typically 'Western' values and approaches" (p.10). They further suggested that the role of social motivation goals on motivation and achievement should be considered alongside the traditional goals such 
as DMB and DJE. Social goals may reflect collectivist and non-Western values and approaches. Changes in two social goals, peer affiliation and teacher affiliation, were supported by effect size differences favouring the MS programmes for both all students and Pasifika students. MS students discussed how family, teachers and friends affected their achievement. Previous research gives useful resources that others considering interventions could consider when leading a discussions about inter-personal motivation orientations and achievement. For example, Meyer et al., (2007) reported that students in their research expressed these ideas about family and motivation and achievement: "Students reported that their families expected them to do well, took an interest in their schoolwork, and even offered specific rewards for achievement outcomes. There were several comments about older siblings who had left school early and had limited career opportunities or other serious difficulties they were less than positive models and were cited as motivators for them to stay in school and achieve so that their future would be better" (p.3).

Meyer et al., (2007) also reported that students in their research expressed positive and negative ideas about teachers and motivation and achievement. "Most of these comments were positive and, not surprisingly, students appreciated teachers who knew their subject but also made learning fun and interesting. They appreciated teachers who treated them with respect, 'like adults'. Without identifying anyone, some gave examples of teachers who seemed to have favourites, were sexist, got angry, and/or who couldn't control their classes" (p.5). Students in the MS programme were provided with opportunities to discuss teacher affiliation and the researcher could address comments that MS students made like "the teacher does not like me" and to consider things that teachers do that help students learn and things that teachers do that do not help students learn.

Finally Meyer et al., (2007) also reported that students in their research expressed positive and negative ideas about their friends and motivation and achievement. "One's friends could motivate higher achievement by supporting study behaviour, by not distracting students with social demands, and through 'friendly competition' with 
one another to see who could get the highest number of Merit and Excellence credits. Friends could also be a negative influence, and students didn't like to be in groups that were predominantly comprised of poorly motivated and low achieving students. They emphasised the difficulties of being motivated and working hard when surrounded by others who didn't seem to care or couldn't do the work" (p.5). Students in the MS programme discussed how peers may support or not support their learning. Discussion about peer affiliation and achievement Students in the MS programme was provided with opportunities to discuss teacher affiliation. The researcher could address comments that MS students made like "the teacher does not like me" and to consider things that friends do that help students learn and things that friends do that do not help students learn.

\section{MS \#7: Attributions and control and motivation}

MS students discussed possible attributions or explanations that they considered responsible for their best and worst marks; these factors were ability, effort, good luck, easy assessment, peers, teachers, and family. Attribution theory has three dimensions - locus, control and stability (Weiner, 1985, 2010), and this discussion with MS focused on two of those dimensions - stability and control. The stability dimension of attributions is important because if a student who is under-achieving believes that their ability is stable or fixed it is likely that the student could adopt a fatalistic approach to test situations and come to believe that there is nothing they can do to prevent failure. If a student believes that effort is unstable, then it is more likely that they could also believe that with more effort they could have achieved better marks in an assessment (Blackwell, Trzesniewski and Dweck, 2007). A student's beliefs about the control dimension when attributing causality for best and worst marks is important: if a student believes they have some control over the reasons why they may have done well or badly in an assessment situation, there is a greater chance that they may engage in study behaviour to do better on future tests.

It was important that the research made the link in the minds of MS students about the importance of effort attributions rather than ability attributions. This is because if 
students believe they have some control over the reasons as to why they may have done well or badly in an assessment situation, there is a greater chance that they may engage in the necessary study behaviour to do better on future assessments. For example McClure et al., (2011) explained that "Attributing outcomes to stable, uncontrollable causes such as ability weakens motivation and in extreme cases leads to learned helplessness" (p.71). Control is associated with mastery and hopefulness, and lack of control is associated with helplessness.

MS students took part in discussions about attributions and control beginning with the traditional attributions of ability, effort, luck and test difficulty. The main aims here were to get MS students to understand that ability is a malleable concept, not a fixed one. As Meyer et al., (2006) reported it was important that MS students understood identity versus incremental views of ability.

Closely related to these ideas are views of intelligence-ability-as either a static entity (an individual characteristic) that cannot be changed or an incremental set of skills and knowledge that can be expanded. Dweck and her colleagues have presented evidence that children and adults can take on one or the other of these concepts of ability (Dweck, 1992; Elliott \& Dweck, 1988; Dweck \& Leggett, 1988) (p.9).

MS students also discussed ideas about effort and strategy as key to improvement and achievement and that luck and test difficulty ideas are outside of students' control (Craven et al., 1991; Martin, 2009; Martin et al., 2001). Meyer and her colleagues also reported that attributions can be modified. During the MS intervention the researcher followed ideas reported by Meyer et al., (2009) including that:

One practical implication of Weiner's theory and research is that when teachers see students struggling with new tasks, statements such as "Keep trying, it's easy!" are likely to affect students negatively rather than encouraging them. If they succeed on something the teacher said was "easy," the accomplishment has been devalued. If they fail, they are likely to infer that they lack the required ability because, after all, the teacher said this task was supposed to be easy. Thus, a more helpful thing to say would be: "This is a difficult task, and you really have to work at it. Keep trying, and I'll check later to see if you need some help." (p.8) 
An integral part of attribution theory is the idea of decreasing uncertain control. Many under-achieving students may fail to succeed because they do not understand that some practical reasons for student success at school are under their control whereas other factors are not. Students in the MS intervention programme learned to decrease uncertain control by following a three-step strategy outlined by Martin (2014) - why I've done well or not so well in the past; what I can control; and keys to my control. Martin (2014) explained that the first step in building a sense of control was for a student to look at the reasons why they had done well or not so well in the past in a test by considering the following factors: hard work or lack of work, good luck or bad luck, easy test or difficult test, being smart or not so smart, and how family, teachers and friends affected achievement. Students were invited to write lists under two headings - things I can control versus things out of my control. Then students discussed these items they had listed as being in their control or not in their control. For example, the amount of study that a student might do would be considered within a student's control whereas the difficulty of the test is up to the teacher and out of the student's control. Sitting with friends who distract you versus sitting with groups of friends who work hard in class was also discussed. MS students were therefore encouraged to focus on those aspects related to attributions for best and worst marks that they could control rather than on those factors which are up to others. Finally students were encouraged to practice these controllable factors such as effort, to increase their sense of confidence that they could achieve well in tests and could succeed at school. As the detail of this material is copyright, the reader is referred to Martin, A. J. (2014). The Motivation and Engagement Workbook (14th Edition). Sydney, Australia: Lifelong Achievement Group (www.lifelongachievement.com). 


\section{Appendix C \\ Motivation and Engagement Scale - High School (MES-HS)}

Source: Andrew J. Martin PhD (C) 2009 Lifelong Achievement Group

(www.lifelongachievement.com)

A selection of the questions from the MES-HS includes:

PLEASE CIRCLE ONE NUMBER FOR EACH STATEMENT

$1=$ Disagree Strongly

$2=$ Disagree

$3=$ Disagree Somewhat

$4=$ Neither Agree nor Disagree

$5=$ Agree

$6=$ Agree Somewhat

$7=$ Agree Strongly

Sample questions:

1. If I can't understand my schoolwork at first, I keep going over it until I do

2. I feel very pleased with myself when I really understand what I'm taught at school

3. When I study, I usually study in places where I can concentrate

4. I'm able to use some of the things I learn at school in other parts of my life 


\section{Appendix D Survey of NCEA Goals: Year 10 and Year 11 Students}

Source: Meyer, L.H., McClure, J., Walkey, F., Weir, K.F., McKenzie, L. (2008)

Victoria University of Wellington College of Education

Te Whanau o Ako Pai ki Te Whare Wananga o te Upoko o te Ika a Maui

A selection of the questions from the Survey of NCEA goals includes:

Please rate each sentence listed below using this scale, and circle the number closest to your opinion:

$1=$ this is not at all like me

$2=$ this is sometimes like me and sometimes not like me

$3=$ this is mostly like me

$4=$ this is definitely like me

9. I expect to get Excellence or at least Merit when I do NCEA

11. If I get just NCEA Level 1 or possibly NCEA Level 2 before I leave school, I'll be satisfied and have no plans to finish Level 3

15. I get involved when we do group work in class

18. I want to take credits that allow me to try for Merit or Excellence, rather than just Achieved

19. My learning benefits when students are encouraged to help one another in a subject

21. I'll learn more in a subject when the teacher cares how well I do 
25. It matters to me that I can work for the NCEA Certificate endorsed for Merit or Excellence

\section{What has influenced how well you do in school? (Attributions)}

Please rate each sentence listed below using this scale, and circle the number closest to your opinion:

$$
\begin{aligned}
& 1=\text { no influence } \\
& 2=\text { little influence } \\
& 3=\text { some influence } \\
& 4=\text { big influence }
\end{aligned}
$$

27. Think back to times when you got your best marks on assessments in any subject. Now rate the following possible influences on those marks:

- My ability

- My effort

- The assessment was easy

- Good luck

- My family/whanau

- The teacher

- My friends $\begin{array}{llll}1 & 2 & 3 & 4\end{array}$

$\begin{array}{llll}1 & 2 & 3 & 4\end{array}$

$\begin{array}{llll}1 & 2 & 3 & 4\end{array}$

$\begin{array}{llll}1 & 2 & 3 & 4\end{array}$

$\begin{array}{llll}1 & 2 & 3 & 4\end{array}$

$\begin{array}{llll}1 & 2 & 3 & 4\end{array}$

$\begin{array}{llll}1 & 2 & 3 & 4\end{array}$




\section{Appendix E \\ Information Sheet for Principals and Teachers Research Project: The Effectiveness of Study Programmes on Achievement Outcomes}

My name is Peter Sanders and I have worked in secondary education in New Zealand for 28 years. This present study is for a doctorate $(\mathrm{PhD})$ and involves the effectiveness of study programmes on achievement outcomes. I am interested in finding out if the achievement, motivation, engagement and attendance outcomes of students who participate in a Traditional Study (TS) programme are different to the outcomes of students who participate in a Motivation-enhanced Study (MS) programme.

I would like to operate two study programmes aimed at Year 11 students who are undertaking study in NCEA Level 1 . The study programme will have three aims: (a) to provide a regular place for students to complete study; (b) to offer one-on-one assistance to students, particularly with literacy activities, but also in other subject areas; and (c) to offer a programme of general study skills. The programme has a special focus on effective strategies for Pasifika students, so teachers are invited to identify Pasifika students who would benefit from this programme. Another focus of the programme is students who may consider that study beyond Levels 2 and 3 of NCEA is not useful for them, so again teachers are invited to identify students who fit this category. I will personally operate each of the seven one-hour sessions in the programme and there will be no charge to the school or to the students. Following the delivery of the programme I would like to interview some of the students to gain their perceptions on its effectiveness. Following the interviews, participants will be offered 
the opportunity to view transcripts of the interviews to enable them to check for accuracy.

Yours sincerely

Peter Sanders

Work: 463-5233x8954

Email: peter.sanders@vuw.ac.nz

Supervisor: Professor Luanna H. Meyer, PhD

Director, Jessie Hetherington Centre for Educational Research

Professor of Education (Research)

VUW College of Education

Email: luanna.meyer@vuw.ac.nz 


\section{Appendix F Consent Form for Principals of Participating Schools}

\section{Research Project: The Effectiveness of Study Programmes on Achievement Outcomes}

Researcher: Peter Sanders

I have read Peter Sanders' introductory letter which explains this research project and I agree to Year 11 students from this school participating in the project. I understand that:

- Written permission will be sought from each student's parents/caregivers

- Names of the students will remain confidential to the researcher and $\mathrm{PhD}$ supervisor

- Students do not have to take part in this research and parents/caregivers can choose to withdraw consent for their participation in this research without having to give a reason, up to and including the final point of data collection.

- Some students will be asked to be involved in focus-group interviews and that the conversations of the interviews will be audio-taped and then written up. Following the interviews, participants will be offered the opportunity to view transcripts of the interviews to enable them to check for accuracy.

- Data collected will be seen only by the researcher, his PhD supervisor 
Motivation Interventions via Study Programmes for Under-achieving Students

and a typist, will be stored securely in a locked cabinet in a locked

room at Victoria University of Wellington, and will be destroyed

after five years

- Research findings may be published and will be shared with teachers

and other interested people but individuals will not be identifiable

回

- Useful information from the study will be shared with the school

- The researcher has sought advice for questions and research

methodology from an experienced Samoan teacher educator who has

agreed to be a cultural advisor for this study. The cultural advisor will not view any data or help the researcher to interpret the data.

Name of principal:

Signature:

Name of school:

Date:

Thank you for your assistance

Peter Sanders

Work: 463-5233x8954

Email: peter.sanders@vuw.ac.nz

Supervisor: Professor Luanna H. Meyer, PhD

Director, Jessie Hetherington Centre for Educational Research

Professor of Education (Research)

VUW College of Education

Email: luanna.meyer@vuw.ac.nz 


\section{Appendix G Parents/Caregivers Consent Form for their Child}

Dear Parents/Caregivers

My name is Peter Sanders and I have worked in secondary education in New Zealand for 28 years. I am doing research on the effectiveness of study programmes on student achievement. I will be operating two study programmes aimed at Year 11 students who are undertaking study in NCEA Level 1 . The study programme has three aims: (a) to provide a regular place for students to complete study; (b) to offer one-onone assistance to students, particularly with literacy activities, but also in other subject areas; and (c) to offer a programme of general study skills.

The school principal supports this research and has given permission for the programme to be offered to your son/daughter. I will personally operate each of the five one-hour sessions in the programme and there will be no charge to the school or to the students. Following the delivery of the study programme I would like to interview some of the students to gain their perceptions on its effectiveness. The discussions will be tape recorded and then written down but no students will be identified by their names. Following the interviews, participants will be offered the opportunity to view transcripts of the interviews to enable them to check for accuracy.

The information collected will be seen only by me, my supervisors and a typist and it will be stored securely in a locked cabinet at Victoria University and destroyed after 
five years. The findings of the research may be published and will be shared with teachers and other interested people. When the research is completed I will give a short report to the school and request that this is made available to the parents of the students who have taken part in the study. The names of the students will remain confidential and they do not have to take part in this research. If they do take part, you can withdraw your consent at any time without having to give a reason. It is anticipated that you would encourage your son/daughter to attend all five sessions. All students who complete the full programme will receive formal recognition. If you agree to your son/daughter taking part in this research would you please read and sign this consent form and return it to the school.

I agree for my son/daughter to take part in the above research.

Name of student:

Name of Parent/Caregiver:

Signature:

Date:

Thank you very much for your assistance

Peter Sanders

Work: 463-5233x8954

Email: peter.sanders@vuw.ac.nz

Supervisor: Professor Luanna H. Meyer, PhD

Director, Jessie Hetherington Centre for Educational Research

Professor of Education (Research)

VUW College of Education

Email: luanna.meyer@vuw.ac.nz 


\section{Appendix $\mathrm{H}$ Student consent form}

Dear student

My name is Peter Sanders and I have worked in secondary education in New Zealand for 28 years. I am doing research on the effectiveness of study programmes on student achievement. I will be operating two study programmes aimed at Year 11 students who are undertaking study in NCEA Level 1 . The study programme has three aims: (a) to provide a regular place for students to complete study; (b) to offer one-onone assistance to students, particularly with literacy activities, but also in other subject areas; and (c) to offer a programme of general study skills.

The school principal supports this research and has given permission for the programme to be offered to you. I will personally operate each of the five one-hour sessions in the programme and there will be no charge to the school or to the students. Following the delivery of the study programme I would like to interview some students to gain their perceptions on its effectiveness. The discussions will be tape recorded and then written down but no students will be identified by their names. Following the interviews, participants will be offered the opportunity to view transcripts of the interviews to enable you to check for accuracy. The information collected will be seen only by me, my supervisors and a typist and it will be stored securely in a locked cabinet at Victoria University and destroyed after five years. The findings of the research may be published and will be shared with teachers and other 
interested people. When the research is completed I will give a short report to the school and request that this is made available to students who have taken part in the study. The names of the students will remain confidential and you do not have to take part in this research. If you do take part, you can withdraw your consent at any time without having to give a reason. I would encourage you to attend all five sessions. All students who complete the full programme will receive formal recognition. If you agree to taking part in this research would you please read and sign this consent form and return it to the school.

I agree to take part in the above research and I am willing to be interviewed.

Name of student:

Signature:

Date:

Thank you very much for your assistance

Peter Sanders

Work: 463-5233×8954

Email: peter.sanders@vuw.ac.nz

Supervisor: Professor Luanna H. Meyer, PhD

Director, Jessie Hetherington Centre for Educational Research

Professor of Education (Research)

VUW College of Education

Email: luanna.meyer@vuw.ac.nz 